\title{
Cochrane
}

Library

Cochrane Database of Systematic Reviews

\section{Non-absorbable disaccharides versus placebo/no intervention and lactulose versus lactitol for the prevention and treatment of hepatic encephalopathy in people with cirrhosis (Review)}

Gluud LL, Vilstrup H, Morgan MY

Gluud LL, Vilstrup H, Morgan MY.

Non-absorbable disaccharides versus placebo/no intervention and lactulose versus lactitol for the prevention and treatment of hepatic encephalopathy in people with cirrhosis.

Cochrane Database of Systematic Reviews 2016, Issue 5. Art. No.: CD003044.

DOI: 10.1002/14651858.CD003044.pub4.

www.cochranelibrary.com

Non-absorbable disaccharides versus placebo/no intervention and lactulose versus lactitol for the prevention and treatment of hepatic encephalopathy in people with cirrhosis (Review)

Copyright (c) 2016 The Cochrane Collaboration. Published by John Wiley \& Sons, Ltd. 
TABLE OF CONTENTS

ABSTRAC

PLAIN LANGUAGE SUMMARY

SUMMARY OF FINDINGS

BACKGROUND

OBJECTIVES

METHODS

RESULTS

Figure 1.

Figure 2.

Figure 3.

Figure 4.

Figure 5.

Figure 6.

DISCUSSION

AUTHORS' CONCLUSIONS

ACKNOWLEDGEMENTS

REFERENCES

CHARACTERISTICS OF STUDIES

DATA AND ANALYSES

Analysis 1.1. Comparison 1 Non-absorbable disaccharides versus placebo/no intervention, Outcome 1 Mortality.

Analysis 1.2. Comparison 1 Non-absorbable disaccharides versus placebo/no intervention, Outcome 2 Mortality in trials with a low risk of bias.

Analysis 1.3. Comparison 1 Non-absorbable disaccharides versus placebo/no intervention, Outcome 3 Hepatic encephalopathy.

Analysis 1.4. Comparison 1 Non-absorbable disaccharides versus placebo/no intervention, Outcome 4 Serious adverse events.

Analysis 1.5. Comparison 1 Non-absorbable disaccharides versus placebo/no intervention, Outcome 5 Quality of life: sickness impact profile.

Analysis 1.6. Comparison 1 Non-absorbable disaccharides versus placebo/no intervention, Outcome 6 Non-serious adverse events.

Analysis 1.7. Comparison 1 Non-absorbable disaccharides versus placebo/no intervention, Outcome 7 Number connection test, end of treatment.

Analysis 1.8. Comparison 1 Non-absorbable disaccharides versus placebo/no intervention, Outcome 8 Ammonia end of treatment.

Analysis 1.9. Comparison 1 Non-absorbable disaccharides versus placebo/no intervention, Outcome 9 Ammonia change from baseline.

Analysis 1.10. Comparison 1 Non-absorbable disaccharides versus placebo/no intervention, Outcome 10 Mortality in worstcase scenario analyses.

Analysis 1.11. Comparison 1 Non-absorbable disaccharides versus placebo/no intervention, Outcome 11 Hepatic encephalopathy worst-case scenario analysis.

Analysis 1.12. Comparison 1 Non-absorbable disaccharides versus placebo/no intervention, Outcome 12 Serious adverse events worst-case scenario analysis.

Analysis 2.1. Comparison 2 Prevention trials: non-absorbable disaccharides versus placebo/no intervention, Outcome 1 Mortality.

Analysis 2.2. Comparison 2 Prevention trials: non-absorbable disaccharides versus placebo/no intervention, Outcome 2 Mortality and bias control.

Analysis 2.3. Comparison 2 Prevention trials: non-absorbable disaccharides versus placebo/no intervention, Outcome 3 Hepatic encephalopathy.

Analysis 2.4. Comparison 2 Prevention trials: non-absorbable disaccharides versus placebo/no intervention, Outcome 4 Serious adverse events.

Analysis 2.5. Comparison 2 Prevention trials: non-absorbable disaccharides versus placebo/no intervention, Outcome 5 Nonserious adverse events.

Analysis 3.1. Comparison 3 Treatment trials: non-absorbable disaccharides versus placebo/no intervention, Outcome 1 Mortality.

Non-absorbable disaccharides versus placebo/no intervention and lactulose versus lactitol for the prevention and treatment of hepatic encephalopathy in people with cirrhosis (Review)

Copyright ( 2016 The Cochrane Collaboration. Published by John Wiley \& Sons, Ltd. 
Analysis 3.2. Comparison 3 Treatment trials: non-absorbable disaccharides versus placebo/no intervention, Outcome 2 Mortality in trials with a low risk of bias.

Analysis 3.3. Comparison 3 Treatment trials: non-absorbable disaccharides versus placebo/no intervention, Outcome 3 Mortality in acute or chronic hepatic encephalopathy.

Analysis 3.4. Comparison 3 Treatment trials: non-absorbable disaccharides versus placebo/no intervention, Outcome 4 Hepatic encephalopathy.

Analysis 3.5. Comparison 3 Treatment trials: non-absorbable disaccharides versus placebo/no intervention, Outcome 5 Acute or chronic hepatic encephalopathy.

Analysis 3.6. Comparison 3 Treatment trials: non-absorbable disaccharides versus placebo/no intervention, Outcome 6 Serious adverse events.

Analysis 3.7. Comparison 3 Treatment trials: non-absorbable disaccharides versus placebo/no intervention, Outcome 7 Serious adverse events in acute or chronic hepatic encephalopathy.

Analysis 3.8. Comparison 3 Treatment trials: non-absorbable disaccharides versus placebo/no intervention, Outcome 8 Nonserious adverse events.

Analysis 4.1. Comparison 4 Lactulose versus lactitol, Outcome 1 Mortality.

Analysis 4.2. Comparison 4 Lactulose versus lactitol, Outcome 2 Hepatic encephalopathy.

Analysis 4.3. Comparison 4 Lactulose versus lactitol, Outcome 3 Serious adverse events.

Analysis 4.4. Comparison 4 Lactulose versus lactitol, Outcome 4 Non-serious adverse events.

Analysis 4.5. Comparison 4 Lactulose versus lactitol, Outcome 5 Number Connection Test: end of treatment.

Analysis 4.6. Comparison 4 Lactulose versus lactitol, Outcome 6 Number Connection Test: change from baseline.

Analysis 4.7. Comparison 4 Lactulose versus lactitol, Outcome 7 Venous blood ammonia: end of treatment.

Analysis 4.8. Comparison 4 Lactulose versus lactitol, Outcome 8 Venous blood ammonia: change from baseline. 
[Intervention Review]

\section{Non-absorbable disaccharides versus placebo/no intervention and lactulose versus lactitol for the prevention and treatment of hepatic encephalopathy in people with cirrhosis}

Lise Lotte Gluud ${ }^{1}$, Hendrik Vilstrup², Marsha Y Morgan³

1Gastrounit, Medical Division, Copenhagen University Hospital Hvidovre, Hvidovre, Denmark. 2Department of Hepatology and Gastroenterology, Aarhus Kommunehospital, Aarhus C, Denmark. ${ }^{U}$ UCL Institute for Liver \& Digestive Health, Division of Medicine, Royal Free Campus, University College London, London, UK

Contact: Lise Lotte Gluud, Gastrounit, Medical Division, Copenhagen University Hospital Hvidovre, Kettegaards Alle, Hvidovre, 2650, Denmark. liselottegluud@yahoo.dk.

Editorial group: Cochrane Hepato-Biliary Group.

Publication status and date: New search for studies and content updated (conclusions changed), published in Issue 5, 2016.

Citation: Gluud LL, Vilstrup H, Morgan MY. Non-absorbable disaccharides versus placebo/no intervention and lactulose versus lactitol for the prevention and treatment of hepatic encephalopathy in people with cirrhosis. Cochrane Database of Systematic Reviews 2016, Issue 5. Art. No.: CD003044. DOI: 10.1002/14651858.CD003044.pub4.

Copyright ( 2016 The Cochrane Collaboration. Published by John Wiley \& Sons, Ltd.

\section{A B S T R A C T}

\section{Background}

Non-absorbable disaccharides (lactulose and lactitol) are recommended as first-line treatment for hepatic encephalopathy. The previous (second) version of this review included 10 randomised clinical trials (RCTs) evaluating non-absorbable disaccharides versus placebo/no intervention and eight RCTs evaluating lactulose versus lactitol for people with cirrhosis and hepatic encephalopathy. The review found no evidence to either support or refute the use of the non-absorbable disaccharides and no differences between lactulose versus lactitol.

\section{Objectives}

To assess the beneficial and harmful effects of i) non-absorbable disaccharides versus placebo/no intervention and ii) lactulose versus lactitol in people with cirrhosis and hepatic encephalopathy.

\section{Search methods}

We carried out electronic searches of the Cochrane Hepato-Biliary Group Controlled Trials Register, the Cochrane Central Register of Controlled Trials (CENTRAL 2015, Issue 10), MEDLINE, EMBASE, and Science Citation Index Expanded to 19 October 2015; manual searches of meetings and conference proceedings; checks of bibliographies; and correspondence with investigators and pharmaceutical companies.

\section{Selection criteria}

We included RCTs, irrespective of publication status, language, or blinding.

\section{Data collection and analysis}

Two review authors, working independently, retrieved data from published reports and correspondence with investigators. The primary outcomes were mortality, hepatic encephalopathy, and serious adverse events. We presented the results of meta-analyses as risk ratios (RR) and mean differences (MD) with 95\% confidence intervals (CI). We assessed the quality of the evidence using 'Grading of Recommendations Assessment Development and Evaluation' (GRADE) and bias control using the Cochrane Hepato-Biliary Group domains. Our analyses included regression analyses of publication bias and other small study effects, Trial Sequential Analyses to detect type 1 and type 2 errors, and subgroup and sensitivity analyses. 


\section{Main results}

We included 38 RCTs with a total of 1828 participants. Eight RCTs had a low risk of bias in the assessment of mortality. All trials had a high risk of bias in the assessment of the remaining outcomes. Random-effects meta-analysis showed a beneficial effect of non-absorbable disaccharides versus placebo/no intervention on mortality when including all RCTs with extractable data (RR $0.59,95 \% \mathrm{Cl} 0.40$ to 0.87 ; 1487 participants; 24 RCTs; $1^{2}=0 \%$; moderate quality evidence) and in the eight RCTs with a low risk of bias (RR $0.63,95 \%$ Cl 0.41 to $0.97 ; 705$ participants). The Trial Sequential Analysis with the relative risk reduction (RRR) reduced to $30 \%$ confirmed the findings when including all RCTs, but not when including only RCTs with a low risk of bias or when we reduced the RRR to $22 \%$. Compared with placebo/no intervention, the non-absorbable disaccharides were associated with beneficial effects on hepatic encephalopathy (RR $0.58,95 \% \mathrm{Cl} 0.50$ to $0.69 ; 1415$ participants; 22 RCTs; $1^{2}=32 \%$; moderate quality evidence). Additional analyses showed that non-absorbable disaccharides can help to reduce serious adverse events associated with the underlying liver disease including liver failure, hepatorenal syndrome, and variceal bleeding (RR $0.47,95 \% \mathrm{Cl} 0.36$ to $0.60 ; 1487$ participants; $24 \mathrm{RCTs} ; \mathrm{I}=0 \%$; moderate quality evidence). We confirmed the results in Trial Sequential Analysis. Tests for subgroup differences showed no statistical differences between RCTs evaluating prevention, overt, or minimal hepatic encephalopathy. The evaluation of secondary outcomes showed a potential beneficial effect of the non-absorbable disaccharides on quality of life, but we were not able to include the data in an overall meta-analysis (very low quality evidence). Nonabsorbable disaccharides were associated with non-serious (mainly gastrointestinal) adverse events (very low quality evidence). None of the RCTs comparing lactulose versus lactitol evaluated quality of life. The review found no differences between lactulose and lactitol for the remaining outcomes (very low quality evidence).

\section{Authors' conclusions}

This review includes a large number of RCTs evaluating the prevention or treatment of hepatic encephalopathy. The analyses found evidence that non-absorbable disaccharides may be associated with a beneficial effect on clinically relevant outcomes compared with placebo/no intervention.

\section{PLAIN LANGUAGE SUMMARY}

\section{Are non-absorbable disaccharides associated with beneficial or harmful effects in people with cirrhosis and hepatic encephalopathy?}

\section{Background}

Cirrhosis is a chronic disorder of the liver. People with cirrhosis may develop hepatic encephalopathy, a condition that results in poor brain functioning. Hepatic encephalopathy may be clinically obvious (overt) with changes including poor concentration, tremor, and alterations in consciousness. Others have no obvious clinical changes (minimal) but, when tested, some aspects of brain function such as attention and the ability to perform complex tasks are impaired.

The reason why people develop hepatic encephalopathy is complex. The accumulation of ammonia plays a key role. The non-absorbable disaccharides, lactulose and lactitol, are indigestible sugars that reduce the levels of ammonia in the blood.

\section{Review question}

We investigated the use of non-absorbable disaccharides for the prevention and treatment of hepatic encephalopathy in people with cirrhosis by reviewing randomised clinical trials (RCTs).

\section{Search date}

The search date was October 2015.

\section{Study funding sources}

Seven RCTs received financial support and 11 RCTs received lactitol or inactive placebo free of charge from a pharmaceutical company.

\section{Study characteristics}

We included 29 RCTs comparing non-absorbable disaccharides with inactive placebo or no intervention and nine RCTs comparing lactulose with lactitol. Seven of the included RCTs evaluated the prevention of hepatic encephalopathy and 31 evaluated the treatment of hepatic encephalopathy. Sixteen of the treatment RCTs included people with overt hepatic encephalopathy while 15 included people with minimal hepatic encephalopathy. The duration of treatment varied depending on the type of hepatic encephalopathy from five days to one year.

\section{Key results}

People who received non-absorbable disaccharides were less likely to die than people given a placebo or no treatment. They were also less likely to develop serious complications of their liver disease such as liver failure, bleeding, and infections. The non-absorbable disaccharides were also effective in preventing the development of hepatic encephalopathy and increased the number of participants who recovered from hepatic encephalopathy. There was some evidence from a small number of trials that lactulose has a beneficial effect

Non-absorbable disaccharides versus placebo/no intervention and lactulose versus lactitol for the prevention and treatment of hepatic encephalopathy in people with cirrhosis (Review)

Copyright (c) 2016 The Cochrane Collaboration. Published by John Wiley \& Sons, Ltd. 
on the quality of life, but we were unable to include the data in an overall analysis. The non-absorbable disaccharides were associated with adverse events including diarrhoea, nausea, bloating, and flatulence. None of the RCTs comparing lactulose versus lactitol reported quality of life. The analyses showed no differences between the two interventions for the remaining outcomes.

\section{Quality of the evidence}

In the comparison of non-absorbable disaccharides versus placebo/no intervention, we found moderate quality evidence of benefit for the outcomes of death, hepatic encephalopathy, and serious complications. The evidence for the remaining outcomes was of very low quality. 
SUMMARYOF FINDINGS

Summary of findings for the main comparison. Non-absorbable disaccharides versus placebo/no intervention for the prevention and treatment of hepatic encephalopathy in people with cirrhosis

Non-absorbable disaccharides versus placebo/no intervention for the prevention and treatment of hepatic encephalopathy in people with cirrhosis

Population: prevention and treatment of hepatic encephalopathy in people with cirrhosis

Intervention: non-absorbable disaccharides (lactulose and lactitol)

Control: placebo/no intervention

Setting: in-hospital (overt hepatic encephalopathy) and outpatient (minimal hepatic encephalopathy and prevention trials)

Duration of follow-up: the duration depended on the type of encephalopathy with 5 days for acute, 74 days for chronic, 70 days for minimal, and 207 days for prevention of hepatic encephalopathy

\begin{tabular}{|c|c|c|c|c|c|c|}
\hline \multirow[t]{3}{*}{ Outcomes } & \multicolumn{2}{|c|}{$\begin{array}{l}\text { Illustrative comparative risks }{ }^{\star}(95 \% \\
\mathrm{Cl})\end{array}$} & \multirow[t]{3}{*}{$\begin{array}{l}\text { Relative effect } \\
(95 \% \mathrm{Cl})\end{array}$} & \multirow{3}{*}{$\begin{array}{l}\text { No of partici- } \\
\text { pants } \\
\text { (studies) }\end{array}$} & \multirow{3}{*}{$\begin{array}{l}\text { Quality of the } \\
\text { evidence } \\
\text { (GRADE) }\end{array}$} & \multirow[t]{3}{*}{ Comments } \\
\hline & Assumed risk & $\begin{array}{l}\text { Corresponding } \\
\text { risk }\end{array}$ & & & & \\
\hline & Control & $\begin{array}{l}\text { Non-absorbable } \\
\text { disaccharides ver- } \\
\text { sus placebo/no in- } \\
\text { tervention }\end{array}$ & & & & \\
\hline \multirow[t]{4}{*}{ Mortality } & \multicolumn{2}{|c|}{ Study population } & \multirow{4}{*}{$\begin{array}{l}\text { RR } \mathbf{0 . 5 9}(0.40 \\
\text { to } 0.87) \text { when } \\
\text { including all } \\
\text { RCTs; RR } \mathbf{0 . 6 3} \\
\text { (0.41 to } 0.97) \\
\text { when including } \\
\text { RCTs with a low } \\
\text { risk of bias }\end{array}$} & \multirow{4}{*}{$\begin{array}{l}1487 \\
\text { (24 studies) }\end{array}$} & \multirow{4}{*}{$\begin{array}{l}\oplus \oplus \oplus \ominus \\
\text { moderate } 1\end{array}$} & \multirow{4}{*}{$\begin{array}{l}\text { Trial Sequential Analysis: } \\
\text { The Trial Sequential Analysis found a beneficial ef- } \\
\text { fect of the intervention including all RCTs, but when } \\
\text { the analysis only included RCTs with a low risk of } \\
\text { bias. } \\
\text { Assessment method: Assessed based on the total } \\
\text { number of participants who died. }\end{array}$} \\
\hline & 88 per 1000 & $\begin{array}{l}\mathbf{4 9} \text { per } 1000 \\
(32 \text { to } 75)\end{array}$ & & & & \\
\hline & \multicolumn{2}{|l|}{ Moderate } & & & & \\
\hline & 20 per 1000 & $\begin{array}{l}11 \text { per } 1000 \\
\text { ( } 7 \text { to } 17)\end{array}$ & & & & \\
\hline \multirow{3}{*}{$\begin{array}{l}\text { Hepatic en- } \\
\text { cephalopathy }\end{array}$} & \multicolumn{2}{|c|}{ Study population } & \multirow{3}{*}{$\begin{array}{l}\text { RR } 0.58 \\
(0.5 \text { to } 0.69)\end{array}$} & \multirow{3}{*}{$\begin{array}{l}1415 \\
\text { (22 studies) }\end{array}$} & \multirow{3}{*}{$\begin{array}{l}\oplus \oplus \oplus \ominus \\
\text { moderate } 2\end{array}$} & \multirow{3}{*}{$\begin{array}{l}\text { Trial Sequential Analysis: } \\
\text { The Trial Sequential Analysis found a beneficial ef- } \\
\text { fect of the intervention including all RCTs, but when } \\
\text { the analysis only included RCTs with a low risk of } \\
\text { bias. }\end{array}$} \\
\hline & 469 per 1000 & $\begin{array}{l}\mathbf{2 7 2} \text { per } \mathbf{1 0 0 0} \\
\text { (234 to } 323)\end{array}$ & & & & \\
\hline & Moderate & & & & & \\
\hline
\end{tabular}




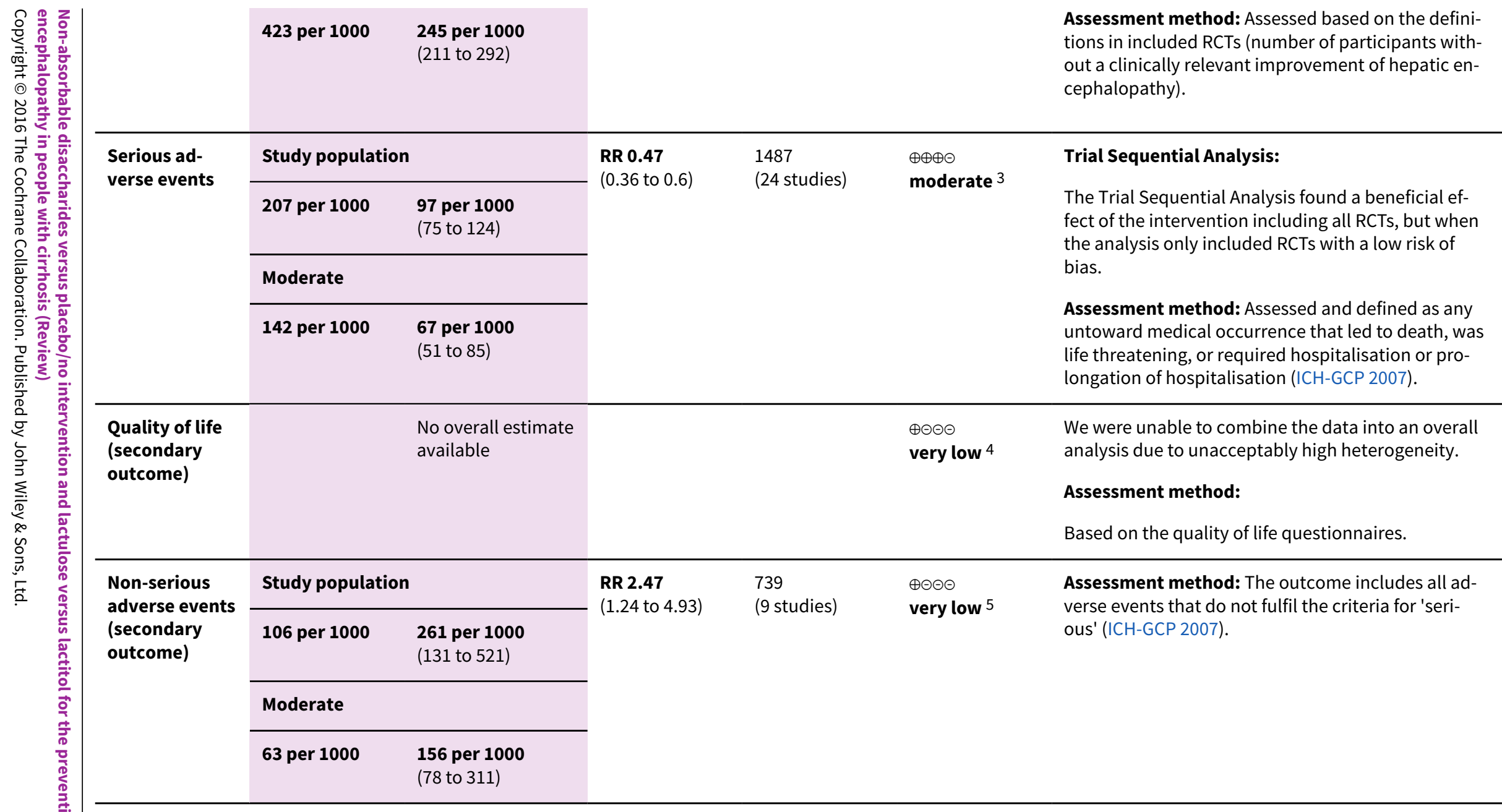

*The basis for the assumed risk (e.g. the median control group risk across studies) is provided in footnotes. The corresponding risk (and its $95 \%$ confidence interval) is based on the assumed risk in the comparison group and the relative effect of the intervention (and its $95 \% \mathrm{Cl}$ ).

Cl: confidence interval; $\mathbf{R C T}$ : randomised clinical trial; RR: risk ratio

GRADE Working Group grades of evidence

High quality: Further research is very unlikely to change our confidence in the estimate of effect.

Moderate quality: Further research is likely to have an important impact on our confidence in the estimate of effect and may change the estimate.

Low quality: Further research is very likely to have an important impact on our confidence in the estimate of effect and is likely to change the estimate.

Very low quality: We are very uncertain about the estimate.

1Mortality is downgraded one level to 'moderate quality evidence' because the Trial Sequential Analysis found insufficient evidence when we limited the analysis to include only RCTs with a low risk of bias. 
2Hepatic encephalopathy is downgraded one level to 'moderate quality evidence' because none of the RCTs had a low risk of bias in the overall assessment. ${ }^{3}$ Serious adverse events is downgraded one level to 'moderate quality evidence' because none of the RCTs had a low risk of bias in the overall assessment.

${ }^{4}$ Quality of life is downgraded three levels to 'very low quality evidence' because i) none of the included RCTs had a low risk of bias, ii) the heterogeneity was considerable, and iii) we were unable to combine the data in an overall analysis.

${ }^{5}$ Non-serious adverse events is downgraded three levels to 'very low quality evidence' because i) none of the included RCTs had a low risk of bias, ii) the confidence intervals were wide (uncertainty), and iii) we were only able to include data from nine RCTs in our meta-analysis.

\section{Summary of findings 2. Lactulose versus lactitol for the prevention and treatment of hepatic encephalopathy in people with cirrhosis}

\section{Lactulose versus lactitol for the prevention and treatment of hepatic encephalopathy in people with cirrhosis}

Population: prevention and treatment of hepatic encephalopathy in people with cirrhosis

Intervention: lactulose

Control: lactitol

Setting: in-hospital (overt hepatic encephalopathy) and outpatient (minimal hepatic encephalopathy and prevention trials)

Duration of follow-up: the duration depended on the type of encephalopathy with 5 days for acute, 74 days for chronic, 70 days for minimal, and 207 days for prevention of hepatic encephalopathy

\begin{tabular}{|c|c|c|c|c|c|c|}
\hline \multirow[t]{3}{*}{ Outcomes } & \multicolumn{2}{|c|}{$\begin{array}{l}\text { Illustrative comparative risks }{ }^{\star}(95 \% \\
\mathrm{Cl})\end{array}$} & \multirow[t]{3}{*}{$\begin{array}{l}\text { Relative effect } \\
(95 \% \mathrm{CI})\end{array}$} & \multirow{3}{*}{$\begin{array}{l}\text { No of partici- } \\
\text { pants } \\
\text { (studies) }\end{array}$} & \multirow{3}{*}{$\begin{array}{l}\text { Quality of the } \\
\text { evidence } \\
\text { (GRADE) }\end{array}$} & \multirow[t]{3}{*}{ Comments } \\
\hline & Assumed risk & Corresponding risk & & & & \\
\hline & Control & $\begin{array}{l}\text { Lactulose versus } \\
\text { lactitol }\end{array}$ & & & & \\
\hline \multirow[t]{4}{*}{ Mortality } & \multicolumn{2}{|c|}{ Study population } & \multirow{4}{*}{$\begin{array}{l}\text { RR } 1.3 \\
\text { (0.59 to } 2.85)\end{array}$} & \multirow{4}{*}{$\begin{array}{l}225 \\
\text { (8 studies) }\end{array}$} & \multirow{4}{*}{$\begin{array}{l}\oplus \ominus \odot \odot \\
\text { very low } 1\end{array}$} & \multirow{4}{*}{$\begin{array}{l}\text { Trial Sequential Analysis: } \\
\text { The Trial Sequential Analysis found no evidence to } \\
\text { support or refute a difference between the } 2 \text { inter- } \\
\text { ventions being compared. } \\
\text { Assessment method: Assessed based on the total } \\
\text { number of participants who died. }\end{array}$} \\
\hline & 71 per 1000 & $\begin{array}{l}92 \text { per } 1000 \\
\text { (42 to } 202)\end{array}$ & & & & \\
\hline & \multicolumn{2}{|l|}{ Moderate } & & & & \\
\hline & 0 per 1000 & $\begin{array}{l}0 \text { per } 1000 \\
(0 \text { to } 0)\end{array}$ & & & & \\
\hline \multirow{2}{*}{$\begin{array}{l}\text { Hepatic en- } \\
\text { cephalopathy }\end{array}$} & \multicolumn{2}{|c|}{ Study population } & \multirow{2}{*}{$\begin{array}{l}\text { RR } 1 \\
(0.84 \text { to } 1.19)\end{array}$} & \multirow{2}{*}{$\begin{array}{l}194 \\
\text { ( } 7 \text { studies) }\end{array}$} & \multirow{2}{*}{$\begin{array}{l}\oplus \ominus \ominus \ominus \\
\text { very low } 1\end{array}$} & Trial Sequential Analysis: \\
\hline & 286 per 1000 & $\begin{array}{l}\mathbf{2 8 6} \text { per } \mathbf{1 0 0 0} \\
\text { (240 to } 340)\end{array}$ & & & & $\begin{array}{l}\text { The Trial Sequential Analysis found no evidence to } \\
\text { support or refute a difference between the } 2 \text { inter- } \\
\text { ventions being compared. }\end{array}$ \\
\hline
\end{tabular}




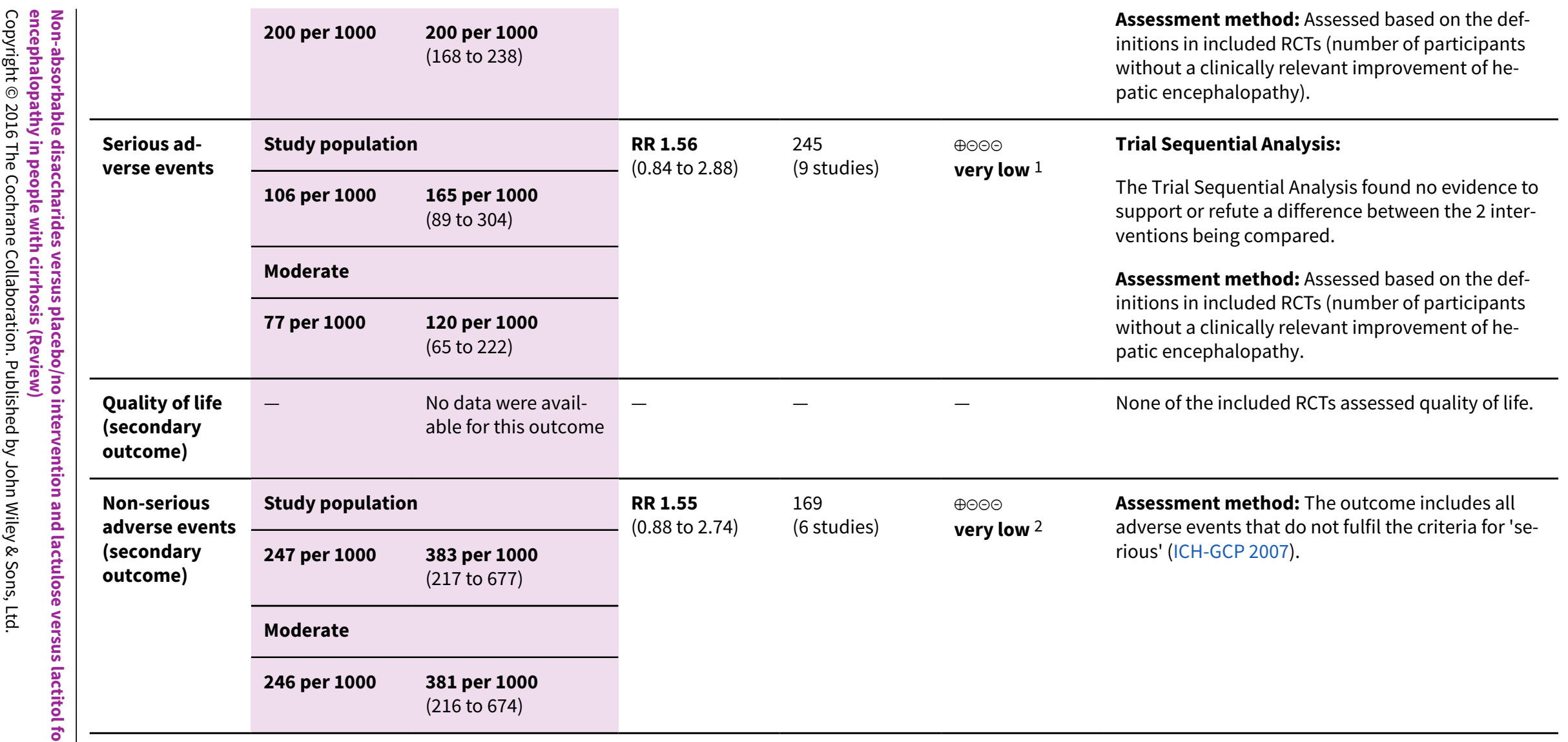

*The basis for the assumed risk (e.g. the median control group risk across studies) is provided in footnotes. The corresponding risk (and its $95 \%$ confidence interval) is based on the assumed risk in the comparison group and the relative effect of the intervention (and its $95 \% \mathrm{Cl}$ ).

Cl: confidence interval; RCT: randomised clinical trial; RR: risk ratio

GRADE Working Group grades of evidence

High quality: Further research is very unlikely to change our confidence in the estimate of effect.

Moderate quality: Further research is likely to have an important impact on our confidence in the estimate of effect and may change the estimate.

Low quality: Further research is very likely to have an important impact on our confidence in the estimate of effect and is likely to change the estimate.

Very low quality: We are very uncertain about the estimate.

1Mortality, hepatic encephalopathy, and serious adverse events are downgraded three levels to 'very low quality evidence' because i) the Trial Sequential Analysis found insufficient evidence to support or refute a difference between the intervention and control group, ii) the confidence intervals were wide, and ii) none of the included RCTs had a low risk of bias in the overall assessment of bias control.

${ }^{2}$ Non-serious adverse events is downgraded three levels to 'very low quality evidence' because i) none of the included RCTs had a low risk of bias in the overall assessment of bias control, ii) only six RCTs reported the outcome, and iii) the confidence intervals were wide (uncertainty). 


\section{B A C K G R O U N D}

\section{Description of the condition}

The term hepatic encephalopathy refers to a spectrum of neuropsychiatric changes occurring in people with liver disease. The joint guideline from the European and American Associations for the Study of the Liver defines hepatic encephalopathy as a brain dysfunction associated with liver insufficiency or portal systemic shunting (EASL and AASLD guideline 2014a; EASL and AASLD guideline 2014b). Clinically apparent or overt hepatic encephalopathy manifests as a neuropsychiatric syndrome encompassing a wide spectrum of mental and motor disorders (Weissenborn 1998; Ferenci 2002). Events such as gastrointestinal bleeding, infection, and alcohol misuse can trigger this socalled acute or episodic hepatic encephalopathy. Fifty per cent of instances occur with no obvious cause. Episodes may recur. Between episodes, people may return to their baseline neuropsychiatric status or show clinical evidence of impairment (Bajaj 2010b). Less frequently, people present with persistent neuropsychiatric abnormalities, which are always present to some degree, but may vary in seriousness. Often people with persistent abnormalities have extensive spontaneous portalsystemic shunting or else a surgically created or transjugular intrahepatic portosystemic shunt (TIPS).

Changes in mental state range from subtle alterations in personality, intellectual capacity, and cognitive function to more profound alterations in consciousness leading to deep coma with decerebrate posturing. The changes in motor function may include rigidity, disorders of speech production, resting- and movement-induced tremor, asterixis, delayed diadochocinetic movements, hyperreflexia, hyporeflexia, choreoathetoid movements, Babinsky's sign, and transient focal symptoms (Victor 1965; Weissenborn 1998; Cadranel 2001). Asterixis (flapping tremor) is the best known motor abnormality. Individuals with overt hepatic encephalopathy also show a wide spectrum of other abnormalities, including impaired psychometric performance (Schomerus 1998), disturbed neurophysiological function (Parsons-Smith 1957; Chu 1997), altered cerebral neurochemical/neurotransmitter homeostasis (Taylor-Robinson 1994), reductions in global and regional cerebral blood flow and metabolism (O'Carroll 1991), and changes in cerebral fluid homeostasis (Haussinger 2000). In general, the degree of impairment in these parameters increases as the clinical condition worsens. The term minimal hepatic encephalopathy (in the older literature subclinical or latent) refers to people with cirrhosis who are 'clinically normal', but who show abnormalities in neuropsychometric or neurophysiological performance (Ferenci 2002).

The diagnosis of hepatic encephalopathy may present no problems, but without the background information and an obvious precipitating event, it may go unrecognised. We have no gold standard for the diagnosis (Montagnese 2004), but techniques that we can use singly or in combination. The diagnosis or exclusion of overt hepatic encephalopathy should include a careful and detailed neuropsychiatric history and examination (Montagnese 2004), with particular attention paid to changes in memory, concentration, cognition, and consciousness. Clinicians and researchers often use the West Haven Criteria to grade mental state (Conn 1977), and the Glasgow Coma Score to grade the level of consciousness (Teasdale 1974). The neurological examination should be comprehensive, looking particularly for evidence of subtle motor abnormalities. The assessment should consider and exclude other potential causes of neuropsychiatric abnormalities including concomitant neurological disorders and metabolic abnormalities such as those associated with diabetes, renal failure, drug, or alcohol intoxication. People with hepatic encephalopathy have impaired psychometric performance (Montagnese 2004; Randolph 2009). Those with minimal hepatic encephalopathy show deficits in attention, visuo-spatial abilities, fine motor skills, and memory while their other cognitive functions are relatively well preserved. People with overt hepatic encephalopathy show additional disturbances in psychomotor speed, executive function, and concentration. Psychometric test batteries to assess cognitive function form part of the evaluation. The Psychometric Hepatic Encephalopathy Score has a high specificity for the diagnosis (Schomerus 1998; Weissenborn 2001). The test employs five paper and pencil tests to assess attention, visual perception and visuoconstructive abilities. Test scores have to be normalised to take account of factors such as age, gender, and educational level. At present, normative databases are available in Germany, Italy, Denmark, Spain, Mexico, Korea, India, and Great Britain.

People with hepatic encephalopathy may have a number of neurophysiological abnormalities (Guérit 2009). The electroencephalogram, which primarily reflects cortical neuronal activity, may show progressive slowing of the background activity and abnormal wave morphology. Recent advances in electroencephalogram analysis should provide better quantifiable and more informative data. Other potential diagnostic techniques include the Critical Flicker Fusion Frequency (Kircheis 2002), and the Inhibitory Control Test (Bajaj 2008). The tests need further validation. Studies using structural and functional cerebral imaging techniques have helped to unravel the pathophysiology of hepatic encephalopathy, but they currently offer little diagnostically (Grover 2006; Berding 2009).

\section{Description of the intervention}

The non-absorbable disaccharides lactulose and lactitol are poorly absorbed sugars, which act as osmotic laxatives in the treatment of constipation (Johanson 2007; Miller 2014). Lactulose (Montgomery 1929) is dispensed as a syrup, which is contaminated with other sugars; a pure crystalline preparation is also available. Lactitol, a second-generation disaccharide, is dispensed as a powder. The mode of administration is generally enteral.

\section{How the intervention might work}

The exact pathogenesis of hepatic encephalopathy is unknown. Ammonia plays a key role (Butterworth 2014). The main sources of ammonia include nitrogenous products in the diet, bacterial metabolism of urea and proteins in the colon, and deamination of glutamine in the small intestine. Non-absorbable disaccharides lower ammonia levels through a number of mechanisms: (i) a laxative effect: the colonic metabolism of lactulose and lactitol results in an increase in intraluminal gas formation, an increase in intraluminal osmolality, a reduction in intraluminal $\mathrm{pH}$, and an overall decrease in transit time; (ii) bacterial uptake of ammonia: the intraluminal changes in $\mathrm{pH}$ result in a leaching of ammonia from the circulation into the colon. The colonic bacteria use the released volatile fatty acids as substrate and proliferate. In doing so, they use the trapped colonic ammonia as a nitrogen source for protein synthesis. The increase in bacterial numbers additionally 'bulks' 
the stool and contributes to the cathartic effect; (iii) reduction of intestinal ammonia production: non-absorbable disaccharides inhibit glutaminase activity and interfere with the intestinal uptake of glutamine and its subsequent metabolism to ammonia; (iv) beneficial effects on the gut microbiome: cirrhosis is associated with dysbiosis and changes in the colonic mucosal microbiome (Qin 2014). Further changes may be observed in patients with hepatic encephalopathy(Bajaj 2012). Non-absorbable disaccharides can beneficially affect microbiota composition (Riggio 1990b; Bajaj 2012).

\section{Why it is important to do this review}

The prevalence of hepatic encephalopathy varies. About $10 \%$ to $14 \%$ have overt hepatic encephalopathy when first diagnosed with cirrhosis (Saunders 1981). In studies in people with decompensated cirrhosis, about $20 \%$ have overt hepatic encephalopathy (D'Amico 1986; de Jongh 1992; Zipprich 2012). The cumulated incidence of overt hepatic encephalopathy is as high as $40 \%$ (Randolph 2009; Bajaj 2011a). The prevalence of minimal hepatic encephalopathy varies in different studies, but it may be more than $50 \%$ or higher in people with previous overt hepatic encephalopathy (Sharma 2010; Lauridsen 2011). The presence of hepatic encephalopathy, whether minimal or overt, is associated with significant impairment in the performance of complex tasks, such as driving (Schomerus 1981; Bajaj 2009; Kircheis 2009). The condition is also associated with a detrimental effect on quality of life (Groeneweg 1998) and safety (Roman 2011). In addition, the presence of overt hepatic encephalopathy in people with cirrhosis awaiting liver transplantation has a detrimental effect on neurocognitive function following the procedure (Sotil 2009) and on overall survival (Bustamante 1999; D'Amico 2006; Stewart 2007; Bajaj 2011a; Patidar 2014). The survival probability in people with cirrhosis after their first episode of hepatic encephalopathy is $42 \%$ at one year and $23 \%$ at three years (Bustamante 1999). Thus, more than $50 \%$ die within one year and more than $75 \%$ within three years. Overt hepatic encephalopathy also poses a substantial burden for the caregivers of affected people (Bajaj 2011b), and a significant financial burden on healthcare systems (Poordad 2007; Stepanova 2012).

Since 1966 (Bircher 1966), when lactulose was first introduced into clinical practice, several RCTs have evaluated non-absorbable disaccharides for hepatic encephalopathy. Previous meta-analyses have found that lactitol may be more beneficial than lactulose (Blanc 1992), or that lactulose and lactitol had comparable effects (Camma 1993). The previous versions of this review did not find sufficient evidence to recommend lactulose or lactitol for routine clinical use in people with cirrhosis and hepatic encephalopathy (Als-Nielsen 2000; Als-Nielsen 2004a; AlsNielsen 2004b; Als-Nielsen 2005). Methodological issues including unclear bias control and lack of statistical power weakened the strength of the conclusions. A subsequent guideline from the European and American Association for the Study of Liver Diseases recommended lactulose as the intervention of choice for overt hepatic encephalopathy and its secondary prevention after an index event (EASL and AASLD guideline 2014a; EASL and AASLD guideline 2014b). The guideline did not recommend primary prevention of encephalopathy nor the routine treatment of minimal hepatic encephalopathy. Clinicians may consider treating minimal hepatic encephalopathy on a case by case basis under certain circumstances such as impaired driving skills, work performance, quality of life issues, or cognitive impairment. The original Cochrane review and the current European and American Associations for the Study of the Liver guidelines provide discrepant views about the role of lactulose. We therefore conducted this updated review.

\section{O B JECT IVES}

To assess the beneficial and harmful effects of i) non-absorbable disaccharides versus placebo/no intervention and ii) lactulose versus lactitol in people with cirrhosis and hepatic encephalopathy.

To avoid overlap with another planned Cochrane review, we did not evaluate non-absorbable disaccharides versus antibiotics (Kimer 2015).

\section{METHODS}

\section{Criteria for considering studies for this review}

\section{Types of studies}

We included RCTs, regardless of publication status, language, or blinding.

\section{Types of participants}

We included people with cirrhosis from RCTs on the prevention (primary or secondary) or treatment of hepatic encephalopathy, regardless of sex, age, aetiology of the underlying liver disease, type of hepatic encephalopathy, or precipitating factors.

\section{Types of interventions}

The intervention comparisons were i) non-absorbable disaccharides (lactulose or lactitol) versus placebo/no intervention and ii) lactulose versus lactitol. We included RCTs, irrespective of the doses, treatment durations, and modes of administration and allowed co-interventions if administered equally to allocation trial arms.

\section{Types of outcome measures}

We assessed all outcomes at the maximum duration of follow-up (Gluud 2015).

\section{Primary outcomes}

1. Mortality.

2. Hepatic encephalopathy. We based our assessment of hepatic encephalopathy on the definitions in included RCTs.

3. Serious adverse events defined as any untoward medical occurrence that led to death, was life threatening, or required hospitalisation or prolongation of hospitalisation (ICH-GCP 2007). We analysed serious adverse events as a composite outcome (Gluud 2015).

\section{Secondary outcomes}

1. Quality of life.

2. Non-serious adverse events: all adverse events that did not fulfil the criteria for a serious adverse event.

3. Surrogate outcomes: Number Connection Test results and blood ammonia concentrations. 


\section{Search methods for identification of studies}

\section{Electronic searches}

We searched the Cochrane Hepato-Biliary Group Controlled Trials Register, Cochrane Central Register of Controlled Trials (CENTRAL), MEDLINE, EMBASE, and Science Citation Index Expanded using the strategies described in Appendix 1. The last search update was 19 October 2015.

\section{Searching other resources}

We scanned the reference lists of relevant articles and proceedings from meetings of the British Society for Gastroenterology (BSG), the British Association for the Study of the Liver (BASL), the European Association for the Study of the Liver (EASL), the United European Gastroenterology Week (UEGW), the American Gastroenterological Association (AGA), the American Association for the Study of Liver Diseases (AASLD), and the International Society for Hepatic Encephalopathy and Nitrogen Metabolism (ISHEN). We wrote to the principal authors of RCTs and the pharmaceutical companies involved in the production of non-absorbable disaccharides for additional information about completed RCTs and for information about any ongoing RCTs, and searched the database ClinicalTrials.gov (clinicaltrials.gov/) and the World Health Organization (WHO) online trial meta-register (apps.who.int/trialsearch/).

\section{Data collection and analysis}

\section{Selection of studies}

Two review authors (Lise L Gluud and Marsha Y Morgan) read the electronic searches, performed additional manual searches, and listed potentially eligible RCTs. All authors read the potentially eligible trial reports and participated in the final selection of those to be included in the analyses. We reached the final selection through consensus. For RCTs reported in more than one publication, we selected the paper reporting the longest duration of follow-up as the primary reference. We listed details of all included RCTs (Characteristics of included studies) and excluded studies (Characteristics of excluded studies).

\section{Data extraction and management}

Two review authors (Lise L Gluud and Marsha $Y$ Morgan) independently collected data and resolved contrary opinions through discussion. The collected data included information on: i) RCTs: design (cross-over or parallel), settings (number of clinical sites; outpatient or inpatient; inclusion period), country of origin; ii) participants: mean age, proportion of men, aetiology of cirrhosis, type of hepatic encephalopathy, previous history of hepatic encephalopathy and iii) interventions: type, dose, duration of therapy, mode of administration. We gathered the primary and secondary outcome data, including the criteria used in the assessment of hepatic encephalopathy, and bias control information. A commercial translation services or medical personnel fluent in the language translated foreign language (nonEnglish) papers (Acknowledgements). We requested missing data and other information from authors of included RCTs.

\section{Assessment of risk of bias in included studies}

We assessed bias control using the domains described in the Cochrane Hepato-Biliary (CHB) module and classified the risk of bias for each domain as high, unclear, or low and the overall assessment as high or low (Gluud 2015).

\section{Allocation sequence generation}

- Low risk of bias: sequence generation achieved using computer random number generation or a random number table. Drawing lots, tossing a coin, shuffling cards, or throwing dice are adequate if performed by an independent person not otherwise involved in the trial.

- Unclear risk of bias: the method of sequence generation was not specified.

- High risk of bias: the sequence generation method was not random.

\section{Allocation concealment}

- Low risk of bias: the participant allocations could not have been foreseen in advance of, or during, enrolment. Allocation was controlled by a central and independent randomisation unit. The allocation sequence was unknown to the investigators (for example, if the allocation sequence was hidden in sequentially numbered, opaque, and sealed envelopes).

- Unclear risk of bias: the method used to conceal the allocation was not described so that intervention allocations may have been foreseen in advance of, or during, enrolment.

- High risk of bias: the allocation sequence was likely to be known to the investigators who assigned the participants.

\section{Blinding of participants, personnel, and outcome assessors}

- Low risk of bias: blinding was performed adequately. We defined lack of blinding (detection and performance bias) as not likely to affect the assessment of the outcome mortality.

- Unclear risk of bias: there was insufficient information to assess whether blinding was likely to induce bias in the results.

- High risk of bias: no blinding or incomplete blinding, and the assessment of outcomes was likely to be influenced by lack of blinding.

\section{Incomplete outcome data}

- Low risk of bias: missing data were unlikely to make treatment effects depart from plausible values. The investigators used sufficient methods, such as intention-to-treat analyses with multiple imputations or carry-forward analyses to handle missing data.

- Unclear risk of bias: there was insufficient information to assess whether missing data in combination with the method used to handle missing data induced bias in the results.

- High risk of bias: the results were likely to be biased due to missing data.

\section{Selective outcome reporting}

- Low risk of bias: the trial reported clinically relevant outcomes (mortality, hepatic encephalopathy, and serious adverse events). If we had access to the original trial protocol, the outcomes selected were those called for in that protocol. If we obtained information from a trial registry (such as www.clinicaltrials.gov), we only used that information if the investigators registered the trial before inclusion of the first participant. 
- Unclear risk of bias: not all pre-defined outcomes were reported fully, or it was unclear whether data on these outcomes were recorded or not.

- High risk of bias: one or more predefined outcomes were not reported.

\section{For-profit bias}

- Low risk of bias: the trial was free of industry sponsorship or other type of for-profit support that may influence the trial design, conduct, or results.

- Unclear risk of bias: no information on clinical trial support or sponsorship was available.

- High risk of bias: the trial was sponsored by industry, received support in the form of lactulose, lactitol, or placebo, or received any other type of support.

\section{Other bias}

- Low risk of bias: the trial appeared to be free of other biases including: medicinal dosing problems or follow-up (as defined below).

- Unclear risk of bias: the trial may or may not have been free of other domains that could put it at risk of bias.

- High risk of bias: there were other factors in the trial that could put it at risk of bias such as the administration of inappropriate treatments being given to the controls (e.g. an inappropriate dose) or follow-up (e.g. the trial included different follow-up schedules for participants in the allocation groups).

\section{Overall bias assessment}

- Low risk of bias: all domains were low risk of bias using the definitions described above.

- High risk of bias: one or more of the bias domains were of unclear or high risk of bias.

\section{Measures of treatment effect}

We used risk ratios (RR) for dichotomous outcomes and the mean differences (MD) for continuous outcomes, both with $95 \%$ confidence intervals $(\mathrm{Cl})$. For primary outcomes, we calculated the number needed to treat to benefit (NNTB) as 1 / risk difference (RD) based on the highest quality evidence (RCTs with a low risk of bias where available).

\section{Unit of analysis issues}

We included data from the first treatment period of cross-over trials (Higgins 2011a).

\section{Dealing with missing data}

We extracted data on all randomised participants in order to allow intention-to-treat analyses. To evaluate the importance of missing data, we conducted a worst-case scenario analysis with simple imputation (Higgins 2008), with inclusion of missing outcomes as treatment failures. We also conducted an 'extreme' worst-case scenario analysis in which we included missing outcome data as treatment failures (intervention group) or successes (control group).

\section{Assessment of heterogeneity}

We expressed heterogeneity as $1^{2}$ values using the following thresholds: $0 \%$ to $40 \%$ (unimportant), $40 \%$ to $60 \%$ (moderate), $60 \%$ to $80 \%$ (substantial), and $>80 \%$ (considerable). This information is included in the 'Summary of findings' tables (GRADEpro).

\section{Assessment of reporting biases}

For meta-analyses with at least 10 RCTs, we assessed reporting biases through regression analyses using the Harbord test (Harbord 2006), which regresses $Z / \operatorname{sqrt}(V)$ against sqrt(V), where $Z$ is the efficient score and $V$ is Fisher's information (the variance of $Z$ under the null hypothesis). All meta-analyses of continuous outcomes included fewer than 10 RCTs.

\section{Data synthesis}

We performed the analyses in Review Manager 5 (RevMan 2014), STATA (Stata), and Trial Sequential Analysis (Thorlund 2011; TSA 2011).

\section{Meta-analysis}

We undertook random-effects and fixed-effect meta-analyses. Although the conclusion of the two models concurred, the randomeffects meta-analysis provides the most conservative estimate of intervention effects. Therefore, we report the random-effects metaanalyses in our results.

\section{Trial Sequential Analysis}

We performed a Trial Sequential Analysis (Higgins 2008; Thorlund 2011), and defined the required information size (also known as the heterogeneity adjusted required information size) as the number of participants needed to detect or reject an intervention effect based on the relative risk reduction (RRR) and CGR. The analyses show firm evidence if the Z-curve crosses the monitoring boundary (also known as the trial sequential monitoring boundary) before reaching the required information size. We constructed futility boundaries to evaluate the uncertainty of obtaining a chance negative finding and performed the analyses with alpha set to $5 \%$, power to $80 \%$, and model-based diversity. Based on previous evidence (Thorlund 2011; EASL and AASLD guideline 2014a; EASL and AASLD guideline $2014 \mathrm{~b}$ ), we set the relative risk reduction (RRR) to $30 \%$ and the CGR to $15 \%$ (mortality), 45\% (hepatic encephalopathy), and 30\% (serious adverse events). In the analysis of mortality, we conducted the analysis with inclusion of i) all RCTs and ii) RCTs with a low risk of bias (only possible in mortality analyses). We repeated the analyses with the RRR reduced to $20 \%$ and with diversity increased by $20 \%$ (from $0 \%$ to $20 \%$ in the analyses of mortality and serious adverse events and from $30 \%$ to $50 \%$ in the analysis of hepatic encephalopathy).

\section{Subgroup analysis and investigation of heterogeneity}

We undertook subgroup analyses to investigate the effect of non-absorbable disaccharides in RCTs evaluating the prevention or treatment of hepatic encephalopathy. We also evaluated heterogeneity based on stratification of RCTs by:

- primary or secondary prevention of hepatic encephalopathy;

- overt or minimal hepatic encephalopathy;

- acute or chronic hepatic encephalopathy. 


\section{Sensitivity analysis}

We performed a sensitivity analysis including only RCTs with a low risk of bias (as described above) and worse-case scenario analysis as described above.

\section{'Summary of findings' tables}

We used the GRADE system to evaluate the quality of the evidence for outcomes reported in the review considering the withinstudy risk of bias (methodological quality), directness of evidence, heterogeneity, precision of effect estimate, and risk of publication bias (GRADEpro).

\section{RESULTS}

\section{Description of studies}

We included 38 RCTs in our qualitative analyses (Characteristics of included studies) and excluded 24 studies (Characteristics of excluded studies). We were able to gather data for our quantitative analyses from 34 RCTs.

\section{Results of the search}

We identified 1378 potentially relevant references in electronic databases and 10 additional records through manual searches (Figure 1). After removing duplicates and references that were clearly irrelevant, we identified 38 RCTs described in 56 references that fulfilled our inclusion criteria (Elkington 1969; Simmons 1970; Brown 1971; Germain 1973; Rodgers 1973; Corazza 1982; McClain 1984; Heredia 1987; Morgan 1987a; Morgan 1987b; Uribe 1987a; Uribe 1987b; Heredia 1988; Morgan 1989; Riggio 1989; Grandi 1991; Pai 1995; Jankovic 1996; Horsmans 1997; Quero 1997; Shi 1997; Watanabe 1997; Li 1999; Dhiman 2000; Xing 2003; Zeng 2003; Raza 2004; Riggio 2005; Prasad 2007; Sharma 2009; Mittal 2011; Sharma 2011; Agrawal 2012; Sharma 2012; Jain 2013; Wen 2013; Ziada 2013; Yao 2014). 
Figure 1. Trial flow diagram.

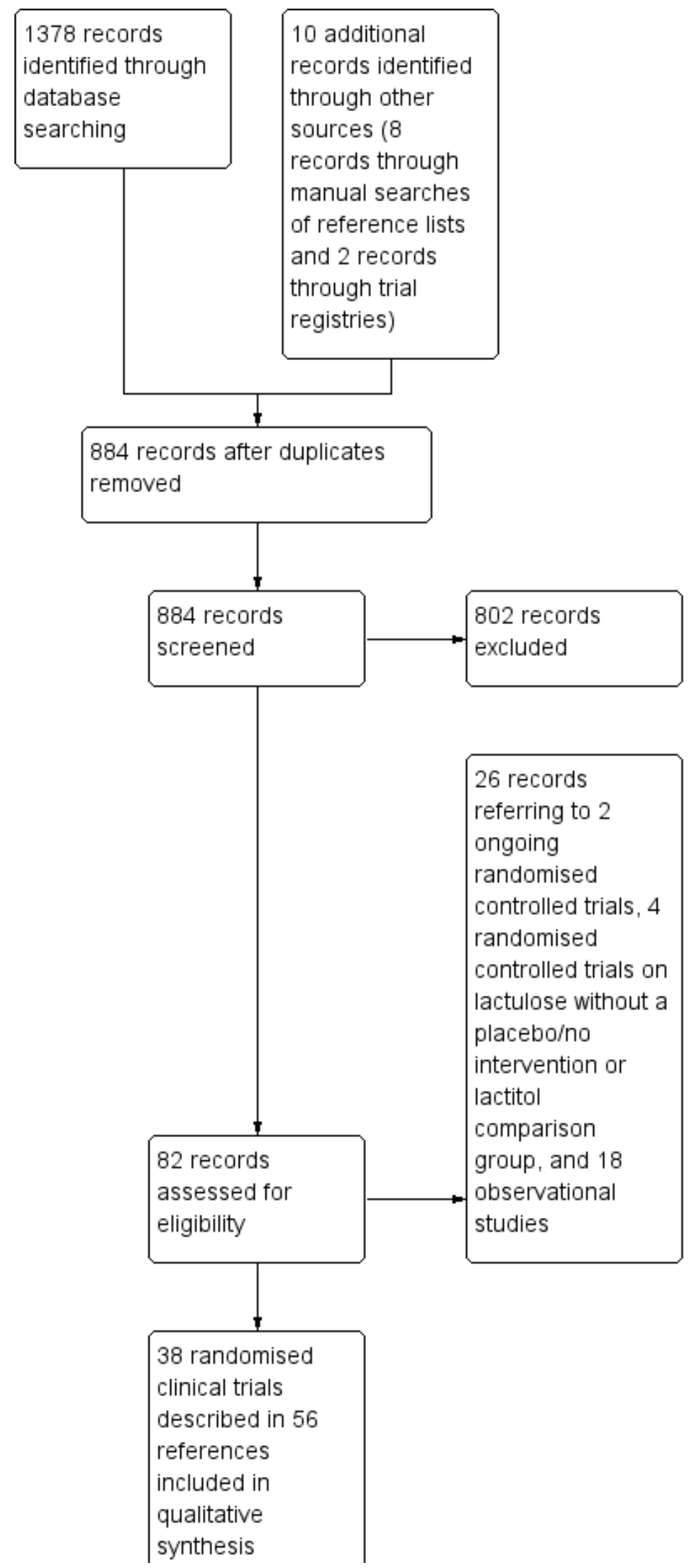


Figure 1. (Continued)

\begin{tabular}{l}
$\begin{array}{l}\text { yualıauve } \\
\text { synthesis }\end{array}$ \\
$\begin{array}{l}34 \text { randomised } \\
\text { clinical trials } \\
\text { described in } 52 \\
\text { references } \\
\text { included in } \\
\text { quantitative } \\
\text { synthesis } \\
\text { (meta-analysis) }\end{array}$ \\
\hline
\end{tabular}

We were unable to obtain outcome data from four RCTs (Elkington 1969; Brown 1971; Rodgers 1973; Shi 1997), and we included the remaining 34 RCTs, all published as full paper articles, in our quantitative analyses (Simmons 1970; Germain 1973; Corazza 1982; McClain 1984; Heredia 1987; Morgan 1987a; Morgan 1987b; Uribe 1987a; Uribe 1987b; Heredia 1988; Morgan 1989; Riggio 1989; Grandi 1991; Pai 1995; Jankovic 1996; Horsmans 1997; Quero 1997; Watanabe 1997; Li 1999; Dhiman 2000; Xing 2003; Zeng 2003; Raza 2004; Riggio 2005; Prasad 2007; Sharma 2009; Mittal 2011; Sharma 2011; Agrawal 2012; Sharma 2012; Jain 2013; Wen 2013; Ziada 2013; Yao 2014)

The countries of origin were India (Dhiman 2000; Prasad 2007; Sharma 2009; Mittal 2011; Sharma 2011; Agrawal 2012; Sharma 2012; Jain 2013), the USA (Elkington 1969; Simmons 1970; Brown 1971; Rodgers 1973; McClain 1984), China (Shi 1997; Xing 2003; Zeng 2003; Wen 2013; Li 1999; Yao 2014), Italy (Corazza 1982; Riggio 1989; Grandi 1991; Riggio 2005), the United Kingdom (Morgan 1987a; Morgan 1987b; Morgan 1989), Spain (Heredia 1987; Heredia 1988), Mexico (Uribe 1987a; Uribe 1987b), Belgium (Horsmans 1997), Egypt (Ziada 2013), France (Germain 1973), Holland (Quero 1997), Pakistan (Raza 2004), Serbia (Jankovic 1996), and Taiwan (Pai 1995).

\section{Included studies}

\section{Participants}

The total number of participants was 1828 . Their mean age ranged from 41 to 67 years and the proportion of men from $11 \%$ to $100 \%$. The proportion of participants with cirrhosis secondary to hepatitis $\mathrm{B} / \mathrm{C}$ infection ranged from $0 \%$ to $81 \%$, while the proportion with alcohol-related cirrhosis ranged from $0 \%$ to $100 \%$.

Seven RCTs evaluated the prevention of hepatic encephalopathy. Three RCTs evaluated primary (Sharma 2012), or secondary prevention of hepatic encephalopathy (Sharma 2009; Agrawal 2012), in participants with no obvious risks. Four included participants with an increased risk of hepatic encephalopathy due to gastrointestinal bleeding (Sharma 2011; Wen 2013), recent insertion of a transjugular intrahepatic portosystemic shunt (Riggio 2005), or portosystemic shunt surgery (Riggio 1989). In 16 RCTs, participants had overt hepatic encephalopathy (Table 1) classed as acute (Simmons 1970; Heredia 1987; Morgan 1987a; Uribe 1987a; Pai 1995; Jankovic 1996; Raza 2004), or chronic (Elkington
1969; Brown 1971; Germain 1973; Rodgers 1973; Corazza 1982; Morgan 1987b; Uribe 1987b; Heredia 1988; Grandi 1991). In 15 RCTs, participants had minimal hepatic encephalopathy (McClain 1984; Morgan 1989; Horsmans 1997; Quero 1997; Shi 1997; Watanabe 1997; Li 1999; Dhiman 2000; Xing 2003; Zeng 2003; Prasad 2007; Mittal 2011; Jain 2013; Ziada 2013; Yao 2014).

\section{Interventions}

Twenty-nine RCTs assessed non-absorbable disaccharides versus placebo/no intervention (Elkington 1969; Simmons 1970; Brown 1971; Germain 1973; Rodgers 1973; Corazza 1982; McClain 1984; Uribe 1987a; Uribe 1987b; Horsmans 1997; Quero 1997; Shi 1997; Watanabe 1997; Li 1999; Dhiman 2000; Xing 2003; Zeng 2003; Raza 2004; Riggio 2005; Prasad 2007; Sharma 2009; Mittal 2011; Sharma 2011; Agrawal 2012; Sharma 2012; Jain 2013; Wen 2013; Ziada 2013; Yao 2014). Of these, 25 assessed lactulose (Elkington 1969; Simmons 1970; Brown 1971; Germain 1973; Rodgers 1973; Corazza 1982; McClain 1984; Horsmans 1997; Quero 1997; Watanabe 1997; Li 1999; Dhiman 2000; Xing 2003; Zeng 2003; Raza 2004; Prasad 2007; Sharma 2009; Mittal 2011; Sharma 2011; Agrawal 2012; Sharma 2012; Jain 2013; Wen 2013; Ziada 2013; Yao 2014), and four assessed lactitol (Uribe 1987a; Uribe 1987b; Shi 1997; Riggio 2005).

Nine RCTs compared lactulose versus lactitol (Heredia 1987; Morgan 1987a; Morgan 1987b; Heredia 1988; Morgan 1989; Riggio 1989; Grandi 1991; Pai 1995; Jankovic 1996).

\section{Outcomes}

We were unable to extract outcome data from four RCTs with 64 participants (Elkington 1969; Brown 1971; Rodgers 1973; Shi 1997).

In total, our quantitative analyses included 34 RCTs with 1764 participants (Simmons 1970; Germain 1973; Corazza 1982; McClain 1984; Heredia 1987; Morgan 1987a; Morgan 1987b; Uribe 1987a; Uribe 1987b; Heredia 1988; Morgan 1989; Riggio 1989; Grandi 1991; Pai 1995; Jankovic 1996; Horsmans 1997; Quero 1997; Watanabe 1997; Li 1999; Dhiman 2000; Xing 2003; Zeng 2003; Raza 2004; Riggio 2005; Prasad 2007; Sharma 2009; Mittal 2011; Sharma 2011; Agrawal 2012; Sharma 2012; Jain 2013; Wen 2013; Yao 2014).

Thirty-one RCTs followed participants to the end of the intervention (Simmons 1970; Germain 1973; Corazza 1982; McClain 1984; Heredia 1987; Morgan 1987b; Uribe 1987a; Uribe 1987b; Heredia

Non-absorbable disaccharides versus placebo/no intervention and lactulose versus lactitol for the prevention and treatment of hepatic 
1988; Morgan 1989; Riggio 1989; Grandi 1991; Pai 1995; Horsmans 1997; Watanabe 1997; Li 1999; Dhiman 2000; Xing 2003; Zeng 2003; Raza 2004; Riggio 2005; Prasad 2007; Sharma 2009; Mittal 2011; Sharma 2011; Agrawal 2012; Sharma 2012; Jain 2013; Wen 2013; Ziada 2013; Yao 2014). Three parallel-arm RCTs followed participants for an additional 13 days (Jankovic 1996), one month (Morgan 1987a), or three months after the end of treatment (Quero 1997). The duration of the intervention depended on the type of hepatic encephalopathy. Overall, the RCTs followed participants for 89 days (range 4 to 360 days) after randomisation. In prevention RCTs, the duration was 207 days (range 5 to 360 days). For participants with overt hepatic encephalopathy, the mean duration was 49 days (range 4 to 360) with a shorter duration in RCTs on acute (mean 5 days; range 4 to 7 days) and chronic hepatic encephalopathy (mean 74 days; range 10 to 360 days). The mean duration was 70 days in RCTs on minimal hepatic encephalopathy (range 14 to 180 ).

Investigators assessed overt (Table 1) and minimal hepatic encephalopathy using several different neuropsychiatric assessments and variables (Characteristics of included studies). Eight RCTs used the Portal Systemic Encephalopathy Index and Ratio (Morgan 1987a; Morgan 1987b; Uribe 1987a; Uribe 1987b; Heredia 1988; Riggio 1989; Pai 1995; Riggio 2005), which comprises mental status (West Haven Criteria), asterixis, Number Connection Test A results, blood ammonia concentrations, and the electroencephalogram mean cycle frequency. Two RCTs used a modified version of the test without the electroencephalogram (Grandi 1991; Raza 2004), while one additionally replaced Number Connection Test A with the Digit Symbol test (Raza 2004).

Ten of the remaining RCTs also used West Haven Criteria to assess mental status (Jankovic 1996; Prasad 2007; Sharma 2009; Mittal 2011; Sharma 2011; Agrawal 2012; Sharma 2012; Jain 2013; Wen 2013; Ziada 2013). Three RCTs used the Conn Score, which is similar to the West Haven Criteria (Heredia 1987; Morgan 1989; Watanabe 1997). Thirty-two RCTs employed the Number Connection Test (Germain 1973; McClain 1984; Heredia 1987; Morgan 1987a; Morgan 1987b; Uribe 1987a; Uribe 1987b; Heredia 1988; Morgan 1989; Riggio 1989; Grandi 1991; Pai 1995; Jankovic 1996; Horsmans 1997; Quero 1997; Shi 1997; Watanabe 1997; Li 1999; Dhiman 2000; Xing 2003; Zeng 2003; Raza 2004; Riggio 2005; Prasad 2007; Sharma 2009; Mittal 2011; Agrawal 2012; Sharma 2012; Jain 2013; Wen 2013; Ziada 2013; Yao 2014). Twenty-five RCTs measured blood ammonia in plasma, venous, or arterial blood (Elkington 1969; Simmons 1970; Brown 1971; Germain 1973; Corazza 1982; Heredia 1987; Morgan 1987a; Morgan 1987b; Uribe 1987a; Uribe 1987b; Heredia
1988; Riggio 1989; Grandi 1991; Pai 1995; Quero 1997; Shi 1997; Xing 2003; Zeng 2003; Raza 2004; Riggio 2005; Mittal 2011; Sharma 2011; Agrawal 2012; Jain 2013; Ziada 2013), and 22 assessed the electroencephalogram mean cycle frequency (Elkington 1969; Brown 1971; Germain 1973; Rodgers 1973; Corazza 1982; Heredia 1987; Morgan 1987a; Morgan 1987b; Uribe 1987a; Uribe 1987b; Heredia 1988; Morgan 1989; Riggio 1989; Pai 1995; Jankovic 1996; Horsmans 1997; Quero 1997; Xing 2003; Zeng 2003; Raza 2004; Riggio 2005; Agrawal 2012).

\section{Excluded studies}

We excluded four RCTs and 20 observational studies (Characteristics of excluded studies). Three RCTs compared lactulose versus probiotics (Sharma 2008), polyethylene glycol followed by lactulose (Rahimi 2014), or a carbon adsorbent (Pockros 2009), while one RCT compared mannitol lavage versus a combination of lactulose and the antibiotic kanamycin (Quinton 1982). Five case series described the effects of lactulose on minimal (Salerno 1994) or recurrent hepatic encephalopathy (Brown 1970; Rorsman 1970; Zeegen 1970; Bircher 1971). One additional study looked at the differential effects of lactitol and lactulose on chronic hepatic encephalopathy (Lanthier 1985), while another looked at the effect of lactulose in preventing hepatic encephalopathy following insertion of a transjugular intrahepatic portosystemic shunt (Piotraschke 1996). Three studies of participants with cirrhosis described compliance with nonabsorbable disaccharides, the predictors of recurrence of hepatic encephalopathy, and the predictors of response (Bajaj 2010b; Sharma 2009a; Sharma 2010). Three studies describe the prevalence and characteristics of participants with overt or minimal hepatic encephalopathy (Schomerus 1993; Sharma 2010a), or young people admitted with overt hepatic encephalopathy (Sharma 2011a). Six studies describe the effects of non-absorbable disaccharides on cerebral blood flow and metabolism (James 1971), fat excretion (Merli 1992), terminal ileal and colonic $\mathrm{pH}$ (Patil 1987), blood ammonia, atrial natriuretic peptide and amino acid concentrations (Trovato 1995), blood ammonia, Number Connection Test results and lymphocyte subpopulations (Vendemiale 1992), and benzodiazepine-like compounds (Venturini 2005).

\section{Risk of bias in included studies}

We based our bias assessment on the published descriptions combined with additional information from investigators (Figure 2). 
Figure 2. 'Risk of bias' summary: review authors' judgements about each risk of bias item for each included study.

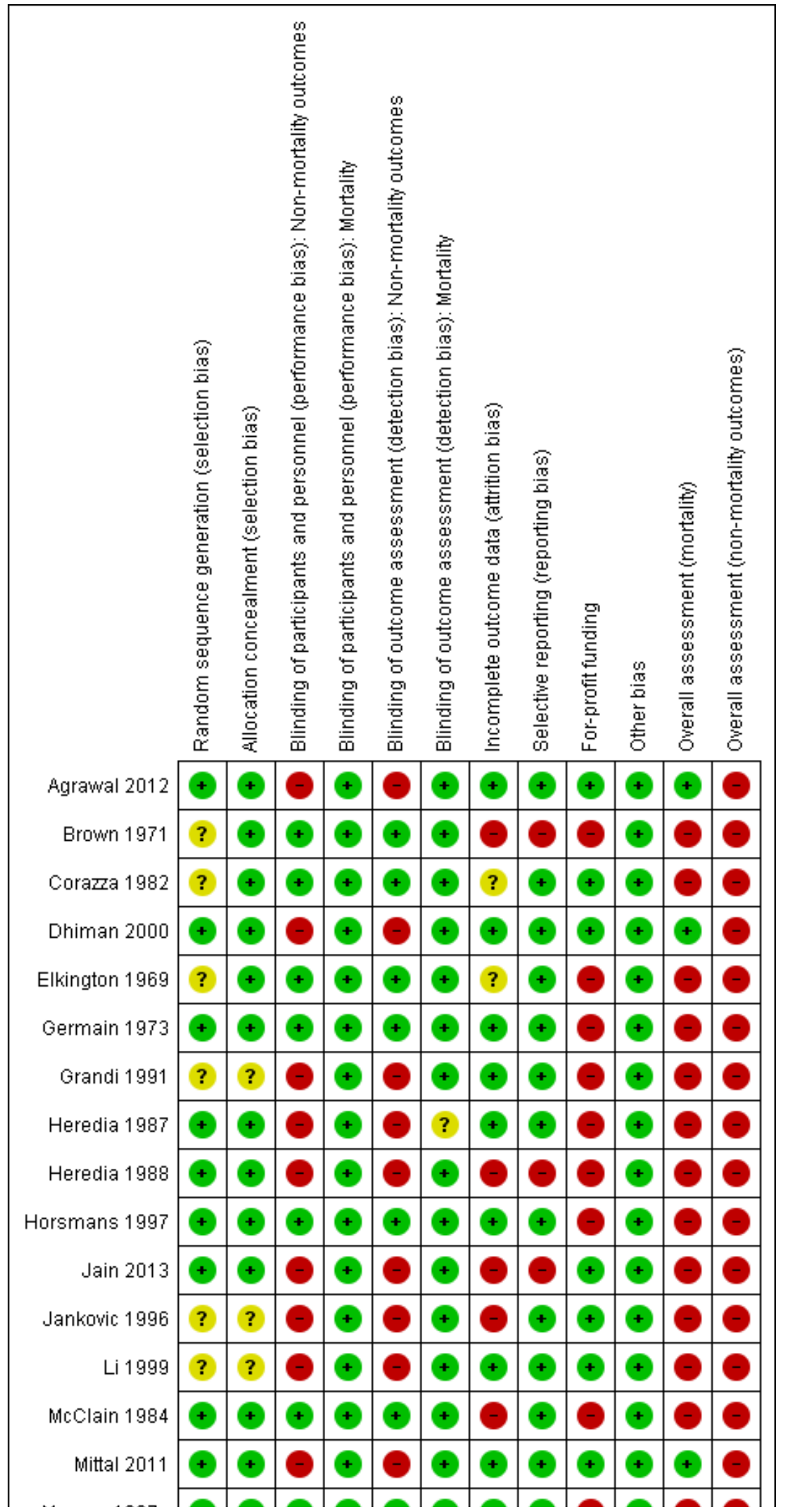

Non-absorbable disaccharides versus placebo/no intervention and lactulose versus lactitol for the prevention and treatment of hepatic 
Figure 2. (Continued)

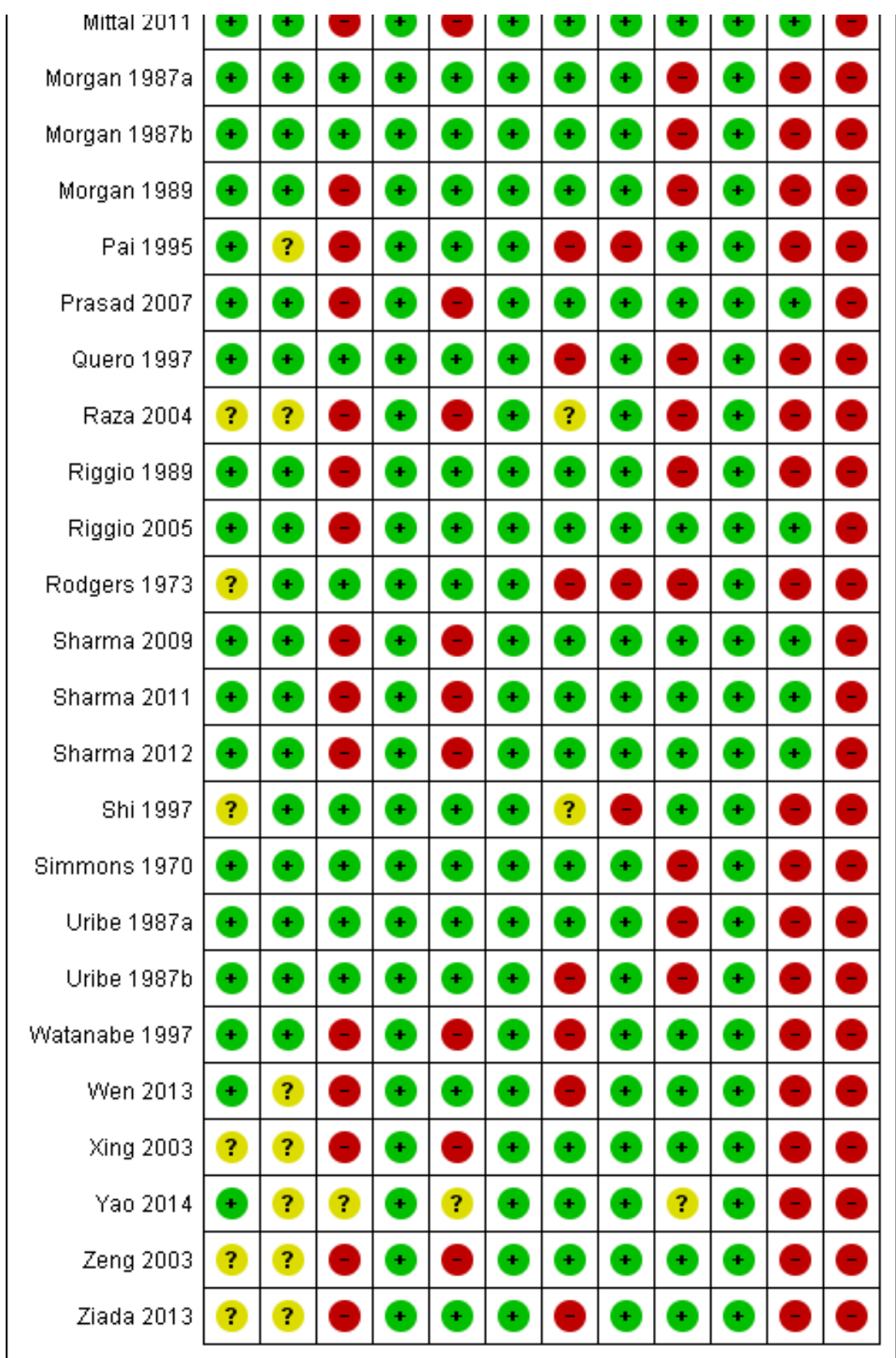

\section{Allocation}

In 26 RCTs, investigators generated the allocation sequence based on a table of random numbers or computer-generated random numbers (Simmons 1970; Germain 1973; McClain 1984; Heredia 1987; Morgan 1987a; Morgan 1987b; Uribe 1987a; Uribe 1987b; Heredia 1988; Morgan 1989; Riggio 1989; Pai 1995; Horsmans 1997; Quero 1997; Watanabe 1997; Dhiman 2000; Riggio 2005; Prasad 2007; Sharma 2009; Mittal 2011; Sharma 2011; Agrawal 2012; Sharma 2012; Jain 2013; Wen 2013; Yao 2014).

In 28 RCTs, the allocation concealment involved randomisation via a central independent unit, serially numbered, opaque, sealed envelopes, or blinded administration of identically appearing drug containers (Elkington 1969; Simmons 1970; Brown 1971; Germain
1973; Rodgers 1973; Corazza 1982; McClain 1984; Heredia 1987; Morgan 1987a; Morgan 1987b; Uribe 1987a; Uribe 1987b; Heredia 1988; Morgan 1989; Riggio 1989; Horsmans 1997; Quero 1997; Shi 1997; Watanabe 1997; Dhiman 2000; Riggio 2005; Prasad 2007; Sharma 2009; Mittal 2011; Sharma 2011; Agrawal 2012; Sharma 2012; Jain 2013).

We classified 23 RCTs as having low risk of selection bias (Simmons 1970; Germain 1973; McClain 1984; Heredia 1987; Morgan 1987a; Morgan 1987b; Uribe 1987a; Uribe 1987b; Heredia 1988; Morgan 1989; Riggio 1989; Horsmans 1997; Quero 1997; Watanabe 1997; Dhiman 2000; Riggio 2005; Prasad 2007; Sharma 2009; Mittal 2011; Sharma 2011; Agrawal 2012; Sharma 2012; Jain 2013).

Non-absorbable disaccharides versus placebo/no intervention and lactulose versus lactitol for the prevention and treatment of hepatic 
We classified 15 RCTs as having unclear risk of selection bias (Elkington 1969; Brown 1971; Rodgers 1973; Corazza 1982; Grandi 1991; Pai 1995; Jankovic 1996; Shi 1997; Li 1999; Xing 2003; Zeng 2003; Raza 2004; Wen 2013; Ziada 2013; Yao 2014).

\section{Blinding}

We classified five single-blind RCTs with blinded outcome assessment as having low risk of detection bias (Morgan 1989; Riggio 1989; Pai 1995; Riggio 2005; Wen 2013), and 14 doubleblind RCTs as having low risk of performance and detection bias (Elkington 1969; Simmons 1970; Brown 1971; Germain 1973; Rodgers 1973; Corazza 1982; McClain 1984; Morgan 1987a; Morgan 1987b; Uribe 1987a; Uribe 1987b; Horsmans 1997; Quero 1997; Shi 1997).

The remaining 19 RCTs were open and we classified them as having high risk of performance and detection bias (Heredia 1987; Heredia 1988; Grandi 1991; Jankovic 1996; Watanabe 1997; Li 1999; Dhiman 2000; Xing 2003; Zeng 2003; Raza 2004; Prasad 2007; Sharma 2009; Mittal 2011; Sharma 2011; Agrawal 2012; Sharma 2012; Jain 2013; Ziada 2013; Yao 2014).

\section{Incomplete outcome data}

In 12 trials, the authors described missing outcome data and excluded participants who were dropouts or withdrawals from their analyses (Brown 1971; Rodgers 1973; McClain 1984; Uribe 1987b; Heredia 1988; Pai 1995; Jankovic 1996; Quero 1997; Watanabe 1997; Jain 2013; Wen 2013; Ziada 2013). We classified these RCTs as having high risk of attrition bias and four RCTs as having unclear risk of attrition bias because the trial reports did not describe dropouts or withdrawals or the handling of missing outcome data in the analyses (Elkington 1969; Corazza 1982; Shi 1997; Raza 2004).

The remaining 22 RCTs had no missing outcome data and the analyses included all participants based on the intention-totreat principle using adequate methods including last observation carried forward or multiple imputation (Simmons 1970; Germain 1973; Heredia 1987; Morgan 1987a; Morgan 1987b; Uribe 1987a; Morgan 1989; Riggio 1989; Grandi 1991; Horsmans 1997; Li 1999; Dhiman 2000; Xing 2003; Zeng 2003; Riggio 2005; Prasad 2007; Sharma 2009; Mittal 2011; Sharma 2011; Agrawal 2012; Sharma 2012; Yao 2014). We classified these RCTs as having low risk of attrition bias.

\section{Selective reporting}

Thirty-two RCTs reported predefined, clinically relevant outcome measures suggesting a low risk of selective reporting (Elkington 1969; Simmons 1970; Germain 1973; Corazza 1982; McClain 1984; Morgan 1987a; Morgan 1987b; Uribe 1987a; Uribe 1987b; Heredia 1988; Morgan 1989; Riggio 1989; Grandi 1991; Pai 1995; Jankovic 1996; Horsmans 1997; Quero 1997; Watanabe 1997; Li 1999; Dhiman 2000; Xing 2003; Zeng 2003; Raza 2004; Riggio 2005; Prasad 2007; Sharma 2009; Mittal 2011; Sharma 2011; Agrawal 2012; Sharma 2012; Wen 2013; Yao 2014).

One trial reported different primary and secondary outcomes in the electronic trial register (Jain 2013). The remaining five RCTs did not report mortality (Brown 1971; Rodgers 1973; Heredia 1988; Shi 1997; Ziada 2013). We therefore classed these six RCTs as having a high risk of selective reporting.

\section{For-profit funding}

Twenty RCTs did not receive funding or had other involvement with for-profit companies (Corazza 1982; Heredia 1987; Pai 1995; Jankovic 1996; Shi 1997; Watanabe 1997; Li 1999; Dhiman 2000; Xing 2003; Zeng 2003; Riggio 2005; Prasad 2007; Sharma 2009; Mittal 2011; Sharma 2011; Agrawal 2012; Sharma 2012; Jain 2013; Wen 2013; Ziada 2013).

In 10 RCTs, investigators received lactitol, lactulose, or placebo from a pharmaceutical company (Simmons 1970; McClain 1984; Morgan 1987a; Morgan 1987b; Heredia 1988; Morgan 1989; Riggio 1989; Grandi 1991; Horsmans 1997; Raza 2004).

Seven RCTs received financial or other support from a pharmaceutical company (Brown 1971; Elkington 1969; Germain 1973; Quero 1997; Rodgers 1973; Uribe 1987a; Uribe 1987b).

One RCT did not report funding (Yao 2014).

\section{Other potential sources of bias}

We found no other potential sources of bias and therefore classified all RCTs as having low risk of bias for this domain (Elkington 1969; Simmons 1970; Brown 1971; Germain 1973; Rodgers 1973; Corazza 1982; McClain 1984; Heredia 1987; Morgan 1987a; Morgan 1987b; Uribe 1987a; Uribe 1987b; Heredia 1988; Morgan 1989; Riggio 1989; Grandi 1991; Pai 1995; Jankovic 1996; Horsmans 1997; Quero 1997; Shi 1997; Watanabe 1997; Li 1999; Dhiman 2000; Xing 2003; Zeng 2003; Raza 2004; Riggio 2005; Prasad 2007; Sharma 2009; Mittal 2011; Sharma 2011; Agrawal 2012; Sharma 2012; Jain 2013; Wen 2013; Ziada 2013; Yao 2014).

\section{Overall bias assessment}

We classified eight RCTs as having low risk of bias in the assessment of mortality (Dhiman 2000; Riggio 2005; Prasad 2007; Sharma 2009; Mittal 2011; Sharma 2011; Agrawal 2012; Sharma 2012), and none of the RCTs as having low risk of bias in the assessment of the remaining outcomes.

\section{Effects of interventions}

See: Summary of findings for the main comparison Nonabsorbable disaccharides versus placebo/no intervention for the prevention and treatment of hepatic encephalopathy in people with cirrhosis; Summary of findings $\mathbf{2}$ Lactulose versus lactitol for the prevention and treatment of hepatic encephalopathy in people with cirrhosis

\section{Non-absorbable disaccharides versus placebo/no intervention}

\section{Primary outcomes}

Our meta-analysis of mortality included 24 RCTs with 1487 participants (Analysis 1.1). Compared with placebo/no intervention, non-absorbable disaccharides were associated with a beneficial effect on mortality when including all randomised clinical trials (risk ratio (RR) $0.59,95 \%$ confidence interval (CI) 0.40 to $0.87 ; 1^{2}=0 \%$ ) or the eight RCTs with a low risk of bias (RR 0.63 , $95 \% \mathrm{Cl} 0.41$ to 0.97 ; number needed to treat to benefit (NNTB) 19; Analysis 1.2).

Our meta-analysis of hepatic encephalopathy included 22 RCTs with 1415 participants (Analysis 1.3) and showed that compared with placebo/no intervention, non-absorbable disaccharides were

Non-absorbable disaccharides versus placebo/no intervention and lactulose versus lactitol for the prevention and treatment of hepatic 
associated with a beneficial effect on hepatic encephalopathy (RR $0.58,95 \% \mathrm{Cl} 0.48$ to $0.69 ; 1^{2}=43 \%$; NNTB six participants). Twentyfour RCTs with 1487 participants reported serious adverse events (Analysis 1.4) that reflected liver-related morbidity such as liver failure, hepatorenal syndrome, and variceal bleeding (Table 2). Non-absorbable disaccharides had a beneficial effect on serious adverse events (RR $0.47,95 \% \mathrm{Cl} 0.36$ to $0.60 ; \mathrm{I}^{2}=0 \%$; Analysis 1.4 ). None of the RCTs evaluating hepatic encephalopathy or serious adverse events had a low risk of bias.

We conducted the Trial Sequential Analyses of primary outcomes with the relative risk reduction (RRR) downgraded to $30 \%$. In the analysis of mortality, we set the CGR to $15 \%$. When including all 24 RCTs (Figure 3), the cumulative Z-curve crossed the monitoring boundary after 1037 participants before reaching the heterogeneity adjusted information size. The cumulative Z-curve did not cross the monitoring boundary when we reduced the RRR to $20 \%$ and increased the diversity to $20 \%$, or when we only included RCTs with a low risk of bias (Figure 4). When we conducted the Trial Sequential Analysis for the outcome hepatic encephalopathy, we initially set the CGR to $45 \%$ (Figure 5). The analysis found that the Z-curve crossed the monitoring boundary before reaching the information size of 581 participants and the analysis was confirmed when we decreased the RRR to $20 \%$ (information size 1337 participants) and increased diversity from $30 \%$ (model based) to 50\% (information size 814 participants). Likewise, when analysing serious adverse events with the CGR set to $30 \%$, the Z-curve crossed the monitoring boundary before reaching the required information size (737 participants; Figure 6). We confirmed the result in an analysis with RRR of $20 \%$ and diversity $20 \%$ (information size 1719 participants).

Figure 3. Trial Sequential Analysis of mortality in 24 RCTs evaluating non-absorbable disaccharides versus placebo/ no intervention. The primary meta-analysis found a RR of $0.59(95 \% \mathrm{Cl} 0.40$ to 0.87$)$. When we set the RRR to $30 \%$ and CGR to $15 \%$, (power $80 \%$, alpha $5 \%$, and diversity $0 \%$ ), the cumulative Z-curve (the green line) crossed the monitoring boundary (inward sloping line) after 1037 participants before reaching the heterogeneity adjusted information size. The cumulative Z-curve did not cross the monitoring boundary when we increased the diversity to $20 \%$ and reduced the RRR to $20 \%$.

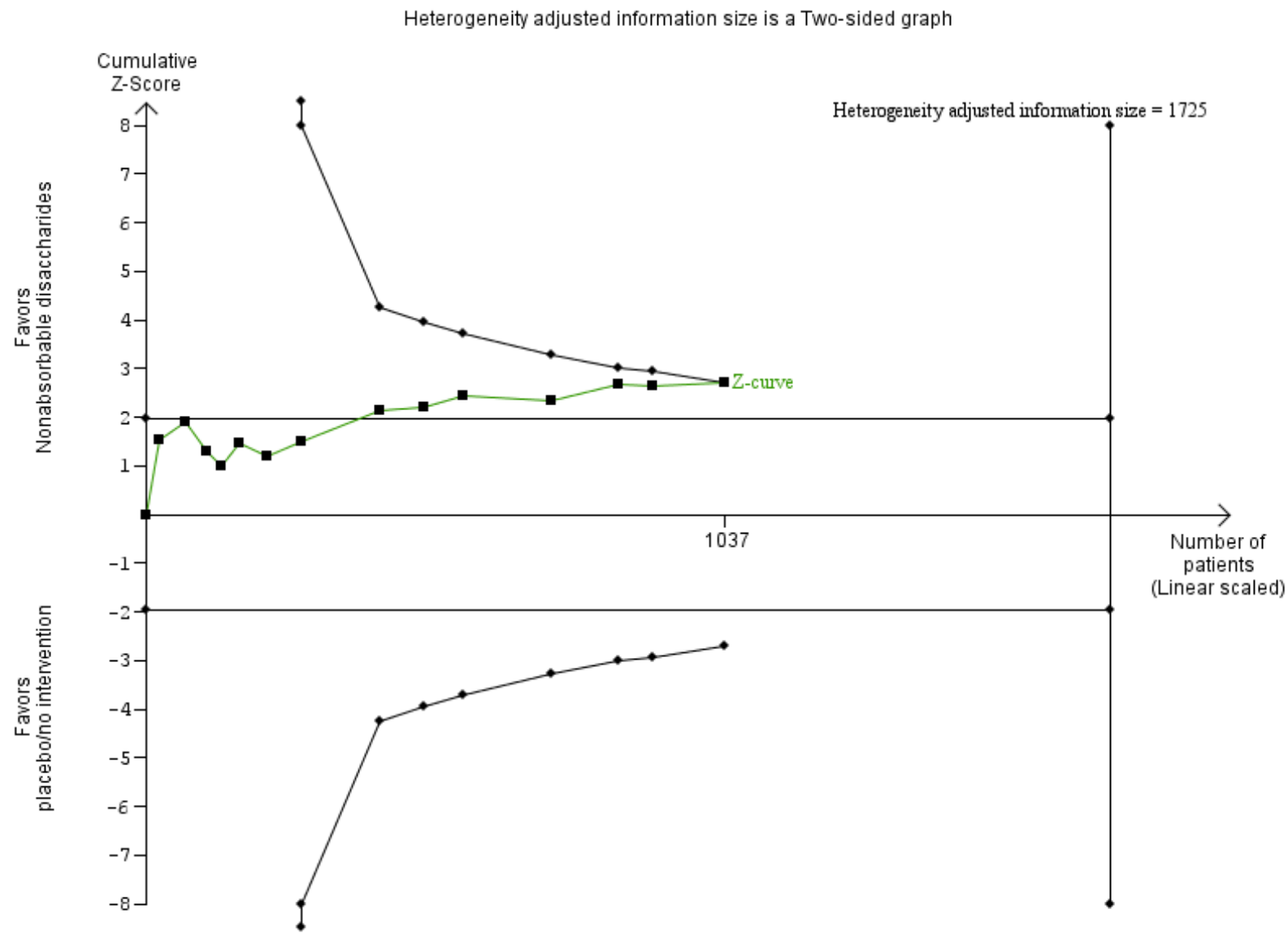

Non-absorbable disaccharides versus placebo/no intervention and lactulose versus lactitol for the prevention and treatment of hepatic 
Figure 4. Trial Sequential Analysis of mortality in 8 RCTs with a low risk of bias. The RCTs compare non-absorbable disaccharides versus placebo/no intervention and the primary meta-analysis found an effect of non-absorbable disaccharides with a RR of 0.63 (95\% $\mathrm{Cl} 0.41$ to 0.97$)$. When we set the RRR to $30 \%$ and CGR to $45 \%$ (power $80 \%$, alpha $5 \%$, and diversity $0 \%$ ), the cumulative Z-curve (the green line) did not cross the monitoring boundary (inward sloping line). The heterogeneity adjusted information size was 1725 participants.

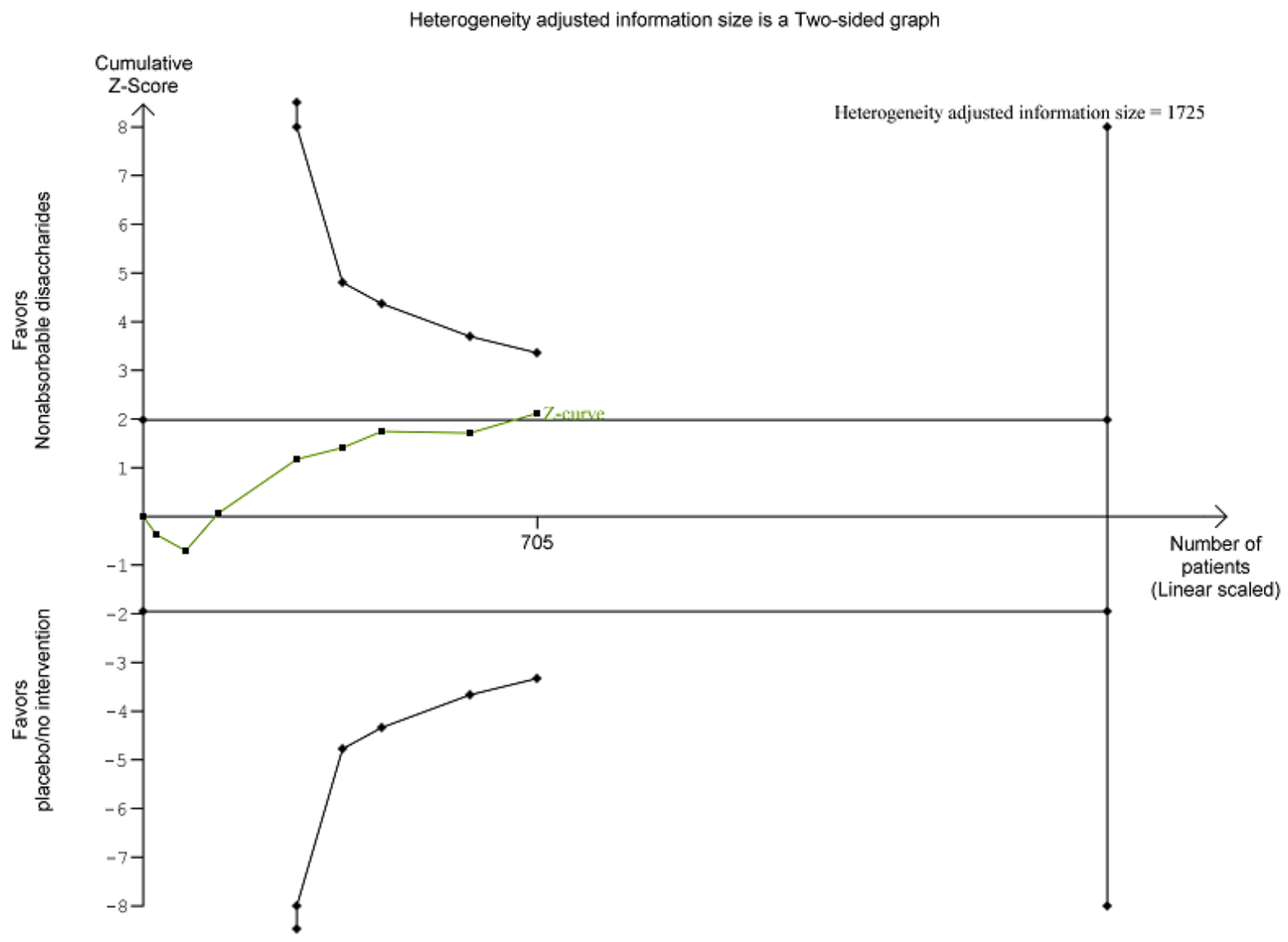


Figure 5. Trial Sequential Analysis of hepatic encephalopathy in 22 RCTs evaluating non-absorbable disaccharides versus placebo/no intervention. A meta-analysis including all trials found a RR of $0.58(95 \% \mathrm{Cl} 0.48$ to 0.69$)$. The analysis includes a RRR of $30 \%$ and CGR of $45 \%$ (power $80 \%$, alpha 5\%, and diversity $30 \%$ ). The analysis found that the Z-curve (green line) crossed the monitoring boundary (inward sloping black line) before reaching the information size of $\mathbf{5 8 1}$ participants. None of the RCTs were low risk of bias in the overall assessment. The Zcurve crossed the monitoring boundary before reaching the information size when we decreased the RRR to $20 \%$ (information size 1337 participants) and when we increased diversity to $50 \%$ (814 participants).

Heterogeneity adjusted information size is a Two-sided graph

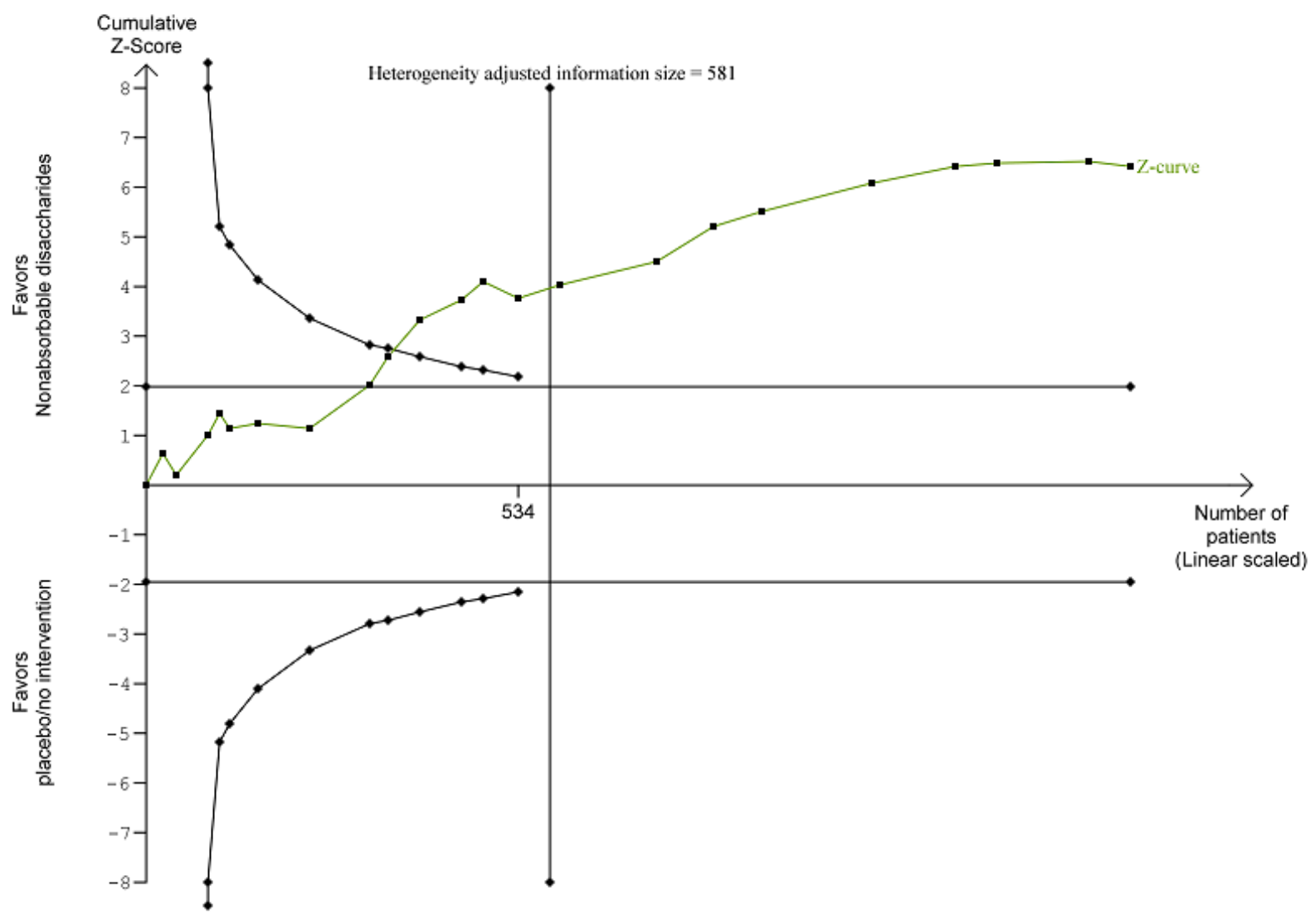


Figure 6. Trial Sequential Analysis of serious adverse events including 24 RCTs evaluating non-absorbable disaccharides versus placebo/no intervention. The primary meta-analysis found a beneficial intervention effect with a RR of 0.47 ( $95 \% \mathrm{Cl} 0.36$ to 0.60 ). None of the included RCTs had a low risk of bias in the overall assessment. When conducting the Trial Sequential Analysis with RRR 30\%, CGR 30\%, power 80\%, alpha 5\%, and diversity $0 \%$, the Z-curve crossed the monitoring boundary before reaching the required information size of 737 participants. The Z-curve also crossed the monitoring boundary before reaching the required information size when we reduced the RRR to $20 \%$ (information size 1719 participants) and when we increased diversity to $20 \%$ (information size 921 participants).

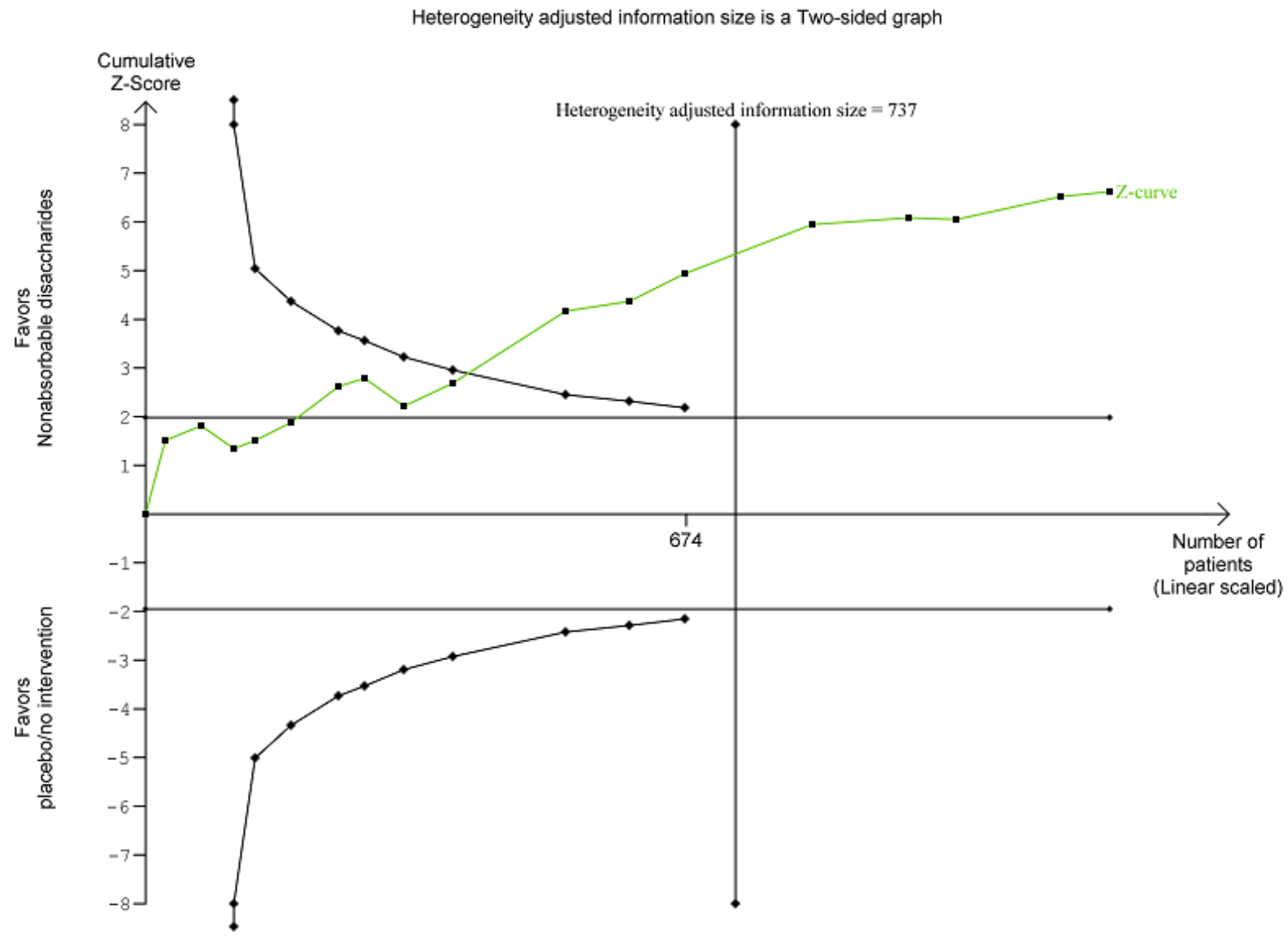

Worst-case scenario analyses (missing outcome data counted as failures) showed that the non-absorbable disaccharides were associated with a beneficial effect on mortality (RR $0.61,95 \% \mathrm{Cl}$ 0.42 to 0.88 ; Analysis 1.10), hepatic encephalopathy (RR $0.59,95 \%$ $\mathrm{Cl} 0.50$ to 0.69; Analysis 1.11), and serious adverse events (RR $0.47,95 \% \mathrm{Cl} 0.37$ to 0.61 ; Analysis 1.12 ). The 'extreme worst-case scenario' analyses (missing outcome data counted as failures in the non-absorbable disaccharide group and successes in the control group) reached the same conclusions (Analysis 1.10, Analysis 1.11, and Analysis 1.12).

Regression analyses and funnel plots showed no evidence of small study effects in the analysis of mortality $(P$ value $=0.73$ ), hepatic encephalopathy ( $P$ value $=0.93)$, or serious adverse events ( $P$ value $=0.96$ ).

\section{Secondary outcomes}

Six RCTs included quality of life assessments (McClain 1984; Quero 1997; Watanabe 1997; Zeng 2003; Prasad 2007; Mittal 2011).
Three RCTs, Quero 1997, Prasad 2007 and Mittal 2011, evaluated 160 participants with minimal hepatic encephalopathy using the Sickness Impact Profile (Table 3; Table 4; Table 5), which includes 136 questions about health-related dysfunction (Gilson 1975; SF 36 questionnaire). The responses to these questions are divided into 12 categories: ambulation, body care/movement, mobility, emotional behaviour, social interaction, alertness behaviour, communication, work, sleep and rest, eating, home management, and recreation/pastimes. These, in turn, are used to inform the two major summative domains physical and psychosocial health. Two RCTs defined the alteration in the total score after treatment as the change in the overall quality of life (Prasad 2007; Mittal 2011). The third trial compared the end of treatment values (Quero 1997). The three RCTs individually found a beneficial effect of lactulose. However, the heterogeneity between RCTs was considerable so we did not conduct a meta-analysis (Analysis 1.5).

One trial, Zeng 2003, used an abbreviated version of the World Health Organization quality of life 100 questionnaire (WHOQOL

Non-absorbable disaccharides versus placebo/no intervention and lactulose versus lactitol for the prevention and treatment of hepatic 
1998), which evaluates the domains: physical health, psychological health, social relationships, and environment. The trial report includes a table showing a selection of subscores from the questionnaire (Table 6). The analyses showed that lactulose improved the domains of physical and psychological health, and social relationships ( $P$ value $<0.05$ for all subscores).

One trial described the effect of lactulose on the quality of life without specifying the assessment method (Watanabe 1997). The abstract states that lactulose improved the quality of life without providing quantitative data. One further trial, McClain 1984 , assessed quality of life using the Katz functioning scale (Katz 1963), which evaluates the adjustment and social behaviour in the community. The investigators state that there were no differences between the intervention groups before or after treatment, but do not provide quantitative data.

The non-absorbable disaccharides increased the risk of gastrointestinal non-serious adverse events ( $R R 2.47,95 \% \mathrm{Cl} 1.24$ to 4.93; 739 participants; nine RCTs; $\left.\right|^{2}=64 \%$; Analysis 1.6 ), including diarrhoea, bloating, flatulence, and nausea. Participants allocated to placebo/no intervention had a higher risk of constipation.

The surrogate outcomes included Number Connection Test results (mean difference (MD) $-5.56,95 \% \mathrm{Cl}-11.59$ to 0.47 ; Analysis 1.7) and blood ammonia concentrations assessed at the end of the trials (MD $-11.64,95 \% \mathrm{Cl}-21.14$ to -2.14 ; Analysis 1.8 ) and as the change from baseline to the end of follow-up (MD 18.97, 95\% Cl 8.86 to 29.09; Analysis 1.9). The analyses included a small number of participants and considerable heterogeneity.

\section{Prevention RCTs}

The meta-analysis evaluating primary or secondary prevention showed a beneficial effect on mortality when including all six RCTs (RR $0.63,95 \% \mathrm{Cl} 0.40$ to $0.98 ; 668$ participants; Analysis 2.1 ), or the five RCTs with a low risk of bias (RR $0.64,95 \% \mathrm{Cl}$ 0.41 to 0.99 ; 538 participants; Analysis 2.2). The non-absorbable disaccharides also had beneficial effects on the prevention of hepatic encephalopathy (RR $0.47,95 \% \mathrm{Cl} 0.33$ to 0.68 ; Analysis 2.3), and serious adverse events (RR $0.48,95 \% \mathrm{Cl} 0.33$ to 0.70 , Analysis 2.4). Additional analyses including four RCTs showed that nonabsorbable disaccharides increased the risk of non-serious adverse events (RR 2.78, 95\% Cl 1.50 to 5.13; 548 participants; Analysis 2.5).

\section{Treatment RCTs}

The meta-analysis evaluating the treatment of overt or minimal hepatic encephalopathy showed no effect of non-absorbable disaccharides on mortality when including all 18 RCTs (RR 0.49 , $95 \% \mathrm{Cl} 0.23$ to $1.05 ; 819$ participants; Analysis 3.1), or the three RCTs with a low risk of bias (RR $0.56,95 \% \mathrm{Cl} 0.12$ to 2.68; 167 participants; three RCTs; Analysis 3.2). The analyses showed beneficial effect of non-absorbable disaccharides on mortality in RCTs evaluating acute, overt hepatic encephalopathy (RR 0.36, 95\% $\mathrm{Cl} 0.14$ to $0.94 ; 172$ participants; six RCTs), but not in RCTs evaluating minimal hepatic encephalopathy (RR $0.82,95 \% \mathrm{Cl} 0.24$ to 2.86 ; 647 participants; 12 RCTs). No events occurred in RCTs evaluating chronic hepatic encephalopathy (Analysis 3.3).

The non-absorbable disaccharides had beneficial effects on overt and minimal hepatic encephalopathy (RR $0.63,95 \% \mathrm{Cl} 0.53$ to 0.74; 747 participants; 16 RCTs; Analysis 3.4). The effect was similar in RCTs evaluating acute or chronic hepatic encephalopathy
(Analysis 3.5). Non-absorbable disaccharides had a beneficial effect on serious adverse events (RR $0.42,95 \% \mathrm{Cl} 0.26$ to $0.69 ; 819$ participants; 18 RCTs; Analysis 3.6) with no difference between the acute and chronic hepatic encephalopathy subgroups (Analysis 3.7). Non-absorbable disaccharides did not increase the risk of non-serious adverse events (RR 2.12, $95 \% \mathrm{Cl} 0.62$ to $7.28 ; 191$ participants; five RCTs; Analysis 3.7).

\section{Lactulose versus lactitol}

Meta-analyses showed no difference between lactulose versus lactitol in the assessment of mortality (RR $1.30,95 \% \mathrm{Cl} 0.59$ to 2.85; 225 participants; eight RCTs; $1^{2}=0 \%$; Analysis 4.1), hepatic encephalopathy (RR $1.00,95 \% \mathrm{Cl} 0.84$ to 1.19 ; Analysis 4.2), or serious adverse events (RR $1.56,95 \% \mathrm{Cl} 0.84$ to 2.88; Analysis 4.3). All Trial Sequential Analyses ignored the monitoring boundaries because the information size was insufficient. None of the RCTs assessed the quality of life. The non-serious adverse events were mainly gastrointestinal (RR $1.55,95 \% \mathrm{Cl} 0.88$ to 2.74 ; Analysis 4.4). We found no differences between interventions for the surrogate outcomes Number Connection Test (end of treatment Analysis 4.5 or change from baseline Analysis 4.6), or blood ammonia concentrations (end of treatment Analysis 4.7 or change from baseline Analysis 4.8). We found no differences between subgroups for any outcomes. We only found evidence of missing outcome data in two RCTs (Pai 1995; Jankovic 1996). The trials did not provide information about the number of participants in the two groups (lactulose or lactitol) with missing outcome data. Therefore, we were unable to conduct worst-case scenario or extreme worst-case scenario analyses.

\section{'Summary of findings' tables}

In the analyses comparing non-absorbable disaccharides versus placebo/no intervention (Summary of findings table 1), we downgraded the quality of the evidence to 'moderate' for the outcome mortality because the Trial Sequential Analysis of RCTs with a low risk of bias found no evidence to support or refute an intervention effect. Likewise, we downgraded the quality of evidence for the outcomes hepatic encephalopathy and serious adverse events one level to 'moderate' because none of the included RCTs had a low risk of bias. We downgraded the outcome quality of life three levels to 'very low quality evidence' because none of the included RCTs had a low risk of bias, the heterogeneity was considerable, and we were unable to combine the data in an overall analysis. We also downgraded the outcome non-serious adverse events three levels to 'very low quality evidence' because none of the included RCTs had a low risk of bias, the confidence intervals were wide, and we were only able to include data from nine RCTs in our meta-analysis.

In the analyses comparing lactulose versus lactitol (Summary of findings table 2), we downgraded the evidence three levels to 'very low quality' due to imprecision, uncertainty, and a methodological quality (none of the included RCTs had a low risk of bias).

\section{DISCUSSION}

\section{Summary of main results}

This review includes descriptive information from 38 randomised clinical trials (RCTs) with 1828 participants and quantitative data from 34 RCTs with 1764 participants. The primary analyses show that use of the non-absorbable disaccharides, lactulose 
and lactitol, is associated with reduced mortality compared with placebo/no intervention when including all RCTs and when including the RCTs with a low risk of bias. In subgroup analyses, we found no statistical differences between RCTs stratified by the type of hepatic encephalopathy. We found a beneficial effect on mortality in RCTs evaluating prevention and RCTs evaluating acute hepatic encephalopathy, but not in RCTs evaluating chronic or minimal hepatic encephalopathy (where the mortality rates overall were extremely low). The quality of the evidence was moderate.

Use of non-absorbable disaccharides is associated with a beneficial effect on the prevention and treatment of hepatic encephalopathy (moderate quality evidence). Additional analyses showed that nonabsorbable disaccharides can help to reduce serious adverse events associated with the underlying liver disease including liver failure, variceal bleeding, and hepatorenal syndrome (moderate quality evidence). Six RCTs suggested a beneficial effect on quality of life, but we were unable to combine the results in a meta-analysis (very low quality evidence). As expected, the non-absorbable disaccharides increased the risk of non-serious gastrointestinal adverse events (very low quality evidence). None of the RCTs comparing lactulose versus lactitol assessed quality of life. Analyses of the remaining outcomes found no differences between the two interventions (very low quality evidence).

\section{Overall completeness and applicability of evidence}

The most important outcomes for people with cirrhosis and hepatic encephalopathy are mortality, morbidity, adverse events, and quality of life (Bajaj 2011a). We included information on all of these outcomes. The RCTs evaluated improvement in hepatic encephalopathy using a variety of methods. This partly reflects that fact that the included RCTs were conducted between 1969 and 2014 during which time diagnostic criteria changed on more than one occasion. The included RCTs often used clinical or composite scoring systems and a categorical approach to define improvement (or lack thereof). The investigators did not use the same thresholds to define improvement, so we chose to use the definitions that they defined as clinically relevant. The diagnostic classification of hepatic encephalopathy also changed during the time period (EASL and AASLD guideline 2014a; EASL and AASLD guideline 2014b). Thus, we made a decision a priori to utilise the individual primary investigators' classification of the type of hepatic encephalopathy and the outcome criteria for hepatic encephalopathy, based on the argument that these decisions will have been made using the criteria that were most clinically relevant when the investigators conducted the trial.

The older RCTs often used co-interventions such as dietary protein restriction. Although the RCTs did not use the co-interventions consistently, participants randomised to experimental or control groups within a given RCT would have had equal access to them. This might result in heterogeneity, but not in systematic differences between groups.

Hepatic encephalopathy varies widely in its manifestations. The RCTs included in our review represent the entire spectrum of the syndrome encountered in people with cirrhosis. Thus, RCTs included people experiencing an acute episode of hepatic encephalopathy, chronic hepatic encephalopathy associated with advanced liver disease, spontaneous or surgically created portal-systemic shunts, and minimal hepatic encephalopathy. In addition, the included RCTs explored the use of non-absorbable disaccharides for primary and secondary prevention of hepatic encephalopathy. The fact that the RCTs address all the objectives of the review strengthens the completeness of the evidence. We included all RCTs with extractable data in our primary analyses. We also conducted subgroup, sensitivity, and regression analyses to determine the differential effects of intervention on the clinical variants. Our analyses showed that non-absorbable disaccharides are associated with stable beneficial effects on clinically important outcomes across the different groups. This supports the external validity of our findings.

This review includes the two commercially available disaccharides, lactulose and lactitol. However, only four of the 28 RCTs of nonabsorbable disaccharides versus placebo/no treatment utilised lactitol (Uribe 1987a; Uribe 1987b; Shi 1997; Riggio 2005). Nine RCTs with a total of 248 participants compared lactulose versus lactitol (Heredia 1987; Morgan 1987a; Morgan 1987b; Heredia 1988; Morgan 1989; Riggio 1989; Grandi 1991; Pai 1995; Jankovic 1996). We found no differences between the two interventions, but the statistical power was insufficient.

People with non-cirrhotic portal hypertension and those with fulminant hepatic failure may also develop hepatic encephalopathy. They are encountered much less frequently in clinical practice and were not represented in the included trials. There is no reason to suppose that our results cannot be extrapolated to people with hepatic encephalopathy associated with non-cirrhotic portal hypertension, e.g. portal vein block. However, the situation in people with fulminant hepatic failure is much more complex and the result may not be directly applicable.

Episodes of hepatic encephalopathy often develop in response to a precipitating event such as infection, gastrointestinal bleeding, alcohol misuse, or electrolyte disturbances. Identification and treatment of these precipitating factors is key to the management of affected individuals although no obvious precipitating factor is identified in 50\% of instances (EASL and AASLD guideline 2014a; EASL and AASLD guideline 2014b). Avoiding likely precipitants such as constipation, dietary indiscretion, and certain medications can also reduce the risk of developing hepatic encephalopathy in the longer term. It is not clear whether use of non-absorbable disaccharides provides additional benefit in situations where hepatic encephalopathy is precipitated by a treatable event. The RCTs included in our review do not provide detailed information on possible precipitating events, on the effects of interventions designed to ameliorate them, or on the effects, if any, of the addition of a non-absorbable disaccharide. However, in two of the included RCTs, non-absorbable disaccharides, used together with measures to manage upper gastrointestinal haemorrhage, prevented the development of hepatic encephalopathy (Sharma 2012; Wen 2013).

Non-adherence to non-absorbable disaccharides is generally ascribed to adverse gastrointestinal effects such as unpredictable diarrhoea, bloating, flatulence, and abdominal pain (Bajaj 2010c; Volk 2012). Although we did find that treatment with lactulose or lactitol was associated with a higher risk of these non-serious adverse events, none of the RCTs included in our review evaluated compliance in a manner that allowed us to assess the potential influence of these gastrointestinal effects. Other factors may, however, be important in determining compliance with treatment both on the part of the person receiving treatment and the physician prescribing it. Thus, people with hepatic encephalopathy 
may be unaware of the need for long-term treatment, may be unable to effectively titrate the dosage, and may find the side effects inconvenient especially when away from home. The physician may fail to explain the multiple ways in which nonabsorbable disaccharides produce their beneficial effects and by placing undue focus on the need for them to pass two semi-soft stools/day may foster the belief that as long as this is achieved, there is no real need to take the medication. They may also erroneously assume that people will comply with treatment and hence fail to check adherence.

Hepatic encephalopathy imposes a significant burden on healthcare systems and the resource utilisation associated with the management of people with hepatic encephalopathy is increasing (Poordad 2007). The increased costs do not seem to reflect the duration of hospitalisation, which has decreased, but a combination of direct and indirect factors such as the costs of treatment and rehabilitation after hospitalisation (Neff 2010). None of the RCTs included in the present review assessed the costs associated with hospitalisation, but we found a clear beneficial effect of non-absorbable disaccharides in preventing the development and recurrence of hepatic encephalopathy that would generally require hospitalisation. Use of non-absorbable disaccharides is also associated with a reduction in the occurrence of serious liver-related complications. This will also result in reduced hospitalisations and lengths of hospital stay.

\section{Quality of the evidence}

The previous version of this review identified several potential biases in included RCTs (Als-Nielsen 2004). In this updated review, we identified a larger number of RCTs and additional information on essential aspects of bias control. As recommended, we combined the individual bias domains in an overall assessment (Gluud 2015). We also included an assessment of individual domains, focusing on RCTs with a low risk of selection bias (Higgins 2011a; Higgins 2011b; Savovic 2012). Based on previous evidence (Savovic 2012), we defined mortality, but not serious adverse events, as an outcome that is robust to performance and detection bias. This decision can be questioned as lack of blinding is not likely to influence the assessment of events such as variceal bleeding, hepatorenal syndrome, and liver failure. We included 14 doubleblind RCTs and cannot exclude the possibility that our analyses overestimate the effect of non-absorbable disaccharides on hepatic encephalopathy due to lack of blinding. In contrast to the previous version of this review, we included any type of for-profit funding as a bias domain (Gluud 2015). The decision to include this domain is debatable (Higgins 2011a; Higgins 2011b). The fact that we included gratuitous supply of interventions or placebo was the main reason why we did not identify RCTs comparing lactulose versus lactitol with a low risk of bias in the overall assessment. Based on the revised assessment of bias control combined with the assessment of the directness of evidence, heterogeneity, precision of effect estimate, and risk of publication bias we classified the quality of the evidence as moderate for the assessment of our primary outcomes mortality, hepatic encephalopathy, and serious adverse events.

The included RCTs were conducted world-wide. The country/ continent of origin included India/Pakistan (Dhiman 2000; Raza 2004; Prasad 2007; Sharma 2009; Mittal 2011; Sharma 2011; Agrawal 2012; Sharma 2012; Jain 2013), the USA (Elkington 1969; Simmons 1970; Brown 1971; Rodgers 1973; McClain 1984), the Far-East (Pai 1995; Shi 1997; Li 1999; Xing 2003; Zeng 2003; Wen 2013),
Europe (Germain 1973; Corazza 1982; Heredia 1987; Morgan 1987a; Morgan 1987b; Heredia 1988; Morgan 1989; Riggio 1989; Grandi 1991; Jankovic 1996; Horsmans 1997; Quero 1997; Riggio 2005), Mexico (Uribe 1987a; Uribe 1987b), and Egypt (Ziada 2013). A single centre in India conducted eight of the RCTs (Dhiman 2000; Prasad 2007; Sharma 2009; Mittal 2011; Sharma 2011; Agrawal 2012; Sharma 2012; Jain 2013). Four of these RCTs involved participants with minimal hepatic encephalopathy (Dhiman 2000; Prasad 2007; Mittal 2011; Jain 2013), and four evaluated primary and secondary prophylaxis (Sharma 2009; Sharma 2011; Agrawal 2012; Sharma 2012). The results of the RCTs evaluating minimal hepatic encephalopathy did not differ substantially from those in the similar RCTs undertaken in centres outside of India. We found no comparable prevention studies undertaken outside of India. Two prevention RCTs conducted in Italy looked at the effects of non-absorbable disaccharides following transjugular intrahepatic portosystemic shunt insertion (Riggio 1989; Riggio 2005). The RCTs found no benefit on mortality, hepatic encephalopathy, or serious adverse events. However, this is a notoriously difficult situation to manage and one that depends more on careful pre-selection of candidates than on post-hoc exhibition of pharmacotherapy. One RCT conducted in China looked at the effect of lactulose in the prevention of hepatic encephalopathy following an acute upper gastrointestinal bleed and observed significant benefit (Wen 2013). We observed clinical variation in participant demographics between the prevention RCTs conducted in India and those conducted elsewhere, but variables such as age, gender, and the aetiology of the cirrhosis did not confound the results. RCTs evaluating the effects of non-absorbable disaccharides for primary and secondary prevention conducted in countries outside of India would strengthen the external validity of our findings.

\section{Potential biases in the review process}

A recent methodological review drew attention to outcome reporting bias in systematic reviews (Page 2014). Changes between the outcomes in protocols and published systematic reviews include the statistical significance of the results for those outcomes. We updated this review to incorporate current recommendations (Higgins 2011a; Higgins 2011b; Gluud 2015). The methods used in this update differ from those in the previous version (Als-Nielsen 2004a; Als-Nielsen 2004b; Als-Nielsen 2005). As part of the update, we changed the definition of our primary outcomes to provide information on benefits as well as harms. Accordingly, we now include serious adverse events as a primary rather than a secondary outcome measure.

The selective publication of RCTs with a positive result increases the risk of outcome reporting bias (Dwan 2008). The RCTs included in the present review were all published as full paper articles and this might be interpreted as a potential publication bias. However, we combined our electronic searches with extensive manual searches of reference lists and conference proceedings. We identified a large number of abstracts, but all were published subsequently as full papers. We found no evidence of publication bias or other small study effects and very few RCTs showed evidence of outcome reporting bias. Of the 29 RCTs on non-absorbable disaccharides versus placebo or no intervention, we were unable to include data for primary outcomes from four RCTs with 64 participants (Elkington 1969; Brown 1971; Rodgers 1973; Shi 1997). The RCTs are small and the narrative information in the published reports suggested that the intervention had a beneficial effect on hepatic

Non-absorbable disaccharides versus placebo/no intervention and lactulose versus lactitol for the prevention and treatment of hepatic 26 encephalopathy in people with cirrhosis (Review)

Copyright (c) 2016 The Cochrane Collaboration. Published by John Wiley \& Sons, Ltd. 
encephalopathy. Exclusion of these four RCTs is unlikely to change our conclusions.

\section{Agreements and disagreements with other studies or reviews}

The previous version of this review assessed the effect of nonabsorbable disaccharides versus placebo/no intervention and lactulose versus lactitol based on a total of 19 RCTs (Als-Nielsen 2004). Eleven RCTs compared lactulose or lactitol versus placebo/ no intervention (Elkington 1969; Simmons 1970; Germain 1973; Rodgers 1973; Corazza 1982; Uribe 1987a; Uribe 1987b; Shi 1997; Watanabe 1997; Li 1999; Dhiman 2000), and eight RCTs compared lactulose versus lactitol (Heredia 1987; Morgan 1987a; Morgan 1987b; Heredia 1988; Morgan 1989; Riggio 1989; Grandi 1991; Pai 1995). Based on a meta-analyses including four RCTs with 85 participants, the review found no effect of non-absorbable disaccharides on mortality compared with placebo/no intervention (Simmons 1970; Germain 1973; Uribe 1987a; Dhiman 2000). A meta-analysis including six RCTs with 207 participants showed a beneficial effect on hepatic encephalopathy (Simmons 1970; Germain 1973; Uribe 1987a; Watanabe 1997; Li 1999; Dhiman 2000), but the effect was not confirmed in an analysis that only included RCTs with a low risk of bias. We included 38 RCTs (1828 participants) in our qualitative evaluation and 34 RCTs in our qualitative analyses. Our analyses include several different groups of participants from several countries. In spite of the clinical differences, our analyses showed negligible or moderate statistical heterogeneity. Our findings disagree with previous evidence, mainly because previous reviews included fewer RCTs.

The joint guidelines from the European and American Associations for the Study of the Liver made four recommendations of relevance to this review (EASL and AASLD guideline 2014a; EASL and AASLD guideline 2014b). First, that lactulose should be the first-choice treatment for an acute episode of overt hepatic encephalopathy in people with cirrhosis. Second, that lactulose should be used for prevention of recurrent episodes of hepatic encephalopathy after the initial episode. Third, that minimal hepatic encephalopathy should not be treated routinely. Fourth, that primary prophylaxis for prevention of the development of hepatic encephalopathy is not required in people with cirrhosis except if they are known to be at high risk.

In agreement with the guideline recommendations, we found a beneficial effect of non-absorbable disaccharides on clinical outcomes in RCTs evaluating secondary prevention and treatment. The guidelines do not recommend routine treatment of minimal hepatic encephalopathy or primary prevention of hepatic encephalopathy. Our analyses provide a large body of evidence showing that people with minimal hepatic encephalopathy benefit from non-absorbable disaccharides in relation to cognitive functioning and probably quality of life, and some evidence that non-absorbable disaccharides may be considered in primary prevention.

\section{AUTHORS' CONCLUSIONS}

\section{Implications for practice}

This review includes randomised clinical trials (RCTs) evaluating the prevention and treatment of hepatic encephalopathy in people with cirrhosis. The analyses found that non- absorbable disaccharides are associated with beneficial effects on mortality and hepatic encephalopathy and that non-absorbable disaccharides can help to reduce serious adverse events associated with the underlying liver disease including liver failure, hepatorenal syndrome, and variceal bleeding. The quality of the evidence was moderate. The interventions may also have a beneficial effect on quality of life, but we were unable to combine the data in metaanalyses. The non-serious gastrointestinal adverse events are well known and include diarrhoea, bloating, and flatulence. The quality of the evidence was very low for the secondary outcomes (quality of life and non-serious adverse events). The mean treatment duration depended on the type of encephalopathy, with five days for acute, 74 days for chronic, 70 days for minimal, and 207 days for prevention of hepatic encephalopathy. None of the RCTs comparing lactulose versus lactitol evaluated quality of life. The review found no differences between lactulose and lactitol for the remaining outcomes. The quality of the evidence was very low.

\section{Implications for research}

We used the EPICOT format (Brown 2006) in the definition of implications for research:

Evidence (what is the current state of the evidence?): this review includes 38 RCTs and provides moderate quality evidence that non-absorbable disaccharides have a beneficial effect on clinical outcomes. Additional research may be needed to further evaluate the effect of the intervention in specific subgroups.

Participants (what is the population of interest?): the largest body of evidence evaluated prevention of hepatic encephalopathy and people with minimal hepatic encephalopathy. Only a relatively small proportion of participants had chronic hepatic encephalopathy or an acute episode of hepatic encephalopathy. Future research may address the effect of non-absorbable disaccharides in these groups.

Interventions (what are the interventions of interest?): the interventions assessed include lactulose and lactitol.

Comparisons (what are the comparisons of interest?): placebocontrolled RCTs as well as RCTs comparing lactulose versus lactitol seem relevant. Future RCTs should also evaluate the effect of cointerventions.

Outcomes (what are the outcomes of interest?): RCTs should include an assessment of mortality, hepatic encephalopathy, and adverse events. Additional evidence evaluating the effect on quality of life is also needed.

Time stamp (date of literature search): October 2015.

\section{ACKNOWLEDGEMENTS}

We would like to thank Mr Ee Teng Goh, Dr Jian Ping Liu, Dr Srdan Novovic, and Ms Grith Block who translated the non-English language papers (Chinese, French, Serbian, Italian, and Spanish). We also thank Ms. Sarah Klingenberg from the Cochrane HepatoBiliary Group for her help with the electronic searches and Dr. Bodil Als-Nielsen and Christian Gluud who contributed to the previous version of this review.

Peer reviewers: Goran Bjelakovic, Serbia; Arun Sanyal, USA. 
Contact editors: Kurinchi S Gurusamy, UK; Janus Christian Jakobsen, Denmark.

Copyright (c) 2016 The Cochrane Collaboration. Published by John Wiley \& Sons, Ltd. 


\section{REFERE N CES}

\section{References to studies included in this review}

Agrawal 2012 \{published and unpublished data\}

* Agrawal A, Sharma BC, Sharma P, Sarin SK. Secondary prophylaxis of hepatic encephalopathy in cirrhosis: an openlabel, randomized controlled trial of lactulose, probiotics, and no therapy. American Journal of Gastroenterology 2012;107:1043-50. [PUBMED: 22710579]

Agrawal A, Sharma P, Sharma B, Sarin S. Secondary prophylaxis of hepatic encephalopathy in cirrhosis: An open label, randomized controlled trial of lactulose, probiotics and notherapy [abstract]. American Journal of Gastroenterology 2010; Vol. 105:S105. [DOI: 10.1038/ajg.2010.320-5; CN-01004953]

Brown 1971 \{published data only\}

Brown H, Trey C, McDermott WV Jr. Lactulose treatment of hepatic encephalopathy in outpatients. Archives of Surgery 1971;102:25-7. [PUBMED: 5538764]

\section{Corazza 1982 \{published data only\}}

Corazza GR, Tacconi C, Zoli G. Use of pyridoxine-alphaketoglutarate (PAK) in hepatic encephalopathy. International Journal of Clinical Pharmacology Research 1982;2(Suppl 1):7-13. [CN-00189390]

\section{Dhiman 2000 \{published data only\}}

Dhiman RK, Sawhney MS, Chawla YK, Das G, Ram S, Dilawari JB. Efficacy of lactulose in cirrhotic patients with subclinical hepatic encephalopathy. Digestive Diseases and Sciences 2000;45:1549-52. [MEDLINE: 20460170]

\section{Elkington 1969 \{published data only\}}

Elkington SG, Floch MH, Conn HO. Lactulose in the treatment of chronic portal-systemic encephalopathy. A double-blind clinical trial. New England Journal of Medicine 1969;281:408-12. [MEDLINE: 69242833]

\section{Germain 1973 \{published data only\}}

Germain L, Frexinos J, Louis A, Ribet A. Double blind study of lactulose in 18 patients with chronic hepatic encephalopathy after portocaval shunt [Étude en double aveugle du lactulose chez 18 malades atteints d'encéphalopathie hépatique chronique après shunt porto-cave]. Archives Francaises des Maladies de L'appareil Digestif 1973;62:293-302. [MEDLINE: 74133808]

\section{Grandi 1991 \{published data only\}}

Grandi M, Sacchetti C, Pederzoli S, Celani MF. A clinical comparative study of crystalline pure lactulose and powder pure lactitol in portosystemic encephalopathy in cirrhotic patients [Studio clinico di confronto tra lattulosio puro in cristalli e lactitolo puro in polvere nella encefalopatia portosistemica del paziente cirrotico]. Minerva Gastroenterologica e Dietologica 1991;37:225-30. [PMID: 1805974]

\footnotetext{
Heredia 1987 \{published and unpublished data\}

* Heredia D, Caballeria J, Arroyo V, Ravelli G, Rodès J. Lactitol versus lactulose in the treatment of acute portal systemic
}

encephalopathy (PSE). A controlled trial. Journal of Hepatology 1987;4:293-8. [MEDLINE: 1989035379]

\section{Heredia 1988 \{published and unpublished data\}}

* Heredia D, Teres J, Orteu N, Rodès J. Lactitol vs. lactulose in the treatment of chronic recurrent portal-systemic encephalopathy. Journal of Hepatology 1988;7:106-10. [MEDLINE: PMID: 3053887]

\section{Horsmans 1997 \{published data only\}}

Geubel AP, Solbreux PM, Horsmans Y, Desager JP, Harvengt C, Dive C. Effect of lactulose in cirrhotic patients with portalsystemic shunting and without clinical encephalopathy: A randomized controlled trial [abstract]. Acta Gastroenterologica Belgica 1991;54:C8. [CN-00266808]

* Horsmans Y, Solbreux PM, Daenens C, Desager JP, Geubel AP. Lactulose improves psychometric testing in cirrhotic patients with subclinical encephalopathy. Alimentary Pharmacology \& Therapeutics 1997;11:165-70. [PUBMED: 9042989]

Jain 2013 \{published and unpublished data\}

Jain L, Sharma BC, Srivastava S, Puri SK, Sharma P, Sarin S. Serum endotoxin, inflammatory mediators, and magnetic resonance spectroscopy before and after treatment in patients with minimal hepatic encephalopathy. Journal of Gastroenterology and Hepatology 2013;28:1187-93. [PUBMED: 23425082]

\section{Jankovic 1996 \{published data only\}}

Jankovic G, Pavicevic V, Pavlovic A, Krstic M, Cabric I, Crnobaric M, et al. Lactitol in the treatment of acute hepatic encephalopathy in liver cirrhosis [Laktitol u therapiji akutne hepatičke encephalopatije]. Archives of Gastroenterohepatology 1996;15:22-4. [CN-00182347]

\section{Li 1999 \{published data only\}}

Li Z, Zhang H, Hong Y, Yu D, Gui X. Clinical effect of lactulose in the treatment of subclinical hepatic encephalopathy. Chinese Journal of Integrated Traditional \& Western Medicine on Liver Diseases 1999;9:13-5.

\section{McClain 1984 \{published data only\}}

McClain CJ, Potter TJ, Kromhout JP, Zieve L. The effect of lactulose on psychomotor performance tests in alcoholic cirrhotics without overt hepatic encephalopathy. Journal of Clinical Gastroenterology 1984;6:325-9. [PUBMED: 6481115]

\section{Mittal 2011 \{published and unpublished data}

* Mittal VV, Sharma BC, Sharma P, Sarin SK. A randomized controlled trial comparing lactulose, probiotics, and Lornithine L-aspartate in treatment of minimal hepatic encephalopathy. European Journal of Gastroenterology \& Hepatology 2011;23:725-32. [PUBMED: 21646910]

Mittal VV, Sharma P, Sharma B, Sarin SK. Treatment of minimal hepatic encephalopathy: a randomized controlled trial comparing lactulose, probiotics \& L-ornithine L-aspartate with placebo [abstract]. Hepatology 2009; Vol. 50, issue Suppl 2:471A. [CN-00739663]

Non-absorbable disaccharides versus placebo/no intervention and lactulose versus lactitol for the prevention and treatment of hepatic 
Morgan 1987a \{published and unpublished data\}

Hawley KE, Morgan MY. A randomised controlled double-blind trial of lactitol and lactulose in acute hepatic encephalopathy in cirrhotic patients [abstract]. Journal of Hepatology 1986; Vol. 3:86.

Hawley KE, Morgan MY. Lactitol vs lactulose in the treatment of acute hepatic encephalopathy in cirrhotic patients: a doubleblind randomised trial [abstract]. Hepatology 1986;6:1148.

Hawley KE, Morgan MY. Randomised controlled double blind trial of lactitol and lactulose in acute hepatic encephalopathy in cirrhotic patients [abstract]. Gut 1986;27:A1266.

* Morgan MY, Hawley KE. Lactitol vs. lactulose in the treatment of acute hepatic encephalopathy in cirrhotic patients: a doubleblind, randomized trial. Hepatology 1987;7:1278-84. [MEDLINE: 88056766]

\section{Morgan 1987b \{published and unpublished data}

Morgan MY, Hawley KE, Stambuk D. Lactitol versus lactulose in the treatment of chronic hepatic encephalopathy. A doubleblind, randomised, cross-over study. Journal of Hepatology 1987;4:236-44. [MEDLINE: 87223884]

\section{Morgan 1989 \{published and unpublished data\}}

* Morgan MY, Alonso M, Stanger LC. Lactitol and lactulose for the treatment of subclinical hepatic encephalopathy in cirrhotic patients. A randomized cross-over study. Journal of Hepatology 1989;8:208-17. [MEDLINE: PMID: 2654285]

Stanger LC, Alonso M, Morgan MY. Lactitol and lactulose for the treatment of subclinical hepatic encephalopathy: a randomised cross-over study [abstract]. Journal of Hepatology 1988;7:179.

\section{Pai 1995 \{published data only\}}

Pai CH, Huang YS, Jeng WC, Chan CY, Lee SD. Treatment of porto-systemic encephalopathy with lactulose: a randomized controlled study. Chinese Medical Journal 1995;55:31-6.

\section{Prasad 2007 \{published and unpublished data\}}

Prasad S, Dhiman RK, Duseja A, Chawla YK, Sharma A, Agarwal R. Lactulose improves cognitive functions and healthrelated quality of life in patients with cirrhosis who have minimal hepatic encephalopathy. Hepatology 2007;45:549-59. [PUBMED: 17326150]

\section{Quero 1997 \{published data only\}}

* Quero JC, Groeneweg M, Meulstee J, Hop WCJ, Schalm SW. Does a low-dose of lactulose improve quality of life in patients with liver cirrhosis?. In: Record C, Al-Mardini H editor(s). Advances in Hepatic Encephalopathy \& Metabolism in Liver Disease: Proceedings of the 9th International Symposium on Ammonia. Vol. 64, Newcastle upon Tyne, UK: Ipswich Book Company Ltd, 1997:459-65. [CN-00363147]

Quero JC, Groeneweg M, Meulstee J, Schalm SW. Does a lowdose of lactulose improve quality of life in patients with liver cirrhosis? [abstract]. European Journal of Gastroenterology and Hepatology 1996;18:A19. [CN-00250860]
Raza 2004 \{published data only\}

Raza MA, Bhatti RS, Akram J. Effect of rectal lactulose administration with oral therapy on time to recovery from hepatic encephalopathy: a randomized study. Annals of Saudi Medicine 2004;24:374-7. [PUBMED: 15573853]

Riggio 1989 \{published and unpublished data\}

* Riggio O, Balducci G, Ariosto F, Merli M, Pieche U, Pinto G, et al. Lactitol in prevention of recurrent episodes of hepatic encephalopathy in cirrhotic patients with portal-systemic shunt. Digestive Diseases and Sciences 1989;34:823-9. [MEDLINE: 1989250975]

Riggio O, Balducci G, Ariosto F, Merli M, Romiti A, Tremiterra S, et al. Lactitol in the treatment of severe chronic hepatic encephalopathy. A randomized cross-over comparison with lactulose [abstract]. Journal of Hepatology 1988; Vol. 7:168.

Riggio O, Balducci G, Ariosto F, Merli M, Tremiterra S, Ziparo V, et al. Lactitol in the treatment of chronic hepatic encephalopathy - a randomized cross-over comparison with lactulose. HepatoGastroenterology 1990;37:524-7. [MEDLINE: PMID: 2253931]

Riggio 2005 \{published and unpublished data\}

* Riggio O, Masini A, Efrati C, Nicolao F, Angeloni S, Salvatori FM, et al. Pharmacological prophylaxis of hepatic encephalopathy after transjugular intrahepatic portosystemic shunt: a randomized controlled study. Journal of Hepatology 2005;42:674-9. [PUBMED: 15826716]

Riggio O, Masini A, Efrati C, Nicolao F, Attili AF, Merli M. Randomized controlled trial for the prevention of early post-tips hepatic encephalopathy: comparison between rifaximin, lactitol and no treatment [abstract]. Hepatology 2001;34:1510.

\section{Rodgers 1973 \{published data only\}}

Rodgers JB Jr, Kiley JE, Balint JA. Comparison of results of long-term treatment of chronic hepatic encephalopathy with lactulose and sorbitol. American Journal of Gastroenterology 1973;60:459-65. [PMID: 4587191]

\section{Sharma 2009 \{published and unpublished data\}}

Sharma BC, Sharma P, Agrawal A, Sarin SK. Secondary prophylaxis of hepatic encephalopathy: an open-label randomized controlled trial of lactulose versus placebo. Gastroenterology 2009;137:885-91. [PUBMED: 19501587]

\section{Sharma 2011 \{published and unpublished data\}}

Sharma P, Agrawal A, Sharma BC, Sarin SK. Prophylaxis of hepatic encephalopathy in acute variceal bleed: a randomized controlled trial of lactulose versus no lactulose. Journal of Gastroenterology and Hepatology 2011;26:996-1003. [PUBMED: 21129028]

\section{Sharma 2012 \{published and unpublished data\}}

Agrawal A, Sharma P, Sharma BC, Sarin SK. Primary prophylaxis of hepatic encephalopathy in patients with cirrhosis: an open labelled randomized controlled trial of lactulose versus no lactulose [abstract]. Journal of Hepatology 2012;56(Suppl 2):S238. [CN-00844674] 
Chander SB, Praveen S, Amit A, Kumar SS. Primary prophylaxis of hepatic encephalopathy in patients with cirrhosis: A open labelled randomized controlled trial of lactulose versus no lactulose [abstract]. Journal of Gastroenterology and Hepatology 2010; Vol. 25:A13. [DOI: 10.1111/j.1440-1746.2009.06493.x; CN-00789741]

* Sharma P, Sharma BC, Agrawal A, Sarin SK. Primary prophylaxis of overt hepatic encephalopathy in patients with cirrhosis: an open labelled randomized controlled trial of lactulose versus no lactulose. Journal of Gastroenterology and Hepatology 2012;27:1329-35. [PUBMED: 22606978]

\section{Shi 1997 \{published data only\}}

Shi H, Liu HY, Fu Z, Zhu L, Chen WZ. Lactitol in treatment of subclinical hepatic encephalopathy: a double blind placebocontrolled randomised trial. Chinese Journal of Digestion 1997; 17:221-3.

\section{Simmons 1970 \{published data only\}}

Simmons F, Goldstein H, Boyle JD. A controlled clinical trial of lactulose in hepatic encephalopathy. Gastroenterology 1970; Vol. 59:827-32. [MEDLINE: 71054874]

Uribe 1987a \{published and unpublished data\}

* Uribe M, Campollo O, Vargas F, Ravelli GP, Mundo F, Zapata L, et al. Acidifying enemas (lactitol and lactose) vs. nonacidifying enemas (tap water) to treat acute portal-systemic encephalopathy: a double-blind, randomized clinical trial. Hepatology 1987;7:639-43.

Uribe M, Gil S, Perez F, Toledo H, Ballesteros A, GarciaRamos G. Successful use of lactitol in acute portal systemic encephalopathy. A double blind controlled trial [abstract]. Hepatology 1984;4:765.

\section{Uribe 1987b \{published and unpublished data\}}

Uribe M, Toledo H, Perez F, Vargas F, Gil S, Garcia-Ramos G, et al. Lactitol, a second-generation disaccharide for treatment of chronic portal-systemic encephalopathy. A double-blind, crossover, randomized clinical trial. Digestive Diseases and Sciences 1987;32:1345-53.

\section{Watanabe 1997 \{published data only\}}

Suzuki H, Sato S, Suzuki K, Muto Y, Watanabe A, Kuriyama K. Phase III study with lactitol (NS-4) for the patients of hyperammonemia: comparative study with lactulose. Rinsho lyaku (Journal of Clinical Therapeutics and Medicines) 1995; Vol. 11:1439-73. [CN-00542601]

Watanabe A, Sakai T, Sato S. Does lactulose improve psychometric tests and quality of life in cirrhotic patients with subclinical hepatic encephalopathy? [abstract]. Hepatology 1996;24:452A.

* Watanabe A, Sakai T, Sato S, Imai F, Ohto M, Arakawa Y, et al. Clinical efficacy of lactulose in cirrhotic patients with and without subclinical hepatic encephalopathy. Hepatology 1997;26:1410-4. [PUBMED: 9397979]
Wen 2013 \{published data only\}

Wen J, Liu Q, Song J, Tong M, Peng L, Liang H. Lactulose is highly potential in prophylaxis of hepatic encephalopathy in patients with cirrhosis and upper gastrointestinal bleeding: results of a controlled randomized trial. Digestion 2013;87:132-8. [PUBMED: 23485720]

Xing 2003 \{published data only\}

Xing Q, Liu L. Research of lactulose in the treatment of minimal hepatic encephalopathy. World Chinese Journal of Digestion 2003;11:108-9.

\section{Yao 2014 \{published data only\}}

Yao C, Huang G, Wang M, Xia M, Yao F, Niu D, et al. Chinese herbal medicine formula Jieduhuayu granules improves cognitive and neurophysiological functions in patients with cirrhosis who have minimal hepatic encephalopathy: a randomized controlled trial. Complementary Therapies in Medicine 2014;22:977-85. [PUBMED: 25453517]

Zeng 2003 \{published data only\}

Nie YQ, Zeng Z, Li YY, Sha WH, Ping L, Dai SJ. Long-term efficacy of lactulose in patients with subclinical hepatic encephalopathy. Zhonghua Nei Ke Za Zhi 2003;42:261-3. [PUBMED: 12887812]

* Zeng Z, Li YY. Effects of lactulose treatment on the course of subclinical hepatic encephalopathy. Zhonghua Yi Xue Za Zhi 2003;83:1126-9. [PUBMED: 12921628]

Zeng Z, Li YY, Jia L, Nie Y-Q. Influence of lactulose on the cognitive level and quality of life in patients with minimal hepatic encephalopathy. Chinese Journal of Clinical Rehabilitation 2006; Vol. 10:165-7. [CN-00613050]

Ziada 2013 \{published data only\}

Ziada DH, Soliman HH, El Yamany SA, Hamisa MF, Hasan AM. Can Lactobacillus acidophilus improve minimal hepatic encephalopathy? A neurometabolite study using magnetic resonance spectroscopy. Arab Journal of Gastroenterology 2013;14:116-22. [PUBMED: 24206740]

\section{References to studies excluded from this review}

Bajaj 2010a \{published data only\}

Bajaj JS, Sanyal AJ, Bell D, Gilles H, Heuman DM. Predictors of the recurrence of hepatic encephalopathy in lactulosetreated patients. Alimentary Pharmacology \& Therapeutics 2010;31:1012-7. [PUBMED: 20136802]

\section{Bircher 1971 \{published data only\}}

Bircher J, Haemmerli UP, Scollo-Lavizzari G, Hoffmann K. Treatment of chronic portal-systemic encephalopathy with lactulose. Report of six patients and review of the literature. American Journal of Medicine 1971;51:148-59. [PUBMED: 5095524]

\section{Brown 1970 \{published data only\}}

Brown H, Trey C, McDermott WV Jr. Encephalopathy after portacaval shunting managed with lactulose. American Journal of Surgery 1970;119:132-7. [PUBMED: 5440784]

Non-absorbable disaccharides versus placebo/no intervention and lactulose versus lactitol for the prevention and treatment of hepatic 
James 1971 \{published data only\}

James IM, Garassini M. Effect of lactulose on cerebral metabolism in patients with chronic portosystemic encephalopathy. Gut 1971;12:702-4. [PUBMED: 5098325]

\section{Lanthier 1985 \{published data only\}}

Lanthier PL, Morgan MY. Lactitol in the treatment of chronic hepatic encephalopathy: an open comparison with lactulose. Gut 1985;26:415-20. [PUBMED: 3979914]

\section{Merli 1992 \{published data only\}}

Merli M, Caschera M, Piat C, Pinto G, Diofebi M, Riggio O. The effect of lactulose and lactitol administration on fecal fat excretion in patients with liver cirrhosis. Journal of Clinical Gastroenterology 1992; Vol. 15:125-7. [CN-00087562]

\section{Patil 1987 \{published data only\}}

Patil DH, Westaby D, Mahida YR, Palmer KR, Rees R, Clark ML, et al. Comparative modes of action of lactitol and lactulose in the treatment of hepatic encephalopathy. Gut 1987;28:255-9. [PUBMED: 3570029]

\section{Piotraschke 1996 \{published data only\}}

Piotraschke J, Berger E, Haag K, Ochs A, Görtelmeyer R, Rössle M. Effect of lactulose on latent hepatic encephalopathy and plasma ammonia concentration in outpatients with TIPS [abstract]. Journal of Hepatology 1996;25:98.

\section{Pockros 2009 \{published data only\}}

Pockros P, Hassanein T, Vierling J, Heuman D, Hillebrand D, Chojkier M. Phase 2, multicenter, randomized study of AST-120 (spherical carbon adsorbent) vs. lactulose in the treatment of low-grade hepatic encephalopathy (HE) [abstract]. Journal of Hepatology 2009; Vol. 50:S43. [CN-00715816]

\section{Quinton 1982 \{published data only\}}

Quinton A, Lamouliatte H, Plane D, Delteil L. Randomized study of mannitol lavage and of a combination of lactulose and kanamycin in prevention and treatment of posthemorrhagic encephalopathy in patients with cirrhosis [abstract]. Gastroenterologie Clinique et Biologique 1982;6:124A.

\section{Rahimi 2014 \{published data only\}}

Rahimi RS, Singal AG, Cuthbert JA, Rockey DC. Lactulose vs polyethylene glycol 3350-electrolyte solution for treatment of overt hepatic encephalopathy: The HELP Randomized Clinical Trial. JAMA Internal Medicine 2014;174:1727-33.

\section{Riggio 1990 \{published data only\}}

Riggio O, Varriale M, Testore GP, Di Rosa R, Di Rosa E, Merli M, et al. Effect of lactitol and lactulose administration on the fecal flora in cirrhotic patients. Journal of Clinical Gastroenterology 1990;12:433-6. [PUBMED: 2398251]

\section{Rorsman 1970 \{published data only\}}

Rorsman G, Sulg I. Lactulose treatment of chronic hepatoportal encephalopathy. A clinical and electroencephalographic study. Acta Medica Scandinavica 1970;187:337-46. [PUBMED: 5526951]

\section{Salerno 1994 \{published data only\}}

Salerno F, Moser P, Maggi A, Vitaliani G, Benetti G. Effects of long-term administration of low-dose lactitol in patients with cirrhosis but without overt encephalopathy. Journal of Hepatology 1994;21:1092-6. [PUBMED: 7699233]

\section{Schomerus 1993 \{published data only\}}

Schomerus H, Schreiegg J. Prevalence of latent portasystemic encephalopathy in an unselected population of patients with liver cirrhosis in general practice. Zeitschrift fur Gastroenterologie 1993;31:231-4. [PUBMED: 8493802]

\section{Sharma 2008 \{published data only\}}

Sharma P, Sharma BC, Puri V, Sarin SK. An open-label randomized controlled trial of lactulose and probiotics in the treatment of minimal hepatic encephalopathy. European Journal of Gastroenterology \& Hepatology 2008;20:506-11. [PUBMED: 18467909]

\section{Sharma 2009a \{published data only\}}

Sharma P, Sharma BC, Sarin SK. Predictors of nonresponse to lactulose for minimal hepatic encephalopathy in patients with cirrhosis. Liver International 2009;29:1365-71. [PUBMED: 19555401]

\section{Sharma 2010 \{published data only\}}

Sharma P, Sharma BC, Sarin SK. Predictors of nonresponse to lactulose in patients with cirrhosis and hepatic encephalopathy. European Journal of Gastroenterology \& Hepatology 2010;22:526-31. [PUBMED: 20009938]

\section{Sharma 2010a \{published data only\}}

Sharma P, Sharma BC, Sarin SK. Prevalence of abnormal psychometric tests and critical flicker frequency after clinical recovery of overt hepatic encephalopathy. Neurology India 2010;58:220-4. [PUBMED: 20508339]

\section{Sharma 2011a \{published data only\}}

Sharma P, Sharma BC. Profile of hepatic encephalopathy in children with cirrhosis and response to lactulose. Saudi Journal of Gastroenterology 2011;17:138-41. [PUBMED: 21372353]

\section{Trovato 1995 \{published data only\}}

Trovato GM, Catalano D, Carpinteri G, Runcio N, Mazzone O. Effects of lactitol on hepatic encephalopathy and plasma amino-acid imbalance. Recenti Progressi in Medicina 1995;86:299-303. [MEDLINE: PMID: 7569287]

Vendemiale 1992 \{published data only\}

Vendemiale G, Palasciano G, Cirelli F, Altamura M, De Vincentiis A, Altomare E. Crystalline lactulose in the therapy of hepatic cirrhosis. Evaluation of clinical and immunological parameters. Preliminary results. Arzneimittel-Forschung 1992;42:969-72. [PMID: 1418064]

\section{Venturini 2005 \{published data only\}}

Venturini I, Ferrieri A, Farina F, Cosenza F, Avallone R, Corsi L, et al. Evaluation of rifaximin, placebo and lactulose in reducing the levels of benzodiazepine-like compounds in patients with liver cirrhosis: a pilot study. Drugs under Experimental and Clinical Research 2005;31:161-8. [PUBMED: 16223206]

Non-absorbable disaccharides versus placebo/no intervention and lactulose versus lactitol for the prevention and treatment of hepatic 
Zeegen 1970 \{published data only\}

Zeegen R, Drinkwater JE, Fenton JC, Vince A, Dawson AM. Some observations on the effects of treatment with lactulose on patients with chronic hepatic encephalopathy. Quarterly Journal of Medicine 1970;39:245-63. [PUBMED: 5449591]

\section{References to ongoing studies}

Salih 2007 \{unpublished data only\}

Lactulose for the prevention of hepatic encephalopathy in participants with cirrhosis and upper gastrointestinal haemorrhage. Ongoing study 2007.

\section{Wang 2012 \{unpublished data only\}}

Impact of lactulose treatment on cognition, assessment of quality of life and changes of intestinal flora in minimal hepatic encephalopathy participants: a multicentre, randomised, openlabel and controlled clinical study. Ongoing study 2012.

\section{Additional references}

\section{Bajaj 2008}

Bajaj JS, Hafeezullah M, Franco J, Varma RR, Hoffmann RG, Knox JF, et al. Inhibitory control test for the diagnosis of minimal hepatic encephalopathy. Gastroenterology 2008;135:1591-600. [PUBMED: 18723018]

\section{Bajaj 2009}

Bajaj JS, Wade JB, Sanyal AJ. Spectrum of neurocognitive impairment in cirrhosis: implications for the assessment of hepatic encephalopathy. Hepatology 2009;50:2014-21. [PUBMED: 19787808]

\section{Bajaj 2010b}

Bajaj JS, Schubert CM, Heuman DM, Wade JB, Gibson DP, Topaz A, et al. Persistence of cognitive impairment after resolution of overt hepatic encephalopathy. Gastroenterology 2010;138:2332-40. [PUBMED: 20178797]

\section{Bajaj 2010c}

Bajaj JS, Sanyal AJ, Bell D, Gilles H, Heuman DM. Predictors of the recurrence of hepatic encephalopathy in lactulosetreated patients. Alimentary Pharmacology \& Therapeutics 2010;31:1012-7. [PUBMED: 20136802]

\section{Bajaj 2011a}

Bajaj JS, Cordoba J, Mullen KD, Amodio P, Shawcross DL, Butterworth RF, et al. Review article: the design of clinical trials in hepatic encephalopathy--an International Society for Hepatic Encephalopathy and Nitrogen Metabolism (ISHEN) consensus statement. Alimentary Pharmacology \& Therapeutics 2011;33:739-47. [PUBMED: 21306407]

\section{Bajaj 2011b}

Bajaj JS, Wade JB, Gibson DP, Heuman DM, Thacker LR, Sterling RK, et al. The multi-dimensional burden of cirrhosis and hepatic encephalopathy on patients and caregivers. American Journal of Gastroenterology 2011;106:1646-53. [PUBMED: 21556040]

\section{Bajaj 2012}

Bajaj JS, Gillevet PM, Patel NR, Ahluwalia V, Ridlon JM, Kettenmann B, et al. A longitudinal systems biology analysis of lactulose withdrawal in hepatic encephalopathy. Metabolic Brain Disease 2012;27:205-15. [PUBMED: 22527995]

\section{Berding 2009}

Berding G, Banati RB, Buchert R, Chierichetti F, Grover VP, Kato $A$, et al. Radiotracer imaging studies in hepatic encephalopathy: ISHEN practice guidelines. Liver International 2009;29:621-8. [PUBMED: 19413665]

\section{Bircher 1966}

Bircher J, Müller J, Guggenheim P, Haemmerli UP. Treatment of chronic portal-systemic encephalopathy with lactulose. Lancet 1966;1:890.

\section{Blanc 1992}

Blanc P, Daures JP, Rouillon JM, Peray P, Pierrugues R, Larrey D, et al. Lactitol or lactulose in the treatment of chronic hepatic encephalopathy: results of a meta-analysis. Hepatology 1992;15:222-8. [PUBMED: 1531204]

\section{Brown 2006}

Brown P, Brunnhuber K, Chalkidou K, Chalmers I, Clarke M, Fenton $\mathrm{M}$, et al. How to formulate research recommendations. BMJ (Clinical Research Ed.) 2006;333:804-6.

\section{Bustamante 1999}

Bustamante J, Rimola A, Ventura PJ, Navasa M, Cirera I, Reggiardo V, et al. Prognostic significance of hepatic encephalopathy in patients with cirrhosis. Journal of Hepatology 1999;30:890-5. [PUBMED: 10365817]

\section{Butterworth 2014}

Butterworth RF. Hepatic encephalopathy in alcoholic cirrhosis. Handbook of Clinical Neurology 2014;125:589-602. [PUBMED: 25307598]

\section{Cadranel 2001}

Cadranel JF, Lebiez E, Di Martino V, Bernard B, El Koury S, Tourbah A, et al. Focal neurological signs in hepatic encephalopathy in cirrhotic patients: an underestimated entity?. American Journal of Gastroenterology 2001;96:515-8. [PUBMED: 11232699]

\section{Camma 1993}

Camma C, Fiorello F, Tine F, Marchesini G, Fabbri A, Pagliaro L. Lactitol in treatment of chronic hepatic encephalopathy. A meta-analysis. Digestive Diseases and Sciences 1993;38:916-22. [PUBMED: 8482191]

\section{Chu 1997}

Chu NS, Yang SS, Liaw YF. Evoked potentials in liver diseases. Journal of Gastroenterology and Hepatology 1997;12:S288-93. [PUBMED: 9407349]

\section{Conn 1977}

Conn HO, Leevy CM, Vlahcevic ZR, Rodgers JB, Maddrey WC, Seeff $L$, et al. Comparison of lactulose and neomycin in the treatment of chronic portal-systemic encephalopathy. A

Non-absorbable disaccharides versus placebo/no intervention and lactulose versus lactitol for the prevention and treatment of hepatic 
double blind controlled trial. Gastroenterology 1977;72:573-83. [PUBMED: 14049]

\section{D'Amico 1986}

D'Amico G, Morabito A, Pagliaro L, Marubini E. Survival and prognostic indicators in compensated and decompensated cirrhosis. Digestive Diseases and Sciences 1986;31:468-75. [PUBMED: 3009109]

\section{D'Amico 2006}

D'Amico G, Garcia-Tsao G, Pagliaro L. Natural history and prognostic indicators of survival in cirrhosis: a systematic review of 118 studies. Journal of Hepatology 2006;44:217-31.

\section{de Jongh 1992}

de Jongh FE, Janssen HL, de Man RA, Hop WC, Schalm SW, van Blankenstein $M$. Survival and prognostic indicators in hepatitis B surface antigen-positive cirrhosis of the liver. Gastroenterology 1992;103:1630-5. [PUBMED: 1426884]

\section{Dwan 2008}

Dwan K, Altman DG, Arnaiz JA, Bloom J, Chan AW, Cronin E, et al. Systematic review of the empirical evidence of study publication bias and outcome reporting bias. PloS One 2008;3:e3081. [CMR-12056]

\section{EASL and AASLD guideline 2014a}

Anonymous. Hepatic encephalopathy in chronic liver disease: 2014 Practice Guideline by the European Association for the Study of the Liver and the American Association for the Study of Liver Diseases. Journal of Hepatology 2014;61:642-59. [PUBMED: 25015420]

\section{EASL and AASLD guideline 2014b}

Vilstrup H, Amodio P, Bajaj J, Cordoba J, Ferenci P, Mullen KD, et al. Hepatic encephalopathy in chronic liver disease: 2014 Practice Guideline by the American Association for the Study of Liver Diseases and the European Association for the Study of the Liver. Hepatology 2014;60:715-35. [PUBMED: 25042402]

\section{Ferenci 2002}

Ferenci P, Lockwood A, Mullen K, Tarter R, Weissenborn K, Blei AT. Hepatic encephalopathy--definition, nomenclature, diagnosis, and quantification: final report of the working party at the 11th World Congresses of Gastroenterology, Vienna, 1998. Hepatology 2002;35:716-21. [PUBMED: 11870389]

\section{Gilson 1975}

Gilson BS, Gilson JS, Bergner M, Bobbit RA, Kressel S, Pollard WE, et al. The sickness impact profile. Development of an outcome measure of health care. American Journal of Public Health 1975;65:1304-10. [PUBMED: 1200192]

\section{Gluud 2015}

Gluud C, Nikolova D, Klingenberg SL. Cochrane Hepato-Biliary Group. About Cochrane (Cochrane Review Groups (CRGs)) 2015, Issue 2. Art. No.: LIVER.

\section{GRADEpro [Computer program]}

Brozek J, Oxman A, Schünemann H. GRADEpro. Version 3.2 for Windows. Grade Working Group, 2008.

\section{Groeneweg 1998}

Groeneweg M, Quero JC, De Bruijn I, Hartmann IJ, Essinkbot ML, Hop WC, et al. Subclinical hepatic encephalopathy impairs daily functioning. Hepatology 1998;28:45-9. [PUBMED: 9657095]

\section{Grover 2006}

Grover VP, Dresner MA, Forton DM, Counsell S, Larkman DJ, Patel N, et al. Current and future applications of magnetic resonance imaging and spectroscopy of the brain in hepatic encephalopathy. World Journal of Gastroenterology 2006;12:2969-78. [PUBMED: 16718775]

\section{Guérit 2009}

Guérit JM, Amantini A, Fischer C, Kaplan PW, Mecarelli O, Schnitzler A, et al. Neurophysiological investigations of hepatic encephalopathy: ISHEN practice guidelines. Liver International 2009;29:789-96. [PUBMED: 19638107]

\section{Harbord 2006}

Harbord RM, Egger M, Sterne JA. A modified test for smallstudy effects in meta-analyses of controlled trials with binary endpoints. Statistics in Medicine 2006;25:3443-57. [PUBMED: 16345038]

\section{Haussinger 2000}

Haussinger D, Kircheis G, Fischer R, Schliess F, vom Dahl S. Hepatic encephalopathy in chronic liver disease: a clinical manifestation of astrocyte swelling and low-grade cerebral edema?. Journal of Hepatology 2000;32:1035-8. [PUBMED: 10898326]

\section{Higgins 2008}

Higgins J, White IR, Wood AM. Imputation methods for missing outcome data in meta-analysis of clinical trials. Clinical Trials 2008;5:225-39.

\section{Higgins 2011a}

Higgins JPT, Green S (editors). Cochrane Handbook for Systematic Reviews of Interventions Version 5.1.0 [updated March 2011]. The Cochrane Collaboration, 2011. Available from www.cochrane-handbook.org.

\section{Higgins 2011b}

Higgins JPT, Altman DG, Sterne JAC. Chapter 8: Assessing risk of bias in included studies. In: Higgins JPT, Green S (editors). Cochrane Handbook for Systematic Reviews of Interventions Version 5.1.0 [updated March 2011]. The Cochrane Collaboration, 2011. Available from www.cochranehandbook.org.

\section{ICH-GCP 2007}

International Conference on Harmonisation Expert Working Group. International conference on harmonisation of technical requirements for registration of pharmaceuticals for human use. ICH harmonised tripartite guideline. Guideline for good clinical practice CFR \& ICH Guidelines. Vol. 1, Pennsylvania: Barnett International/PAREXEL, 1997.

Non-absorbable disaccharides versus placebo/no intervention and lactulose versus lactitol for the prevention and treatment of hepatic 


\section{Johanson 2007}

Johanson JF. Review of the treatment options for chronic constipation. MedGenMed: Medscape General Medicine 2007;9:25. [PUBMED: 17955081]

\section{Katz 1963}

Katz MM, Lyerly SB. Methods for measuring adjustment and social behavior in the community: i. Rationale, description, discriminative validity and scale development. Psychological Reports 1963;13:503-35.

\section{Kimer 2015}

Kimer N, Krag A, Møller S, Bendtsen F, Gluud L. Rifaximin for people with hepatic encephalopathy. Cochrane Database of Systematic Reviews 2015, Issue 3. [DOI: 10.1002/14651858.CD011585]

\section{Kircheis 2002}

Kircheis G, Wettstein M, Timmermann L, Schnitzler A, Haussinger D. Critical flicker frequency for quantification of lowgrade hepatic encephalopathy. Hepatology 2002;35:357-66. [PUBMED: 11826409]

\section{Kircheis 2009}

Kircheis G, Knoche A, Hilger N, Manhart F, Schnitzler A, Schulze $\mathrm{H}$, et al. Hepatic encephalopathy and fitness to drive. Gastroenterology 2009;137:1706-15. [PUBMED: 19686744]

\section{Lauridsen 2011}

Lauridsen MM, Jepsen P, Vilstrup H. Critical flicker frequency and continuous reaction times for the diagnosis of minimal hepatic encephalopathy: a comparative study of 154 patients with liver disease. Metabolic Brain Disease 2011;26:135-9. [PUBMED: 21484318]

\section{Miller 2014}

Miller LE, Tennila J, Ouwehand AC. Efficacy and tolerance of lactitol supplementation for adult constipation: a systematic review and meta-analysis. Clinical and Experimental Gastroenterology 2014;7:241-8. [PUBMED: 25050074]

\section{Montagnese 2004}

Montagnese S, Amodio P, Morgan MY. Methods for diagnosing hepatic encephalopathy in patients with cirrhosis: a multidimensional approach. Metabolic Brain Disease 2004;19:281-312. [PUBMED: 15554423]

\section{Montgomery 1929}

Montgomery E, Hudson CS. Transformation of lactose to a new disaccharide, lactulose. Science 1929;69:556.

\section{Neff 2010}

Neff G. Pharmacoeconomics of hepatic encephalopathy. Pharmacotherapy 2010;30:28S-32S. [PUBMED: 20412038]

\section{O'Carroll 1991}

O'Carroll RE, Hayes PC, Ebmeier KP, Dougall N, Murray C, Best JJ, et al. Regional cerebral blood flow and cognitive function in patients with chronic liver disease. Lancet 1991;337:1250-3. [PUBMED: 1674063]

\section{Page 2014}

Page MJ, McKenzie JE, Kirkham J, Dwan K, Kramer S, Green S, et al. Bias due to selective inclusion and reporting of outcomes and analyses in systematic reviews of randomised trials of healthcare interventions. Cochrane Database of Systematic Reviews 2014, Issue 10. [DOI: 10.1002/14651858.MR000035.pub2; MR000035]

\section{Parsons-Smith 1957}

Parsons-Smith BG, Summerskill WH, Dawson AM, Sherlock S. The electroencephalograph in liver disease. Lancet 1957;273:867-71. [PUBMED: 13482229]

\section{Patidar 2014}

Patidar KR, Thacker LR, Wade JB, Sterling RK, Sanyal AJ, Siddiqui MS, et al. Covert hepatic encephalopathy is independently associated with poor survival and increased risk of hospitalization. American Journal of Gastroenterology 2014;109(11):1757-63. [PUBMED: 25178701]

\section{Poordad 2007}

Poordad FF. Review article: the burden of hepatic encephalopathy. Alimentary Pharmacology \& Therapeutics 2007;25:3-9. [PUBMED: 17295846]

\section{Qin 2014}

Qin N, Yang F, Li A, Prifti E, Chen Y, Shao L, et al. Alterations of the human gut microbiome in liver cirrhosis. Nature 2014;513(7516):59-64. [PUBMED: 25079328]

\section{Randolph 2009}

Randolph C, Hilsabeck R, Kato A, Kharbanda P, Li YY, Mapelli D, et al. Neuropsychological assessment of hepatic encephalopathy: ISHEN practice guidelines. Liver International 2009;29:629-35. [PUBMED: 19302444]

\section{RevMan 2014 [Computer program]}

The Nordic Cochrane Centre, The Cochrane Collaboration. Review Manager (RevMan). Version 5.3. Copenhagen: The Nordic Cochrane Centre, The Cochrane Collaboration, 2014.

\section{Riggio 1990b}

Riggio O, Varriale M, Testore GP, Di Rosa R, Di Rosa E, Merli M, et al. Effect of lactitol and lactulose administration on the fecal flora in cirrhotic patients. Journal of Clinical Gastroenterology 1990;12(4):433-6. [PUBMED: 2398251]

\section{Roman 2011}

Roman E, Córdoba J, Torrens M, Torras X, Villanueva C, Vargas V, et al. Minimal hepatic encephalopathy is associated with falls. American Journal of Gastroenterology 2011;106:476-82.

\section{Saunders 1981}

Saunders JB, Walters JR, Davies AP, Paton A. A 20-year prospective study of cirrhosis. BMJ (Clinical Research Ed.) 1981;282:263-6. [PUBMED: 6779978]

\section{Savovic 2012}

Savovic J, Jones HE, Altman DG, Harris RJ, Juni P, Pildal J, et al. Influence of reported study design characteristics on intervention effect estimates from randomized, controlled

Non-absorbable disaccharides versus placebo/no intervention and lactulose versus lactitol for the prevention and treatment of hepatic 
trials. Annals of Internal Medicine 2012;157:429-38. [PUBMED: 22945832]

\section{Schomerus 1981}

Schomerus H, Hamster W, Blunck H, Reinhard U, Mayer K, Dolle W. Latent portosystemic encephalopathy. I. Nature of cerebral functional defects and their effect on fitness to drive. Digestive Diseases and Sciences 1981;26:622-30. [PUBMED: 7249898]

\section{Schomerus 1998}

Schomerus H, Hamster W. Neuropsychological aspects of portal-systemic encephalopathy. Metabolic Brain Disease 1998;13:361-77. [PUBMED: 10206827]

\section{SF 36 questionnaire}

Short Form 36 questionnaire (SF 36). www.sf-36.org (accessed 20 November 2014).

\section{Sotil 2009}

Sotil EU, Gottstein J, Ayala E, Randolph C, Blei AT. Impact of preoperative overt hepatic encephalopathy on neurocognitive function after liver transplantation. Liver Transplantation 2009;15:184-92.

\section{Stata [Computer program]}

Stata Corp, Texas, USA. Stata 13. Stata Corp, Texas, USA, 2007.

\section{Stepanova 2012}

Stepanova M, Mishra A, Venkatesan C, Younossi ZM. In-hospital mortality and economic burden associated with hepatic encephalopathy in the United States from 2005 to 2009. Clinical Gastroenterology and Hepatology 2012;10:1034-41. [PUBMED: 22642955]

\section{Stewart 2007}

Stewart CA, Malinchoc M, Kim WR, Kamath PS. Hepatic encephalopathy as a predictor of survival in patients with endstage liver disease. Liver Transplantation 2007;13:1366-71.

\section{Taylor-Robinson 1994}

Taylor-Robinson SD, Sargentoni J, Marcus CD, Morgan MY, Bryant DJ. Regional variations in cerebral proton spectroscopy in patients with chronic hepatic encephalopathy. Metabolic Brain Disease 1994;9:347-59. [PUBMED: 7898401]

\section{Teasdale 1974}

Teasdale G, Jennett B. Assessment of coma and impaired consciousness. A practical scale. Lancet 1974;2:81-4. [PUBMED: 4136544]

\section{Thorlund 2011}

Thorlund K, Engstrøm J, Wetterslev J, Brok J, Imberger G, Gluud C. User manual for Trial Sequential Analysis (TSA). ctu.dk/ tsa/files/tsa_manual.pdf 2011 (accessed 6 June 2015).

\section{TSA 2011 [Computer program]}

Copenhagen Trial Unit. TSA - Trial Sequential Analysis. Version 0.9 Beta. Copenhagen: Copenhagen Trial Unit, 2011.

\section{Victor 1965}

Victor M, Adams RD, Cole M. The acquired (non-Wilsonian) type of chronic hepatocerebral degeneration. Medicine 1965;44:345-96. [PUBMED: 5318075]

\section{Volk 2012}

Volk ML, Tocco RS, Bazick J, Rakoski MO, Lok AS. Hospital readmissions among patients with decompensated cirrhosis. American Journal of Gastroenterology 2012;107:247-52. [PUBMED: 21931378]

\section{Weissenborn 1998}

Weissenborn K. Diagnosis of encephalopathy. Digestion 1998;59(Suppl 2):22-4.

\section{Weissenborn 2001}

Weissenborn K, Ennen JC, Schomerus H, Ruckert N, Hecker H. Neuropsychological characterization of hepatic encephalopathy. Journal of Hepatology 2001;34:768-73. [PUBMED: 11434627]

\section{WHOQOL 1998}

The WHOQOL Group. Development of the World Health Organization WHOQOL-BREF quality of life assessment. Psychological Medicine 1998;28:551-8. [PUBMED: 9626712]

\section{Zipprich 2012}

Zipprich A, Garcia-Tsao G, Rogowski S, Fleig WE, Seufferlein T, Dollinger MM. Prognostic indicators of survival in patients with compensated and decompensated cirrhosis. Liver International 2012;32:1407-14. [PUBMED: 22679906]

\section{References to other published versions of this review Als-Nielsen 2000}

Als-Nielsen B, Gluud LL, Gluud C. Nonabsorbable disaccharides for hepatic encephalopathy. Cochrane Database of Systematic Reviews 2000, Issue 4. [DOI: 10.1002/14651858.CD003044]

\section{Als-Nielsen 2004a}

Als-Nielsen B, Gluud LL, Gluud C. Non-absorbable disaccharides for hepatic encephalopathy. Cochrane Database of Systematic Reviews 2004, Issue 2. [DOI: 10.1002/14651858.CD003044.pub2]

\section{Als-Nielsen 2004b}

Als-Nielsen B, Gluud LL, Gluud C. Non-absorbable disaccharides for hepatic encephalopathy: systematic review of randomised trials. BMJ (Clinical Research Ed.) 2004;328(7447):1046.

\section{Als-Nielsen 2005}

Als-Nielsen BE, Gluud LL, Gluud CN. Nonabsorbable disaccharides for the treatment of hepatic encephalopathy-a systemic review of randomized clinical trials--a secondary publication. Ugeskrift for Laeger 2005;167:179-82.

\section{Gluud 2016}

Gluud LL, Vilstrup H, Morgan MY. Non-absorbable disaccharides for hepatic encephalopathy: a systematic review and metaanalysis. Hepatology 2016 Apr 15 [Epub ahead of print]. [DOI: 10.1002/hep.28598] 


\section{CHARACTERISTICS OF STUDIES}

Characteristics of included studies [ordered by study ID]

\section{Agrawal 2012}

\begin{tabular}{ll}
\hline Methods & Open, parallel-arm, single-centre, outpatient trial \\
\hline Participants & $\begin{array}{l}\text { The trial includes } 158 \text { participants (see notes) with cirrhosis and a history, but no current evidence, of } \\
\text { overt hepatic encephalopathy. In total, } 71 \% \text { of participants in the lactulose group and } 73 \% \text { in the con- } \\
\text { trol group had minimal hepatic encephalopathy at inclusion. }\end{array}$ \\
& Age (mean \pm SD) \\
- Lactulose group $41 \pm 10.7$ years & - Control group $46.0 \pm 11.2$ years \\
& Proportion of men \\
- Lactulose group $85.0 \%$ & - Control group $78.2 \%$ \\
Aetiology of cirrhosis & - Alcohol $40.0 \%$ \\
- Hepatitis B $20.9 \%$ \\
- Hepatitis C $15.3 \%$
\end{tabular}

Interventions Lactulose syrup versus no intervention for 12 months

\begin{tabular}{ll}
\hline Outcomes & Neuropsychiatric assessment \\
- Mental status (West Haven Criteria) \\
- Number Connection Tests A and B \\
- Bigure Connection Tests A and B \\
- Digit symbol test \\
- Critical Flicker Frequency \\
- Arterial blood ammonia
\end{tabular}

Outcomes included in meta-analyses
Mortality, hepatic encephalopathy, adverse events, and blood ammonia concentrations assessed after 12 months

Inclusion period October 2008 to December 2009

Country of origin India

\section{Notes}

- The trial includes 158 participants randomly allocated to lactulose or no intervention and a third intervention arm with 77 participants allocated to a probiotic. The probiotic group is not included in our analyses.

- The diagnosis of minimal hepatic encephalopathy was based on the presence of at least 2 abnormal psychometric tests.

- The primary outcome of the trial was the development of overt hepatic encephalopathy, graded using the West Haven Criteria, at 12 months.

- Secondary prophylaxis was defined as the prevention of recurrence of hepatic encephalopathy during the follow-up period in participants who had recovered from a previous episode of overt hepatic encephalopathy. 
- The model of end stage liver disease (MELD) score (mean \pm SD) at inclusion was $19.2 \pm 5.5$ in the lactulose group and $18.5 \pm 4.2$ in the control group.

\section{Risk of bias}

\begin{tabular}{|c|c|c|}
\hline Bias & Authors' judgement & Support for judgement \\
\hline $\begin{array}{l}\text { Random sequence genera- } \\
\text { tion (selection bias) }\end{array}$ & Low risk & Table of random numbers \\
\hline $\begin{array}{l}\text { Allocation concealment } \\
\text { (selection bias) }\end{array}$ & Low risk & Numbered, opaque, sealed envelopes \\
\hline $\begin{array}{l}\text { Blinding of participants } \\
\text { and personnel (perfor- } \\
\text { mance bias) } \\
\text { Non-mortality outcomes }\end{array}$ & High risk & Open trial. No blinding of participants or personnel. \\
\hline $\begin{array}{l}\text { Blinding of participants } \\
\text { and personnel (perfor- } \\
\text { mance bias) } \\
\text { Mortality }\end{array}$ & Low risk & Performance bias unlikely to influence the outcome \\
\hline $\begin{array}{l}\text { Blinding of outcome as- } \\
\text { sessment (detection bias) } \\
\text { Non-mortality outcomes }\end{array}$ & High risk & Open trial. No blinding of the outcome assessment. \\
\hline $\begin{array}{l}\text { Blinding of outcome as- } \\
\text { sessment (detection bias) } \\
\text { Mortality }\end{array}$ & Low risk & Detection bias unlikely to influence the outcome \\
\hline $\begin{array}{l}\text { Incomplete outcome data } \\
\text { (attrition bias) } \\
\text { All outcomes }\end{array}$ & Low risk & $\begin{array}{l}\text { The investigators account for all participants randomised and report inten- } \\
\text { tion-to-treat analyses that included all participants. Missing outcome data are } \\
\text { unlikely to affect the analyses or to be associated with the outcome. }\end{array}$ \\
\hline $\begin{array}{l}\text { Selective reporting (re- } \\
\text { porting bias) }\end{array}$ & Low risk & Predefined outcomes reported \\
\hline For-profit funding & Low risk & No for-profit funding \\
\hline Other bias & Low risk & No other biases \\
\hline $\begin{array}{l}\text { Overall assessment (mor- } \\
\text { tality) }\end{array}$ & Low risk & Low risk \\
\hline $\begin{array}{l}\text { Overall assessment (non- } \\
\text { mortality outcomes) }\end{array}$ & High risk & High risk \\
\hline
\end{tabular}

Brown 1971

\begin{tabular}{ll}
\hline Methods & Double-blind, cross-over, single-centre inpatient/outpatient trial \\
\hline Participants & $\begin{array}{l}\text { The trial includes } 20 \text { participants with advanced cirrhosis stabilised in hospital on a low protein diet } \\
\text { and then given increasing amounts of protein until they developed overt hepatic encephalopathy. They } \\
\text { were then randomised to treatment with lactulose or placebo (sorbitol), which they received for pre- } \\
\text { scribed, but not standardised periods of time in rotation }\end{array}$
\end{tabular}

Non-absorbable disaccharides versus placebo/no intervention and lactulose versus lactitol for the prevention and treatment of hepatic 
Brown 1971 (Continued)

- Patient characteristics: not reported

Interventions Lactulose syrup versus placebo (sorbitol) for a maximum of 30 months (see notes)

\begin{tabular}{|c|c|}
\hline Outcomes & $\begin{array}{l}\text { Neuropsychiatric assessment } \\
\text { - Clinical status (no specific overall score) } \\
\text { - Subjective improvement e.g. ability to return to work } \\
\text { - Blood ammonia } \\
\text { - Electroencephalogram } \\
\text { - Number of hospitalisations }\end{array}$ \\
\hline $\begin{array}{l}\text { Outcomes included in } \\
\text { meta-analyses }\end{array}$ & No outcomes included in meta-analyses (see notes) \\
\hline Inclusion period & Not reported \\
\hline Country of origin & USA \\
\hline Notes & $\begin{array}{l}\text { - The investigators initially evaluated participants in hospital, but continued follow-up on an outpatient } \\
\text { basis. Based on the text, we estimated that the maximum treatment duration was } 30 \text { months. } \\
\text { - The published report excludes } 11 \text { participants for the following reasons: i) follow-up too short }(n=2) \text {; } \\
\text { ii) non-compliant with treatment }(n=3) \text {; iii) managed with protein restriction alone }(n=3) \text {; iv) died } \\
\text { due to acute alcoholic hepatitis }(n=2) \text { or lymphoma }(n=1) \text {. The authors report that } 9 \text { of the remaining } \\
\text { participants responded well with a reduction in the number of hospitalisations during treatment with } \\
\text { lactulose. Illustrative narrative data are provided on } 5 \text { of these } 9 \text { participants. } \\
\text { - We were unable to extract qualitative outcome data. } \\
\text { - The investigators did not assess the quality of life directly, but indirectly via the subjective overall } \\
\text { assessment of improvement (e.g. return to work). }\end{array}$ \\
\hline
\end{tabular}

\section{Risk of bias}

\begin{tabular}{|c|c|c|}
\hline Bias & Authors' judgement & Support for judgement \\
\hline $\begin{array}{l}\text { Random sequence genera- } \\
\text { tion (selection bias) }\end{array}$ & Unclear risk & Not described \\
\hline $\begin{array}{l}\text { Allocation concealment } \\
\text { (selection bias) }\end{array}$ & Low risk & Blinded administration of interventions \\
\hline $\begin{array}{l}\text { Blinding of participants } \\
\text { and personnel (perfor- } \\
\text { mance bias) } \\
\text { Non-mortality outcomes }\end{array}$ & Low risk & Double-blind, placebo-controlled. Blinding of participants and personnel. \\
\hline $\begin{array}{l}\text { Blinding of participants } \\
\text { and personnel (perfor- } \\
\text { mance bias) } \\
\text { Mortality }\end{array}$ & Low risk & Performance bias unlikely to influence the outcome \\
\hline $\begin{array}{l}\text { Blinding of outcome as- } \\
\text { sessment (detection bias) } \\
\text { Non-mortality outcomes }\end{array}$ & Low risk & Double-blind, placebo-controlled. Blinding of outcome assessment. \\
\hline $\begin{array}{l}\text { Blinding of outcome as- } \\
\text { sessment (detection bias) } \\
\text { Mortality }\end{array}$ & Low risk & Detection bias unlikely to influence the outcome \\
\hline
\end{tabular}

Non-absorbable disaccharides versus placebo/no intervention and lactulose versus lactitol for the prevention and treatment of hepatic 
Brown 1971 (Continued)

Incomplete outcome data High risk The investigators do not account for all participants randomised (see notes). (attrition bias)

All outcomes

\begin{tabular}{lll}
\hline $\begin{array}{l}\text { Selective reporting (re- } \\
\text { porting bias) }\end{array}$ & High risk & Mortality data incomplete \\
\hline For-profit funding & High risk & $\begin{array}{l}\text { The trial received support in the form of a grant from a pharmaceutical compa- } \\
\text { ny. }\end{array}$ \\
\hline Other bias & Low risk & No other biases \\
\hline $\begin{array}{l}\text { Overall assessment (mor- } \\
\text { tality) }\end{array}$ & High risk & High risk \\
\hline $\begin{array}{l}\text { Overall assessment (non- } \\
\text { mortality outcomes) }\end{array}$ & High risk & High risk \\
\hline
\end{tabular}

\section{Corazza 1982}

\begin{tabular}{ll}
\hline Methods & Double-blind, parallel-arm, single-centre inpatient trial \\
\hline Participants & The trial includes 32 participants with cirrhosis and chronic hepatic encephalopathy \\
& Age (mean \pm SD) \\
- Lactulose group $53.7 \pm 2.6$ years \\
- Control group $54.1 \pm 2.9$ years \\
Proportion of men \\
- Lactulose group $37.5 \%$ \\
- Control group $50.0 \%$ \\
Aetiology of cirrhosis \\
- Alcohol $87.5 \%$ \\
- Hepatitis B $12.5 \%$
\end{tabular}

\begin{tabular}{ll}
\hline Interventions $\quad$ Lactulose syrup versus placebo for 10 days \\
\hline
\end{tabular}

Outcomes Neuropsychiatric assessment

- Mental status (Encephalopathy Intensity Score)

- Blood ammonia

- Electroencephalogram

\begin{tabular}{ll}
\hline $\begin{array}{l}\text { Outcomes included in } \\
\text { meta-analyses }\end{array}$ & Mortality, adverse events, and blood ammonia concentrations assessed after 10 days \\
\hline Inclusion period & Not reported \\
\hline Country of origin & Italy \\
\hline Notes & $\begin{array}{l}\text { The trial includes } 32 \text { participants allocated to lactulose or placebo and a third allocation arm with } 20 \\
\text { participants allocated to pyridoxine-alpha-ketoglutarate. The pyridoxine-alpha-ketoglutarate group } \\
\text { is not included in our analyses. }\end{array}$ \\
\hline
\end{tabular}

Non-absorbable disaccharides versus placebo/no intervention and lactulose versus lactitol for the prevention and treatment of hepatic 
- The trial describes the effects of the interventions on hepatic encephalopathy based on an overall score, but does not provide an assessment of the changes in the score from basal (improved or not improved); thus, we were unable to include the post-intervention scores in our analyses.

- The authors give the impression that none of the included participants died.

\section{Risk of bias}

\begin{tabular}{|c|c|c|}
\hline Bias & Authors' judgement & Support for judgement \\
\hline $\begin{array}{l}\text { Random sequence genera- } \\
\text { tion (selection bias) }\end{array}$ & Unclear risk & Not described \\
\hline $\begin{array}{l}\text { Allocation concealment } \\
\text { (selection bias) }\end{array}$ & Low risk & Blinded administration of interventions \\
\hline $\begin{array}{l}\text { Blinding of participants } \\
\text { and personnel (perfor- } \\
\text { mance bias) } \\
\text { Non-mortality outcomes }\end{array}$ & Low risk & Double-blind, placebo-controlled. Blinding of participants and personnel. \\
\hline $\begin{array}{l}\text { Blinding of participants } \\
\text { and personnel (perfor- } \\
\text { mance bias) } \\
\text { Mortality }\end{array}$ & Low risk & Performance bias unlikely to influence the outcome \\
\hline $\begin{array}{l}\text { Blinding of outcome as- } \\
\text { sessment (detection bias) } \\
\text { Non-mortality outcomes }\end{array}$ & Low risk & Double-blind, placebo-controlled. Blinding of outcome assessment. \\
\hline $\begin{array}{l}\text { Blinding of outcome as- } \\
\text { sessment (detection bias) } \\
\text { Mortality }\end{array}$ & Low risk & Detection bias unlikely to influence the outcome \\
\hline $\begin{array}{l}\text { Incomplete outcome data } \\
\text { (attrition bias) } \\
\text { All outcomes }\end{array}$ & Unclear risk & $\begin{array}{l}\text { Unclear outcome data for participants who did not complete the trial. The tri- } \\
\text { al does not appear to have post-randomisation exclusions although this is not } \\
\text { specifically stated. }\end{array}$ \\
\hline $\begin{array}{l}\text { Selective reporting (re- } \\
\text { porting bias) }\end{array}$ & Low risk & Predefined outcomes reported \\
\hline For-profit funding & Low risk & Not reported \\
\hline Other bias & Low risk & No for-profit funding \\
\hline $\begin{array}{l}\text { Overall assessment (mor- } \\
\text { tality) }\end{array}$ & High risk & High risk \\
\hline $\begin{array}{l}\text { Overall assessment (non- } \\
\text { mortality outcomes) }\end{array}$ & High risk & High risk \\
\hline
\end{tabular}

\section{Dhiman 2000}

\begin{tabular}{ll}
\hline Methods & Open, parallel-arm, single-centre, outpatient trial \\
\hline Participants & $\begin{array}{l}\text { The trial includes } 26 \text { participants with cirrhosis and minimal hepatic encephalopathy. None had a past } \\
\text { history of overt hepatic encephalopathy (see notes). }\end{array}$ \\
\hline
\end{tabular}

Non-absorbable disaccharides versus placebo/no intervention and lactulose versus lactitol for the prevention and treatment of hepatic 
Dhiman 2000 (Continued)

\author{
Age (mean \pm SD) \\ - Lactulose group $44.1 \pm 18.0$ years \\ - Control group $47.8 \pm 13.5$ years \\ Proportion of men \\ - Lactulose group $85.7 \%$ \\ - Control group $33.3 \%$ \\ Aetiology of cirrhosis \\ - Alcohol $36 \%$ \\ - Hepatitis B 23\%
}

\begin{tabular}{|c|c|}
\hline Interventions & Lactulose syrup versus no intervention for 3 months \\
\hline Outcomes & $\begin{array}{l}\text { Neuropsychiatric assessment } \\
\text { - Number Connection Tests A and B } \\
\text { - Figure Connection Tests A and B } \\
\text { - Block Design Test } \\
\text { - Picture Completion Test }\end{array}$ \\
\hline $\begin{array}{l}\text { Outcomes included in } \\
\text { meta-analyses }\end{array}$ & Mortality, hepatic encephalopathy, and adverse events assessed after 3 months \\
\hline Inclusion period & Not reported \\
\hline Country of origin & India \\
\hline Notes & $\begin{array}{l}\text { The investigators screened } 40 \text { people with cirrhosis and no past history or current evidence of overt } \\
\text { hepatic encephalopathy using a battery of psychometric tests. The trial includes the } 26 \text { participants } \\
\text { diagnosed as having minimal hepatic encephalopathy on the basis of impaired performance on at } \\
\text { least } 2 \text { of the } 6 \text { psychometric tests administered. These } 26 \text { participants received lactulose }(n=14) \text { or } \\
\text { no treatment }(n=12) \text {. The paper also provides data on the remaining } 14 \text { people who did not have } \\
\text { minimal hepatic encephalopathy ( } 6 \text { of whom were tested at baseline and after } 3 \text { months). We included } \\
\text { data for participants with minimal hepatic encephalopathy in our analyses. } \\
\text { - The report provides the mean number of abnormal tests in the lactulose and control group post in- } \\
\text { tervention. } \\
\text { - The proportion of participants with Child's Grade } B / C \text { at baseline was } 71 \% \text { in the lactulose group and } \\
67 \% \text { in the control group. }\end{array}$ \\
\hline
\end{tabular}

\title{
Risk of bias
}

\begin{tabular}{lll}
\hline Bias & Authors' judgement & Support for judgement \\
\hline $\begin{array}{l}\text { Random sequence genera- } \\
\text { tion (selection bias) }\end{array}$ & Low risk & Table of random numbers \\
\hline $\begin{array}{l}\text { Allocation concealment } \\
\text { (selection bias) }\end{array}$ & Low risk & Numbered opaque sealed envelopes \\
\hline $\begin{array}{l}\text { Blinding of participants } \\
\text { and personnel (perfor- } \\
\text { mance bias) } \\
\text { Non-mortality outcomes }\end{array}$ & High risk & Open trial. No blinding of participants or personnel. \\
\hline
\end{tabular}

Non-absorbable disaccharides versus placebo/no intervention and lactulose versus lactitol for the prevention and treatment of hepatic 
Dhiman 2000 (Continued)

\begin{tabular}{|c|c|c|}
\hline $\begin{array}{l}\text { Blinding of participants } \\
\text { and personnel (perfor- } \\
\text { mance bias) } \\
\text { Mortality }\end{array}$ & Low risk & Performance bias unlikely to influence the outcome \\
\hline $\begin{array}{l}\text { Blinding of outcome as- } \\
\text { sessment (detection bias) } \\
\text { Non-mortality outcomes }\end{array}$ & High risk & Open trial. No blinding of outcome assessment. \\
\hline $\begin{array}{l}\text { Blinding of outcome as- } \\
\text { sessment (detection bias) } \\
\text { Mortality }\end{array}$ & Low risk & Detection bias unlikely to influence the outcome \\
\hline $\begin{array}{l}\text { Incomplete outcome data } \\
\text { (attrition bias) } \\
\text { All outcomes }\end{array}$ & Low risk & $\begin{array}{l}\text { The investigators account for all participants randomised and include all par- } \\
\text { ticipants randomised in the analyses. Missing outcome data unlikely to affect } \\
\text { the analyses or be associated with the outcome. }\end{array}$ \\
\hline $\begin{array}{l}\text { Selective reporting (re- } \\
\text { porting bias) }\end{array}$ & Low risk & Predefined outcomes reported \\
\hline For-profit funding & Low risk & No for-profit funding \\
\hline Other bias & Low risk & No other biases \\
\hline $\begin{array}{l}\text { Overall assessment (mor- } \\
\text { tality) }\end{array}$ & Low risk & Low risk \\
\hline
\end{tabular}

Overall assessment (non- High risk High risk

mortality outcomes)

High risk High risk

\section{Elkington 1969}

\begin{tabular}{ll}
\hline Methods & Double-blind, cross-over, single-centre, outpatient trial \\
\hline Participants & $\begin{array}{l}\text { The trial includes } 7 \text { participants with cirrhosis and chronic hepatic encephalopathy (25\%) or previous } \\
\text { overt hepatic encephalopathy (75\%). All participants had advanced decompensated liver disease. } \\
\text { - Participant's characteristics are not reported (the paper states that participants had decompensated } \\
\text { cirrhosis). }\end{array}$
\end{tabular}

\begin{tabular}{ll}
\hline Interventions & Lactulose syrup versus placebo (sorbitol) for 15 days \\
\hline Outcomes & Neuropsychiatric assessment \\
& - Mental status (modified Parson-Smith criteria) \\
& - Electroencephalography \\
\hline $\begin{array}{l}\text { Outcomes included in } \\
\text { meta-analyses }\end{array}$ & $\begin{array}{l}\text { No outcomes included in our primary meta-analyses. Mortality and hepatic encephalopathy assessed } \\
\text { Inclusion period }\end{array}$ \\
\hline Country of origin & Not reported \\
\hline
\end{tabular}

Non-absorbable disaccharides versus placebo/no intervention and lactulose versus lactitol for the prevention and treatment of hepatic 
Elkington 1969 (Continued)

Notes
- The trial describes 7 participants who were randomised to lactulose or placebo (sorbitol) and then after a wash-out period crossed over to the other treatment. We were unable to extract data on the individual treatment periods. We therefore excluded the trial from our analyses.

\section{Risk of bias}

\begin{tabular}{|c|c|c|}
\hline Bias & Authors' judgement & Support for judgement \\
\hline $\begin{array}{l}\text { Random sequence genera- } \\
\text { tion (selection bias) }\end{array}$ & Unclear risk & Not described \\
\hline $\begin{array}{l}\text { Allocation concealment } \\
\text { (selection bias) }\end{array}$ & Low risk & Blinded allocation of interventions \\
\hline $\begin{array}{l}\text { Blinding of participants } \\
\text { and personnel (perfor- } \\
\text { mance bias) } \\
\text { Non-mortality outcomes }\end{array}$ & Low risk & Double-blind, placebo-controlled. Blinding of participants and personnel. \\
\hline $\begin{array}{l}\text { Blinding of participants } \\
\text { and personnel (perfor- } \\
\text { mance bias) } \\
\text { Mortality }\end{array}$ & Low risk & Performance bias unlikely to influence the outcome \\
\hline $\begin{array}{l}\text { Blinding of outcome as- } \\
\text { sessment (detection bias) } \\
\text { Non-mortality outcomes }\end{array}$ & Low risk & Double-blind, placebo-controlled. Blinding of outcome assessment. \\
\hline $\begin{array}{l}\text { Blinding of outcome as- } \\
\text { sessment (detection bias) } \\
\text { Mortality }\end{array}$ & Low risk & Detection bias unlikely to influence the outcome \\
\hline $\begin{array}{l}\text { Incomplete outcome data } \\
\text { (attrition bias) } \\
\text { All outcomes }\end{array}$ & Unclear risk & $\begin{array}{l}\text { No losses to follow-up or dropouts seemed to occur post-randomisation (clin- } \\
\text { ical outcome data are presented for all participants). The trial report does not } \\
\text { include information about the number of participants allocated to the inter- } \\
\text { vention and control group during the first period. }\end{array}$ \\
\hline $\begin{array}{l}\text { Selective reporting (re- } \\
\text { porting bias) }\end{array}$ & Low risk & Predefined outcomes described \\
\hline For-profit funding & High risk & A pharmaceutical company provided financial support \\
\hline Other bias & Low risk & No other biases \\
\hline $\begin{array}{l}\text { Overall assessment (mor- } \\
\text { tality) }\end{array}$ & High risk & High risk \\
\hline $\begin{array}{l}\text { Overall assessment (non- } \\
\text { mortality outcomes) }\end{array}$ & High risk & High risk \\
\hline
\end{tabular}

Germain 1973

\begin{tabular}{ll}
\hline Methods & Double-blind, parallel-arm, single-centre, outpatient trial \\
\hline Participants & $\begin{array}{l}\text { The trial includes } 18 \text { participants with cirrhosis who developed overt hepatic encephalopathy after por- } \\
\text { tal-systemic shunt surgery. }\end{array}$ \\
\hline
\end{tabular}

Non-absorbable disaccharides versus placebo/no intervention and lactulose versus lactitol for the prevention and treatment of hepatic 
Germain 1973 (Continued)

$$
\begin{aligned}
& \text { Age (mean } \pm \text { SD) } \\
& \text { - Lactulose group } 47.0 \pm 14.2 \text { years } \\
& \text { - Control group } 46.2 \pm 16.6 \text { years } \\
& \text { Proportion of men } \\
& \text { - Lactulose group } 77.7 \% \\
& \text { - Control group } 66.6 \% \\
& \text { Aetiology of cirrhosis not reported }
\end{aligned}
$$

\begin{tabular}{|c|c|c|}
\hline Bias & Authors' judgement & Support for judgement \\
\hline $\begin{array}{l}\text { Random sequence genera- } \\
\text { tion (selection bias) }\end{array}$ & Low risk & Table of random numbers \\
\hline $\begin{array}{l}\text { Allocation concealment } \\
\text { (selection bias) }\end{array}$ & Low risk & Central randomisation \\
\hline $\begin{array}{l}\text { Blinding of participants } \\
\text { and personnel (perfor- } \\
\text { mance bias) } \\
\text { Non-mortality outcomes }\end{array}$ & Low risk & Double-blind, placebo-controlled. Blinding of participants and personnel. \\
\hline $\begin{array}{l}\text { Blinding of participants } \\
\text { and personnel (perfor- } \\
\text { mance bias) } \\
\text { Mortality }\end{array}$ & Low risk & Performance bias unlikely to influence the outcome \\
\hline $\begin{array}{l}\text { Blinding of outcome as- } \\
\text { sessment (detection bias) } \\
\text { Non-mortality outcomes }\end{array}$ & Low risk & Double-blind, placebo-controlled. Blinding of outcome assessment. \\
\hline $\begin{array}{l}\text { Blinding of outcome as- } \\
\text { sessment (detection bias) } \\
\text { Mortality }\end{array}$ & Low risk & Detection bias unlikely to influence the outcome \\
\hline
\end{tabular}

\begin{tabular}{ll}
\hline Interventions & Lactulose syrup versus placebo (saccharose-based) for 15 days \\
\hline Outcomes & Neuropsychiatric assessment \\
& - Mental state (modified Parson-Smith criteria) \\
& - Venous blood ammonia \\
& - Electroencephalography \\
\hline $\begin{array}{l}\text { Outcomes included in } \\
\text { meta-analyses }\end{array}$ & Mortality, hepatic encephalopathy, and adverse events assessed after 15 days \\
\hline Inclusion period & Not reported \\
\hline Country of origin & France \\
\hline Notes & Published in French \\
\hline
\end{tabular}

\section{Risk of bias}

Non-absorbable disaccharides versus placebo/no intervention and lactulose versus lactitol for the prevention and treatment of hepatic 
Germain 1973 (Continued)

$\begin{array}{ll}\text { Incomplete outcome data Low risk } & \text { The investigators account for all participants randomised. There are no miss- } \\ \text { (attrition bias) } & \text { ing outcome data and no dropouts or losses to follow-up post-randomisation }\end{array}$

All outcomes

\begin{tabular}{lll}
\hline $\begin{array}{l}\text { Selective reporting (re- } \\
\text { porting bias) }\end{array}$ & Low risk & Predefined outcomes reported \\
\hline For-profit funding & High risk & A pharmaceutical company was involved in the trial. \\
\hline Other bias & Low risk & No other biases \\
\hline $\begin{array}{l}\text { Overall assessment (mor- } \\
\text { tality) }\end{array}$ & High risk & High risk \\
\hline $\begin{array}{l}\text { Overall assessment (non- } \\
\text { mortality outcomes) }\end{array}$ & High risk & High risk \\
\hline
\end{tabular}

Grandi 1991

\begin{tabular}{ll}
\hline Methods & Open, cross-over, single-centre, inpatient trial \\
\hline Participants & The trial includes 40 participants with cirrhosis and chronic hepatic encephalopathy \\
& Age (median) \\
- Both groups 59.3 years & Proportion of men \\
- Both groups $62.5 \%$ \\
Aetiology of cirrhosis \\
- Not reported \\
\hline Interventions
\end{tabular}

\section{Outcomes Neuropsychiatric assessment}

- Modified Portal Systemic Encephalopathy Index comprising:

a. Mental state (West Haven Criteria)

b. Asterixis

c. Number Connection Test $\mathrm{A}$

d. Venous blood ammonia

Outcomes included in Mortality, hepatic encephalopathy, and adverse events (see notes) assessed after 60 days meta-analyses

\begin{tabular}{ll}
\hline Inclusion period & Not reported \\
\hline Country of origin & Italy \\
\hline Notes & - Published in Italian \\
& - All participants had Child's class B or C cirrhosis
\end{tabular}


Grandi 1991 (Continued)

- The trial does not describe the number of participants with or without an overall improvement in manifestations of hepatic encephalopathy, but describes the intervention effect using the overall score. We were therefore not able to include the trial in the analyses evaluating hepatic encephalopathy.

\section{Risk of bias}

\begin{tabular}{|c|c|c|}
\hline Bias & Authors' judgement & Support for judgement \\
\hline $\begin{array}{l}\text { Random sequence genera- } \\
\text { tion (selection bias) }\end{array}$ & Unclear risk & Not described \\
\hline $\begin{array}{l}\text { Allocation concealment } \\
\text { (selection bias) }\end{array}$ & Unclear risk & Not described \\
\hline $\begin{array}{l}\text { Blinding of participants } \\
\text { and personnel (perfor- } \\
\text { mance bias) } \\
\text { Non-mortality outcomes }\end{array}$ & High risk & Open trial. No blinding of participants or personnel. \\
\hline $\begin{array}{l}\text { Blinding of participants } \\
\text { and personnel (perfor- } \\
\text { mance bias) } \\
\text { Mortality }\end{array}$ & Low risk & Performance bias unlikely to influence the outcome \\
\hline $\begin{array}{l}\text { Blinding of outcome as- } \\
\text { sessment (detection bias) } \\
\text { Non-mortality outcomes }\end{array}$ & High risk & Open trial. No blinding of outcome assessment. \\
\hline $\begin{array}{l}\text { Blinding of outcome as- } \\
\text { sessment (detection bias) } \\
\text { Mortality }\end{array}$ & Low risk & Detection bias unlikely to influence the outcome \\
\hline $\begin{array}{l}\text { Incomplete outcome data } \\
\text { (attrition bias) } \\
\text { All outcomes }\end{array}$ & Low risk & $\begin{array}{l}\text { The investigators account for all participants randomised and there are no } \\
\text { post-randomisation dropouts or losses to follow-up. }\end{array}$ \\
\hline $\begin{array}{l}\text { Selective reporting (re- } \\
\text { porting bias) }\end{array}$ & Low risk & Predefined outcomes reported \\
\hline For-profit funding & High risk & $\begin{array}{l}\text { Pharmaceutical companies supplied the interventions, but were not otherwise } \\
\text { involved in the trial }\end{array}$ \\
\hline Other bias & Low risk & No other biases \\
\hline $\begin{array}{l}\text { Overall assessment (mor- } \\
\text { tality) }\end{array}$ & High risk & High risk \\
\hline $\begin{array}{l}\text { Overall assessment (non- } \\
\text { mortality outcomes) }\end{array}$ & High risk & High risk \\
\hline
\end{tabular}

Heredia 1987

\begin{tabular}{ll}
\hline Methods & Open, parallel-arm, single-centre, inpatient trial \\
\hline Participants & $\begin{array}{l}\text { The trial includes } 40 \text { participants with cirrhosis and an acute episode of hepatic encephalopathy. In to- } \\
\text { tal, } 65 \% \text { had a previous history of overt hepatic encephalopathy. }\end{array}$
\end{tabular}

Non-absorbable disaccharides versus placebo/no intervention and lactulose versus lactitol for the prevention and treatment of hepatic 
Heredia 1987 (Continued)

\author{
Age (mean \pm SD) \\ - Lactulose group $59.3 \pm 3$ years \\ - Lactitol group $60.0 \pm 3$ years \\ Proportion of men \\ - Lactulose group $55 \%$ \\ - Lactitol group $45 \%$ \\ Aetiology of cirrhosis \\ - Alcohol $48 \%$ \\ - Hepatitis B/C not reported
}

\begin{tabular}{ll}
\hline Interventions & Lactulose syrup versus lactitol for 5 days \\
\hline Outcomes & Neuropsychiatric assessment \\
& - Mental state (modified Conn Scale) \\
& - Venous blood ammonia \\
& Moctroencephalography \\
\hline Outcomes included in & Motality, adverse events, and blood ammonia assessed after 5 days \\
\hline Inclusion period & Spain \\
\hline Country of origin & 4 participants (10\%) had undergone portal systemic shunt surgery \\
\hline Notes &
\end{tabular}

\title{
Risk of bias
}

\begin{tabular}{lll}
\hline Bias & Authors' judgement & Support for judgement \\
\hline $\begin{array}{l}\text { Random sequence genera- } \\
\text { tion (selection bias) }\end{array}$ & Low risk & Random number table \\
\hline $\begin{array}{l}\text { Allocation concealment } \\
\text { (selection bias) }\end{array}$ & Low risk & Numbered, sealed envelopes \\
\hline $\begin{array}{l}\text { Blinding of participants } \\
\text { and personnel (perfor- } \\
\text { mance bias) }\end{array}$ & High risk & Open trial. No blinding of participants or personnel. \\
$\begin{array}{l}\text { Non-mortality outcomes } \\
\text { Blinding of participants } \\
\text { and personnel (perfor- } \\
\text { mance bias) }\end{array}$ & Low risk & \\
\begin{tabular}{l} 
Mortality \\
\hline
\end{tabular} & & \\
\hline
\end{tabular}

\begin{tabular}{lll}
\hline $\begin{array}{l}\text { Blinding of outcome as- } \\
\text { sessment (detection bias) } \\
\text { Non-mortality outcomes }\end{array}$ & High risk & Open trial. No blinding of outcome assessment. \\
\hline $\begin{array}{l}\text { Blinding of outcome as- } \\
\text { sessment (detection bias) }\end{array}$ & Unclear risk & Detection bias unlikely to influence the outcome \\
\hline
\end{tabular}

Non-absorbable disaccharides versus placebo/no intervention and lactulose versus lactitol for the prevention and treatment of hepatic 
Heredia 1987 (Continued)

Mortality

\begin{tabular}{lll}
\hline $\begin{array}{l}\text { Incomplete outcome data } \\
\text { (attrition bias) } \\
\text { All outcomes }\end{array}$ & Low risk & $\begin{array}{l}\text { The investigators account for all participants randomised and there are no } \\
\text { post-randomisation dropouts or losses to follow-up. }\end{array}$ \\
\hline $\begin{array}{l}\text { Selective reporting (re- } \\
\text { porting bias) }\end{array}$ & Low risk & Predefined outcomes reported \\
\hline $\begin{array}{l}\text { For-profit funding } \\
\text { Other bias }\end{array}$ & High risk & $\begin{array}{l}\text { A pharmaceutical company supplied the study drugs, but were not otherwise } \\
\text { involved in the trial. }\end{array}$ \\
\hline $\begin{array}{l}\text { Overall assessment (mor- } \\
\text { tality) }\end{array}$ & High risk & No other biases \\
\hline $\begin{array}{l}\text { Overall assessment (non- } \\
\text { mortality outcomes) }\end{array}$ & High risk & High risk \\
\hline
\end{tabular}

Heredia 1988

\begin{tabular}{ll}
\hline Methods & Open, cross-over, single-centre, outpatient trial \\
\hline Participants & $\begin{array}{l}\text { The trial includes } 20 \text { participants with cirrhosis and previous portal-systemic shunt surgery with chron- } \\
\text { ic hepatic encephalopathy } \\
\text { Age (mean } \pm \text { SD) } \\
\text { - Both groups } 54.5 \pm 2.1 \text { years } \\
\text { Proportion of men } \\
\text { - Both groups } 70 \% \\
\text { Aetiology of cirrhosis } \\
\text { - Alcohol } 60 \% \\
\text { - Hepatitis B/C } 24 \%\end{array}$ \\
\hline Lactulose syrup versus lactitol for 3 months \\
\hline
\end{tabular}

\section{Outcomes Neuropsychiatric assessment}

- Quantified neurological status

- Portal Systemic Encephalopathy Sum and Index comprising:

a. Mental state (West Haven Criteria)

b. Asterixis

c. Number Connection Test A

d. Venous blood ammonia

e. Electroencephalogram

Outcomes included in

meta-analyses

Mortality and adverse events assessed after 3 months (see notes) 
Heredia 1988 (Continued)

\begin{tabular}{ll} 
Country of origin & Spain \\
\hline Notes & The trial includes 25 participants. 2 died and 3 dropped out of the study. The trial report does not \\
provide information about the allocation arm (lactulose or lactitol) of the participants who dropped \\
out. \\
- The authors reports the effect on hepatic encephalopathy using the overall Portal Systemic En- \\
cephalopathy Sum, but do not describe the number of participants with (or without) an overall im- \\
provement in hepatic encephalopathy.
\end{tabular}

\section{Risk of bias}

\begin{tabular}{|c|c|c|}
\hline Bias & Authors' judgement & Support for judgement \\
\hline $\begin{array}{l}\text { Random sequence genera- } \\
\text { tion (selection bias) }\end{array}$ & Low risk & Random number table \\
\hline $\begin{array}{l}\text { Allocation concealment } \\
\text { (selection bias) }\end{array}$ & Low risk & Numbered, sealed envelopes \\
\hline $\begin{array}{l}\text { Blinding of participants } \\
\text { and personnel (perfor- } \\
\text { mance bias) } \\
\text { Non-mortality outcomes }\end{array}$ & High risk & Open trial. No blinding of participants or personnel. \\
\hline $\begin{array}{l}\text { Blinding of participants } \\
\text { and personnel (perfor- } \\
\text { mance bias) } \\
\text { Mortality }\end{array}$ & Low risk & Performance bias unlikely to influence the outcome \\
\hline $\begin{array}{l}\text { Blinding of outcome as- } \\
\text { sessment (detection bias) } \\
\text { Non-mortality outcomes }\end{array}$ & High risk & Open trial. No blinding of outcome assessment. \\
\hline $\begin{array}{l}\text { Blinding of outcome as- } \\
\text { sessment (detection bias) } \\
\text { Mortality }\end{array}$ & Low risk & Detection bias unlikely to influence the outcome \\
\hline $\begin{array}{l}\text { Incomplete outcome data } \\
\text { (attrition bias) } \\
\text { All outcomes }\end{array}$ & High risk & Participants who died or dropped out are excluded from the analyses \\
\hline $\begin{array}{l}\text { Selective reporting (re- } \\
\text { porting bias) }\end{array}$ & High risk & Mortality data incomplete \\
\hline For-profit funding & High risk & $\begin{array}{l}\text { A pharmaceutical company supplied lactitol, but was not otherwise involved } \\
\text { in the trial }\end{array}$ \\
\hline Other bias & Low risk & No other biases \\
\hline $\begin{array}{l}\text { Overall assessment (mor- } \\
\text { tality) }\end{array}$ & High risk & High risk \\
\hline $\begin{array}{l}\text { Overall assessment (non- } \\
\text { mortality outcomes) }\end{array}$ & High risk & High risk \\
\hline
\end{tabular}


Horsmans 1997

\begin{tabular}{|c|c|}
\hline Methods & Double-blind, parallel-arm, single-centre, outpatient trial \\
\hline Participants & $\begin{array}{l}\text { The trial includes } 14 \text { participants with cirrhosis and minimal hepatic encephalopathy. None of the in- } \\
\text { cluded participants had a history of overt hepatic encephalopathy. } \\
\text { Age (mean } \pm \text { SD) } \\
\text { - Lactulose group } 59.0 \pm 8.7 \text { years } \\
\text { - Control group } 56.1 \pm 14.2 \text { years } \\
\text { Proportion of men } \\
\text { - Lactulose group } 42.9 \% \\
\text { - Control group } 57.1 \% \\
\text { Aetiology of cirrhosis } \\
\text { - Alcohol } 35.7 \% \\
\text { - Hepatitis B/C not reported }\end{array}$ \\
\hline
\end{tabular}

Interventions Crystalline lactulose versus placebo (lactose) for 15 days

\begin{tabular}{ll}
\hline Outcomes & Neuropsychiatric assessment \\
& - Number Connection Test A \\
- Race Track Test & Automated sinusoid and psychomotor tests \\
- Electroencephalography & Mortality, hepatic encephalopathy, adverse events, and Number Connection Test results assessed after \\
\hline $\begin{array}{l}\text { Outcomes included in } \\
\text { meta-analyses }\end{array}$ & Not reported \\
\hline Inclusion period & Belgium \\
\hline Country of origin & Participants were not lactose intolerant \\
\hline Notes & $\begin{array}{l}\text { The criteria for the diagnosis of minimal hepatic encephalopathy were not specified; all participants } \\
\text { formance. }\end{array}$
\end{tabular}

\section{Risk of bias}

\begin{tabular}{lll}
\hline Bias & Authors' judgement & Support for judgement \\
\hline $\begin{array}{l}\text { Random sequence genera- } \\
\text { tion (selection bias) }\end{array}$ & Low risk & Table of random numbers \\
\hline $\begin{array}{l}\text { Allocation concealment } \\
\text { (selection bias) }\end{array}$ & Low risk & Numbered sealed envelopes. \\
\hline $\begin{array}{l}\text { Blinding of participants } \\
\text { and personnel (perfor- } \\
\text { mance bias) } \\
\text { Non-mortality outcomes }\end{array}$ & Low risk & Double-blind, placebo-controlled. Blinding of participants and personnel. \\
\hline $\begin{array}{l}\text { Blinding of participants } \\
\begin{array}{l}\text { and personnel (perfor- } \\
\text { mance bias) }\end{array}\end{array}$ & Low risk & Performance bias unlikely to influence the outcome \\
\hline
\end{tabular}

Non-absorbable disaccharides versus placebo/no intervention and lactulose versus lactitol for the prevention and treatment of hepatic 
Horsmans 1997 (Continued) Mortality

\begin{tabular}{|c|c|c|}
\hline $\begin{array}{l}\text { Blinding of outcome as- } \\
\text { sessment (detection bias) } \\
\text { Non-mortality outcomes }\end{array}$ & Low risk & Double-blind, placebo-controlled. Blinding of outcome assessment. \\
\hline $\begin{array}{l}\text { Blinding of outcome as- } \\
\text { sessment (detection bias) } \\
\text { Mortality }\end{array}$ & Low risk & Detection bias unlikely to influence the outcome \\
\hline $\begin{array}{l}\text { Incomplete outcome data } \\
\text { (attrition bias) } \\
\text { All outcomes }\end{array}$ & Low risk & $\begin{array}{l}\text { The investigators account for all participants randomised. All participants } \\
\text { completed the trial. }\end{array}$ \\
\hline $\begin{array}{l}\text { Selective reporting (re- } \\
\text { porting bias) }\end{array}$ & Low risk & Predefined outcomes reported \\
\hline For-profit funding & High risk & $\begin{array}{l}\text { A pharmaceutical company supplied the interventions, but was not otherwise } \\
\text { involved in the trial. }\end{array}$ \\
\hline Other bias & Low risk & No other biases \\
\hline $\begin{array}{l}\text { Overall assessment (mor- } \\
\text { tality) }\end{array}$ & High risk & High risk \\
\hline $\begin{array}{l}\text { Overall assessment (non- } \\
\text { mortality outcomes) }\end{array}$ & High risk & High risk \\
\hline
\end{tabular}

Jain 2013

\begin{tabular}{ll}
\hline Methods & Open, parallel-arm, single-centre, outpatient trial \\
\hline Participants & The trial includes 60 participants with cirrhosis and minimal hepatic encephalopathy \\
Age (median and range) & - Lactulose group 42 (15 to 70$)$ years \\
- Control group 41 (17 to 68$)$ years \\
Proportion of men \\
- Lactulose group $66.7 \%$ \\
- Control group $63.3 \%$ \\
Aetiology of cirrhosis \\
- Alcohol $58.3 \%$ \\
- Hepatitis B $18.3 \%$ \\
- Hepatitis C $15.0 \%$
\end{tabular}

Interventions Lactulose syrup versus no intervention for 3 months

\section{Outcomes}

\section{Neuropsychiatric assessment}

- Mental status (West Haven Criteria)

- Arterial blood ammonia

- Psychometric Hepatic Encephalopathy Score (PHES) comprising:

Non-absorbable disaccharides versus placebo/no intervention and lactulose versus lactitol for the prevention and treatment of hepatic 
Jain 2013 (Continued)
a. Number Connection Tests A and B
b. Digit symbol test
c. Serial dotting test
d. Line drawing test

\begin{tabular}{ll}
\hline $\begin{array}{l}\text { Outcomes included in } \\
\text { meta-analyses }\end{array}$ & Mortality, hepatic encephalopathy, and adverse events assessed after 3 months \\
\hline Inclusion period & October 2011 to February 2012 \\
\hline Country of origin & India \\
\hline Notes & The investigators used the Psychometric Hepatic Encephalopathy Score to diagnose minimal hepatic \\
encephalopathy. & The paper also includes follow-up data on 20 participants who did not have evidence of minimal he- \\
patic encephalopathy. & The median (range) Model of End-stage Liver Disease score at inclusion was 19 (14 to 34$)$ for the lactu- \\
lose and 20 (14 to 32) for the control group. \\
The paper also describes plasma cytokines and cerebral magnetic resonance spectroscopy, which are \\
not included in our analyses.
\end{tabular}

\section{Risk of bias}

\begin{tabular}{lll}
\hline Bias & Authors' judgement & Support for judgement \\
\hline $\begin{array}{l}\text { Random sequence genera- } \\
\text { tion (selection bias) }\end{array}$ & Low risk & Computer-generated random numbers \\
\hline $\begin{array}{l}\text { Allocation concealment } \\
\text { (selection bias) }\end{array}$ & Low risk & Central randomisation \\
\hline $\begin{array}{l}\text { Blinding of participants } \\
\text { and personnel (perfor- } \\
\text { mance bias) }\end{array}$ & High risk & $\begin{array}{l}\text { Open trial. This trial is registered on clinicaltrials.gov as placebo-controlled, } \\
\text { bon-mortality outcomes } \\
\text { ceived no intervention. No blinding of participants or personnel. }\end{array}$ \\
\hline $\begin{array}{l}\text { Blinding of participants } \\
\text { and personnel (perfor- } \\
\text { mance bias) }\end{array}$ & Low risk & Performance bias unlikely to influence the outcome \\
\begin{tabular}{l} 
Mortality \\
\hline
\end{tabular} & & \\
\hline
\end{tabular}

$\begin{array}{lll}\text { Blinding of outcome as- } & \text { High risk } & \text { No blinding of outcome assessment } \\ \text { sessment (detection bias) } & \end{array}$

sessment (detection bias)

Non-mortality outcomes

$\begin{array}{ll}\text { Blinding of outcome as- } & \text { Low risk }\end{array}$ Detection bias unlikely to influence the outcome

Mortality

Incomplete outcome data High risk

(attrition bias)

All outcomes
The investigators account for all participants randomised. 2 participants were lost to follow-up and excluded from the analyses.
Selective reporting (re- High risk porting bias)
In the trial registration, the primary outcome measure was 'improvement of minimal hepatic encephalopathy'. In the published report the primary outcome was the change in arterial blood ammonia, inflammatory mediators, serum endotoxins, and cerebral magnetic resonance spectroscopy. The pub-

Non-absorbable disaccharides versus placebo/no intervention and lactulose versus lactitol for the prevention and treatment of hepatic 
Jain 2013 (Continued)

lished report describes "improvement in minimal hepatic encephalopathy" as a secondary outcome measure (reported for participants receiving lactulose).

\begin{tabular}{lll}
\hline For-profit funding & Low risk & No for-profit funding \\
\hline Other bias & Low risk & No other biases \\
\hline $\begin{array}{l}\text { Overall assessment (mor- } \\
\text { tality) }\end{array}$ & High risk & High risk \\
\hline $\begin{array}{l}\text { Overall assessment (non- } \\
\text { mortality outcomes) }\end{array}$ & High risk & High risk \\
\hline
\end{tabular}

Jankovic 1996

\begin{tabular}{ll}
\hline Methods & Open, parallel-arm, single-centre, inpatient trial \\
\hline Participants & $\begin{array}{l}\text { The trial includes } 16 \text { participants with cirrhosis admitted with an acute episode of hepatic en- } \\
\text { cephalopathy. Participant characteristics not reported. }\end{array}$ \\
\hline Interventions & Lactulose syrup versus lactitol for 5 to 7 days \\
\hline Outcomes & Neuropsychiatric assessment \\
& Mental status (West Haven Criteria) \\
\hline $\begin{array}{l}\text { Outcomes included in } \\
\text { meta-analyses }\end{array}$ & $\begin{array}{l}\text { Mortality and adverse events assessed after } 5 \text { to } 7 \text { days and } 13 \text { days after the end of treatment (see } \\
\text { notes) }\end{array}$ \\
\hline $\begin{array}{l}\text { Inclusion period } \\
\text { Country of origin }\end{array}$ & $\begin{array}{l}\text { Serbia reported } \\
\text { Notes }\end{array}$ \\
\hline $\begin{array}{l}\text { The authors reported the intervention effect on the mean values for the measured variables, but did } \\
\text { therefore unable to include the data in our analysis for the outcome hepatic encephalopathy. }\end{array}$
\end{tabular}

\section{Risk of bias}

\begin{tabular}{lll}
\hline Bias & Authors' judgement & Support for judgement \\
\hline $\begin{array}{l}\text { Random sequence genera- } \\
\text { tion (selection bias) }\end{array}$ & Unclear risk & Not described \\
\hline $\begin{array}{l}\text { Allocation concealment } \\
\text { (selection bias) }\end{array}$ & Unclear risk & Not described \\
\hline $\begin{array}{l}\text { Blinding of participants } \\
\text { and personnel (perfor- } \\
\text { mance bias) } \\
\text { Non-mortality outcomes }\end{array}$ & High risk & Open trial. No blinding of participants or personnel. \\
\hline
\end{tabular}


Jankovic 1996 (Continued)

Blinding of participants Low risk Performance bias unlikely to influence the outcome and personnel (performance bias)

Mortality

\begin{tabular}{lll}
\hline $\begin{array}{l}\text { Blinding of outcome as- } \\
\text { sessment (detection bias) } \\
\text { Non-mortality outcomes }\end{array}$ & High risk & Open trial. No blinding of outcome assessment. \\
\hline $\begin{array}{l}\text { Blinding of outcome as- } \\
\text { sessment (detection bias) } \\
\text { Mortality }\end{array}$ & Low risk & Detection bias unlikely to influence the outcome \\
\hline $\begin{array}{l}\text { Incomplete outcome data } \\
\text { (attrition bias) } \\
\text { All outcomes }\end{array}$ & High risk & Participants with missing outcome data are not described and the analyses do \\
\hline $\begin{array}{l}\text { Selective reporting (re- } \\
\text { porting bias) }\end{array}$ & Low risk & not account for participants with missing outcome data. \\
\hline $\begin{array}{l}\text { For-profit funding } \\
\text { Other bias }\end{array}$ & Low risk & Predefined outcomes reported \\
\hline $\begin{array}{l}\text { Overall assessment (mor- } \\
\text { tality) }\end{array}$ & High risk & No for-profit funding \\
\hline $\begin{array}{l}\text { Overall assessment (non- } \\
\text { mortality outcomes) }\end{array}$ & High risk & No other biases \\
\hline
\end{tabular}

Li 1999

\begin{tabular}{ll}
\hline Methods & Open, parallel-arm, multicentre, outpatient trial \\
\hline Participants & The trial includes 86 participants with cirrhosis and minimal hepatic encephalopathy (see notes). \\
& Age (mean \pm SD) \\
& - Lactulose group $47.6 \pm 10.9$ years \\
& Proportion of men \\
& - Lactulose group $77.1 \%$ \\
Aetiology of cirrhosis not reported & Control group $89.5 \%$ \\
\hline Interventions & Lactulose syrup versus no intervention for 30 days \\
\hline Outcomes & Neuropsychiatric assessment \\
\hline & Number Connection Test A \\
\hline
\end{tabular}

Non-absorbable disaccharides versus placebo/no intervention and lactulose versus lactitol for the prevention and treatment of hepatic 
Li 1999 (Continued)

Outcomes included in Mortality, hepatic encephalopathy, and adverse events assessed after 30 days meta-analyses

\begin{tabular}{ll}
\hline Inclusion period & January 1997 to January 1998 \\
\hline Country of origin & China \\
\hline Notes & Published in Chinese \\
- & The participants had minimal hepatic encephalopathy diagnosed on the basis of impaired perfor- \\
& mance on the Number Connection Test results or Digit Symbol Test \\
- & The proportion of participants with Child's Grades B/C in the lactulose group was $79.2 \%$ and in the \\
& control group $84.2 \%$
\end{tabular}

\section{Risk of bias}

\begin{tabular}{|c|c|c|}
\hline Bias & Authors' judgement & Support for judgement \\
\hline $\begin{array}{l}\text { Random sequence genera- } \\
\text { tion (selection bias) }\end{array}$ & Unclear risk & Not described \\
\hline $\begin{array}{l}\text { Allocation concealment } \\
\text { (selection bias) }\end{array}$ & Unclear risk & Not described \\
\hline $\begin{array}{l}\text { Blinding of participants } \\
\text { and personnel (perfor- } \\
\text { mance bias) } \\
\text { Non-mortality outcomes }\end{array}$ & High risk & Open trial. No blinding of participants or personnel. \\
\hline $\begin{array}{l}\text { Blinding of participants } \\
\text { and personnel (perfor- } \\
\text { mance bias) } \\
\text { Mortality }\end{array}$ & Low risk & Performance bias unlikely to influence the outcome \\
\hline $\begin{array}{l}\text { Blinding of outcome as- } \\
\text { sessment (detection bias) } \\
\text { Non-mortality outcomes }\end{array}$ & High risk & Open trial. No blinding of outcome assessment. \\
\hline $\begin{array}{l}\text { Blinding of outcome as- } \\
\text { sessment (detection bias) } \\
\text { Mortality }\end{array}$ & Low risk & Detection bias unlikely to influence the outcome \\
\hline $\begin{array}{l}\text { Incomplete outcome data } \\
\text { (attrition bias) } \\
\text { All outcomes }\end{array}$ & Low risk & $\begin{array}{l}\text { The investigators account for all participants randomised. All participants } \\
\text { completed the trial. }\end{array}$ \\
\hline $\begin{array}{l}\text { Selective reporting (re- } \\
\text { porting bias) }\end{array}$ & Low risk & Predefined outcomes reported \\
\hline For-profit funding & Low risk & No for-profit funding \\
\hline Other bias & Low risk & No other biases \\
\hline $\begin{array}{l}\text { Overall assessment (mor- } \\
\text { tality) }\end{array}$ & High risk & High risk \\
\hline $\begin{array}{l}\text { Overall assessment (non- } \\
\text { mortality outcomes) }\end{array}$ & High risk & High risk \\
\hline
\end{tabular}

Non-absorbable disaccharides versus placebo/no intervention and lactulose versus lactitol for the prevention and treatment of hepatic 
McClain 1984

\begin{tabular}{ll} 
Methods & Double-blind, parallel-arm, single-centre, outpatient trial \\
\hline Participants & The trial includes 32 participants with cirrhosis and minimal hepatic encephalopathy (see notes). \\
Age (mean \pm SD) \\
- Lactulose group $55 \pm 6.5$ years \\
- Control group $54.0 \pm 9.1$ years \\
Proportion of men \\
- Both groups $96.9 \%$ \\
Aetiology of cirrhosis \\
- Alcohol $100 \%$
\end{tabular}

Interventions Lactulose syrup versus placebo (sucrose) for 3 months

\begin{tabular}{ll}
\hline Outcomes & Neuropsychiatric assessment \\
- Number Connection Tests A and B \\
- Digit Symbol Test \\
- Speed of writing words \\
\hline
\end{tabular}

Outcomes included in Adverse events assessed after 3 months (see notes)

meta-analyses

\begin{tabular}{ll}
\hline Inclusion period & Not reported \\
\hline Country of origin & USA \\
\hline Notes & All included participants had minimal hepatic encephalopathy (psychometric testing shows impaired \\
cognitive function). & The report describes the characteristics of participants who completed the trial (lactulose 10 partic- \\
ipants, placebo 12). \\
- The investigators assessed the quality of life based on the Katz social functioning score. The publica- \\
tion does not include quantitative data, but the authors comment that they saw no changes in the \\
Katz score in response to treatment. \\
- We were unable to gather data on the number with (or without) improvement in hepatic encephalopa- \\
thy because the results are expressed as percentage change over baseline.
\end{tabular}

\section{Risk of bias}

\begin{tabular}{lll}
\hline Bias & Authors' judgement & Support for judgement \\
\hline $\begin{array}{l}\text { Random sequence genera- } \\
\text { tion (selection bias) }\end{array}$ & Low risk & Table of random numbers \\
\hline $\begin{array}{l}\text { Allocation concealment } \\
\text { (selection bias) }\end{array}$ & Low risk & Central independent unit \\
\hline
\end{tabular}

Blinding of participants Low risk Double-blind, placebo-controlled. Blinding of participants and personnel.


McClain 1984 (Continued)

Non-mortality outcomes

Blinding of participants Low risk Performance bias unlikely to influence the outcome
and personnel (perfor-
mance bias)
Mortality

\begin{tabular}{|c|c|c|}
\hline $\begin{array}{l}\text { Blinding of outcome as- } \\
\text { sessment (detection bias) } \\
\text { Non-mortality outcomes }\end{array}$ & Low risk & Double-blind, placebo-controlled. Blinding of outcome assessment. \\
\hline $\begin{array}{l}\text { Blinding of outcome as- } \\
\text { sessment (detection bias) } \\
\text { Mortality }\end{array}$ & Low risk & Detection bias unlikely to influence the outcome \\
\hline $\begin{array}{l}\text { Incomplete outcome data } \\
\text { (attrition bias) } \\
\text { All outcomes }\end{array}$ & High risk & $\begin{array}{l}\text { The paper does not account for participants who did not complete the trial } \\
\text { and the analyses exclude participants with missing outcome data. }\end{array}$ \\
\hline $\begin{array}{l}\text { Selective reporting (re- } \\
\text { porting bias) }\end{array}$ & Low risk & Predefined outcomes reported \\
\hline For-profit funding & High risk & $\begin{array}{l}\text { A pharmaceutical company supplied the interventions, but was not otherwise } \\
\text { involved in the trial. }\end{array}$ \\
\hline Other bias & Low risk & No other biases \\
\hline $\begin{array}{l}\text { Overall assessment (mor- } \\
\text { tality) }\end{array}$ & High risk & High risk \\
\hline $\begin{array}{l}\text { Overall assessment (non- } \\
\text { mortality outcomes) }\end{array}$ & High risk & High risk \\
\hline
\end{tabular}

Mittal 2011

\begin{tabular}{ll}
\hline Methods & Open, parallel-arm, single-centre, outpatient trial \\
\hline Participants & The trial includes 80 participants with cirrhosis and minimal hepatic encephalopathy \\
& Age (mean \pm SD) \\
- Lactulose group $43.9 \pm 10.9$ years & - Control group $41.2 \pm 11.9$ years \\
Proportion of men \\
- Lactulose group $80 \%$ \\
- Control group $75 \%$ \\
Aetiology of cirrhosis \\
- Alcohol $37.5 \%$ \\
- Hepatitis $B / C$ C $35.0 \%$
\end{tabular}


Mittal 2011 (Continued)

- Mental status (West Haven Criteria)

- Number Connection Tests A and B

- Figure Connection Tests A and B

- Picture Completion Test

- Block Design Test

- Arterial blood ammonia

Outcomes included in meta-analyses
Mortality, hepatic encephalopathy, adverse events, quality of life, and blood ammonia concentration assessed after 3 months

\begin{tabular}{|c|c|}
\hline Inclusion period & October 2007 to October 2009 \\
\hline Country of origin & India \\
\hline \multirow[t]{3}{*}{ Notes } & $\begin{array}{l}\text { - The trial includes } 160 \text { participants randomised to lactulose }(n=40) \text {, probiotics }(n=40), \text {-ornithine L- } \\
\text { aspartate }(n=40) \text {, or no treatment }(n=40) \text {. The L-ornithine } L \text {-aspartate and probiotic groups are not } \\
\text { included in our analyses. }\end{array}$ \\
\hline & $\begin{array}{l}\text { - The investigators based the diagnosis of minimal hepatic encephalopathy on the presence of at least } \\
2 \text { abnormal psychometric tests. They expressed the psychometric test results as a } Z \text { score equating to } \\
\text { the difference between the observed result and the population norm. They defined a } Z \text { score of }<-2 \\
\text { as abnormal. }\end{array}$ \\
\hline & $\begin{array}{l}\text { The investigators assessed quality of life with the Sickness Impact Profile questionnaire, which as- } \\
\text { sessed the influence of disease and treatment on daily functioning. The questionnaire consists of } 136 \\
\text { items, which are grouped into } 12 \text { scales such as sleep and rest, eating, work, and home management. } \\
\text { Scores range from } 0 \text { (best score) to } 100 \text { (worst score). Changes in the score were calculated. The scores } \\
\text { were comparable at baseline. After treatment, the score was lower in the lactulose group compared } \\
\text { with controls. }\end{array}$ \\
\hline
\end{tabular}

\section{Risk of bias}

\begin{tabular}{lll}
\hline Bias & Authors' judgement & Support for judgement \\
\hline $\begin{array}{l}\text { Random sequence genera- } \\
\text { tion (selection bias) }\end{array}$ & Low risk & Computer-generated random numbers \\
\hline $\begin{array}{l}\text { Allocation concealment } \\
\text { (selection bias) }\end{array}$ & Low risk & Central randomisation \\
\hline $\begin{array}{l}\text { Blinding of participants } \\
\text { and personnel (perfor- } \\
\text { mance bias) }\end{array}$ & High risk & Open trial. No blinding of participants or personnel. \\
$\begin{array}{l}\text { Non-mortality outcomes } \\
\begin{array}{l}\text { Blinding of participants } \\
\text { and personnel (perfor- } \\
\text { mance bias) }\end{array}\end{array}$ & Low risk \\
$\begin{array}{l}\text { Mortality } \\
\end{array}$ & & Performance bias unlikely to influence the outcome \\
\hline
\end{tabular}

\begin{tabular}{lll}
\hline $\begin{array}{l}\text { Blinding of outcome as- } \\
\text { sessment (detection bias) } \\
\text { Non-mortality outcomes }\end{array}$ & High risk & Open trial. No blinding of outcome assessment. \\
\hline $\begin{array}{l}\text { Blinding of outcome as- } \\
\begin{array}{l}\text { sessment (detection bias) } \\
\text { Mortality }\end{array}\end{array}$ & Low risk & Detection bias unlikely to influence the outcome \\
\hline $\begin{array}{l}\text { Incomplete outcome data } \\
\text { (attrition bias) }\end{array}$ & Low risk & $\begin{array}{l}\text { The investigators account for all participants randomised and used sufficient } \\
\text { methods to handle missing data in the analyses of clinical outcomes (but not }\end{array}$ \\
\hline
\end{tabular}

Non-absorbable disaccharides versus placebo/no intervention and lactulose versus lactitol for the prevention and treatment of hepatic $\mathbf{5 9}$ encephalopathy in people with cirrhosis (Review)

Copyright $\odot 2016$ The Cochrane Collaboration. Published by John Wiley \& Sons, Ltd. 
Mittal 2011 (Continued)

All outcomes

in the analyses of surrogate outcomes). Missing outcome data are unlikely to affect the analyses or to be associated with the outcome.

\begin{tabular}{lll}
\hline $\begin{array}{l}\text { Selective reporting (re- } \\
\text { porting bias) }\end{array}$ & Low risk & Predefined outcomes reported \\
\hline For-profit funding & Low risk & No for-profit funding \\
\hline Other bias & Low risk & No other biases \\
\hline $\begin{array}{l}\text { Overall assessment (mor- } \\
\text { tality) }\end{array}$ & Low risk & Low risk \\
\hline $\begin{array}{l}\text { Overall assessment (non- } \\
\text { mortality outcomes) }\end{array}$ & High risk & High risk \\
\hline
\end{tabular}

\section{Morgan 1987a}

\begin{tabular}{ll}
\hline Methods & Double-blind, parallel-arm, single-centre, inpatient trial \\
\hline Participants & The trial includes 25 participants with cirrhosis and acute hepatic encephalopathy (see notes). \\
Age (mean \pm SD) & - Lactulose group $48.3 \pm 15.8$ years \\
- Lactitol group $48.4 \pm 12.5$ years \\
Proportion of men \\
- Lactulose group $46.7 \%$ \\
- Lactitol group $61.5 \%$ \\
Aetiology of cirrhosis \\
- Alcohol $53.7 \%$ \\
- Hepatitis B/C $0 \%$
\end{tabular}

Interventions Lactulose versus lactitol as identically presented liquids for 5 days

Neuropsychiatric assessment
- Portal Systemic Encephalopathy Sum and Index comprising:
a. Mental state (West Haven Criteria)
b. Asterixis
c. Number Connection Test A
d. Venous blood ammonia
e. Electroencephalogram

Outcomes included in meta-analyses
Mortality, hepatic encephalopathy, adverse events, and Number Connection Test results assessed after 5 days (end of treatment). Additional information retrieved for clinical outcomes 1 month after the end of treatment (see notes).

Inclusion period July 1984 to December 1985


Morgan 1987a (Continued) Notes
- Initially, the investigators evaluated 27 potentially eligible participants, but excluded 2 with fulminant hepatic failure before treatment. The investigators randomised 25 participants, who experienced between them 28 episodes of hepatic encephalopathy.

- 3 participants discontinued treatment with lactitol because they developed severe nausea $(n=1)$, profuse gastrointestinal bleeding $(n=1)$, or ileus $(n=1)$. All 3 participants died after the end of treatment.

- None of the participants died during the trial. Participants who died after the completion of the trial had severely decompensated cirrhosis.

- The investigators reported that the time to improved manifestations of hepatic encephalopathy was shorter in the group of participants allocated to lactitol.

- Participants with autoimmune hepatitis made up $23.1 \%$ of the lactulose group and $13.3 \%$ of the lactitol group.

- All participants had Child's Grade B/C cirrhosis.

- One of the review authors (Marsha Y Morgan) was the primary investigator on the trial.

\section{Risk of bias}

\begin{tabular}{|c|c|c|}
\hline Bias & Authors' judgement & Support for judgement \\
\hline $\begin{array}{l}\text { Random sequence genera- } \\
\text { tion (selection bias) }\end{array}$ & Low risk & Random number table \\
\hline $\begin{array}{l}\text { Allocation concealment } \\
\text { (selection bias) }\end{array}$ & Low risk & Central independent unit \\
\hline $\begin{array}{l}\text { Blinding of participants } \\
\text { and personnel (perfor- } \\
\text { mance bias) } \\
\text { Non-mortality outcomes }\end{array}$ & Low risk & $\begin{array}{l}\text { Double-blind trial with administration of the interventions as identically ap- } \\
\text { pearing solutions. Blinding of participants and personnel. }\end{array}$ \\
\hline $\begin{array}{l}\text { Blinding of participants } \\
\text { and personnel (perfor- } \\
\text { mance bias) } \\
\text { Mortality }\end{array}$ & Low risk & Performance bias unlikely to influence the outcome \\
\hline $\begin{array}{l}\text { Blinding of outcome as- } \\
\text { sessment (detection bias) } \\
\text { Non-mortality outcomes }\end{array}$ & Low risk & Blinding of outcome assessment \\
\hline $\begin{array}{l}\text { Blinding of outcome as- } \\
\text { sessment (detection bias) } \\
\text { Mortality }\end{array}$ & Low risk & Detection bias unlikely to influence the outcome \\
\hline $\begin{array}{l}\text { Incomplete outcome data } \\
\text { (attrition bias) } \\
\text { All outcomes }\end{array}$ & Low risk & $\begin{array}{l}\text { The investigators account for all participants randomised. There are no post- } \\
\text { randomisation exclusions (follow-up assessments and clinical monitoring con- } \\
\text { tinued for all participants, including those who discontinued the interven- } \\
\text { tions). }\end{array}$ \\
\hline $\begin{array}{l}\text { Selective reporting (re- } \\
\text { porting bias) }\end{array}$ & Low risk & Predefined outcomes reported \\
\hline For-profit funding & High risk & $\begin{array}{l}\text { A pharmaceutical company supplied lactitol, but was not otherwise involved } \\
\text { in the trial. }\end{array}$ \\
\hline Other bias & Low risk & No other biases \\
\hline $\begin{array}{l}\text { Overall assessment (mor- } \\
\text { tality) }\end{array}$ & High risk & High risk \\
\hline
\end{tabular}

Non-absorbable disaccharides versus placebo/no intervention and lactulose versus lactitol for the prevention and treatment of hepatic 
Morgan 1987a (Continued)

Overall assessment (nonmortality outcomes)

High risk High risk

\section{Morgan 1987b}

\begin{tabular}{ll} 
Methods & Double-blind, cross-over, single-centre, outpatient trial \\
\hline Participants & The trial includes 12 participants with cirrhosis and chronic hepatic encephalopathy. \\
Age (mean \pm SD) & - Both groups $57.3 \pm 11.5$ years \\
Proportion of men \\
- Both groups $55.6 \%$ \\
Aetiology of cirrhosis \\
- Alcohol $44 \%$ \\
- Hepatitis B/C $0 \%$
\end{tabular}

Interventions Lactulose versus lactitol as identically presented liquids for 3 months

\begin{tabular}{|c|c|}
\hline Outcomes & $\begin{array}{l}\text { Neuropsychiatric assessment } \\
\text { - Portal Systemic Encephalopathy Sum and Index comprising: } \\
\text { a. Mental status (West Haven Criteria) } \\
\text { b. Asterixis } \\
\text { c. Number Connection Test A } \\
\text { d. Venous blood ammonia } \\
\text { e. Electroencephalogram }\end{array}$ \\
\hline $\begin{array}{l}\text { Outcomes included in } \\
\text { meta-analyses }\end{array}$ & $\begin{array}{l}\text { Mortality, hepatic encephalopathy, adverse events, Number Connection Test results, and blood ammo- } \\
\text { nia concentrations assessed after } 3 \text { months }\end{array}$ \\
\hline Inclusion period & November 1985 to February 1986 \\
\hline Country of origin & United Kingdom \\
\hline Notes & $\begin{array}{l}\text { - } 3 \text { of } 9 \text { participants had surgical portal-systemic shunts. } \\
\text { - In total, } 56 \% \text { of participants had cryptogenic cirrhosis. } \\
\text { - } 3 \text { of } 12 \text { participants did not complete the trial because they died }(n=1) \text { or began to abuse alcohol and } \\
\text { were non-compliant in the early phase of the first treatment period }(n=2) \text {. Data on all participants } \\
\text { are included in our analyses. } \\
\text { - One of the review authors (Marsha Y Morgan) was primary investigator on the trial. }\end{array}$ \\
\hline
\end{tabular}

\section{Risk of bias}

\begin{tabular}{lll}
\hline Bias & Authors' judgement & Support for judgement \\
\hline $\begin{array}{l}\text { Random sequence genera- } \\
\text { tion (selection bias) }\end{array}$ & Low risk & Random number table \\
\hline
\end{tabular}


Morgan 1987b (Continued)

\begin{tabular}{lll}
$\begin{array}{l}\text { Allocation concealment } \\
\text { (selection bias) }\end{array}$ & Low risk & Central independent unit \\
\hline $\begin{array}{l}\text { Blinding of participants } \\
\begin{array}{l}\text { and personnel (perfor- } \\
\text { mance bias) }\end{array}\end{array}$ & Low risk & $\begin{array}{l}\text { Double-blind trial with administration of the interventions as identically ap- } \\
\text { pearing solutions. Blinding of participants and personnel. }\end{array}$
\end{tabular}

mance bias)

Non-mortality outcomes

Blinding of participants Low risk Performance bias unlikely to influence the outcome
and personnel (perfor-
mance bias)
Mortality

\begin{tabular}{|c|c|c|}
\hline $\begin{array}{l}\text { Blinding of outcome as- } \\
\text { sessment (detection bias) } \\
\text { Non-mortality outcomes }\end{array}$ & Low risk & Blinding of outcome assessment \\
\hline $\begin{array}{l}\text { Blinding of outcome as- } \\
\text { sessment (detection bias) } \\
\text { Mortality }\end{array}$ & Low risk & Detection bias unlikely to influence the outcome \\
\hline $\begin{array}{l}\text { Incomplete outcome data } \\
\text { (attrition bias) } \\
\text { All outcomes }\end{array}$ & Low risk & $\begin{array}{l}\text { The investigators account for all participants randomised and there are no } \\
\text { missing outcome data. }\end{array}$ \\
\hline $\begin{array}{l}\text { Selective reporting (re- } \\
\text { porting bias) }\end{array}$ & Low risk & Predefined outcomes reported \\
\hline For-profit funding & High risk & $\begin{array}{l}\text { A pharmaceutical company supplied lactitol, but was not otherwise involved } \\
\text { in the trial. }\end{array}$ \\
\hline Other bias & Low risk & No other biases \\
\hline $\begin{array}{l}\text { Overall assessment (mor- } \\
\text { tality) }\end{array}$ & High risk & High risk \\
\hline $\begin{array}{l}\text { Overall assessment (non- } \\
\text { mortality outcomes) }\end{array}$ & High risk & High risk \\
\hline
\end{tabular}

Morgan 1989

\begin{tabular}{|c|c|}
\hline Methods & Single-blind, cross-over, single-centre, outpatient trial \\
\hline Participants & $\begin{array}{l}\text { The trial includes } 20 \text { participants with cirrhosis, minimal hepatic encephalopathy, and no history of } \\
\text { previous overt hepatic encephalopathy (see notes). } \\
\text { Age (mean and range) } \\
\text { - Both groups } 52.0 \text { ( } 37 \text { to } 66 \text { ) years } \\
\text { Proportion of men } \\
\text { - Both groups } 78.6 \% \\
\text { Aetiology of cirrhosis } \\
\text { - Alcohol } 100 \%\end{array}$ \\
\hline
\end{tabular}

Non-absorbable disaccharides versus placebo/no intervention and lactulose versus lactitol for the prevention and treatment of hepatic 
Morgan 1989 (Continued)

Interventions Lactulose syrup versus lactitol for 2 months.

Neuropsychiatric assessment
- Mental status (Modified Conn Score)
- Number Connection Tests A and B
- Digit Symbol Test
- Digit Copying Test
- Computer-based visual reaction time
- Computer-based perceptual maze test
- Electroencephalography

Outcomes included in meta-analyses
Mortality, hepatic encephalopathy, adverse events, and Number Connection Test results assessed after 2 months

\begin{tabular}{ll}
\hline Inclusion period & October 1986 to April 1988 \\
\hline Country of origin & United Kingdom \\
\hline Notes & - All participants were abstinent from alcohol. \\
- & 6 of the initially randomised participants did not complete 2 weeks of treatment because of non-se- \\
& rious adverse events (lactitol $n=1$ ) or for reasons unrelated to the trial (lactulose: $\mathrm{n}=2 ;$ lactitol: $\mathrm{n}=$ \\
& 3). 14 participants completed the trial. None died. We included data on all randomised participants \\
in our analyses. & One of the review authors (Marsha Y Morgan) was the primary investigator on the trial.
\end{tabular}

\section{Risk of bias}

\begin{tabular}{|c|c|c|}
\hline Bias & Authors' judgement & Support for judgement \\
\hline $\begin{array}{l}\text { Random sequence genera- } \\
\text { tion (selection bias) }\end{array}$ & Low risk & Random number table \\
\hline $\begin{array}{l}\text { Allocation concealment } \\
\text { (selection bias) }\end{array}$ & Low risk & Numbered, opaque, sealed envelopes \\
\hline $\begin{array}{l}\text { Blinding of participants } \\
\text { and personnel (perfor- } \\
\text { mance bias) } \\
\text { Non-mortality outcomes }\end{array}$ & High risk & Open, single-blind trial. No blinding of participants or personnel. \\
\hline $\begin{array}{l}\text { Blinding of participants } \\
\text { and personnel (perfor- } \\
\text { mance bias) } \\
\text { Mortality }\end{array}$ & Low risk & Performance bias unlikely to influence the outcome \\
\hline $\begin{array}{l}\text { Blinding of outcome as- } \\
\text { sessment (detection bias) } \\
\text { Non-mortality outcomes }\end{array}$ & Low risk & Open, single-blind trial. Blinding of outcome assessment. \\
\hline $\begin{array}{l}\text { Blinding of outcome as- } \\
\text { sessment (detection bias) } \\
\text { Mortality }\end{array}$ & Low risk & Detection bias unlikely to influence the outcome \\
\hline $\begin{array}{l}\text { Incomplete outcome data } \\
\text { (attrition bias) } \\
\text { All outcomes }\end{array}$ & Low risk & $\begin{array}{l}\text { The investigators account for all participants randomised and there are no } \\
\text { missing outcome data. }\end{array}$ \\
\hline
\end{tabular}

Non-absorbable disaccharides versus placebo/no intervention and lactulose versus lactitol for the prevention and treatment of hepatic 
Morgan 1989 (Continued)

Selective reporting (reporting bias)

\begin{tabular}{lll}
\hline For-profit funding & High risk & $\begin{array}{l}\text { A pharmaceutical company supplied lactitol, but was not otherwise involved } \\
\text { in the trial. }\end{array}$ \\
\hline Other bias & Low risk & No other biases \\
\hline $\begin{array}{l}\text { Overall assessment (mor- } \\
\text { tality) }\end{array}$ & High risk & High risk \\
\hline $\begin{array}{l}\text { Overall assessment (non- } \\
\text { mortality outcomes) }\end{array}$ & High risk & High risk \\
\hline
\end{tabular}

\section{Pai 1995}

\begin{tabular}{ll}
\hline Methods & Single-blind, parallel-arm, single-centre, inpatient trial \\
\hline Participants & The trial includes 41 participants with cirrhosis and acute hepatic encephalopathy. \\
Age (mean \pm SD) & - Lactulose group $65.9 \pm 9.8$ years \\
- Lactitol group $67.5 \pm 4.9$ years \\
Proportion of men \\
- Lactulose group $75.0 \%$ \\
- Lactitol group $95.0 \%$ \\
Aetiology of cirrhosis \\
- Alcohol $18 \%$. \\
- Hepatitis B/C $69 \%$
\end{tabular}

Interventions Lactulose syrup versus lactitol for 5 days

\section{Outcomes Neuropsychiatric assessment}

- Portal Systemic Encephalopathy Sum and Index comprising:
a. Mental state (West Haven Criteria)
b. Asterixis
c. Number Connection Test $\mathrm{A}$
d. Venous blood ammonia
e. Electroencephalogram

\begin{tabular}{ll}
\hline $\begin{array}{l}\text { Outcomes included in } \\
\text { meta-analyses }\end{array}$ & Mortality, hepatic encephalopathy, and adverse events assessed after 5 days \\
\hline Inclusion period & April 1993 to April 1994 \\
\hline Country of origin & Taiwan \\
\hline Notes & All participants had Child's Grade B/C cirrhosis
\end{tabular}

\section{Risk of bias}

Non-absorbable disaccharides versus placebo/no intervention and lactulose versus lactitol for the prevention and treatment of hepatic

Copyright (c) 2016 The Cochrane Collaboration. Published by John Wiley \& Sons, Ltd. 
Pai 1995 (Continued)

\begin{tabular}{|c|c|c|}
\hline Bias & Authors' judgement & Support for judgement \\
\hline $\begin{array}{l}\text { Random sequence genera- } \\
\text { tion (selection bias) }\end{array}$ & Low risk & Random number table \\
\hline $\begin{array}{l}\text { Allocation concealment } \\
\text { (selection bias) }\end{array}$ & Unclear risk & Not described \\
\hline $\begin{array}{l}\text { Blinding of participants } \\
\text { and personnel (perfor- } \\
\text { mance bias) } \\
\text { Non-mortality outcomes }\end{array}$ & High risk & Open, single-blind trial. No blinding of participants or $\mathrm{p}$ \\
\hline $\begin{array}{l}\text { Blinding of participants } \\
\text { and personnel (perfor- } \\
\text { mance bias) } \\
\text { Mortality }\end{array}$ & Low risk & Performance bias unlikely to influence the outcome \\
\hline
\end{tabular}

\begin{tabular}{|c|c|c|}
\hline $\begin{array}{l}\text { Blinding of outcome as- } \\
\text { sessment (detection bias) } \\
\text { Non-mortality outcomes }\end{array}$ & Low risk & Open, single-blind trial. Blinding of outcome assessment. \\
\hline $\begin{array}{l}\text { Blinding of outcome as- } \\
\text { sessment (detection bias) } \\
\text { Mortality }\end{array}$ & Low risk & Detection bias unlikely to influence the outcome \\
\hline $\begin{array}{l}\text { Incomplete outcome data } \\
\text { (attrition bias) } \\
\text { All outcomes }\end{array}$ & High risk & $\begin{array}{l}\text { The investigators account for all participants randomised, but do not include } \\
\text { participants who died or dropped out in the reported analyses. }\end{array}$ \\
\hline $\begin{array}{l}\text { Selective reporting (re- } \\
\text { porting bias) }\end{array}$ & High risk & $\begin{array}{l}\text { The trial report does not include information about the allocation group of } \\
\text { participants who died within the first } 5 \text { days after randomisation. }\end{array}$ \\
\hline For-profit funding & Low risk & No for-profit funding \\
\hline Other bias & Low risk & No other biases \\
\hline $\begin{array}{l}\text { Overall assessment (mor- } \\
\text { tality) }\end{array}$ & High risk & High risk \\
\hline $\begin{array}{l}\text { Overall assessment (non- } \\
\text { mortality outcomes) }\end{array}$ & High risk & High risk \\
\hline
\end{tabular}

Prasad 2007

\begin{tabular}{ll}
\hline Methods & Open, parallel-arm, single-centre, outpatient trial \\
\hline Participants & The trial includes 61 participants with cirrhosis and minimal hepatic encephalopathy (see notes). \\
& Age (mean and range) \\
- Lactulose group 48.3 (38.4 to 58.2) years \\
- Control group 50.6 (39.1 to 62.1$)$ years \\
Proportion of men \\
- Lactulose group $87.1 \%$
\end{tabular}

Non-absorbable disaccharides versus placebo/no intervention and lactulose versus lactitol for the prevention and treatment of hepatic 
Prasad 2007 (Continued)

- Control group $93.3 \%$

Aetiology of cirrhosis

- Alcohol 65\%

- Hepatitis B/C $30 \%$

\begin{tabular}{ll}
\hline Interventions & Lactulose syrup versus no intervention \\
\hline Outcomes & Neuropsychiatric assessment \\
- Mini Mental State Examination \\
- Mental status (West Haven Criteria) \\
- Number Connection Tests A and B \\
- Figure Connection Tests A and B \\
- Picture Completion Test \\
- Block Design Test
\end{tabular}

Outcomes included in meta-analyses

Mortality, hepatic encephalopathy, adverse events, and quality of life assessed after 3 months

\begin{tabular}{ll}
\hline Inclusion period & January 2004 to March 2005 \\
\hline Country of origin & India \\
\hline Notes & The investigators based the diagnosis of minimal hepatic encephalopathy on the presence of at least \\
& 2 abnormal psychometric tests. They expressed the psychometric test results as a Z score equating \\
to the difference between the observed result and the population norm. They defined a $Z$ score of \\
$<-2$ as abnormal. The investigators calculated a mean $Z$ score (mZS) for each patient and referred to \\
changes in the number of abnormal tests AbnNP and the mZS at the end of treatment or follow-up \\
as $\Delta$ AbnNP and $\Delta$ mZS \\
- The proportion with Child's Grade B/C was $66.7 \%$ in the lactulose group and $55.2 \%$ in the control \\
group. \\
The investigators describe 29 participants who were neuropsychiatrically unimpaired and followed \\
them for 3 months in the same way as the participants in the randomised clinical trial. \\
The investigators assessed the quality of life based on the Sickness Impact Profile. They defined the \\
change in the total score after follow-up as the estimated change in the overall quality of life. At base- \\
line, participants with minimal hepatic encephalopathy had impairment in 11 of the 12 scales in the \\
score (in particular the social interaction, alertness, emotional behaviour, sleep, work, home manage- \\
ment, recreation and pastime).
\end{tabular}

\section{Risk of bias}

\begin{tabular}{lll}
\hline Bias & Authors' judgement & Support for judgement \\
\hline $\begin{array}{l}\text { Random sequence genera- } \\
\text { tion (selection bias) }\end{array}$ & Low risk & Table of random numbers \\
\hline $\begin{array}{l}\text { Allocation concealment } \\
\text { (selection bias) }\end{array}$ & Low risk & Central randomisation \\
\hline $\begin{array}{l}\text { Blinding of participants } \\
\text { and personnel (perfor- } \\
\text { mance bias) } \\
\text { Non-mortality outcomes }\end{array}$ & High risk & Open trial. No blinding of participants or personnel. \\
\hline
\end{tabular}

Non-absorbable disaccharides versus placebo/no intervention and lactulose versus lactitol for the prevention and treatment of hepatic 


\section{Prasad 2007 (Continued)}

Blinding of participants and personnel (performance bias)

Mortality

\begin{tabular}{|c|c|c|}
\hline $\begin{array}{l}\text { Blinding of outcome as- } \\
\text { sessment (detection bias) } \\
\text { Non-mortality outcomes }\end{array}$ & High risk & Open trial. No blinding of outcome assessment. \\
\hline $\begin{array}{l}\text { Blinding of outcome as- } \\
\text { sessment (detection bias) } \\
\text { Mortality }\end{array}$ & Low risk & Detection bias unlikely to influence the outcome \\
\hline $\begin{array}{l}\text { Incomplete outcome data } \\
\text { (attrition bias) } \\
\text { All outcomes }\end{array}$ & Low risk & $\begin{array}{l}\text { The investigators account for all participants randomised and used sufficient } \\
\text { methods to handle missing data in the analyses of clinical outcomes. } 5 \text { par- } \\
\text { ticipants in the control group and none in the lactulose group were lost to fol- } \\
\text { low-up. Missing outcome data are unlikely to affect the analyses or to be asso- } \\
\text { ciated with the outcome. }\end{array}$ \\
\hline $\begin{array}{l}\text { Selective reporting (re- } \\
\text { porting bias) }\end{array}$ & Low risk & Predefined outcomes reported \\
\hline For-profit funding & Low risk & No for-profit funding \\
\hline Other bias & Low risk & No other biases \\
\hline $\begin{array}{l}\text { Overall assessment (mor- } \\
\text { tality) }\end{array}$ & Low risk & Low risk \\
\hline $\begin{array}{l}\text { Overall assessment (non- } \\
\text { mortality outcomes) }\end{array}$ & High risk & High risk \\
\hline
\end{tabular}

Low risk Performance bias unlikely to influence the outcome 
Quero 1997 (Continued)

- Mental status (criteria not specified)

- Number Connection Test A

- Symbol Digit Test

- Electroencephalogram

- Arterial ammonia concentration

Outcomes included in meta-analyses
Mortality, hepatic encephalopathy, adverse events, and quality of life assessed after a maximum of 9 months ( 3 months after the end of therapy)

\begin{tabular}{ll}
\hline Inclusion period & October 1992 to September 1994 \\
\hline Country of origin & Holland \\
\hline Notes & The investigators diagnosed participants with at least 2 abnormal psychometric tests scores as having \\
& minimal hepatic encephalopathy. \\
- & All participants had elevated blood ammonia levels. \\
- & The investigators assessed quality of life using the Sickness Impact Profile and defined the change in \\
& the total score after follow-up as the estimated change in the overall quality of life. At baseline, par- \\
& ticipants with minimal hepatic encephalopathy had impairment in 11 of the 12 scales in the score (in \\
particular social interaction, alertness, emotional behaviour, sleep, work, home management, recre- \\
ation and pastime).
\end{tabular}

\section{Risk of bias}

\begin{tabular}{|c|c|c|}
\hline Bias & Authors' judgement & Support for judgement \\
\hline $\begin{array}{l}\text { Random sequence genera- } \\
\text { tion (selection bias) }\end{array}$ & Low risk & Table of random numbers \\
\hline $\begin{array}{l}\text { Allocation concealment } \\
\text { (selection bias) }\end{array}$ & Low risk & Centrally prepared, numbered drug containers \\
\hline $\begin{array}{l}\text { Blinding of participants } \\
\text { and personnel (perfor- } \\
\text { mance bias) } \\
\text { Non-mortality outcomes }\end{array}$ & Low risk & Double-blind, placebo-controlled. Blinding of participants and personnel. \\
\hline $\begin{array}{l}\text { Blinding of participants } \\
\text { and personnel (perfor- } \\
\text { mance bias) } \\
\text { Mortality }\end{array}$ & Low risk & Performance bias unlikely to influence the outcome \\
\hline $\begin{array}{l}\text { Blinding of outcome as- } \\
\text { sessment (detection bias) } \\
\text { Non-mortality outcomes }\end{array}$ & Low risk & Double-blind, placebo-controlled. Blinding of outcome assessment. \\
\hline $\begin{array}{l}\text { Blinding of outcome as- } \\
\text { sessment (detection bias) } \\
\text { Mortality }\end{array}$ & Low risk & Detection bias unlikely to influence the outcome \\
\hline $\begin{array}{l}\text { Incomplete outcome data } \\
\text { (attrition bias) } \\
\text { All outcomes }\end{array}$ & High risk & $\begin{array}{l}\text { The investigators account for all participants randomised, but the trial re- } \\
\text { port excludes participants with missing outcomes ( } 2 \text { from both intervention } \\
\text { groups) from the analyses. }\end{array}$ \\
\hline $\begin{array}{l}\text { Selective reporting (re- } \\
\text { porting bias) }\end{array}$ & Low risk & Predefined outcomes not reported \\
\hline
\end{tabular}

Non-absorbable disaccharides versus placebo/no intervention and lactulose versus lactitol for the prevention and treatment of hepatic 
Quero 1997 (Continued)

\begin{tabular}{lll} 
For-profit funding & High risk & The trial received funding from a pharmaceutical company \\
\hline Other bias & Low risk & No other biases identified \\
\hline $\begin{array}{l}\text { Overall assessment (mor- } \\
\text { tality) }\end{array}$ & High risk & High risk \\
\hline $\begin{array}{l}\text { Overall assessment (non- } \\
\text { mortality outcomes) }\end{array}$ & High risk & High risk \\
\hline
\end{tabular}

Raza 2004

\begin{tabular}{|c|c|}
\hline Methods & Open, parallel-arm, single-centre, inpatient trial \\
\hline \multirow[t]{9}{*}{ Participants } & $\begin{array}{l}\text { The trial includes } 31 \text { participants with cirrhosis experiencing an acute episode of hepatic encephalopa- } \\
\text { thy. }\end{array}$ \\
\hline & Age (mean) \\
\hline & - Lactulose group 55.1 years \\
\hline & - Control group 52.4 years \\
\hline & Proportion of men \\
\hline & - Lactulose group $27.8 \%$. \\
\hline & - Control group $46.2 \%$. \\
\hline & Aetiology of cirrhosis \\
\hline & - Hepatitis B/C $100 \%$ \\
\hline
\end{tabular}

Interventions Lactulose enemata versus tap water enemata administered for a mean of 4.5 days depending on clini-
cal response
Outcomes
Neuropsychiatric assessment
- Clinical scoring (Jones and Gammal)
- Portal Systemic Encephalopathy Sum and Index comprising:
a. Mental state (West Haven Criteria)
b. Asterixis
c. Digit Symbol Test (replacing Number Connection Test A)
d. Venous blood ammonia
e. Electroencephalogram

\begin{tabular}{ll}
\hline $\begin{array}{l}\text { Outcomes included in } \\
\text { meta-analyses }\end{array}$ & Mortality and hepatic encephalopathy assessed after a mean duration of 4.5 days \\
\hline Inclusion period & Not reported \\
\hline Country of origin & Pakistan \\
\hline Notes & $\begin{array}{l}\text { The primary outcome was the time to improvement. } \\
\text { The investigators made the assessments at 48 hours and then at the end of treatment, which was on } \\
\text { average } 4 \text { days. }\end{array}$ \\
\hline
\end{tabular}

Non-absorbable disaccharides versus placebo/no intervention and lactulose versus lactitol for the prevention and treatment of hepatic 
Raza 2004 (Continued)

Risk of bias

\begin{tabular}{|c|c|c|}
\hline Bias & Authors' judgement & Support for judgement \\
\hline $\begin{array}{l}\text { Random sequence genera- } \\
\text { tion (selection bias) }\end{array}$ & Unclear risk & $\begin{array}{l}\text { The investigators described the allocation as } 1: 1 \text {, but the allocation sequence } \\
\text { generation is unclear. }\end{array}$ \\
\hline $\begin{array}{l}\text { Allocation concealment } \\
\text { (selection bias) }\end{array}$ & Unclear risk & Not described \\
\hline $\begin{array}{l}\text { Blinding of participants } \\
\text { and personnel (perfor- } \\
\text { mance bias) } \\
\text { Non-mortality outcomes }\end{array}$ & High risk & Open trial. No blinding of participants or personnel. \\
\hline $\begin{array}{l}\text { Blinding of participants } \\
\text { and personnel (perfor- } \\
\text { mance bias) } \\
\text { Mortality }\end{array}$ & Low risk & Performance bias unlikely to influence the outcome \\
\hline $\begin{array}{l}\text { Blinding of outcome as- } \\
\text { sessment (detection bias) } \\
\text { Non-mortality outcomes }\end{array}$ & High risk & Open trial. No blinding of the outcome assessment. \\
\hline $\begin{array}{l}\text { Blinding of outcome as- } \\
\text { sessment (detection bias) } \\
\text { Mortality }\end{array}$ & Low risk & Detection bias unlikely to influence the outcome \\
\hline $\begin{array}{l}\text { Incomplete outcome data } \\
\text { (attrition bias) } \\
\text { All outcomes }\end{array}$ & Unclear risk & $\begin{array}{l}\text { Participants who were excluded or lost to follow-up are not described. The } \\
\text { handling of participants with missing outcomes is unclear. }\end{array}$ \\
\hline For-profit funding & High risk & $\begin{array}{l}\text { A pharmaceutical company supplied the drug, but was not otherwise involved } \\
\text { in the trial. }\end{array}$ \\
\hline Other bias & Low risk & No other biases \\
\hline $\begin{array}{l}\text { Overall assessment (mor- } \\
\text { tality) }\end{array}$ & High risk & High risk \\
\hline $\begin{array}{l}\text { Overall assessment (non- } \\
\text { mortality outcomes) }\end{array}$ & High risk & High risk \\
\hline
\end{tabular}

Riggio 1989

\begin{tabular}{ll} 
Methods & Single-blind, parallel-arm, single-centre, outpatient trial \\
\hline Participants & $\begin{array}{l}\text { The trial includes } 31 \text { participants with cirrhosis who had undergone portal-systemic shunt surgery and } \\
\text { evaluates the prevention of hepatic encephalopathy. In total, } 46.7 \% \text { in the lactulose group and } 37.5 \% \\
\text { in the lactitol group had experienced at least } 1 \text { episode of hepatic encephalopathy within } 1 \text { year of in- } \\
\text { clusion of the trial. } \\
\text { Age (mean } \pm \text { SD) }\end{array}$
\end{tabular}

Non-absorbable disaccharides versus placebo/no intervention and lactulose versus lactitol for the prevention and treatment of hepatic 
Riggio 1989 (Continued)

- Lactulose group $49 \pm 13$ years

- Lactitol group $59 \pm 6$ years

Proportion of men

- Lactulose group $73.3 \%$

- Lactitol group $68.8 \%$

Aetiology of cirrhosis

- Alcohol 19\%

- Hepatitis B/C 19\%

\begin{tabular}{ll}
\hline Interventions & Lactulose syrup versus lactitol for 6 months \\
\hline Outcomes & $\begin{array}{l}\text { Neuropsychiatric assessment } \\
\text { - Portal Systemic Encephalopathy Sum and Index comprising: } \\
\text { a. Mental state (West Haven Criteria) } \\
\text { b. Asterixis } \\
\text { c. Number Connection Test A } \\
\text { d. Venous blood ammonia } \\
\text { e. Electroencephalogram }\end{array}$ \\
\hline $\begin{array}{l}\text { Outcomes included in } \\
\text { meta-analyses }\end{array}$ & $\begin{array}{l}\text { Mortality, hepatic encephalopathy, and adverse events assessed after } 6 \text { months } \\
\text { Inclusion period }\end{array}$ \\
\hline Country of origin & Italy \\
\hline Notes & The proportion of participants with Grade B/C cirrhosis was $13.3 \%$ in the lactulose and $12.5 \%$ in the \\
\hline
\end{tabular}

\section{Risk of bias}

\begin{tabular}{lll}
\hline Bias & Authors' judgement & Support for judgement \\
\hline $\begin{array}{l}\text { Random sequence genera- } \\
\text { tion (selection bias) }\end{array}$ & Low risk & Table of random numbers \\
\hline $\begin{array}{l}\text { Allocation concealment } \\
\text { (selection bias) }\end{array}$ & Low risk & Numbered, opaque, sealed envelopes \\
\hline $\begin{array}{l}\text { Blinding of participants } \\
\text { and personnel (perfor- } \\
\text { mance bias) } \\
\text { Non-mortality outcomes }\end{array}$ & High risk & Open, single-blind trial. No blinding of participants and personnel. \\
\hline $\begin{array}{l}\text { Blinding of participants } \\
\text { and personnel (perfor- } \\
\text { mance bias) }\end{array}$ & Low risk \\
$\begin{array}{l}\text { Mortality } \\
\begin{array}{l}\text { Blinding of outcome as- } \\
\text { sessment (detection bias) } \\
\text { Non-mortality outcomes }\end{array}\end{array}$ & Low risk & Performance bias unlikely to influence the outcome \\
\hline
\end{tabular}

Non-absorbable disaccharides versus placebo/no intervention and lactulose versus lactitol for the prevention and treatment of hepatic 
Riggio 1989 (Continued)

Blinding of outcome as- $\quad$ Low risk Detection bias unlikely to influence the outcome
sessment (detection bias)
Mortality

\begin{tabular}{lll}
\hline $\begin{array}{l}\text { Incomplete outcome data } \\
\text { (attrition bias) } \\
\text { All outcomes }\end{array}$ & Low risk & $\begin{array}{l}\text { The investigators account for all participants randomised; there are no missing } \\
\text { outcome data and all participants are included in the analyses. }\end{array}$ \\
\hline $\begin{array}{l}\text { Selective reporting (re- } \\
\text { porting bias) }\end{array}$ & Low risk & Predefined outcomes reported \\
\hline $\begin{array}{l}\text { For-profit funding } \\
\text { Other bias }\end{array}$ & High risk & $\begin{array}{l}\text { A pharmaceutical company supplied the lactitol, but was not otherwise in- } \\
\text { volved in the trial. }\end{array}$ \\
\hline $\begin{array}{l}\text { Overall assessment (mor- } \\
\text { tality) }\end{array}$ & High risk & No other biases \\
\hline $\begin{array}{l}\text { Overall assessment (non- } \\
\text { mortality outcomes) }\end{array}$ & High risk & High risk \\
\hline
\end{tabular}

\section{Riggio 2005}

\begin{tabular}{|c|c|}
\hline Methods & Single-blind, parallel-arm, single-centre, inpatient/outpatient trial \\
\hline \multirow[t]{10}{*}{ Participants } & $\begin{array}{l}\text { The trial includes } 50 \text { participants with cirrhosis randomised immediately after transjugular intrahepatic } \\
\text { portosystemic shunt (TIPS) placement. } 15 \% \text { ( } 8 \% \text { in the lactitol group and } 24 \% \text { in the control group) had } \\
\text { experienced a previous episode of hepatic encephalopathy. }\end{array}$ \\
\hline & Age (mean \pm SD) \\
\hline & - Lactitol group $60.6 \pm 9.0$ years \\
\hline & - Control group $54.9 \pm 11.7$ years \\
\hline & Proportion of men \\
\hline & - Lactitol group $56 \%$ \\
\hline & - Control group $84 \%$ \\
\hline & Aetiology of cirrhosis \\
\hline & - Alcohol 34\% \\
\hline & - Hepatitis B/C not rep \\
\hline
\end{tabular}

Interventions Lactitol versus no intervention for 6 months

\section{Outcomes Neuropsychiatric assessment}

- Portal Systemic Encephalopathy Sum and Index comprising:
a. Mental state (West Haven Criteria)
b. Asterixis
c. Number Connection Test $\mathrm{A}$
d. Venous blood ammonia
e. Electroencephalogram

Non-absorbable disaccharides versus placebo/no intervention and lactulose versus lactitol for the prevention and treatment of hepatic 
Riggio 2005 (Continued)

Outcomes included in meta-analyses

\begin{tabular}{|c|c|}
\hline Inclusion period & November 1998 to September 2003 \\
\hline Country of origin & Italy \\
\hline Notes & $\begin{array}{l}\text { - The trial includes } 75 \text { participants randomised to no treatment }(n=25) \text {, lactitol }(n=25) \text {, or rifaximin ( } n \\
=25 \text { ). The rifaximin group is not included in our analyses. } \\
\text { - The proportion of participants with Child's B/C cirrhosis was } 76 \% \text { in the lactitol group and } 64 \% \text { in the } \\
\text { control group. }\end{array}$ \\
\hline
\end{tabular}

\section{Risk of bias}

\begin{tabular}{|c|c|c|}
\hline Bias & Authors' judgement & Support for judgement \\
\hline $\begin{array}{l}\text { Random sequence genera- } \\
\text { tion (selection bias) }\end{array}$ & Low risk & Table of random numbers \\
\hline $\begin{array}{l}\text { Allocation concealment } \\
\text { (selection bias) }\end{array}$ & Low risk & Numbered, opaque, sealed envelopes \\
\hline $\begin{array}{l}\text { Blinding of participants } \\
\text { and personnel (perfor- } \\
\text { mance bias) } \\
\text { Non-mortality outcomes }\end{array}$ & High risk & Open trial. No blinding of participants and personnel. \\
\hline $\begin{array}{l}\text { Blinding of participants } \\
\text { and personnel (perfor- } \\
\text { mance bias) } \\
\text { Mortality }\end{array}$ & Low risk & Performance bias unlikely to influence the outcome \\
\hline $\begin{array}{l}\text { Blinding of outcome as- } \\
\text { sessment (detection bias) } \\
\text { Non-mortality outcomes }\end{array}$ & Low risk & Open, single-blind trial. Blinding of outcome assessment. \\
\hline $\begin{array}{l}\text { Blinding of outcome as- } \\
\text { sessment (detection bias) } \\
\text { Mortality }\end{array}$ & Low risk & Detection bias unlikely to influence the outcome \\
\hline $\begin{array}{l}\text { Incomplete outcome data } \\
\text { (attrition bias) } \\
\text { All outcomes }\end{array}$ & Low risk & $\begin{array}{l}\text { The investigators account for all participants randomised and used sufficient } \\
\text { methods to handle missing data. Missing outcome data are unlikely to affect } \\
\text { the analyses or to be associated with the outcome. }\end{array}$ \\
\hline $\begin{array}{l}\text { Selective reporting (re- } \\
\text { porting bias) }\end{array}$ & Low risk & Predefined outcomes reported \\
\hline For-profit funding & Low risk & No for-profit funding \\
\hline Other bias & Low risk & No other biases \\
\hline $\begin{array}{l}\text { Overall assessment (mor- } \\
\text { tality) }\end{array}$ & Low risk & Low risk \\
\hline $\begin{array}{l}\text { Overall assessment (non- } \\
\text { mortality outcomes) }\end{array}$ & High risk & High risk \\
\hline
\end{tabular}

Non-absorbable disaccharides versus placebo/no intervention and lactulose versus lactitol for the prevention and treatment of hepatic 
Rodgers 1973

\begin{tabular}{ll} 
Methods & Double-blind, cross-over, single-centre, outpatient trial \\
\hline Participants & $\begin{array}{l}\text { The trial includes } 6 \text { participants with cirrhosis and chronic hepatic encephalopathy. } 3 \text { are described in } \\
\text { detail. }\end{array}$ \\
Age (mean) \\
- Both groups: 65 years \\
Proportion of men \\
- Both groups: $66 \%$ \\
Aetiology of cirrhosis not reported
\end{tabular}

Interventions Lactulose syrup versus placebo (sorbitol) (see notes)

\begin{tabular}{ll}
\hline Outcomes & Neuropsychiatric assessment \\
& - Clinical grading (criteria not described) \\
- Blood ammonia \\
- Electroencephalography
\end{tabular}

\begin{tabular}{ll}
\hline Inclusion period & 1967 to 1970 \\
\hline Country of origin & USA \\
\hline Notes & $\begin{array}{l}\text { The investigators randomised } 6 \text { participants to treatment with lactulose or placebo (sorbitol) alter- } \\
\text { natively for 2-month periods. The paper describes } 3 \text { of these participants in detail. We were unable to } \\
\text { extract quantitative data from the trial publication. }\end{array}$ \\
\hline
\end{tabular}

\section{Risk of bias}

\begin{tabular}{lll}
\hline Bias & Authors' judgement & Support for judgement \\
\hline $\begin{array}{l}\text { Random sequence genera- } \\
\text { tion (selection bias) }\end{array}$ & Unclear risk & Not described \\
\hline $\begin{array}{l}\text { Allocation concealment } \\
\text { (selection bias) }\end{array}$ & Low risk & Centrally prepared, numbered drug containers \\
\hline $\begin{array}{l}\text { Blinding of participants } \\
\text { and personnel (perfor- } \\
\text { mance bias) }\end{array}$ & Low risk & Double-blind, placebo-controlled. Blinding of participants and personnel. \\
$\begin{array}{l}\text { Non-mortality outcomes } \\
\begin{array}{l}\text { Blinding of participants } \\
\text { and personnel (perfor- } \\
\text { mance bias) }\end{array}\end{array}$ & Low risk \\
$\begin{array}{l}\text { Mortality } \\
\begin{array}{l}\text { Blinding of outcome as- } \\
\text { sessment (detection bias) } \\
\text { Non-mortality outcomes }\end{array}\end{array}$ & Low risk & Performance bias unlikely to influence the outcome \\
\hline \hline
\end{tabular}

Non-absorbable disaccharides versus placebo/no intervention and lactulose versus lactitol for the prevention and treatment of hepatic 
Rodgers 1973 (Continued)

Blinding of outcome as- Low risk Detection bias unlikely to influence the outcome sessment (detection bias) Mortality

\begin{tabular}{lll}
\hline $\begin{array}{l}\text { Incomplete outcome data } \\
\text { (attrition bias) } \\
\text { All outcomes }\end{array}$ & High risk & $\begin{array}{l}\text { The investigators do not account for all participants randomised in the trial re- } \\
\text { port or analysis. }\end{array}$ \\
\hline $\begin{array}{l}\text { Selective reporting (re- } \\
\text { porting bias) }\end{array}$ & High risk & Predefined outcomes not reported \\
\hline $\begin{array}{l}\text { For-profit funding } \\
\text { Other bias }\end{array}$ & High risk & $\begin{array}{l}\text { A pharmaceutical company supported the trial with a grant and supplied the } \\
\text { drug and placebo. }\end{array}$ \\
\hline $\begin{array}{l}\text { Overall assessment (mor- } \\
\text { tality) }\end{array}$ & High risk & No other biases identified \\
\hline $\begin{array}{l}\text { Overall assessment (non- } \\
\text { mortality outcomes) }\end{array}$ & High risk & High risk \\
\hline
\end{tabular}

Sharma 2009

\begin{tabular}{|c|c|}
\hline Methods & Open, parallel-arm, single-centre, outpatient trial \\
\hline \multirow[t]{10}{*}{ Participants } & $\begin{array}{l}\text { The trial includes } 140 \text { participants with cirrhosis who had recovered from an episode of overt hepatic } \\
\text { encephalopathy. The trial evaluates secondary prevention. In total, } 57 \% \text { of included participants had } \\
\text { minimal hepatic encephalopathy. }\end{array}$ \\
\hline & Age $($ mean $\pm S D)$ \\
\hline & - Lactulose group $48.2 \pm 8.4$ years \\
\hline & - Control group $44.9 \pm 10.2$ years \\
\hline & Proportion of men \\
\hline & - Lactulose group $77.1 \%$ \\
\hline & - Control group $71.4 \%$ \\
\hline & Aetiology of cirrhosis \\
\hline & - Alcohol 39.2\% \\
\hline & - Hepatitis B/C $39.2 \%$ \\
\hline
\end{tabular}

Interventions Lactulose syrup versus no intervention for 12 months

\begin{tabular}{ll}
\hline Outcomes & Neuropsychiatric assessment \\
- Mental status (West Haven Criteria) & - Number Connection Tests A and B \\
- Figure Connection Tests A and B \\
- Digit Symbol Test \\
- Object Assembly Test \\
- Critical flicker frequency
\end{tabular}

Non-absorbable disaccharides versus placebo/no intervention and lactulose versus lactitol for the prevention and treatment of hepatic 
Sharma 2009 (Continued)

Outcomes included in meta-analyses

\begin{tabular}{ll}
\hline Inclusion period & January 2006 to June 2008 \\
\hline Country of origin & India \\
\hline Notes & $\begin{array}{l}\text { The investigators defined the primary endpoint as the development of an episode of overt hepatic } \\
\text { encephalopathy } 6 \text { months after randomisation. } \\
\text { - }\end{array}$ \\
& The Model for End-Stage Liver Disease (MELD) score (mean \pm SD) at inclusion was $21.8 \pm 3.4$ in the \\
& lactulose group and $20.6 \pm 2.4$ in the control group.
\end{tabular}

\section{Risk of bias}

\begin{tabular}{|c|c|c|}
\hline Bias & Authors' judgement & Support for judgement \\
\hline $\begin{array}{l}\text { Random sequence genera- } \\
\text { tion (selection bias) }\end{array}$ & Low risk & Computer-generated random numbers \\
\hline $\begin{array}{l}\text { Allocation concealment } \\
\text { (selection bias) }\end{array}$ & Low risk & Central randomisation \\
\hline $\begin{array}{l}\text { Blinding of participants } \\
\text { and personnel (perfor- } \\
\text { mance bias) } \\
\text { Non-mortality outcomes }\end{array}$ & High risk & Open trial. No blinding of participants or personnel. \\
\hline $\begin{array}{l}\text { Blinding of participants } \\
\text { and personnel (perfor- } \\
\text { mance bias) } \\
\text { Mortality }\end{array}$ & Low risk & Performance bias unlikely to influence the outcome \\
\hline $\begin{array}{l}\text { Blinding of outcome as- } \\
\text { sessment (detection bias) } \\
\text { Non-mortality outcomes }\end{array}$ & High risk & $\begin{array}{l}\text { Open trial. The investigators describe the trial as placebo-controlled, but the } \\
\text { placebo intervention is not described in the methods section describes the tri- } \\
\text { al as open. No blinding of outcome assessment. }\end{array}$ \\
\hline $\begin{array}{l}\text { Blinding of outcome as- } \\
\text { sessment (detection bias) } \\
\text { Mortality }\end{array}$ & Low risk & Detection bias unlikely to influence the outcome \\
\hline $\begin{array}{l}\text { Incomplete outcome data } \\
\text { (attrition bias) } \\
\text { All outcomes }\end{array}$ & Low risk & $\begin{array}{l}\text { Open trial. The investigators describe the trial as placebo-controlled in the tri- } \\
\text { al registry, but the placebo intervention is not mentioned in the methods sec- } \\
\text { tion of the published RCT. No blinding of outcome assessment. }\end{array}$ \\
\hline $\begin{array}{l}\text { Selective reporting (re- } \\
\text { porting bias) }\end{array}$ & Low risk & Predefined outcomes reported \\
\hline For-profit funding & Low risk & No for-profit funding \\
\hline Other bias & Low risk & No other biases \\
\hline $\begin{array}{l}\text { Overall assessment (mor- } \\
\text { tality) }\end{array}$ & Low risk & Low risk \\
\hline $\begin{array}{l}\text { Overall assessment (non- } \\
\text { mortality outcomes) }\end{array}$ & High risk & High risk \\
\hline
\end{tabular}

Non-absorbable disaccharides versus placebo/no intervention and lactulose versus lactitol for the prevention and treatment of hepatic 
Sharma 2011

\begin{tabular}{|c|c|}
\hline Methods & Open, parallel-arm, single-centre, inpatient trial \\
\hline Participants & $\begin{array}{l}\text { The trial includes } 70 \text { participants with cirrhosis who were stable after an acute variceal bleed. In total, } \\
\text { the trial included } 16 \% \text { with a previous episode of hepatic encephalopathy ( } 17.1 \% \text { in the lactulose group } \\
\text { and } 14.3 \% \text { in the control group). The trial evaluates prevention of hepatic encephalopathy. } \\
\text { Age (mean } \pm \text { SD) } \\
\text { - Lactulose group } 41.6 \pm 12.9 \text { years } \\
\text { - Control group } 37.2 \pm 16.0 \text { years } \\
\text { Proportion of men } \\
\text { - Lactulose group } 86 \% \\
\text { - Control group } 80 \% \\
\text { Aetiology of cirrhosis } \\
\text { - Alcohol } 47 \% \\
\text { - Hepatitis } B / C 37 \%\end{array}$ \\
\hline
\end{tabular}

Interventions Lactulose syrup versus no intervention for 120 hours

\begin{tabular}{ll}
\hline Outcomes & Neuropsychiatric assessment \\
& - \\
& Mental state (West Haven Criteria) \\
\hline $\begin{array}{l}\text { Outcomes included in } \\
\text { meta-analyses }\end{array}$ & Mortality, hepatic encephalopathy, and adverse events assessed after 120 hours \\
\hline Inclusion period & December 2008 to January 2010 \\
\hline Country of origin & India \\
\hline Notes & $\begin{array}{l}\text { The trial report describes the blood ammonia concentrations for participants who did not did not } \\
\text { develop hepatic encephalopathy, but not the values for participants in the } 2 \text { allocation groups. }\end{array}$ \\
\hline & $\begin{array}{l}\text { The Model for End-Stage Liver Disease (MELD) score (mean } \pm \text { SD) at inclusion was } 16.7 \pm 5.7 \text { in the } \\
\text { lactulose group and } 15.8 \pm 3.8 \text { in the control group. }\end{array}$
\end{tabular}

\section{Risk of bias}

\begin{tabular}{lll}
\hline Bias & Authors' judgement & Support for judgement \\
\hline $\begin{array}{l}\text { Random sequence genera- } \\
\text { tion (selection bias) }\end{array}$ & Low risk & Computer-generated random numbers \\
\hline $\begin{array}{l}\text { Allocation concealment } \\
\text { (selection bias) }\end{array}$ & Low risk & Serially numbered, opaque, sealed envelopes \\
\hline $\begin{array}{l}\text { Blinding of participants } \\
\text { and personnel (perfor- } \\
\text { mance bias) } \\
\text { Non-mortality outcomes }\end{array}$ & High risk & Open trial. No blinding of participants or personnel. \\
\hline
\end{tabular}


Sharma 2011 (Continued)

Blinding of participants Low risk Performance bias unlikely to influence the outcome
and personnel (perfor-
mance bias)
Mortality

\begin{tabular}{lll}
\hline $\begin{array}{l}\text { Blinding of outcome as- } \\
\text { sessment (detection bias) } \\
\text { Non-mortality outcomes }\end{array}$ & High risk & Open trial. No blinding of outcome assessment. \\
\hline $\begin{array}{l}\text { Blinding of outcome as- } \\
\text { sessment (detection bias) } \\
\text { Mortality }\end{array}$ & Low risk & Detection bias unlikely to influence the outcome \\
\hline $\begin{array}{l}\text { Incomplete outcome data } \\
\text { (attrition bias) }\end{array}$ & Low risk & The investigators account for all participants randomised. There are no partici- \\
\hline $\begin{array}{l}\text { All outcomes } \\
\text { pelective reporting (re- }\end{array}$ & Low risk & pants with post-randomisation missing outcome data. \\
\hline $\begin{array}{l}\text { For-profit funding } \\
\text { Other bias }\end{array}$ & Low risk & Predefined outcomes reported \\
\hline $\begin{array}{l}\text { Overall assessment (mor- } \\
\text { tality) }\end{array}$ & Low risk & No for-profit funding \\
\hline $\begin{array}{l}\text { Overall assessment (non- } \\
\text { mortality outcomes) }\end{array}$ & High risk & No other biases \\
\hline
\end{tabular}

Sharma 2012

\begin{tabular}{ll}
\hline Methods & Open, parallel-arm, single-centre, outpatient trial \\
\hline Participants & $\begin{array}{l}\text { The trial includes } 120 \text { participants with cirrhosis and no history of overt hepatic encephalopathy. Of } \\
\text { these, } 57 \% \text { had minimal hepatic encephalopathy at inclusion. The trial evaluates prevention of hepatic } \\
\text { encephalopathy. } \\
\text { Age (mean } \pm \text { SD) } \\
\text { - Lactulose group } 43.4 \pm 12.5 \text { years } \\
\text { - Control group } 42.2 \pm 11.5 \text { years } \\
\text { Proportion of men } \\
\text { - Lactulose group } 80.0 \% \\
\text { - Control group } 88.3 \% \\
\text { Aetiology of cirrhosis } \\
\text { - Alcohol } 30.8 \% \\
\text { - Hepatitis B } 30.0 \% \\
\text { - Hepatitis C } 12.5 \%\end{array}$ \\
\hline Lactulose syrup versus no intervention for 12 months \\
\hline Interventions
\end{tabular}

Non-absorbable disaccharides versus placebo/no intervention and lactulose versus lactitol for the prevention and treatment of hepatic 
Sharma 2012 (Continued)

- Mental status (West Haven Criteria)

- Number Connection Tests A and B

- Figure Connection Tests A and B

- Picture Completion Test

- Digit Symbol Test

- Serial Dotting Test

- Line Tracing Test

- Critical flicker frequency

Outcomes included in meta-analyses
Mortality, hepatic encephalopathy, and adverse events assessed after 12 months

\begin{tabular}{ll}
\hline Inclusion period & January 2008 to September 2009 \\
\hline Country of origin & India \\
\hline Notes & The investigators based the diagnosis of minimal hepatic encephalopathy on the finding of 2 or more \\
& abnormal psychometric tests. \\
- The investigators switched 4 participants from the control to the intervention group. These partici- \\
pants are included in their original allocation group in our analyses. \\
- The Model for End-Stage Liver Disease (MELD) score (mean \pm SD) at inclusion was $13.4 \pm 4.8$ in the \\
lactulose group and $12.3 \pm 4.8$ in the control group.
\end{tabular}

\section{Risk of bias}

\begin{tabular}{|c|c|c|}
\hline Bias & Authors' judgement & Support for judgement \\
\hline $\begin{array}{l}\text { Random sequence genera- } \\
\text { tion (selection bias) }\end{array}$ & Low risk & Table of random numbers \\
\hline $\begin{array}{l}\text { Allocation concealment } \\
\text { (selection bias) }\end{array}$ & Low risk & Central randomisation \\
\hline $\begin{array}{l}\text { Blinding of participants } \\
\text { and personnel (perfor- } \\
\text { mance bias) } \\
\text { Non-mortality outcomes }\end{array}$ & High risk & Open trial. No blinding of participants or personnel. \\
\hline $\begin{array}{l}\text { Blinding of participants } \\
\text { and personnel (perfor- } \\
\text { mance bias) } \\
\text { Mortality }\end{array}$ & Low risk & Performance bias unlikely to influence the outcome \\
\hline $\begin{array}{l}\text { Blinding of outcome as- } \\
\text { sessment (detection bias) } \\
\text { Non-mortality outcomes }\end{array}$ & High risk & Open trial. No blinding of outcome assessment. \\
\hline $\begin{array}{l}\text { Blinding of outcome as- } \\
\text { sessment (detection bias) } \\
\text { Mortality }\end{array}$ & Low risk & Detection bias unlikely to influence the outcome \\
\hline $\begin{array}{l}\text { Incomplete outcome data } \\
\text { (attrition bias) } \\
\text { All outcomes }\end{array}$ & Low risk & $\begin{array}{l}\text { The investigators account for all participants randomised and used sufficient } \\
\text { methods to handle missing data. Missing outcome data are unlikely to affect } \\
\text { the analyses or to be associated with the outcome. }\end{array}$ \\
\hline $\begin{array}{l}\text { Selective reporting (re- } \\
\text { porting bias) }\end{array}$ & Low risk & Predefined outcomes are reported \\
\hline
\end{tabular}

Non-absorbable disaccharides versus placebo/no intervention and lactulose versus lactitol for the prevention and treatment of hepatic 
Sharma 2012 (Continued)

\begin{tabular}{lll} 
For-profit funding & Low risk & No for-profit funding \\
\hline Other bias & Low risk & No other biases \\
\hline $\begin{array}{l}\text { Overall assessment (mor- } \\
\text { tality) }\end{array}$ & Low risk & Low risk \\
\hline $\begin{array}{l}\text { Overall assessment (non- } \\
\text { mortality outcomes) }\end{array}$ & High risk & High risk \\
\hline
\end{tabular}

Shi 1997

\begin{tabular}{ll}
\hline Methods & Double-blind, parallel-arm, single-centre, outpatient trial \\
\hline Participants & The trial includes 31 participants with cirrhosis and minimal hepatic encephalopathy. \\
Mean age \\
- Both groups 54 years \\
Proportion of men \\
- Both groups $87 \%$ \\
Aetiology of cirrhosis \\
- Alcohol $0 \%$ \\
- Hepatitis B/C not described \\
\hline Lactitol versus placebo (glucose) for 2 weeks
\end{tabular}

Outcomes Neuropsychiatric assessment

- Number Connection Test

- Digit Symbol Test

- Somatosensory evoked potentials

- Blood ammonia

Outcomes included in No outcomes (see notes)

meta-analyses

\begin{tabular}{ll}
\hline Inclusion period & Not reported \\
\hline Country of origin & China \\
\hline Notes & - The authors do not describe the criteria used to diagnose minimal hepatic encephalopathy. \\
& - No numerical data are provided. \\
& Published in Chinese.
\end{tabular}

\section{Risk of bias}

\begin{tabular}{lll}
\hline Bias & Authors' judgement & Support for judgement \\
\hline $\begin{array}{l}\text { Random sequence genera- } \\
\text { tion (selection bias) }\end{array}$ & Unclear risk & Not described \\
\hline
\end{tabular}

Non-absorbable disaccharides versus placebo/no intervention and lactulose versus lactitol for the prevention and treatment of hepatic 
Shi 1997 (Continued)

$\begin{aligned} & \text { Allocation concealment } \\ & \text { (selection bias) }\end{aligned} \quad$ Low risk Administration of coded, identical drug containers

$\begin{aligned} & \text { Blinding of participants } \\ & \text { and personnel (perfor- } \\ & \text { mance bias) }\end{aligned}$
$\begin{aligned} & \text { Non-mortality outcomes } \\ & \text { Blinding of participants }\end{aligned}$
$\begin{aligned} & \text { and personnel (perfor- } \\ & \text { mance bias) }\end{aligned}$
$\begin{aligned} & \text { Mortality } \\ & \end{aligned}$

\begin{tabular}{lll}
\hline $\begin{array}{l}\text { Blinding of outcome as- } \\
\text { sessment (detection bias) } \\
\text { Non-mortality outcomes }\end{array}$ & Low risk & Double-blind, placebo-controlled. Blinding of outcome assessment. \\
\hline $\begin{array}{l}\text { Blinding of outcome as- } \\
\text { sessment (detection bias) } \\
\text { Mortality }\end{array}$ & Low risk & Detection bias unlikely to influence the outcome \\
\hline $\begin{array}{l}\text { Incomplete outcome data } \\
\text { (attrition bias) } \\
\text { All outcomes }\end{array}$ & Unclear risk & $\begin{array}{l}\text { Patient with missing outcome data are not described and the handling of par- } \\
\text { ticipants with missing outcomes in the analyses is unclear. }\end{array}$ \\
\hline $\begin{array}{l}\text { Selective reporting (re- } \\
\text { porting bias) }\end{array}$ & High risk & Predefined outcomes not reported \\
\hline $\begin{array}{l}\text { For-profit funding } \\
\text { Other bias }\end{array}$ & Low risk & Low risk \\
\hline $\begin{array}{l}\text { Overall assessment (mor- } \\
\text { tality) }\end{array}$ & High risk & No other biases \\
\hline $\begin{array}{l}\text { Overall assessment (non- } \\
\text { mortality outcomes) }\end{array}$ & High risk & High risk \\
\hline
\end{tabular}

\section{Simmons 1970}

\begin{tabular}{ll}
\hline Methods & Double-blind, parallel-arm, single-centre, inpatient trial \\
\hline Participants & The trial includes 26 participants with cirrhosis and acute hepatic encephalopathy \\
Age (mean \pm SD) & Lactulose group $50.4 \pm 7.6$ years \\
Control group $51.8 \pm 6.7$ years \\
Proportion of men \\
- Both groups $100 \%$ \\
Aetiology of cirrhosis \\
- Alcohol $100 \%$
\end{tabular}

Non-absorbable disaccharides versus placebo/no intervention and lactulose versus lactitol for the prevention and treatment of hepatic 
Simmons 1970 (Continued)

Interventions Lactulose syrup versus placebo (glucose) for 10 days

\begin{tabular}{ll}
\hline Outcomes & Neuropsychiatric assessment \\
& - Mental function tests (Sherlock) \\
& Venous blood ammonia \\
$\begin{array}{l}\text { Outcomes included in } \\
\text { meta-analyses }\end{array}$ & Mortality, hepatic encephalopathy, and adverse events assessed after 10 days \\
\hline Inclusion period & Not reported \\
\hline Country of origin & USA \\
\hline Notes & -
\end{tabular}

\section{Risk of bias}

\begin{tabular}{|c|c|c|}
\hline Bias & Authors' judgement & Support for judgement \\
\hline $\begin{array}{l}\text { Random sequence genera- } \\
\text { tion (selection bias) }\end{array}$ & Low risk & Table of random numbers \\
\hline $\begin{array}{l}\text { Allocation concealment } \\
\text { (selection bias) }\end{array}$ & Low risk & Central randomisation \\
\hline $\begin{array}{l}\text { Blinding of participants } \\
\text { and personnel (perfor- } \\
\text { mance bias) } \\
\text { Non-mortality outcomes }\end{array}$ & Low risk & Double-blind, placebo-controlled. Blinding of participants and personnel. \\
\hline $\begin{array}{l}\text { Blinding of participants } \\
\text { and personnel (perfor- } \\
\text { mance bias) } \\
\text { Mortality }\end{array}$ & Low risk & Performance bias unlikely to influence the outcome \\
\hline $\begin{array}{l}\text { Blinding of outcome as- } \\
\text { sessment (detection bias) } \\
\text { Non-mortality outcomes }\end{array}$ & Low risk & Double-blind, placebo-controlled. Blinding of outcome assessment. \\
\hline $\begin{array}{l}\text { Blinding of outcome as- } \\
\text { sessment (detection bias) } \\
\text { Mortality }\end{array}$ & Low risk & Detection bias unlikely to influence the outcome \\
\hline $\begin{array}{l}\text { Incomplete outcome data } \\
\text { (attrition bias) } \\
\text { All outcomes }\end{array}$ & Low risk & $\begin{array}{l}\text { The investigators account for all participants randomised. There are no miss- } \\
\text { ing outcomes and all participants are included in the analyses. }\end{array}$ \\
\hline $\begin{array}{l}\text { Selective reporting (re- } \\
\text { porting bias) }\end{array}$ & Low risk & Predefined outcomes reported \\
\hline For-profit funding & High risk & $\begin{array}{l}\text { A pharmaceutical company supplied lactulose, but was not otherwise involved } \\
\text { in the trial. }\end{array}$ \\
\hline Other bias & Low risk & No other biases \\
\hline
\end{tabular}


Simmons 1970 (Continued)

\begin{tabular}{lll}
$\begin{array}{l}\text { Overall assessment (mor- } \\
\text { tality) }\end{array}$ & High risk & High risk \\
\hline $\begin{array}{l}\text { Overall assessment (non- } \\
\text { mortality outcomes) }\end{array}$ & High risk & High risk \\
\hline
\end{tabular}

Uribe 1987a

\begin{tabular}{ll}
\hline Methods & Double-blind, cross-over, single-centre, inpatient trial \\
\hline Participants & The trial includes 37 participants with cirrhosis and acute hepatic encephalopathy \\
& Participant characteristics not reported \\
\hline Interventions & Rectal lactitol enemata versus rectal placebo enemata (lactose or tap water) for 4 days \\
\hline Outcomes & Neuropsychiatric assessment \\
- Portal Systemic Encephalopathy Sum and Index comprising: \\
a. Mental state (West Haven Criteria) \\
b. Asterixis \\
c. Number Connection Test A \\
d. Venous blood ammonia \\
e. Electroencephalogram
\end{tabular}

Outcomes included in meta-analyses
Mortality, hepatic encephalopathy, adverse events, Number Connection Test results, and blood ammonia concentrations assessed after 4 days

\begin{tabular}{ll}
\hline Inclusion period & Not reported \\
\hline Country of origin & Mexico \\
\hline Notes & The trial includes 37 participants with cirrhosis experiencing 45 episodes of acute overt hepatic en- \\
cephalopathy. & The investigators undertook a pre-agreed group sequential analysis of response after randomisation \\
& of the first 20 participants to enemata of lactitol ( $\mathrm{n}=10)$, lactose $(\mathrm{n}=5)$, or tap water $(\mathrm{n}=5)$. The \\
& investigators discontinued the tap water arm because the mortality rate was high; the trial continued \\
& with the randomisation of participants to lactitol or lactose. \\
- & In our analyses, we combined participants randomised to the tap water and lactose groups $(\mathrm{n}=23)$. \\
- & None of the participants in the trial was lactose intolerant.
\end{tabular}

\section{Risk of bias}

\begin{tabular}{lll}
\hline Bias & Authors' judgement & Support for judgement \\
\hline $\begin{array}{l}\text { Random sequence genera- } \\
\text { tion (selection bias) }\end{array}$ & Low risk & Table of random numbers \\
\hline $\begin{array}{l}\text { Allocation concealment } \\
\text { (selection bias) }\end{array}$ & Low risk & Blinded administration of coded drug containers \\
\hline $\begin{array}{l}\text { Blinding of participants } \\
\begin{array}{l}\text { and personnel (perfor- } \\
\text { mance bias) }\end{array}\end{array}$ & Low risk & Double-blind, placebo-controlled. Blinding of participants and personnel. \\
\end{tabular}

Non-absorbable disaccharides versus placebo/no intervention and lactulose versus lactitol for the prevention and treatment of hepatic 
Uribe 1987a (Continued)

Non-mortality outcomes

Blinding of participants Low risk Performance bias unlikely to influence the outcome
and personnel (perfor-
mance bias)
Mortality

\begin{tabular}{lll}
\hline $\begin{array}{l}\text { Blinding of outcome as- } \\
\text { sessment (detection bias) } \\
\text { Non-mortality outcomes }\end{array}$ & Low risk & Double-blind, placebo-controlled. Blinding of outcome assessment. \\
\hline $\begin{array}{l}\text { Blinding of outcome as- } \\
\text { sessment (detection bias) } \\
\text { Mortality }\end{array}$ & Low risk & Detection bias unlikely to influence the outcome \\
\hline $\begin{array}{l}\text { Incomplete outcome data } \\
\text { (attrition bias) } \\
\text { All outcomes }\end{array}$ & Low risk & $\begin{array}{l}\text { The investigators account for all participants randomised and there are no } \\
\text { missing outcome data. }\end{array}$ \\
\hline $\begin{array}{l}\text { Selective reporting (re- } \\
\text { porting bias) }\end{array}$ & Low risk & Predefined outcomes are described \\
\hline $\begin{array}{l}\text { For-profit funding } \\
\text { Other bias }\end{array}$ & High risk & $\begin{array}{l}\text { One of the trial investigators was an employee of a pharmaceutical company, } \\
\text { which manufactured the trial drug. }\end{array}$ \\
\hline $\begin{array}{l}\text { Overall assessment (mor- } \\
\text { tality) }\end{array}$ & High risk & No other biases \\
\hline $\begin{array}{l}\text { Overall assessment (non- } \\
\text { mortality outcomes) }\end{array}$ & High risk & High risk \\
\hline
\end{tabular}

Uribe 1987b

\begin{tabular}{ll}
\hline Methods & Double-blind, cross-over, single-centre, outpatient trial \\
\hline Participants & The trial includes 20 participants with cirrhosis and chronic hepatic encephalopathy. \\
& Age (mean \pm SD) \\
- Lactitol group $41.0 \pm 1.5$ years & - Control group $40.8 \pm 2.5$ years \\
& Proportion of men \\
& - Lactitol group $62.5 \%$ \\
& - Control group $40.0 \%$ \\
& Aetiology of cirrhosis \\
& - Alcohol $44 \%$ \\
- Hepatitis B/C $55 \%$
\end{tabular}

Non-absorbable disaccharides versus placebo/no intervention and lactulose versus lactitol for the prevention and treatment of hepatic 
Uribe 1987b (Continued)

- Portal Systemic Encephalopathy Sum and Index comprising:
a. Mental state (West Haven Criteria)
b. Asterixis
c. Number Connection Test $\mathrm{A}$
d. Venous blood ammonia
e. Electroencephalogram

\begin{tabular}{ll}
\hline $\begin{array}{l}\text { Outcomes included in } \\
\text { meta-analyses }\end{array}$ & $\begin{array}{l}\text { Mortality, hepatic encephalopathy, adverse events, Number Connection Test results, and blood ammo- } \\
\text { nia concentrations assessed after } 2 \text { weeks }\end{array}$ \\
\hline Inclusion period & Not reported \\
\hline Country of origin & Mexico \\
\hline Notes & None of the participants in the control group was lactose intolerant
\end{tabular}

\section{Risk of bias}

\begin{tabular}{|c|c|c|}
\hline Bias & Authors' judgement & Support for judgement \\
\hline $\begin{array}{l}\text { Random sequence genera- } \\
\text { tion (selection bias) }\end{array}$ & Low risk & Table of random numbers \\
\hline $\begin{array}{l}\text { Allocation concealment } \\
\text { (selection bias) }\end{array}$ & Low risk & Blinded administration of coded drug containers \\
\hline $\begin{array}{l}\text { Blinding of participants } \\
\text { and personnel (perfor- } \\
\text { mance bias) } \\
\text { Non-mortality outcomes }\end{array}$ & Low risk & Double-blind, placebo-controlled. Blinding of participants and personnel. \\
\hline $\begin{array}{l}\text { Blinding of participants } \\
\text { and personnel (perfor- } \\
\text { mance bias) } \\
\text { Mortality }\end{array}$ & Low risk & Performance bias unlikely to influence the outcome \\
\hline $\begin{array}{l}\text { Blinding of outcome as- } \\
\text { sessment (detection bias) } \\
\text { Non-mortality outcomes }\end{array}$ & Low risk & Double-blind, placebo-controlled. Blinding of outcome assessment. \\
\hline $\begin{array}{l}\text { Blinding of outcome as- } \\
\text { sessment (detection bias) } \\
\text { Mortality }\end{array}$ & Low risk & Detection bias unlikely to influence the outcome \\
\hline $\begin{array}{l}\text { Incomplete outcome data } \\
\text { (attrition bias) } \\
\text { All outcomes }\end{array}$ & High risk & $\begin{array}{l}\text { The investigators account for all participants randomised. There are no miss- } \\
\text { ing data for clinical outcomes, but trial authors exclude } 2 \text { participants from the } \\
\text { reported analyses. The } 2 \text { participants developed complications requiring an- } \\
\text { tibiotics and never received the trial medication. }\end{array}$ \\
\hline $\begin{array}{l}\text { Selective reporting (re- } \\
\text { porting bias) }\end{array}$ & Low risk & Predefined outcomes reported \\
\hline For-profit funding & High risk & $\begin{array}{l}\text { One of the trial investigators was an employee of a pharmaceutical company, } \\
\text { which manufactured the trial drug. }\end{array}$ \\
\hline Other bias & Low risk & No other biases \\
\hline
\end{tabular}

Non-absorbable disaccharides versus placebo/no intervention and lactulose versus lactitol for the prevention and treatment of hepatic 
Uribe 1987b (Continued)

\begin{tabular}{lll}
$\begin{array}{l}\text { Overall assessment (mor- } \\
\text { tality) }\end{array}$ & High risk & High risk \\
\hline $\begin{array}{l}\text { Overall assessment (non- } \\
\text { mortality outcomes) }\end{array}$ & High risk & High risk
\end{tabular}

Watanabe 1997

\begin{tabular}{ll}
\hline Methods & Open, parallel-arm, multicentre, outpatient trial \\
\hline Participants & The trial includes 75 participants with cirrhosis and previous overt hepatic encephalopathy. In total, \\
$48 \%$ had minimal hepatic encephalopathy and $52 \%$ were unimpaired based on neuropsychiatric as- \\
sessment. \\
Age (mean \pm SD) \\
- Lactulose group (unimpaired) $56.7 \pm 9.5$ years \\
- Control group (unimpaired) $58.6 \pm 6.2$ years \\
- Lactulose group (minimal hepatic encephalopathy) $62.0 \pm 7.3$ years \\
- Control group (minimal hepatic encephalopathy) $65.6 \pm 7.1$ years \\
Proportion of men \\
- Lactulose and control group (unimpaired) $62 \%$ \\
- Lactulose and control group (minimal hepatic encephalopathy) $47 \%$ \\
Aetiology of cirrhosis \\
- Alcohol $11 \%$ \\
- Hepatitis B/C $78 \%$
\end{tabular}

Interventions

Lactulose syrup versus no intervention for 8 weeks (see notes)

Outcomes Neuropsychiatric assessment

- Mental state (Conn)

- Number Connection Test part A

- Symbol Digit Test

- Block Design Test

Outcomes included in Mortality, hepatic encephalopathy, adverse events assessed after 8 weeks (see notes) meta-analyses

\begin{tabular}{|c|c|}
\hline Inclusion period & Not reported \\
\hline Country of origin & Japan \\
\hline Notes & $\begin{array}{l}\text { - The primary publication (full paper article) does not describe quality of life, but an earlier published } \\
\text { abstract, reporting the same trial, states that the investigators assessed quality of life "quantitatively } \\
\text { according to the reported criteria" without information about the specific method. The abstract re- } \\
\text { ports that participants randomised to lactulose had improved quality of life (general fatigue and ab- } \\
\text { dominal distension) although no quantitative data are provided. }\end{array}$ \\
\hline & $\begin{array}{l}\text { - The investigators diagnosed } 39 \text { participants as neuropsychiatrically unimpaired and } 36 \text { participants } \\
\text { as having minimal hepatic encephalopathy on the basis of psychometric testing. We combined the } \\
\text { outcomes for the } 2 \text { groups in our primary analysis. }\end{array}$ \\
\hline
\end{tabular}

Non-absorbable disaccharides versus placebo/no intervention and lactulose versus lactitol for the prevention and treatment of hepatic 
- The investigators followed 62 of the 75 participants for 6 months after the trial and registered that 18 participants with minimal hepatic encephalopathy and 11 participants diagnosed as unimpaired continued lactulose. 5 participants with minimal hepatic encephalopathy and 4 participants who were unimpaired started de novo lactulose after completing the trial.

\section{Risk of bias}

\begin{tabular}{|c|c|c|}
\hline Bias & Authors' judgement & Support for judgement \\
\hline $\begin{array}{l}\text { Random sequence genera- } \\
\text { tion (selection bias) }\end{array}$ & Low risk & Random number table \\
\hline $\begin{array}{l}\text { Allocation concealment } \\
\text { (selection bias) }\end{array}$ & Low risk & Numbered, opaque, sealed envelopes \\
\hline $\begin{array}{l}\text { Blinding of participants } \\
\text { and personnel (perfor- } \\
\text { mance bias) } \\
\text { Non-mortality outcomes }\end{array}$ & High risk & Open trial. No blinding of participants or personnel. \\
\hline $\begin{array}{l}\text { Blinding of participants } \\
\text { and personnel (perfor- } \\
\text { mance bias) } \\
\text { Mortality }\end{array}$ & Low risk & Performance bias unlikely to influence the outcome \\
\hline $\begin{array}{l}\text { Blinding of outcome as- } \\
\text { sessment (detection bias) } \\
\text { Non-mortality outcomes }\end{array}$ & High risk & Open trial. No blinding of outcome assessment. \\
\hline $\begin{array}{l}\text { Blinding of outcome as- } \\
\text { sessment (detection bias) } \\
\text { Mortality }\end{array}$ & Low risk & Detection bias unlikely to influence the outcome \\
\hline $\begin{array}{l}\text { Incomplete outcome data } \\
\text { (attrition bias) } \\
\text { All outcomes }\end{array}$ & High risk & $\begin{array}{l}\text { Participants with missing outcome data are excluded from the analyses. The } \\
\text { authors do not include information about the allocation group for participants } \\
\text { with missing outcomes. }\end{array}$ \\
\hline $\begin{array}{l}\text { Selective reporting (re- } \\
\text { porting bias) }\end{array}$ & Low risk & Predefined outcomes reported \\
\hline For-profit funding & Low risk & No for-profit funding \\
\hline Other bias & Low risk & No other biases \\
\hline $\begin{array}{l}\text { Overall assessment (mor- } \\
\text { tality) }\end{array}$ & High risk & High risk \\
\hline $\begin{array}{l}\text { Overall assessment (non- } \\
\text { mortality outcomes) }\end{array}$ & High risk & High risk \\
\hline
\end{tabular}

Wen 2013

Methods Open, parallel-arm, single-centre, inpatient trial


Wen 2013 (Continued)

Participants
The trial includes 130 participants with cirrhosis experiencing an acute upper gastrointestinal haemorrhage. None had overt or minimal hepatic encephalopathy at inclusion. The trial evaluates prevention of hepatic encephalopathy.

Age $($ mean $\pm S D)$

- Lactulose group $53.0 \pm 13.3$ years

- Control group 50,4 \pm 10.2 years

Proportion of men

- Lactulose group $48.4 \%$

- Control group $51.5 \%$

Aetiology of cirrhosis

- Alcohol 8\%

- Hepatitis B/C 75\%

\begin{tabular}{|c|c|}
\hline Interventions & Lactulose syrup versus no intervention for 7 days \\
\hline Outcomes & $\begin{array}{l}\text { Neuropsychiatric assessment } \\
\text { - Mental state (West Haven Criteria) } \\
\text { - Number Connection Test }\end{array}$ \\
\hline $\begin{array}{l}\text { Outcomes included in } \\
\text { meta-analyses }\end{array}$ & Mortality, hepatic encephalopathy, and adverse events assessed after 7 days \\
\hline Inclusion period & May 2007 to July 2011 \\
\hline Country of origin & China \\
\hline Notes & $\begin{array}{l}\text { - The proportion of participants with Child's B/C was } 39.7 \% \text { in the lactulose group and } 49.2 \% \text { in the } \\
\text { control group }\end{array}$ \\
\hline
\end{tabular}

\section{Risk of bias}

\begin{tabular}{lll}
\hline Bias & Authors' judgement & Support for judgement \\
\hline $\begin{array}{l}\text { Random sequence genera- } \\
\text { tion (selection bias) }\end{array}$ & Low risk & Computer-generated random numbers \\
\hline $\begin{array}{l}\text { Allocation concealment } \\
\text { (selection bias) }\end{array}$ & Unclear risk & Not described \\
\hline
\end{tabular}

\begin{tabular}{lll}
$\begin{array}{l}\text { Blinding of participants } \\
\text { and personnel (perfor- } \\
\text { mance bias) }\end{array}$ & High risk & Open trial. No blinding of participants or personnel. \\
Non-mortality outcomes & \\
\hline $\begin{array}{l}\text { Blinding of participants } \\
\begin{array}{l}\text { and personnel (perfor- } \\
\text { mance bias) }\end{array}\end{array}$ & Low risk & Performance bias unlikely to influence the outcome \\
Mortality &
\end{tabular}

\begin{tabular}{ll}
\hline $\begin{array}{l}\text { Blinding of outcome as- } \\
\text { sessment (detection bias) }\end{array}$ & Low risk Open trial. Blinding of outcome assessment. \\
Non-mortality outcomes & \\
\hline
\end{tabular}

Non-absorbable disaccharides versus placebo/no intervention and lactulose versus lactitol for the prevention and treatment of hepatic 
Wen 2013 (Continued)

Blinding of outcome as- $\quad$ Low risk Detection bias unlikely to influence the outcome
sessment (detection bias)

Mortality

\begin{tabular}{lll}
\hline $\begin{array}{l}\text { Incomplete outcome data } \\
\text { (attrition bias) } \\
\text { All outcomes }\end{array}$ & High risk & $\begin{array}{l}\text { The investigators account for all participants randomised. There are no miss- } \\
\text { ing clinical outcomes, but the trial authors exclude 2 participants who were in- } \\
\text { tolerant to lactulose from the reported analyses. }\end{array}$ \\
\hline $\begin{array}{l}\text { Selective reporting (re- } \\
\text { porting bias) }\end{array}$ & Low risk & Predefined outcomes reported \\
\hline $\begin{array}{l}\text { For-profit funding } \\
\text { Other bias }\end{array}$ & Low risk & No for-profit funding \\
\hline $\begin{array}{l}\text { Overall assessment (mor- } \\
\text { tality) }\end{array}$ & High risk & No other biases \\
\hline $\begin{array}{l}\text { Overall assessment (non- } \\
\text { mortality outcomes) }\end{array}$ & High risk & High risk \\
\hline
\end{tabular}

Xing 2003

\begin{tabular}{ll}
\hline Methods & Open, parallel-arm, single-centre, outpatient trial \\
\hline Participants & The trial includes 45 participants with cirrhosis and minimal hepatic encephalopathy. \\
& Age (mean \pm SD) \\
- Lactulose group $33.6 \pm 9.6$ years & - Control group $38.5 \pm 6.8$ years \\
& Proportion of men \\
- Lactulose group $66.7 \%$ & Control group $58.3 \%$ \\
Aetiology of cirrhosis \\
- Alcohol $20.0 \%$ \\
- Hepatitis B/C $68.9 \%$
\end{tabular}

Interventions Lactulose syrup versus no intervention for 4 weeks

\section{Outcomes Neuropsychiatric assessment}

- Number Connection Test

- Verbal and Performance Intelligence Quotient tests

- Blood ammonia

- Electroencephalogram

Outcomes included in Mortality, hepatic encephalopathy, and adverse events assessed after 4 weeks
meta-analyses
meta-analyses 
Xing 2003 (Continued)

\begin{tabular}{ll} 
Country of origin & China \\
\hline Notes & Published in Chinese. \\
- The method used to diagnose minimal hepatic encephalopathy is not described. \\
- Participants in the intervention and control group also received vitamin B and silymarin. \\
- Of the 48 participants randomised, 3 ( 1 assigned to lactulose and 2 to no intervention) did not com- \\
clete the trial according to the protocol. The outcome of these participants is described in the publi-
\end{tabular}

\section{Risk of bias}

\begin{tabular}{|c|c|c|}
\hline Bias & Authors' judgement & Support for judgement \\
\hline $\begin{array}{l}\text { Random sequence genera- } \\
\text { tion (selection bias) }\end{array}$ & Unclear risk & Not described \\
\hline $\begin{array}{l}\text { Allocation concealment } \\
\text { (selection bias) }\end{array}$ & Unclear risk & Not described \\
\hline $\begin{array}{l}\text { Blinding of participants } \\
\text { and personnel (perfor- } \\
\text { mance bias) } \\
\text { Non-mortality outcomes }\end{array}$ & High risk & Open trial. No blinding of participants or personnel. \\
\hline $\begin{array}{l}\text { Blinding of participants } \\
\text { and personnel (perfor- } \\
\text { mance bias) } \\
\text { Mortality }\end{array}$ & Low risk & Performance bias unlikely to influence the outcome \\
\hline $\begin{array}{l}\text { Blinding of outcome as- } \\
\text { sessment (detection bias) } \\
\text { Non-mortality outcomes }\end{array}$ & High risk & Open trial. No blinding of outcome assessment. \\
\hline $\begin{array}{l}\text { Blinding of outcome as- } \\
\text { sessment (detection bias) } \\
\text { Mortality }\end{array}$ & Low risk & Detection bias unlikely to influence the outcome \\
\hline $\begin{array}{l}\text { Incomplete outcome data } \\
\text { (attrition bias) } \\
\text { All outcomes }\end{array}$ & Low risk & $\begin{array}{l}\text { The investigators account for all participants randomised and used sufficient } \\
\text { methods to handle missing data. Missing outcome data are unlikely to affect } \\
\text { the analyses or to be associated with the outcome. }\end{array}$ \\
\hline $\begin{array}{l}\text { Selective reporting (re- } \\
\text { porting bias) }\end{array}$ & Low risk & Predefined outcomes reported \\
\hline For-profit funding & Low risk & No for-profit funding \\
\hline Other bias & Low risk & No other biases \\
\hline $\begin{array}{l}\text { Overall assessment (mor- } \\
\text { tality) }\end{array}$ & High risk & High risk \\
\hline $\begin{array}{l}\text { Overall assessment (non- } \\
\text { mortality outcomes) }\end{array}$ & High risk & High risk \\
\hline
\end{tabular}


Yao 2014

\begin{tabular}{ll}
\hline Methods & Open, parallel-arm, single-centre, outpatient trial \\
\hline Participants & The trial includes 40 participants with cirrhosis and minimal hepatic encephalopathy. \\
Age (mean \pm SD) \\
- Lactulose group $45.52 \pm 6.34$ years \\
- Control group $45.23 \pm 7.46$ years \\
Proportion of men \\
- Lactulose and control group $67.5 \%$ \\
Aetiology of cirrhosis \\
- Alcohol not described \\
- Hepatitis not described
\end{tabular}

Interventions Lactulose syrup versus no intervention for 4 weeks

\begin{tabular}{ll}
\hline Outcomes & Neuropsychiatric assessment \\
& - Number Connection Test \\
& - Digit Symbol Test \\
\hline $\begin{array}{l}\text { Outcomes included in } \\
\text { meta-analyses }\end{array}$ & Mortality and Number Connection Test results assessed after 15 days \\
\hline Inclusion period & May 2011 to July 2013 \\
\hline Country of origin & China \\
\hline Notes & $\begin{array}{l}\text { The trial report describes the effects on lactulose using surrogate outcomes and does not include in- } \\
\text { formation about the number of participants with (or without) an overall improvement of hepatic en- } \\
\text { cephalopathy. }\end{array}$
\end{tabular}

\section{Risk of bias}

\begin{tabular}{lll}
\hline Bias & Authors' judgement & Support for judgement \\
\hline $\begin{array}{l}\text { Random sequence genera- } \\
\text { tion (selection bias) }\end{array}$ & Low risk & Table of random numbers \\
\hline $\begin{array}{l}\text { Allocation concealment } \\
\text { (selection bias) }\end{array}$ & Unclear risk & $\begin{array}{l}\text { The authors specify that allocation was concealed, but do no specify the } \\
\text { method of concealment. }\end{array}$ \\
\hline $\begin{array}{l}\text { Blinding of participants } \\
\text { and personnel (perfor- } \\
\text { mance bias) }\end{array}$ & Unclear risk & Open trial. No blinding of participants or personnel. \\
$\begin{array}{l}\text { Non-mortality outcomes } \\
\begin{array}{l}\text { Blinding of participants } \\
\text { and personnel (perfor- } \\
\text { mance bias) }\end{array}\end{array}$ & Low risk \\
\begin{tabular}{l} 
Mortality \\
\hline
\end{tabular} & & \\
\hline
\end{tabular}

$\begin{array}{ll}\begin{array}{l}\text { Blinding of outcome as- } \\ \text { sessment (detection bias) }\end{array} & \text { Unclear risk } \quad \text { Open trial. No blinding of outcome assessment. }\end{array}$

Non-absorbable disaccharides versus placebo/no intervention and lactulose versus lactitol for the prevention and treatment of hepatic 
Yao 2014 (Continued)

Non-mortality outcomes

\begin{tabular}{lll}
$\begin{array}{l}\text { Blinding of outcome as- } \\
\text { sessment (detection bias) } \\
\text { Mortality }\end{array}$ & Low risk & Detection bias unlikely to influence the outcome \\
\hline $\begin{array}{l}\text { Incomplete outcome data } \\
\text { (attrition bias) } \\
\text { All outcomes }\end{array}$ & Low risk & All participants are described and there are no missing outcome data. \\
\hline $\begin{array}{l}\text { Selective reporting (re- } \\
\text { porting bias) }\end{array}$ & Low risk & Predefined outcomes are reported (see notes). \\
\hline $\begin{array}{l}\text { For-profit funding } \\
\text { Other bias }\end{array}$ & Unclear risk & Funding not described \\
\hline $\begin{array}{l}\text { Overall assessment (mor- } \\
\text { tality) }\end{array}$ & High risk & No other biases \\
\hline $\begin{array}{l}\text { Overall assessment (non- } \\
\text { mortality outcomes) }\end{array}$ & High risk & High risk of bias \\
\hline
\end{tabular}

Zeng 2003

\begin{tabular}{ll}
\hline Methods & Open, parallel-arm, single-centre, outpatient trial \\
\hline Participants & $\begin{array}{l}\text { The trial includes } 60 \text { participants with cirrhosis and minimal hepatic encephalopathy with no previous } \\
\text { history of overt hepatic encephalopathy. } \\
\text { Age (mean } \pm \text { SD) } \\
\text { - Short -term lactulose } 50 \pm 16 \text { years } \\
\text { - Long-term lactulose } 49 \pm 17 \text { years } \\
\text { - Control } 49 \pm 13 \text { years } \\
\text { Proportion of men } \\
\text { - All groups } 85 \% \\
\text { Aetiology of cirrhosis } \\
\text { - Alcohol } 17 \% \\
\text { - Hepatitis } B / C 63 \%\end{array}$ \\
\hline
\end{tabular}

Interventions Lactulose syrup versus no intervention for eight or 24 weeks (see notes)

\section{Outcomes Neuropsychiatric assessment}

- Number Connection Test

- Digit Symbol Test

- Electroencephalography

- Venous blood ammonia

- Sensory Evoked Potentials 
Zeng 2003 (Continued)

Outcomes included in meta-analyses

\begin{tabular}{ll}
\hline Inclusion period & July 1998 to March 2002 \\
\hline Country of origin & China \\
\hline Notes & The investigators assess quality of life using the World Health Organization quality of life BREF (WHO- \\
QOL-BREF) including the domains physical health, psychological health, social relationships, and en- \\
vironment. \\
- The method for diagnosing minimal hepatic encephalopathy is not specified. \\
- The trial includes the following 3 allocation arms: lactulose for 8 weeks, lactulose for 24 weeks, and \\
no intervention. We combined the results of the 2 lactulose arms in our analyses. \\
- All participants in the intervention and control groups also received vitamin B and silymarin. \\
$60 \%$ in the long-term lactulose arm, and $60 \%$ in the control arm.
\end{tabular}

\section{Risk of bias}

\begin{tabular}{|c|c|c|}
\hline Bias & Authors' judgement & Support for judgement \\
\hline $\begin{array}{l}\text { Random sequence genera- } \\
\text { tion (selection bias) }\end{array}$ & Unclear risk & Not described \\
\hline $\begin{array}{l}\text { Allocation concealment } \\
\text { (selection bias) }\end{array}$ & Unclear risk & Not described \\
\hline $\begin{array}{l}\text { Blinding of participants } \\
\text { and personnel (perfor- } \\
\text { mance bias) } \\
\text { Non-mortality outcomes }\end{array}$ & High risk & Open trial. No blinding of participants or personnel. \\
\hline $\begin{array}{l}\text { Blinding of participants } \\
\text { and personnel (perfor- } \\
\text { mance bias) } \\
\text { Mortality }\end{array}$ & Low risk & Performance bias unlikely to influence the outcome \\
\hline $\begin{array}{l}\text { Blinding of outcome as- } \\
\text { sessment (detection bias) } \\
\text { Non-mortality outcomes }\end{array}$ & High risk & Open trial. No blinding of the outcome assessment. \\
\hline $\begin{array}{l}\text { Blinding of outcome as- } \\
\text { sessment (detection bias) } \\
\text { Mortality }\end{array}$ & Low risk & Detection bias unlikely to influence the outcome \\
\hline $\begin{array}{l}\text { Incomplete outcome data } \\
\text { (attrition bias) } \\
\text { All outcomes }\end{array}$ & Low risk & $\begin{array}{l}\text { The investigators account for all participants randomised and used sufficient } \\
\text { methods to handle missing data. Missing outcome data are unlikely to affect } \\
\text { the analyses or to be associated with the outcome. }\end{array}$ \\
\hline $\begin{array}{l}\text { Selective reporting (re- } \\
\text { porting bias) }\end{array}$ & Low risk & Predefined outcomes reported \\
\hline For-profit funding & Low risk & No for-profit funding \\
\hline Other bias & Low risk & No other biases \\
\hline
\end{tabular}

Non-absorbable disaccharides versus placebo/no intervention and lactulose versus lactitol for the prevention and treatment of hepatic 
Zeng 2003 (Continued)

Overall assessment (mor- High risk High risk tality)

Overall assessment (non- High risk

High risk

mortality outcomes)

Ziada 2013

\begin{tabular}{ll} 
Methods & Single-blind, parallel-arm, single-centre, outpatient trial \\
\hline Participants & The trial includes 60 participants with cirrhosis and minimal hepatic encephalopathy. \\
Age (mean \pm SD) & - Lactulose group $48.8 \pm 8.2$ years \\
- Control group $51.2 \pm 7.5$ years \\
Proportion of men \\
- Lactulose group $75.0 \%$ \\
- Control group $72.0 \%$ \\
Aetiology of cirrhosis \\
- Not reported
\end{tabular}

Interventions Lactulose syrup versus no intervention for 4 weeks

Outcomes Neuropsychiatric assessment

- Mental status (West-Haven Criteria)

- Number Connection Test A

- Block Design Test

- Digit Symbol Test

- Serial-dotting test

- Line tracing test

- Blood ammonia

- Cerebral magnetic resonance spectroscopy

Outcomes included in Mortality, hepatic encephalopathy, and adverse events assessed after 4 weeks meta-analyses

\begin{tabular}{ll}
\hline Inclusion period & March 2010 to January 2012 \\
\hline Country of origin & Egypt \\
\hline Notes & The trial includes 90 participants randomised to lactulose $(\mathrm{n}=30)$, a probiotic ( $\mathrm{n}=30)$, or to no treat- \\
& ment $(\mathrm{n}=30)$. We did not include the probiotics group in our analyses. \\
- & The investigators based the diagnosis of minimal hepatic encephalopathy on the finding of at least 2 \\
& abnormal psychometric tests. \\
- & The proportion of participants with Child's B/C cirrhosis was $91.7 \%$ in the lactulose group and $88.0 \%$ \\
& in the control group.
\end{tabular}

\section{Risk of bias}

Non-absorbable disaccharides versus placebo/no intervention and lactulose versus lactitol for the prevention and treatment of hepatic 
Ziada 2013 (Continued)

\begin{tabular}{|c|c|c|}
\hline Bias & Authors' judgement & Support for judgement \\
\hline $\begin{array}{l}\text { Random sequence genera- } \\
\text { tion (selection bias) }\end{array}$ & Unclear risk & Not described \\
\hline $\begin{array}{l}\text { Allocation concealment } \\
\text { (selection bias) }\end{array}$ & Unclear risk & Not described \\
\hline $\begin{array}{l}\text { Blinding of participants } \\
\text { and personnel (perfor- } \\
\text { mance bias) } \\
\text { Non-mortality outcomes }\end{array}$ & High risk & Open, single-blind trial. No blinding of participants or personnel. \\
\hline $\begin{array}{l}\text { Blinding of participants } \\
\text { and personnel (perfor- } \\
\text { mance bias) } \\
\text { Mortality }\end{array}$ & Low risk & Performance bias unlikely to influence the outcome \\
\hline $\begin{array}{l}\text { Blinding of outcome as- } \\
\text { sessment (detection bias) } \\
\text { Non-mortality outcomes }\end{array}$ & Low risk & Open, single-blind trial. Blinding of outcome assessment. \\
\hline $\begin{array}{l}\text { Blinding of outcome as- } \\
\text { sessment (detection bias) } \\
\text { Mortality }\end{array}$ & Low risk & Detection bias unlikely to influence the outcome \\
\hline $\begin{array}{l}\text { Incomplete outcome data } \\
\text { (attrition bias) } \\
\text { All outcomes }\end{array}$ & High risk & Participants with missing outcomes are excluded from the analyses. \\
\hline $\begin{array}{l}\text { Selective reporting (re- } \\
\text { porting bias) }\end{array}$ & Low risk & Predefined outcomes reported \\
\hline For-profit funding & Low risk & No for-profit funding \\
\hline Other bias & Low risk & No other biases \\
\hline $\begin{array}{l}\text { Overall assessment (mor- } \\
\text { tality) }\end{array}$ & High risk & High risk \\
\hline $\begin{array}{l}\text { Overall assessment (non- } \\
\text { mortality outcomes) }\end{array}$ & High risk & High risk \\
\hline
\end{tabular}

RCT: randomised clinical trial

SD: standard deviation

Characteristics of excluded studies [ordered by study ID]

\begin{tabular}{ll}
\hline Study & Reason for exclusion \\
\hline Bajaj 2010a & $\begin{array}{l}\text { Observational study. Retrospective review of participants with cirrhosis maintained on lactulose } \\
\text { following an index episode of hepatic encephalopathy. The outcomes included recurrence of he- } \\
\text { patic encephalopathy, precipitating factors, and compliance with lactulose treatment. The analy- } \\
\text { ses compared participants with/without a recurrence of hepatic encephalopathy and identified the } \\
\text { predictors of recurrence. }\end{array}$
\end{tabular}

Non-absorbable disaccharides versus placebo/no intervention and lactulose versus lactitol for the prevention and treatment of hepatic 


\section{Study Reason for exclusion}

Bircher 1971

Case series reporting the effects of protein intake, lactulose, and neomycin on clinical grading, electroencephalography, and blood ammonia levels in 6 participants with cirrhosis and chronic hepatic encephalopathy.

Brown 1970

Case series reporting neuropsychiatric status and associated variables in 4 participants with cirrhosis and post-shunt hepatic encephalopathy during alternating periods of treatment with lactulose and sorbitol.

James 1971

Observational study. Careful documentation of the effects of treatment with lactulose over 10 days on cerebral blood flow and metabolism in 6 participants with cirrhosis and chronic hepatic encephalopathy.

Observational cross-over study comparing the effects of 3 months of treatment with lactulose and lactitol on mental status, psychometric performance, venous blood ammonia levels, electroencephalography mean cycle frequency, and cerebral blood flow and metabolism in 5 participants with chronic hepatic encephalopathy.

Merli 1992

Observational study on the effects of treatment with lactulose or lactitol on faecal fat excretion in 18 participants with cirrhosis.

Patil 1987

Observational study detailing the differential effects of lactulose and lactitol on (i) an in vitro faecal incubation system and (ii) on terminal ileal and colonic $\mathrm{pH}$ in 6 normal participants using radiotelemetry.

\section{Piotraschke 1996}

Observational open study published in abstract form describing the non-comparative effect of lactulose on preventing hepatic encephalopathy in participants with cirrhosis following insertion of a transjugular intrahepatic portosystemic shunt.

Pockros 2009

Randomised clinical trial of lactulose versus AST-120 (spherical carbon adsorbent). The trial includes 47 participants with cirrhosis and overt hepatic encephalopathy. The trial did not include a placebo or no intervention group.

Quinton 1982

Randomised clinical trial of mannitol lavage versus a combination of lactulose and the antibiotic kanamycin for the prevention of hepatic encephalopathy following gastrointestinal haemorrhage in participants with cirrhosis. The trial did not include a placebo/no intervention group.

Rahimi 2014

Randomised clinical trial on lactulose versus polyethylene glycol for the treatment of acute hepatic encephalopathy. The trial did not include a placebo/no intervention group.

Riggio 1990

Observational study comparing the effect of lactulose or lactitol on the faecal flora of 21 participants with cirrhosis and no evidence of hepatic encephalopathy.

Rorsman 1970

Case series reporting the responses of 3 participants with cirrhosis and post-shunt hepatic encephalopathy to treatment with lactulose.

\section{Salerno 1994}

\section{Schomerus 1993}

Sharma 2008
Observational study on the differential effects of 2 different doses of lactitol on neuropsychiatric status in participants with cirrhosis.
A field study documenting the prevalence of minimal hepatic encephalopathy in ambulatory participants with cirrhosis.

\begin{tabular}{ll} 
& thy. The trial does not include a placebo or no intervention group. \\
\hline Sharma 2009a & $\begin{array}{l}\text { Observational study to identify the predictors of minimal hepatic encephalopathy in participants } \\
\text { with cirrhosis. }\end{array}$
\end{tabular}

Non-absorbable disaccharides versus placebo/no intervention and lactulose versus lactitol for the prevention and treatment of hepatic encephalopathy in people with cirrhosis (Review)

Copyright (c) 2016 The Cochrane Collaboration. Published by John Wiley \& Sons, Ltd. 


\begin{tabular}{ll}
\hline Study & Reason for exclusion \\
\hline Sharma 2010 & $\begin{array}{l}\text { Observational study evaluating predictors of non-response to lactulose in participants with cirrho- } \\
\text { sis and overt hepatic encephalopathy. }\end{array}$ \\
\hline Sharma 2010a & $\begin{array}{l}\text { Observational study evaluating the prevalence of abnormal psychometric tests and critical flicker } \\
\text { frequency after clinical recovery of overt hepatic encephalopathy. }\end{array}$ \\
\hline Sharma 2011a & $\begin{array}{l}\text { Retrospective review of the efficacy of lactulose for the treatment of hepatic encephalopathy in } \\
\text { young people with hepatic encephalopathy. }\end{array}$ \\
\hline Trovato 1995 & $\begin{array}{l}\text { Observational study of the effects of lactitol on clinical status and blood ammonium, atrial natri- } \\
\text { uretic peptide, and amino acid concentrations in } 10 \text { participants with cirrhosis and hepatic en- } \\
\text { cephalopathy. }\end{array}$ \\
\hline Vendemiale 1992 & $\begin{array}{l}\text { An open comparison of the effects of } 10 \text { days treatment with lactulose or no treatment on blood } \\
\text { ammonia levels, Number Connection Test results, and lymphocyte sub-populations in people with } \\
\text { cirrhosis. }\end{array}$ \\
\hline Venturini 2005 & $\begin{array}{l}\text { Randomised clinical trial of the effect of rifaximin, lactulose, and placebo on circulating benzodi- } \\
\text { azepine-like compounds in 18 participants with cirrhosis. None of the included participants had he- } \\
\text { patic encephalopathy. }\end{array}$ \\
\hline Case series describes the effects of treatment with lactulose in 5 participants with cirrhosis and \\
overt hepatic encephalopathy.
\end{tabular}

Characteristics of ongoing studies [ordered by study ID]

Salih 2007

\begin{tabular}{ll}
\hline Trial name or title & $\begin{array}{l}\text { Lactulose for the prevention of hepatic encephalopathy in participants with cirrhosis and up- } \\
\text { per gastrointestinal haemorrhage }\end{array}$ \\
\hline Methods & Randomised clinical trial \\
\hline Participants & Participants with cirrhosis \\
\hline Interventions & Lactulose versus placebo \\
\hline Outcomes & Hepatic encephalopathy \\
\hline Starting date & 2007 \\
\hline Contact information & Aga Kahn University \\
\hline Trial registration number & NCT00553423 \\
\hline Notes & Investigators contacted via email October 2014. No reply \\
\hline
\end{tabular}

\section{Wang 2012}

Trial name or title

Impact of lactulose treatment on cognition, assessment of quality of life and changes of intestinal flora in minimal hepatic encephalopathy participants: a multicentre, randomised, open-label and controlled clinical study

Non-absorbable disaccharides versus placebo/no intervention and lactulose versus lactitol for the prevention and treatment of hepatic 
Wang 2012 (Continued)

\begin{tabular}{ll} 
Methods & Randomised clinical trial \\
\hline Participants & Cirrhosis and minimal hepatic encephalopathy \\
\hline Interventions & Lactulose versus no intervention \\
\hline Outcomes & Recovery from minimal hepatic encephalopathy \\
\hline Starting date & 2012 \\
\hline Contact information & Zhong Shan Hospital, Shanghai, China \\
\hline Trial registration number & ChiCTR-TRC-12002342 \\
\hline Notes & $\begin{array}{l}\text { Investigators contacted via email October 2014 and reported that the final analyses will take place } \\
\text { in October 2014 }\end{array}$ \\
\hline
\end{tabular}

\section{DATA AND ANALYSES}

\section{Comparison 1. Non-absorbable disaccharides versus placebo/no intervention}

\begin{tabular}{|c|c|c|c|c|}
\hline Outcome or subgroup title & No. of studies & $\begin{array}{l}\text { No. of partici- } \\
\text { pants }\end{array}$ & Statistical method & Effect size \\
\hline 1 Mortality & 24 & 1487 & Risk Ratio (IV, Random, 95\% Cl) & $0.59[0.40,0.87]$ \\
\hline $\begin{array}{l}2 \text { Mortality in trials with a } \\
\text { low risk of bias }\end{array}$ & 8 & 705 & Risk Ratio (IV, Random, 95\% CI) & $0.63[0.41,0.97]$ \\
\hline 3 Hepatic encephalopathy & 22 & 1415 & Risk Ratio (IV, Random, 95\% Cl) & $0.58[0.50,0.69]$ \\
\hline 4 Serious adverse events & 24 & 1487 & Risk Ratio (IV, Random, 95\% Cl) & $0.47[0.36,0.60]$ \\
\hline $\begin{array}{l}5 \text { Quality of life: sickness im- } \\
\text { pact profile }\end{array}$ & 3 & & $\begin{array}{l}\text { Mean Difference (IV, Random, 95\% } \\
\mathrm{CI} \text { ) }\end{array}$ & Subtotals only \\
\hline 5.1 Change from baseline & 2 & 120 & $\begin{array}{l}\text { Mean Difference (IV, Random, 95\% } \\
\mathrm{CI})\end{array}$ & $7.18[5.28,9.07]$ \\
\hline 5.2 End of treatment & 1 & 40 & $\begin{array}{l}\text { Mean Difference (IV, Random, 95\% } \\
\mathrm{CI})\end{array}$ & $0.90[-4.13,5.93]$ \\
\hline $\begin{array}{l}6 \text { Non-serious adverse } \\
\text { events }\end{array}$ & 9 & & Risk Ratio (IV, Random, 95\% Cl) & Subtotals only \\
\hline 6.1 Overall & 9 & 739 & Risk Ratio (IV, Random, 95\% Cl) & $2.47[1.24,4.93]$ \\
\hline 6.2 Diarrhoea & 7 & 634 & Risk Ratio (IV, Random, 95\% Cl) & $6.41[1.84,22.40]$ \\
\hline 6.3 Bloating & 6 & 563 & Risk Ratio (IV, Random, 95\% Cl) & $4.50[1.17,17.27]$ \\
\hline 6.4 Nausea & 1 & 60 & Risk Ratio (IV, Random, 95\% Cl) & $11.00[0.64,190.53]$ \\
\hline
\end{tabular}

Non-absorbable disaccharides versus placebo/no intervention and lactulose versus lactitol for the prevention and treatment of hepatic 


\begin{tabular}{|c|c|c|c|c|}
\hline Outcome or subgroup title & No. of studies & $\begin{array}{l}\text { No. of partici- } \\
\text { pants }\end{array}$ & Statistical method & Effect size \\
\hline 6.5 Constipation & 2 & 298 & Risk Ratio (IV, Random, 95\% Cl) & $0.04[0.01,0.29]$ \\
\hline 6.6 Hyponatraemia & 1 & 45 & Risk Ratio (IV, Random, 95\% Cl) & $0.35[0.01,8.11]$ \\
\hline 6.7 Anal fissure & 1 & 45 & Risk Ratio (IV, Random, 95\% Cl) & $0.35[0.01,8.11]$ \\
\hline 6.8 Hyperglycaemia & 1 & 45 & Risk Ratio (IV, Random, 95\% Cl) & $0.35[0.01,8.11]$ \\
\hline $\begin{array}{l}7 \text { Number connection test, } \\
\text { end of treatment }\end{array}$ & 6 & 275 & $\begin{array}{l}\text { Mean Difference (IV, Random, 95\% } \\
\mathrm{Cl} \text { ) }\end{array}$ & $-5.56[-11.59,0.47]$ \\
\hline $\begin{array}{l}8 \text { Ammonia end of treat- } \\
\text { ment }\end{array}$ & 6 & 374 & $\begin{array}{l}\text { Mean Difference (IV, Random, 95\% } \\
\mathrm{Cl} \text { ) }\end{array}$ & $-11.64[-21.14,-2.14]$ \\
\hline 8.1 Venous & 5 & 216 & $\begin{array}{l}\text { Mean Difference (IV, Random, 95\% } \\
\mathrm{CI})\end{array}$ & $-15.66[-27.79,-3.53]$ \\
\hline 8.2 Arterial & 1 & 158 & $\begin{array}{l}\text { Mean Difference (IV, Random, 95\% } \\
\mathrm{CI})\end{array}$ & $-2.23[-6.89,2.43]$ \\
\hline $\begin{array}{l}9 \text { Ammonia change from } \\
\text { baseline }\end{array}$ & 3 & 155 & $\begin{array}{l}\text { Mean Difference (IV, Random, 95\% } \\
\mathrm{CI})\end{array}$ & $18.97[8.86,29.09]$ \\
\hline 9.1 Arterial & 2 & 134 & $\begin{array}{l}\text { Mean Difference (IV, Random, 95\% } \\
\mathrm{CI})\end{array}$ & $10.45[5.60,15.31]$ \\
\hline 9.2 Venous & 1 & 21 & $\begin{array}{l}\text { Mean Difference (IV, Random, 95\% } \\
\mathrm{CI})\end{array}$ & $44.0[32.34,55.66]$ \\
\hline $\begin{array}{l}10 \text { Mortality in worst-case } \\
\text { scenario analyses }\end{array}$ & 24 & & Risk Ratio (IV, Random, 95\% CI) & Subtotals only \\
\hline 10.1 Worst-case scenario & 24 & 1487 & Risk Ratio (IV, Random, 95\% Cl) & $0.61[0.42,0.88]$ \\
\hline $\begin{array}{l}\text { 10.2 Extreme worst-case } \\
\text { scenario analysis }\end{array}$ & 24 & 1487 & Risk Ratio (IV, Random, 95\% Cl) & $0.64[0.44,0.94]$ \\
\hline $\begin{array}{l}11 \text { Hepatic encephalopathy } \\
\text { worst-case scenario analy- } \\
\text { sis }\end{array}$ & 22 & 2830 & Risk Ratio (IV, Random, 95\% Cl) & $0.60[0.54,0.66]$ \\
\hline 11.1 Worst-case scenario & 22 & 1415 & Risk Ratio (IV, Random, 95\% Cl) & $0.59[0.50,0.69]$ \\
\hline $\begin{array}{l}\text { 11.2 Extreme worst-case } \\
\text { scenario }\end{array}$ & 22 & 1415 & Risk Ratio (IV, Random, 95\% Cl) & $0.60[0.51,0.70]$ \\
\hline $\begin{array}{l}12 \text { Serious adverse events } \\
\text { worst-case scenario analy- } \\
\text { sis }\end{array}$ & 24 & 2974 & Risk Ratio (IV, Random, 95\% CI) & $0.48[0.41,0.57]$ \\
\hline $\begin{array}{l}12.1 \text { Worst-case scenario } \\
\text { analysis }\end{array}$ & 24 & 1487 & Risk Ratio (IV, Random, 95\% Cl) & $0.47[0.37,0.61]$ \\
\hline $\begin{array}{l}\text { 12.2 Extreme worst-case } \\
\text { scenario analysis }\end{array}$ & 24 & 1487 & Risk Ratio (IV, Random, 95\% Cl) & $0.49[0.38,0.62]$ \\
\hline
\end{tabular}

Non-absorbable disaccharides versus placebo/no intervention and lactulose versus lactitol for the prevention and treatment of hepatic 
Analysis 1.1. Comparison 1 Non-absorbable disaccharides versus placebo/no intervention, Outcome 1 Mortality.

\begin{tabular}{|c|c|c|c|c|c|}
\hline Study or subgroup & $\begin{array}{c}\text { Disaccharide } \\
\mathrm{n} / \mathrm{N}\end{array}$ & $\begin{array}{c}\text { Control } \\
\mathrm{n} / \mathrm{N}\end{array}$ & $\begin{array}{c}\text { Risk Ratio } \\
\text { IV, Random, } 95 \% \mathrm{CI}\end{array}$ & Weight & $\begin{array}{c}\text { Risk Ratio } \\
\text { IV, Random, } 95 \% \mathrm{CI} \\
\end{array}$ \\
\hline Agrawal 2012 & $13 / 80$ & $16 / 78$ & $\rightarrow$ & $33.39 \%$ & $0.79[0.41,1.54]$ \\
\hline Corazza 1982 & $0 / 16$ & $0 / 16$ & & & Not estimable \\
\hline Dhiman 2000 & $2 / 14$ & $1 / 12$ & + & $2.83 \%$ & $1.71[0.18,16.65]$ \\
\hline Germain 1973 & $0 / 9$ & $0 / 9$ & & & Not estimable \\
\hline Horsmans 1997 & $0 / 7$ & $0 / 7$ & & & Not estimable \\
\hline Jain 2013 & $1 / 30$ & $1 / 30$ & & $1.97 \%$ & $1[0.07,15.26]$ \\
\hline Li 1999 & $0 / 48$ & $0 / 38$ & & & Not estimable \\
\hline Mittal 2011 & $0 / 40$ & $1 / 40$ & & $1.46 \%$ & $0.33[0.01,7.95]$ \\
\hline Prasad 2007 & $0 / 31$ & $3 / 30$ & & $1.71 \%$ & $0.14[0.01,2.57]$ \\
\hline Quero 1997 & $1 / 20$ & $0 / 20$ & & $1.48 \%$ & $3[0.13,69.52]$ \\
\hline Raza 2004 & $1 / 18$ & $2 / 13$ & & $2.79 \%$ & $0.36[0.04,3.57]$ \\
\hline Riggio 2005 & $2 / 25$ & $1 / 25$ & & $2.68 \%$ & $2[0.19,20.67]$ \\
\hline Sharma 2009 & $5 / 70$ & $11 / 70$ & & $14.52 \%$ & $0.45[0.17,1.24]$ \\
\hline Sharma 2011 & $3 / 35$ & $6 / 35$ & $\rightarrow$ & $8.6 \%$ & $0.5[0.14,1.84]$ \\
\hline Sharma 2012 & $5 / 60$ & $10 / 60$ & - & $14.29 \%$ & $0.5[0.18,1.38]$ \\
\hline Simmons 1970 & $3 / 14$ & $6 / 12$ & & $11.04 \%$ & $0.43[0.14,1.36]$ \\
\hline Uribe $1987 a$ & $0 / 22$ & $4 / 23$ & & $1.78 \%$ & $0.12[0.01,2.04]$ \\
\hline Uribe 1987b & $0 / 10$ & $0 / 10$ & & & Not estimable \\
\hline Watanabe 1997 & $0 / 41$ & $0 / 34$ & & & Not estimable \\
\hline Wen 2013 & $0 / 65$ & $1 / 65$ & 1 & $1.45 \%$ & $0.33[0.01,8.03]$ \\
\hline Xing 2003 & $0 / 23$ & $0 / 22$ & & & Not estimable \\
\hline Yao 2014 & $0 / 20$ & $0 / 20$ & & & Not estimable \\
\hline Zeng 2003 & $0 / 40$ & $0 / 20$ & & & Not estimable \\
\hline Ziada 2013 & $0 / 30$ & $0 / 30$ & & & Not estimable \\
\hline Total $(95 \% \mathrm{CI})$ & 768 & 719 & $>$ & $100 \%$ & $0.59[0.4,0.87]$ \\
\hline \multicolumn{6}{|c|}{ Total events: 36 (Disaccharide), 63 (Control) } \\
\hline \multicolumn{6}{|c|}{ Heterogeneity: $\operatorname{Tau}^{2}=0 ; \mathrm{Chi}^{2}=7.16, \mathrm{df}=13(\mathrm{P}=0.89) ; \mathrm{I}^{2}=0 \%$} \\
\hline \multicolumn{6}{|c|}{ Test for overall effect: $Z=2.7(P=0.01)$} \\
\hline
\end{tabular}

Analysis 1.2. Comparison 1 Non-absorbable disaccharides versus placebo/ no intervention, Outcome 2 Mortality in trials with a low risk of bias.

\begin{tabular}{|c|c|c|c|c|c|}
\hline Study or subgroup & $\begin{array}{c}\text { Disaccharide } \\
\mathrm{n} / \mathrm{N} \\
\end{array}$ & $\begin{array}{c}\text { Control } \\
n / N\end{array}$ & $\begin{array}{c}\text { Risk Ratio } \\
\text { IV, Random, 95\% CI }\end{array}$ & Weight & $\begin{array}{c}\text { Risk Ratio } \\
\text { IV, Random, } 95 \% \text { CI } \\
\end{array}$ \\
\hline Sharma 2011 & $3 / 35$ & $6 / 35$ & $\longrightarrow+$ & $10.82 \%$ & $0.5[0.14,1.84]$ \\
\hline Dhiman 2000 & $2 / 14$ & $1 / 12$ & 1 & $3.56 \%$ & $1.71[0.18,16.65]$ \\
\hline Sharma 2012 & $5 / 60$ & $10 / 60$ & $\longrightarrow$ & $17.97 \%$ & $0.5[0.18,1.38]$ \\
\hline Mittal 2011 & $0 / 40$ & $1 / 40$ & 1 & $1.83 \%$ & $0.33[0.01,7.95]$ \\
\hline Sharma 2009 & $5 / 70$ & $11 / 70$ & $\longrightarrow$ & $18.27 \%$ & $0.45[0.17,1.24]$ \\
\hline Prasad 2007 & $0 / 31$ & $3 / 30$ & - & $2.16 \%$ & $0.14[0.01,2.57]$ \\
\hline Agrawal 2012 & $13 / 80$ & $16 / 78$ & 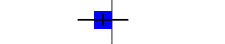 & $42.01 \%$ & $0.79[0.41,1.54]$ \\
\hline Total $(95 \% \mathrm{Cl})$ & 355 & 350 & & $100 \%$ & $0.63[0.41,0.97]$ \\
\hline
\end{tabular}

Non-absorbable disaccharides versus placebo/no intervention and lactulose versus lactitol for the prevention and treatment of hepatic 


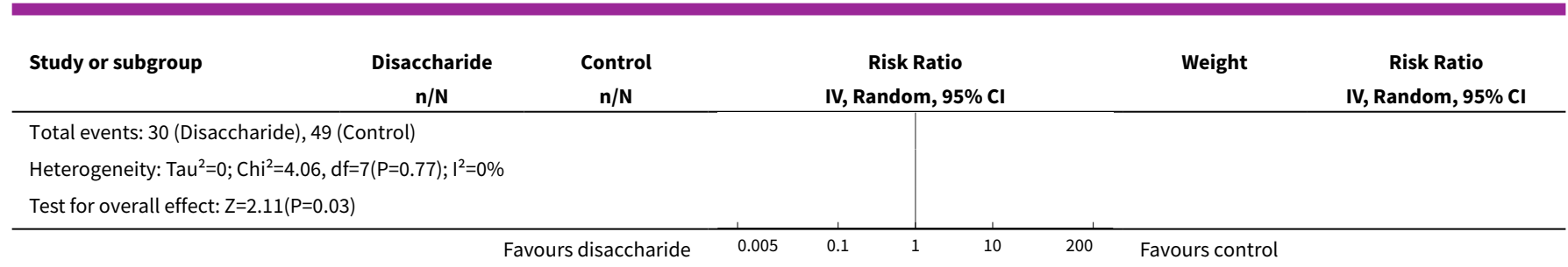

\section{Analysis 1.3. Comparison 1 Non-absorbable disaccharides versus placebo/no intervention, Outcome 3 Hepatic encephalopathy.}

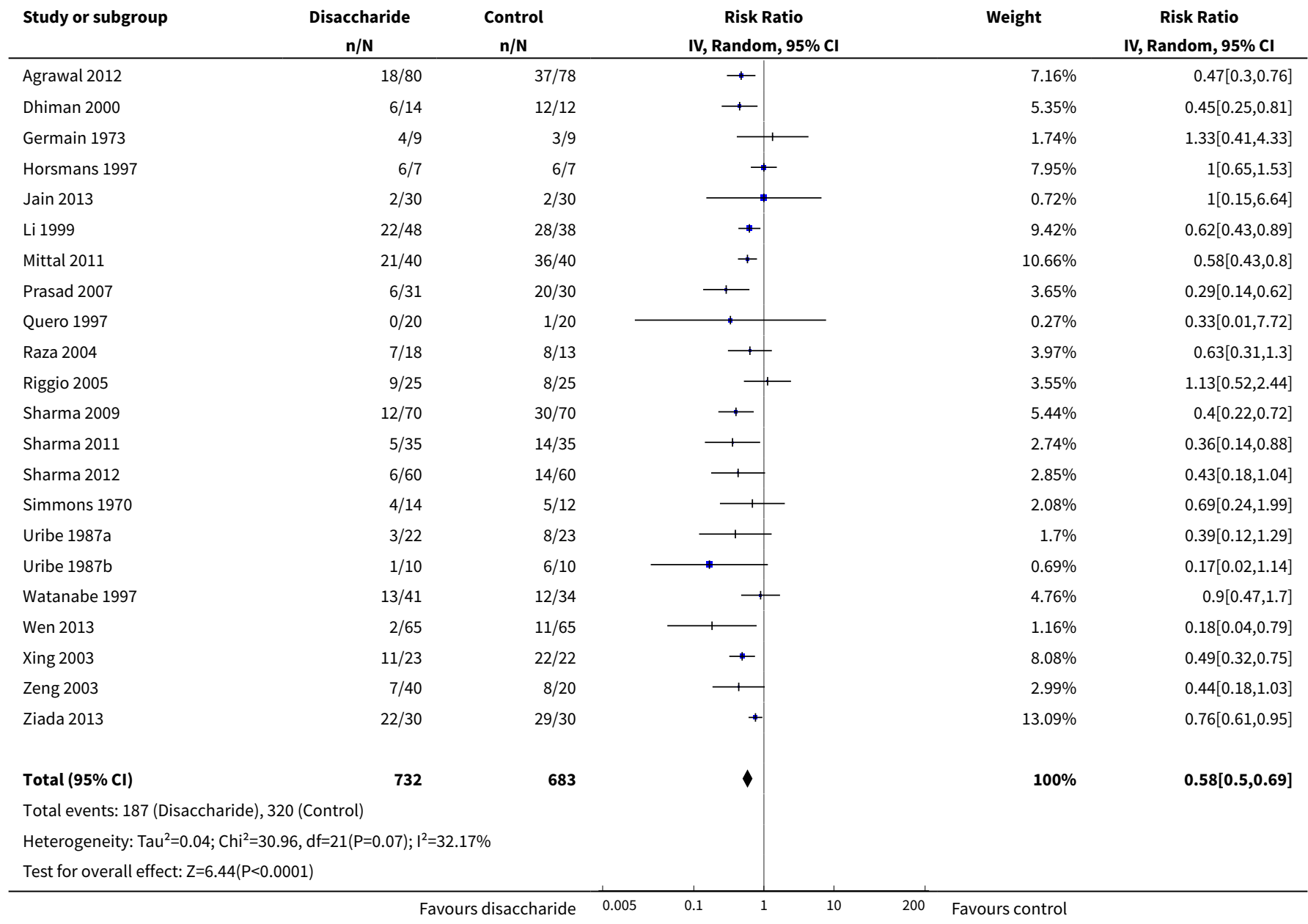

\section{Analysis 1.4. Comparison 1 Non-absorbable disaccharides versus} placebo/no intervention, Outcome 4 Serious adverse events.

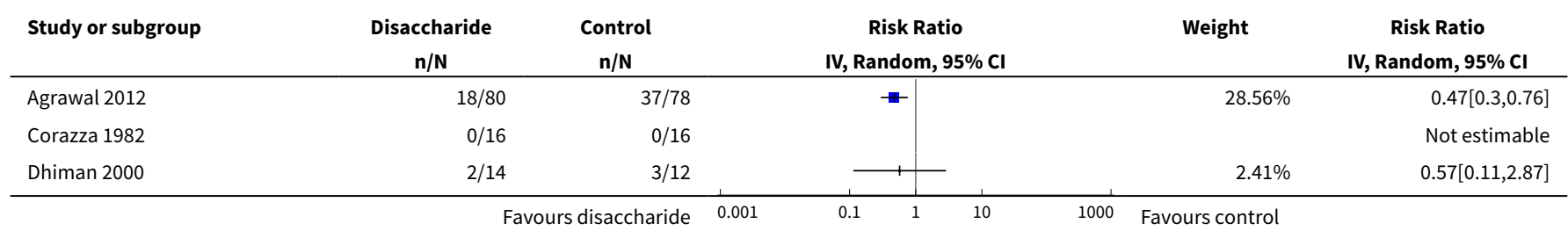

Non-absorbable disaccharides versus placebo/no intervention and lactulose versus lactitol for the prevention and treatment of hepatic 


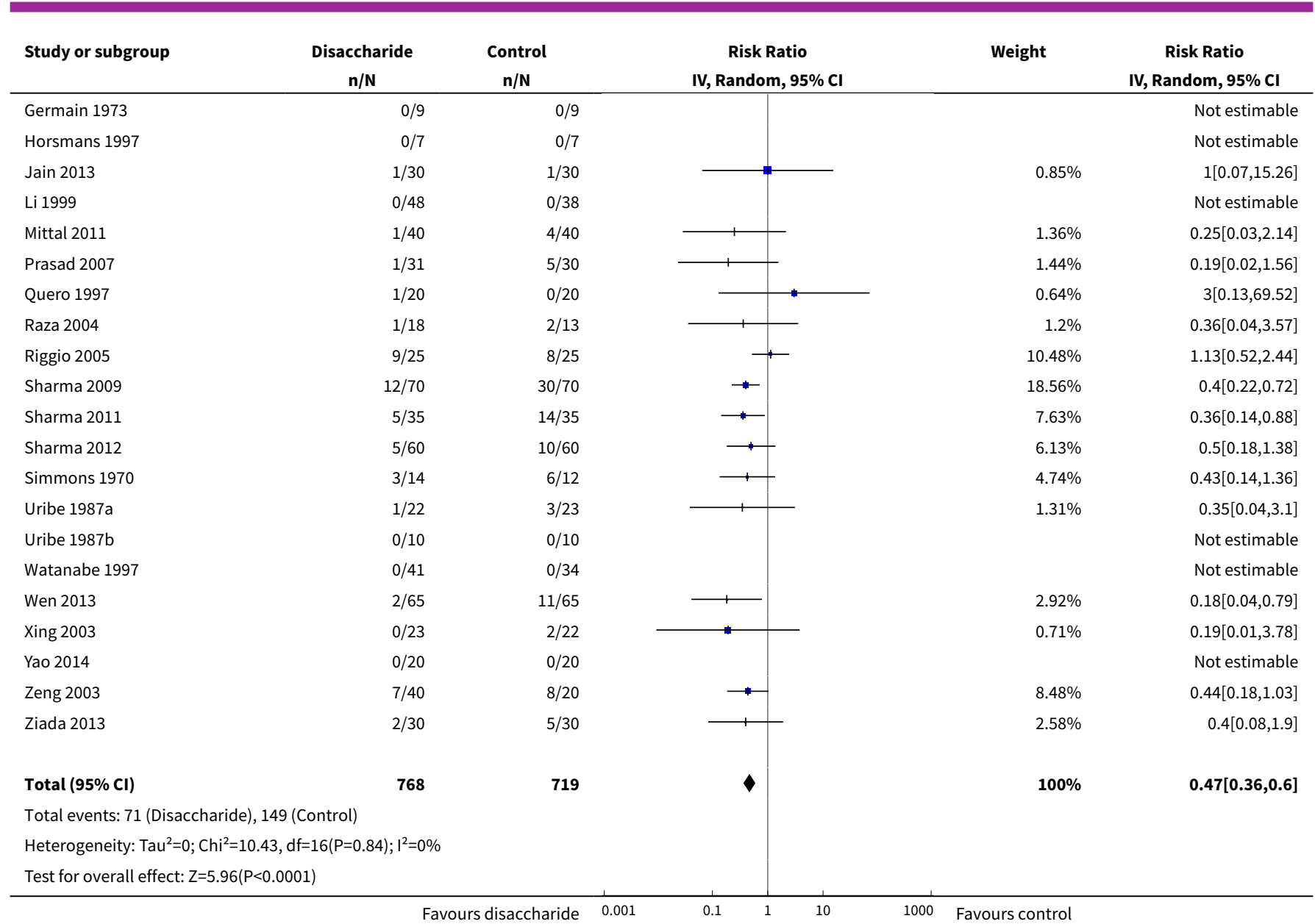

Analysis 1.5. Comparison 1 Non-absorbable disaccharides versus placebo/ no intervention, Outcome 5 Quality of life: sickness impact profile.

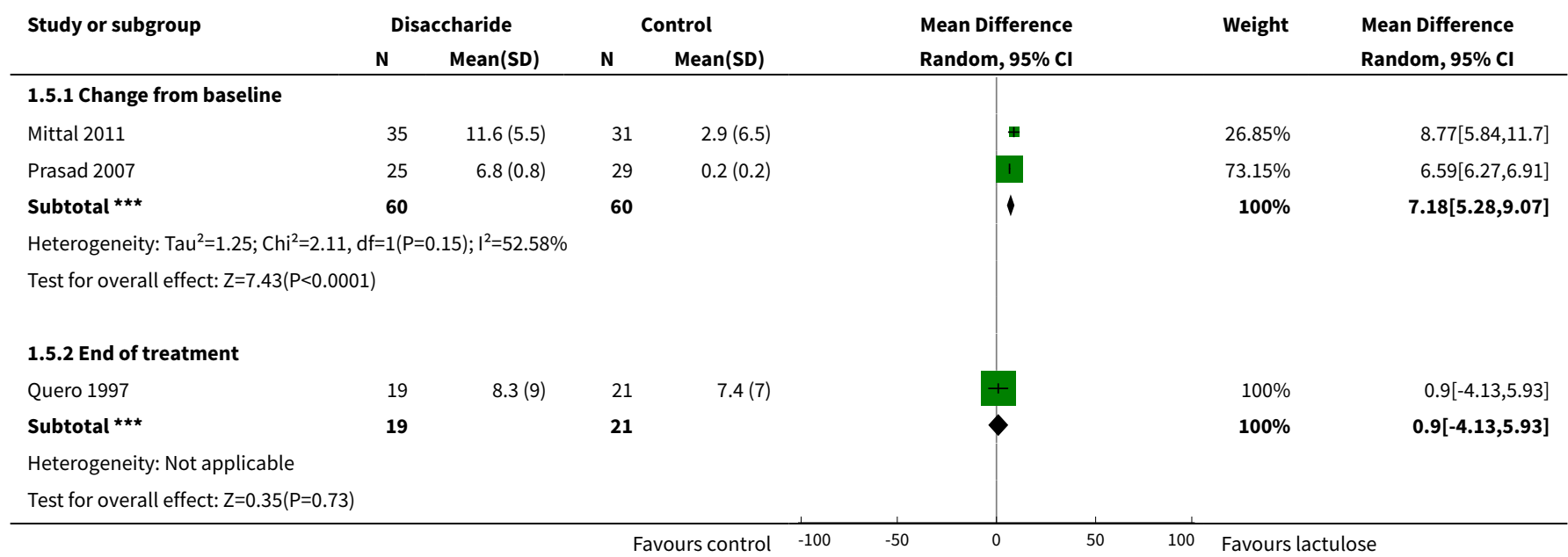


Analysis 1.6. Comparison 1 Non-absorbable disaccharides versus placebo/no intervention, Outcome 6 Non-serious adverse events.

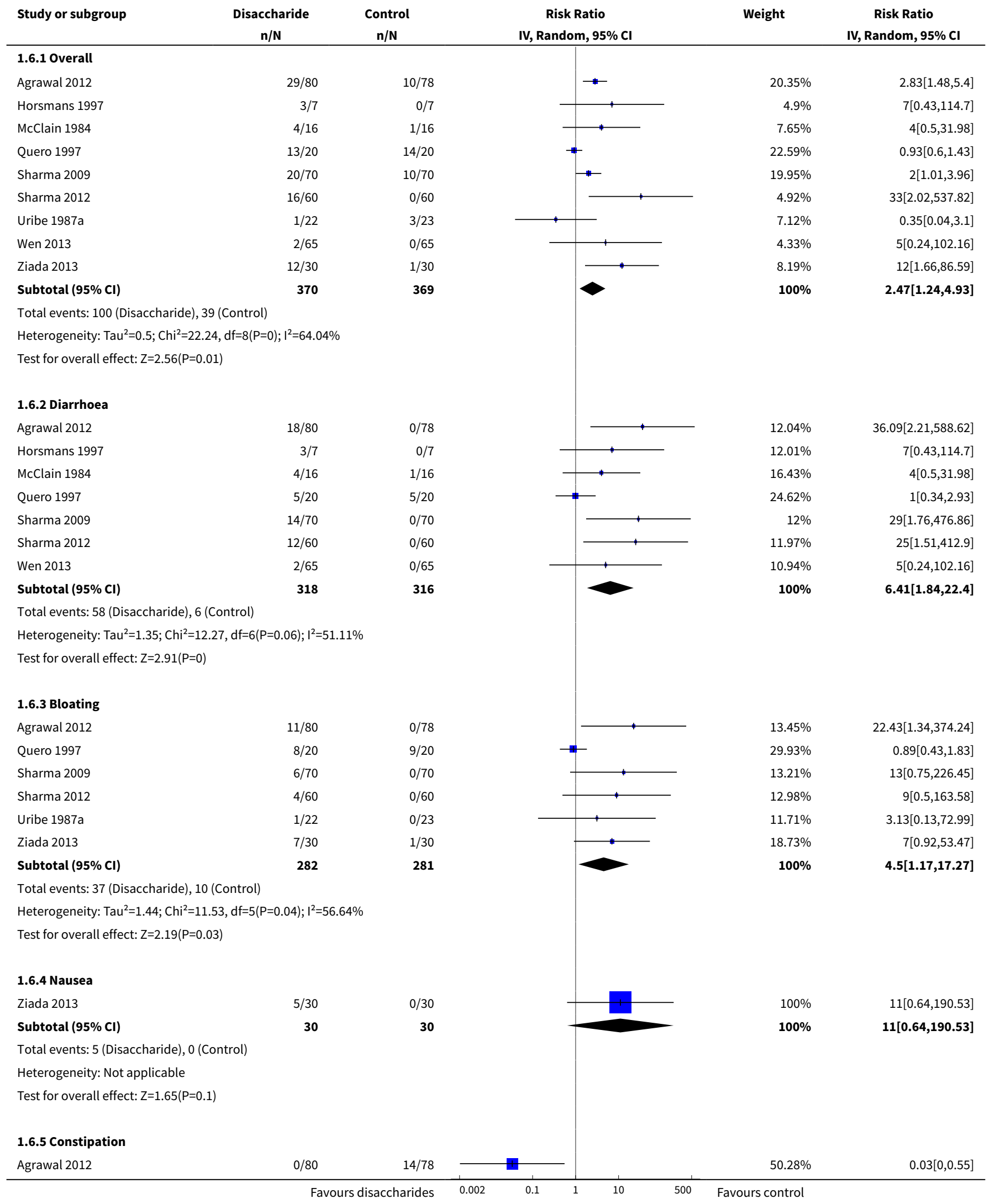

Non-absorbable disaccharides versus placebo/no intervention and lactulose versus lactitol for the prevention and treatment of hepatic 


\begin{tabular}{|c|c|c|c|c|c|}
\hline Study or subgroup & $\begin{array}{c}\text { Disaccharide } \\
n / N\end{array}$ & $\begin{array}{c}\text { Control } \\
n / N\end{array}$ & $\begin{array}{c}\text { Risk Ratio } \\
\text { IV, Random, 95\% CI }\end{array}$ & Weight & $\begin{array}{c}\text { Risk Ratio } \\
\text { IV, Random, } 95 \% \text { CI }\end{array}$ \\
\hline Sharma 2009 & $0 / 70$ & $10 / 70$ & 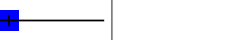 & $49.72 \%$ & $0.05[0,0.8]$ \\
\hline Subtotal $(95 \% \mathrm{Cl})$ & 150 & 148 & & $100 \%$ & $0.04[0.01,0.29]$ \\
\hline \multicolumn{6}{|c|}{ Total events: 0 (Disaccharide), 24 (Control) } \\
\hline \multicolumn{6}{|c|}{ Heterogeneity: $\mathrm{Tau}^{2}=0 ; \mathrm{Chi}^{2}=0.03, \mathrm{df}=1(\mathrm{P}=0.86) ; \mathrm{I}^{2}=0 \%$} \\
\hline \multicolumn{6}{|c|}{ Test for overall effect: $Z=3.18(P=0)$} \\
\hline \multicolumn{6}{|c|}{ 1.6.6 Hyponatraemia } \\
\hline Uribe $1987 a$ & $0 / 22$ & $1 / 23$ & & $100 \%$ & $0.35[0.01,8.11]$ \\
\hline Subtotal $(95 \% \mathrm{Cl})$ & 22 & 23 & & $100 \%$ & $0.35[0.01,8.11]$ \\
\hline \multicolumn{6}{|c|}{ Total events: 0 (Disaccharide), 1 (Control) } \\
\hline \multicolumn{6}{|c|}{ Heterogeneity: Not applicable } \\
\hline \multicolumn{6}{|c|}{ Test for overall effect: $Z=0.66(P=0.51)$} \\
\hline \multicolumn{6}{|l|}{ 1.6.7 Anal fissure } \\
\hline Uribe $1987 a$ & $0 / 22$ & $1 / 23$ & & $100 \%$ & $0.35[0.01,8.11]$ \\
\hline Subtotal $(95 \% \mathrm{Cl})$ & 22 & 23 & & $100 \%$ & $0.35[0.01,8.11]$ \\
\hline \multicolumn{6}{|c|}{ Total events: 0 (Disaccharide), 1 (Control) } \\
\hline \multicolumn{6}{|c|}{ Heterogeneity: Not applicable } \\
\hline \multicolumn{6}{|c|}{ Test for overall effect: $Z=0.66(P=0.51)$} \\
\hline \multicolumn{6}{|c|}{ 1.6.8 Hyperglycaemia } \\
\hline Uribe $1987 a$ & $0 / 22$ & $1 / 23$ & & $100 \%$ & $0.35[0.01,8.11]$ \\
\hline Subtotal $(95 \% \mathrm{Cl})$ & 22 & 23 & & $100 \%$ & $0.35[0.01,8.11]$ \\
\hline \multicolumn{6}{|c|}{ Total events: 0 (Disaccharide), 1 (Control) } \\
\hline \multicolumn{6}{|c|}{ Heterogeneity: Not applicable } \\
\hline Test for overall effect & & & & & \\
\hline
\end{tabular}

Analysis 1.7. Comparison 1 Non-absorbable disaccharides versus placebo/ no intervention, Outcome 7 Number connection test, end of treatment.

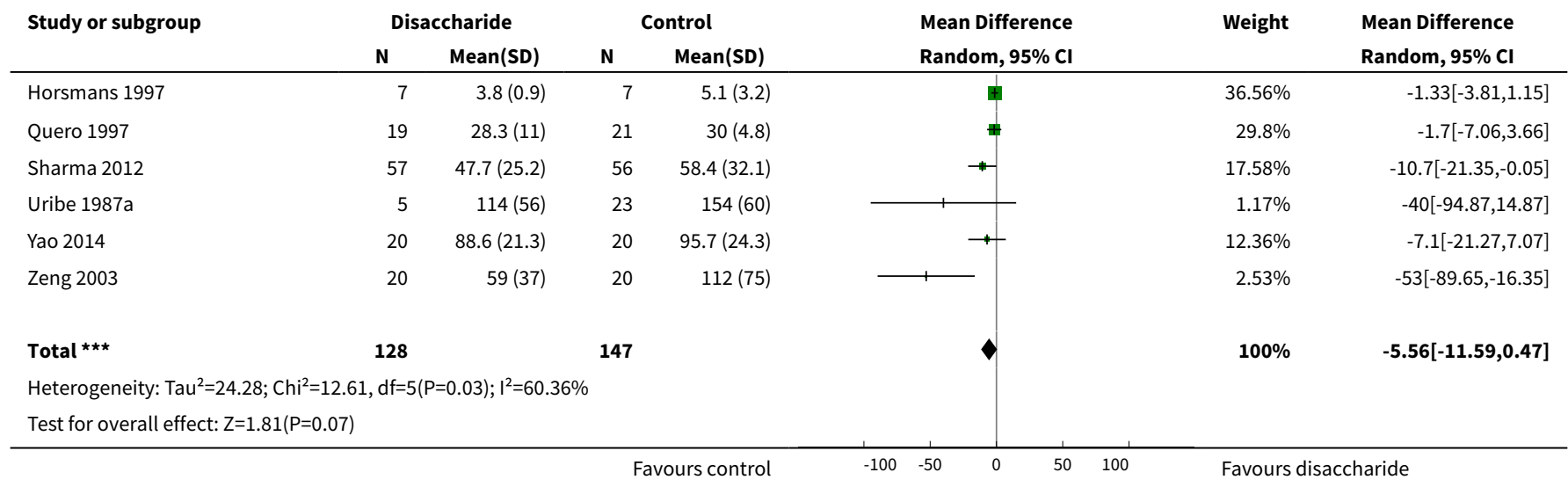


Analysis 1.8. Comparison 1 Non-absorbable disaccharides versus

placebo/no intervention, Outcome $8 \mathrm{Ammonia}$ end of treatment.

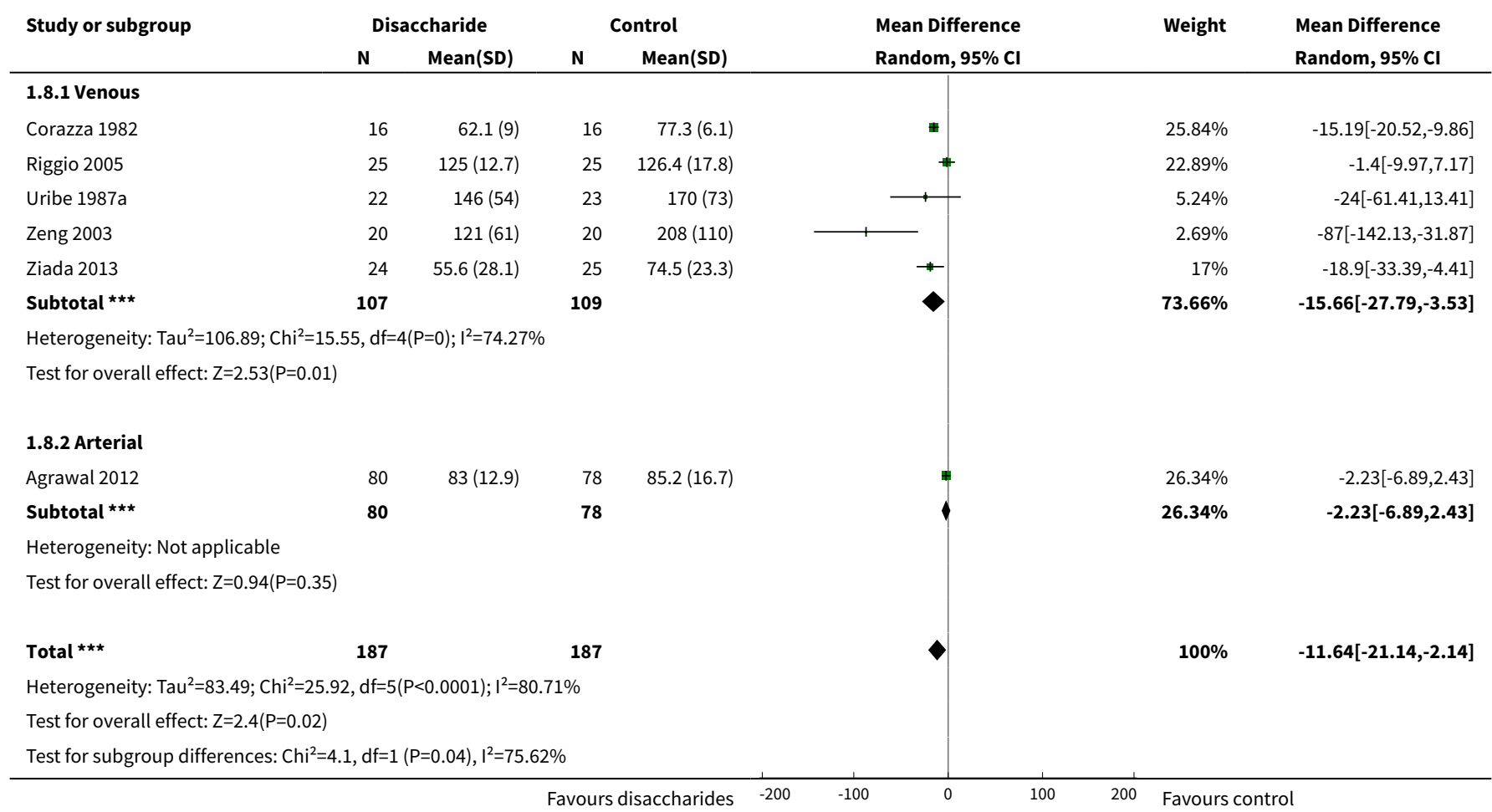

Analysis 1.9. Comparison 1 Non-absorbable disaccharides versus placebo/no intervention, Outcome 9 Ammonia change from baseline.

\begin{tabular}{|c|c|c|c|c|c|c|c|}
\hline \multirow[t]{2}{*}{ Study or subgroup } & \multicolumn{2}{|c|}{ Disaccharide } & \multicolumn{2}{|c|}{ Control } & \multirow{2}{*}{$\begin{array}{l}\text { Mean Difference } \\
\text { Random, 95\% Cl }\end{array}$} & \multirow[t]{2}{*}{ Weight } & \multirow{2}{*}{$\begin{array}{l}\text { Mean Difference } \\
\text { Random, } 95 \% \mathrm{Cl}\end{array}$} \\
\hline & $\mathbf{N}$ & $\operatorname{Mean}(\mathrm{SD})$ & $\mathbf{N}$ & Mean(SD) & & & \\
\hline \multicolumn{8}{|l|}{ 1.9.1 Arterial } \\
\hline Jain 2013 & 27 & $26(7)$ & 27 & $13.1(2.8)$ & & $37.35 \%$ & $12.9[10.08,15.72]$ \\
\hline Mittal 2011 & 40 & $8.5(5.8)$ & 40 & $0.5(7.8)$ & & $37.2 \%$ & $7.95[4.94,10.96]$ \\
\hline Subtotal $\star \star \star ~$ & 67 & & 67 & & & $74.55 \%$ & $10.45[5.6,15.31]$ \\
\hline \multicolumn{8}{|c|}{ Heterogeneity: $\operatorname{Tau}^{2}=10.04 ; \mathrm{Chi}^{2}=5.53, \mathrm{df}=1(\mathrm{P}=0.02) ; \mathrm{I}^{2}=81.92 \%$} \\
\hline \multicolumn{8}{|l|}{ 1.9.2 Venous } \\
\hline Simmons 1970 & 11 & $55(6.7)$ & 10 & $11(17.7)$ & & $25.45 \%$ & $44[32.34,55.66]$ \\
\hline 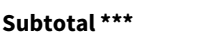 & 11 & & 10 & & & $25.45 \%$ & $44[32.34,55.66]$ \\
\hline \multicolumn{8}{|c|}{ Heterogeneity: Not applicable } \\
\hline \multicolumn{8}{|c|}{ Test for overall effect: $Z=7.39(P<0.0001)$} \\
\hline 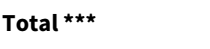 & 78 & & 77 & & & $100 \%$ & $18.97[8.86,29.09]$ \\
\hline \multicolumn{8}{|c|}{ Heterogeneity: $\operatorname{Tau}^{2}=69.24 ; \mathrm{Chi}^{2}=36.1, \mathrm{df}=2(\mathrm{P}<0.0001) ; \mathrm{I}^{2}=94.46 \%$} \\
\hline \multicolumn{8}{|c|}{ Test for overall effect: $Z=3.68(P=0)$} \\
\hline Test for subgroup dif & $09, \mathrm{df}$ & $(P<0.0001)$, & $.31 \%$ & & & & \\
\hline
\end{tabular}


Analysis 1.10. Comparison 1 Non-absorbable disaccharides versus placebo/ no intervention, Outcome 10 Mortality in worst-case scenario analyses.

\begin{tabular}{|c|c|c|c|c|c|}
\hline Study or subgroup & $\begin{array}{c}\text { Disaccharide } \\
n / N\end{array}$ & $\begin{array}{c}\text { Control } \\
n / N\end{array}$ & $\begin{array}{c}\text { Risk Ratio } \\
\text { IV, Random, } 95 \% \text { Cl }\end{array}$ & Weight & $\begin{array}{c}\text { Risk Ratio } \\
\text { IV, Random, } 95 \% \text { CI }\end{array}$ \\
\hline \multicolumn{6}{|c|}{ 1.10.1 Worst-case scenario } \\
\hline Agrawal 2012 & $13 / 80$ & $16 / 78$ & $\rightarrow$ & $30.59 \%$ & $0.79[0.41,1.54]$ \\
\hline Corazza 1982 & $0 / 16$ & $0 / 16$ & & & Not estimable \\
\hline Dhiman 2000 & $2 / 14$ & $1 / 12$ & 1 & $2.59 \%$ & $1.71[0.18,16.65]$ \\
\hline Germain 1973 & $0 / 9$ & $0 / 9$ & & & Not estimable \\
\hline Jain 2013 & $1 / 30$ & $1 / 30$ & & $1.81 \%$ & $1[0.07,15.26]$ \\
\hline Li 1999 & $0 / 48$ & $0 / 38$ & & & Not estimable \\
\hline Mittal 2011 & $0 / 40$ & $1 / 40$ & - & $1.33 \%$ & $0.33[0.01,7.95]$ \\
\hline Prasad 2007 & $0 / 31$ & $3 / 30$ & - & $1.57 \%$ & $0.14[0.01,2.57]$ \\
\hline Quero 1997 & $1 / 20$ & $0 / 20$ & 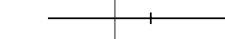 & $1.36 \%$ & $3[0.13,69.52]$ \\
\hline Raza 2004 & $2 / 18$ & $3 / 13$ & 11 & $4.98 \%$ & $0.48[0.09,2.48]$ \\
\hline Sharma 2009 & $5 / 70$ & $11 / 70$ & $\longrightarrow$ & $13.3 \%$ & $0.45[0.17,1.24]$ \\
\hline Sharma 2011 & $3 / 35$ & $6 / 35$ & $\longrightarrow$ & $7.88 \%$ & $0.5[0.14,1.84]$ \\
\hline Sharma 2012 & $5 / 60$ & $10 / 60$ & $\rightarrow$ & $13.09 \%$ & $0.5[0.18,1.38]$ \\
\hline Simmons 1970 & $3 / 14$ & $6 / 12$ & 1 & $10.11 \%$ & $0.43[0.14,1.36]$ \\
\hline Uribe $1987 a$ & $0 / 22$ & $4 / 23$ & - & $1.63 \%$ & $0.12[0.01,2.04]$ \\
\hline Uribe $1987 \mathrm{~b}$ & $0 / 10$ & $0 / 10$ & & & Not estimable \\
\hline Watanabe 1997 & $0 / 41$ & $0 / 34$ & & & Not estimable \\
\hline Wen 2013 & $3 / 65$ & $3 / 65$ & & $5.49 \%$ & $1[0.21,4.77]$ \\
\hline Xing 2003 & $0 / 23$ & $0 / 22$ & & & Not estimable \\
\hline Yao 2014 & $0 / 20$ & $0 / 20$ & & & Not estimable \\
\hline Zeng 2003 & $1 / 40$ & $1 / 20$ & + & $1.81 \%$ & $0.5[0.03,7.59]$ \\
\hline Ziada 2013 & $0 / 30$ & $0 / 30$ & & & Not estimable \\
\hline Subtotal $(95 \% \mathrm{Cl})$ & 768 & 719 & 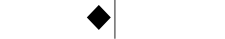 & $100 \%$ & $0.61[0.42,0.88]$ \\
\hline \multicolumn{6}{|c|}{ Test for overall effect: $Z=2.63(P=0.01)$} \\
\hline \multicolumn{6}{|c|}{ 1.10.2 Extreme worst-case scenario analysis } \\
\hline Agrawal 2012 & $13 / 80$ & $16 / 78$ & $\rightarrow$ & $31.94 \%$ & $0.79[0.41,1.54]$ \\
\hline Corazza 1982 & $0 / 16$ & $0 / 16$ & & & Not estimable \\
\hline Dhiman 2000 & $2 / 14$ & $1 / 12$ & 1 & $2.71 \%$ & $1.71[0.18,16.65]$ \\
\hline Germain 1973 & $0 / 9$ & $0 / 9$ & & & Not estimable \\
\hline Horsmans 1997 & $0 / 7$ & $0 / 7$ & & & Not estimable \\
\hline Jain 2013 & $1 / 30$ & $1 / 30$ & & $1.88 \%$ & $1[0.07,15.26]$ \\
\hline Li 1999 & $0 / 48$ & $0 / 38$ & & & Not estimable \\
\hline Mittal 2011 & $0 / 40$ & $1 / 40$ & & $1.39 \%$ & $0.33[0.01,7.95]$ \\
\hline Prasad 2007 & $0 / 31$ & $3 / 30$ & - & $1.64 \%$ & $0.14[0.01,2.57]$ \\
\hline Quero 1997 & $1 / 20$ & $0 / 20$ & & $1.42 \%$ & $3[0.13,69.52]$ \\
\hline Raza 2004 & $2 / 18$ & $2 / 13$ & 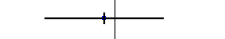 & $4.2 \%$ & $0.72[0.12,4.48]$ \\
\hline Riggio 2005 & $2 / 25$ & $1 / 25$ & 1 & $2.57 \%$ & $2[0.19,20.67]$ \\
\hline Sharma 2009 & $5 / 70$ & $11 / 70$ & $\longrightarrow$ & $13.89 \%$ & $0.45[0.17,1.24]$ \\
\hline Sharma 2011 & $3 / 35$ & $6 / 35$ & $\rightarrow-$ & $8.23 \%$ & $0.5[0.14,1.84]$ \\
\hline Sharma 2012 & $5 / 60$ & $10 / 60$ & $\longrightarrow$ & $13.67 \%$ & $0.5[0.18,1.38]$ \\
\hline Simmons 1970 & $3 / 14$ & $6 / 12$ & 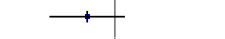 & $10.56 \%$ & $0.43[0.14,1.36]$ \\
\hline Uribe $1987 a$ & $0 / 22$ & $4 / 23$ & - & $1.71 \%$ & $0.12[0.01,2.04]$ \\
\hline Uribe $1987 b$ & $0 / 10$ & $0 / 10$ & & & Not estimable \\
\hline
\end{tabular}

Non-absorbable disaccharides versus placebo/no intervention and lactulose versus lactitol for the prevention and treatment of hepatic 


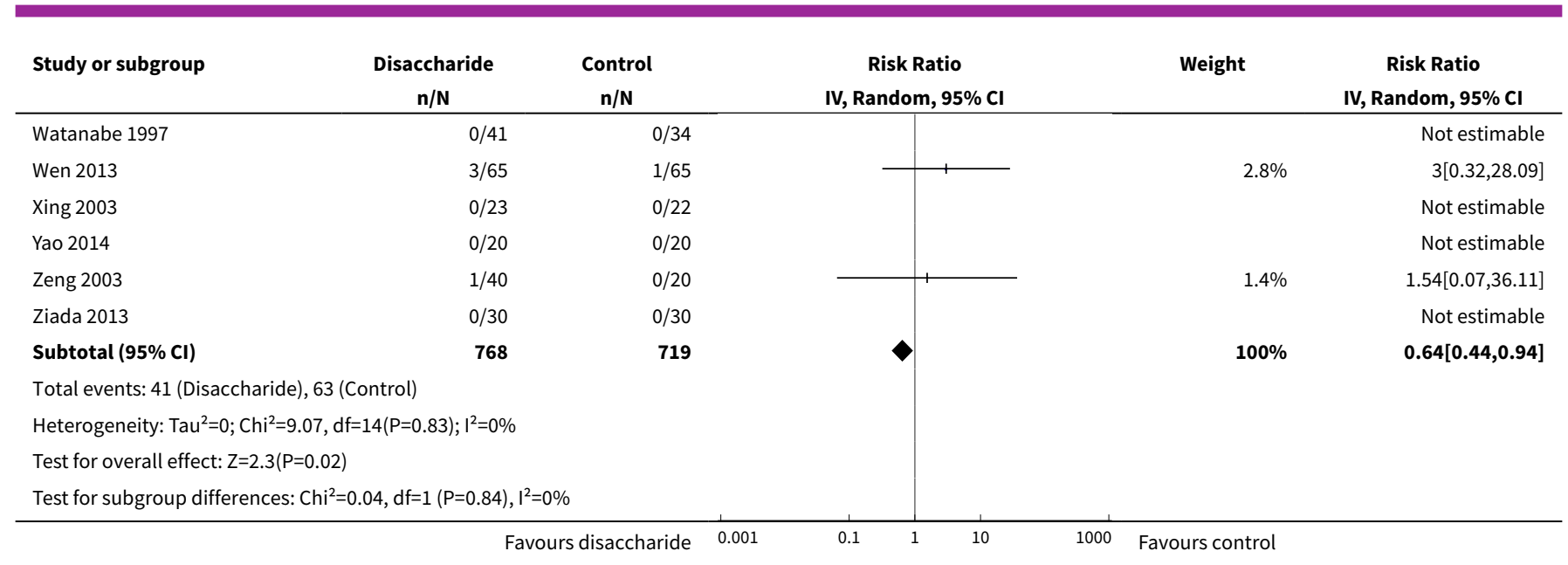

Analysis 1.11. Comparison 1 Non-absorbable disaccharides versus placebo/no intervention, Outcome 11 Hepatic encephalopathy worst-case scenario analysis.

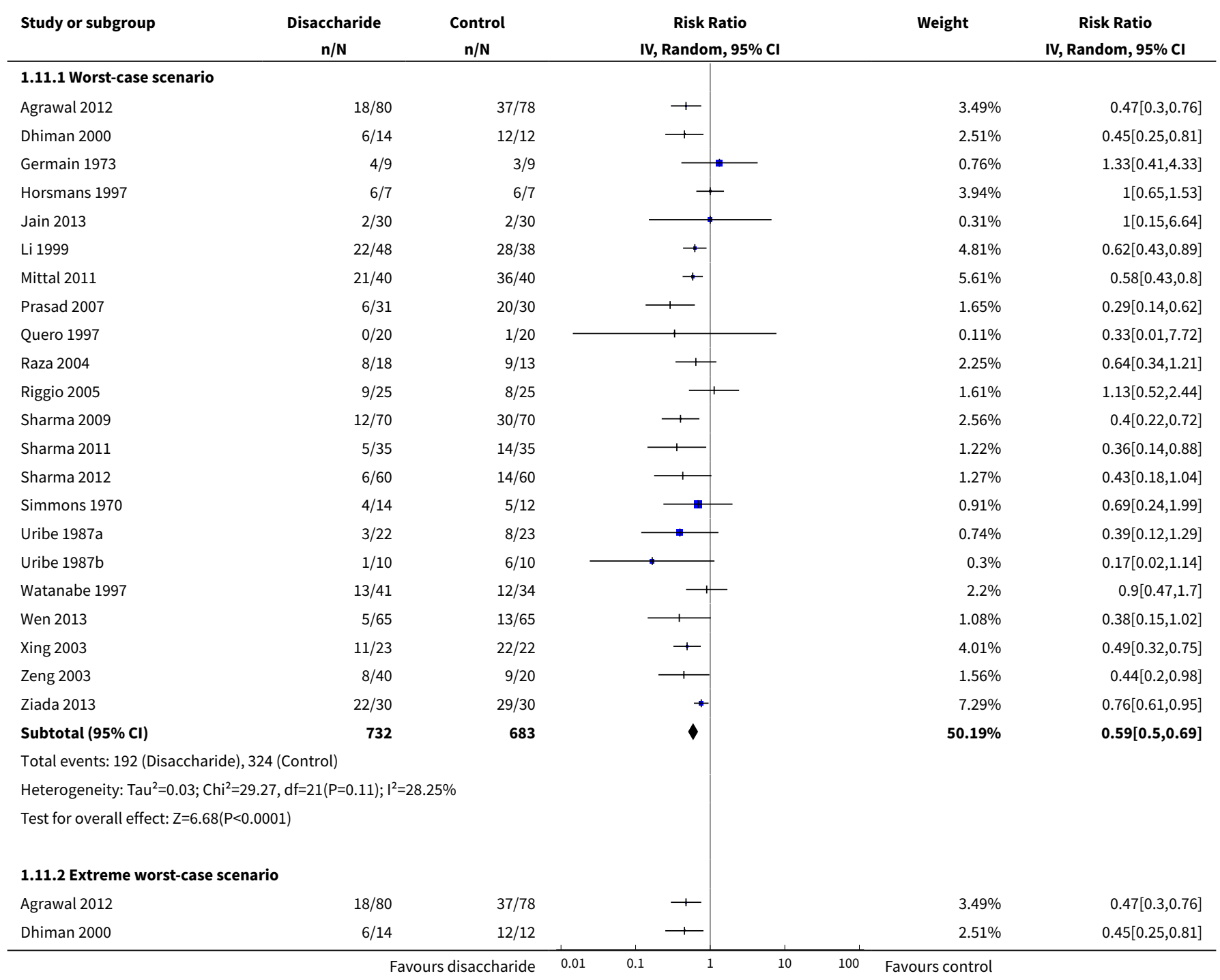




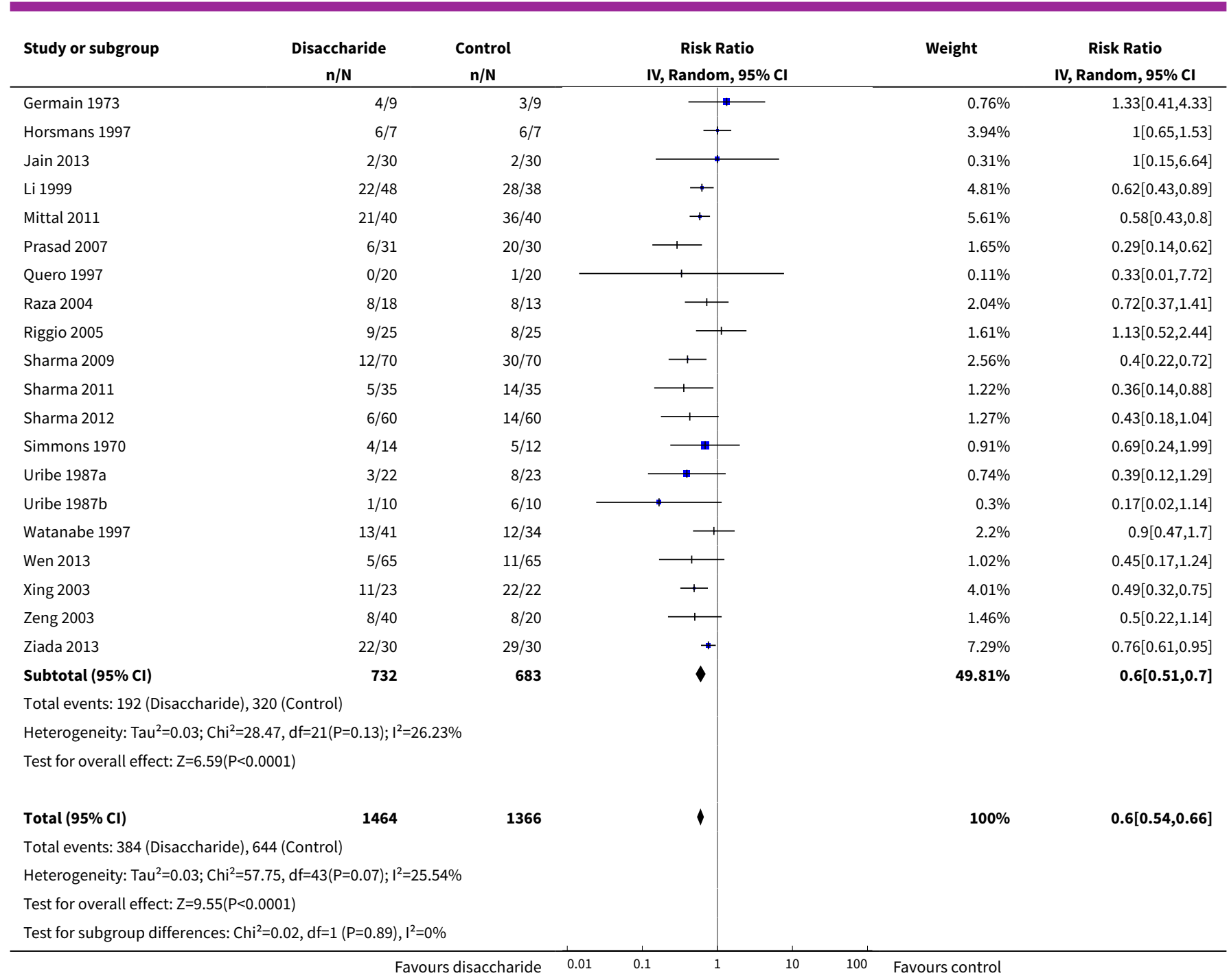

Analysis 1.12. Comparison 1 Non-absorbable disaccharides versus placebo/ no intervention, Outcome 12 Serious adverse events worst-case scenario analysis.

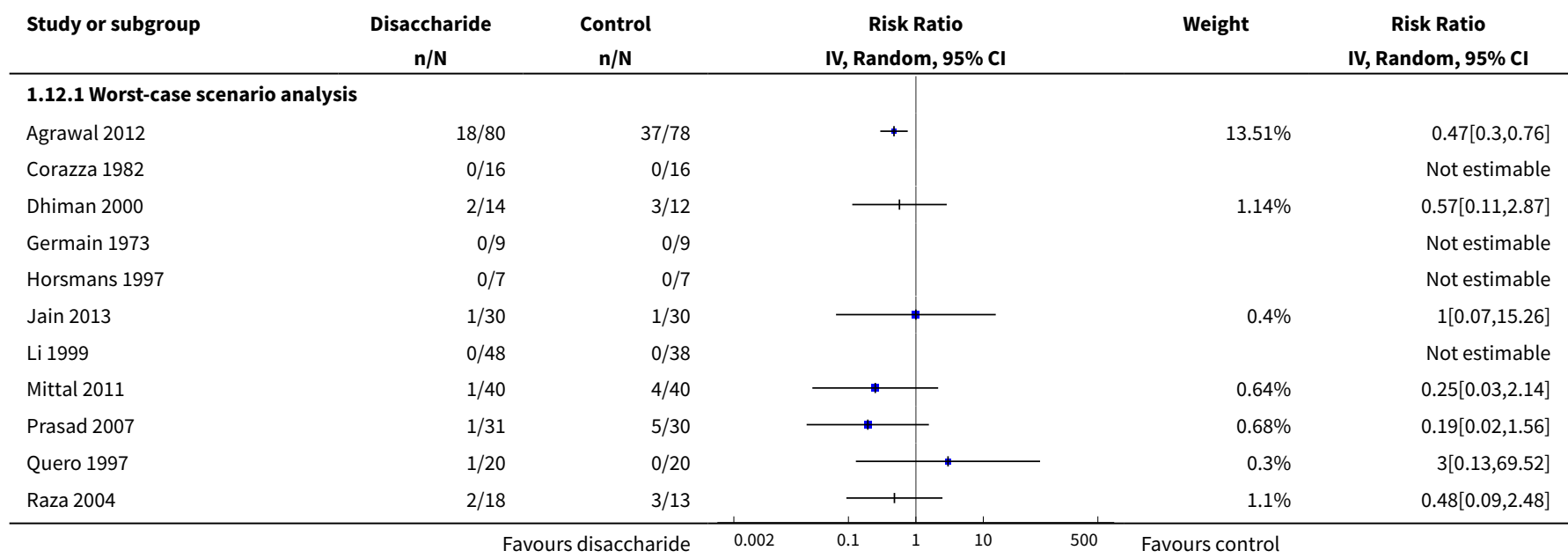

Non-absorbable disaccharides versus placebo/no intervention and lactulose versus lactitol for the prevention and treatment of hepatic 109 encephalopathy in people with cirrhosis (Review)

Copyright (c) 2016 The Cochrane Collaboration. Published by John Wiley \& Sons, Ltd. 


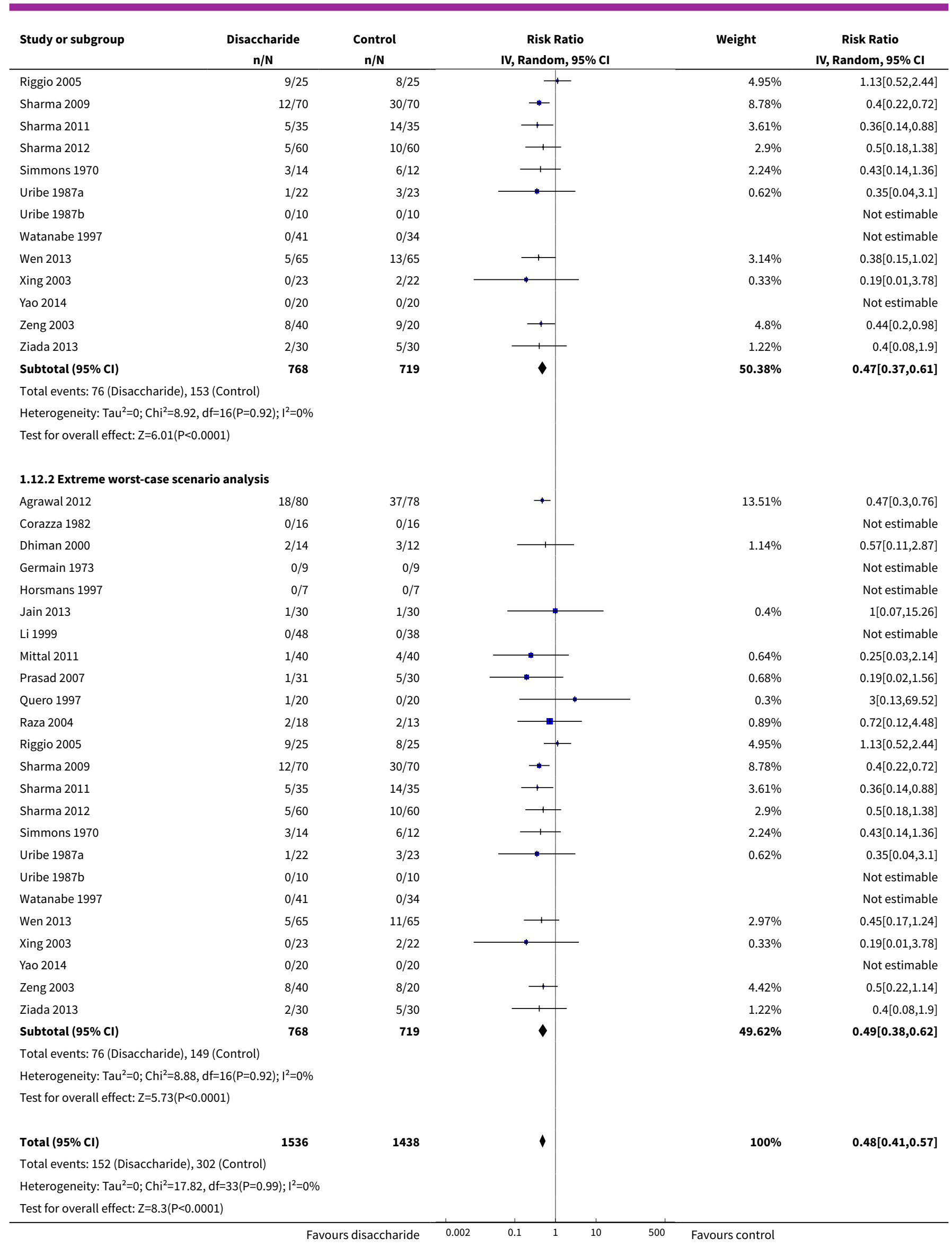

Non-absorbable disaccharides versus placebo/no intervention and lactulose versus lactitol for the prevention and treatment of hepatic 


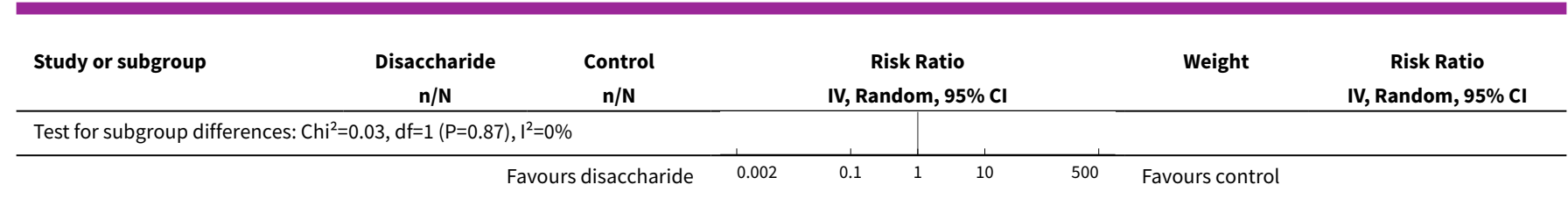

\section{Comparison 2. Prevention trials: non-absorbable disaccharides versus placebo/no intervention}

\begin{tabular}{|c|c|c|c|c|}
\hline $\begin{array}{l}\text { Outcome or subgroup } \\
\text { title }\end{array}$ & No. of studies & $\begin{array}{l}\text { No. of partici- } \\
\text { pants }\end{array}$ & Statistical method & Effect size \\
\hline 1 Mortality & 6 & 668 & Risk Ratio (IV, Random, 95\% CI) & $0.63[0.40,0.98]$ \\
\hline 1.1 Primary & 4 & 370 & Risk Ratio (IV, Random, 95\% CI) & $0.56[0.27,1.17]$ \\
\hline 1.2 Secondary & 2 & 298 & Risk Ratio (IV, Random, 95\% CI) & $0.67[0.39,1.16]$ \\
\hline $\begin{array}{l}2 \text { Mortality and bias con- } \\
\text { trol }\end{array}$ & 6 & 668 & Risk Ratio (IV, Random, 95\% CI) & $0.63[0.40,0.98]$ \\
\hline 2.1 Low risk of bias & 5 & 538 & Risk Ratio (IV, Random, 95\% CI) & $0.64[0.41,0.99]$ \\
\hline 2.2 High risk of bias & 1 & 130 & Risk Ratio (IV, Random, 95\% CI) & $0.33[0.01,8.03]$ \\
\hline $\begin{array}{l}3 \text { Hepatic encephalopa- } \\
\text { thy }\end{array}$ & 6 & 668 & Risk Ratio (IV, Random, 95\% CI) & $0.47[0.33,0.68]$ \\
\hline 3.1 Primary & 4 & 370 & Risk Ratio (IV, Random, 95\% CI) & $0.48[0.23,0.98]$ \\
\hline 3.2 Secondary & 2 & 298 & Risk Ratio (IV, Random, 95\% CI) & $0.44[0.31,0.64]$ \\
\hline 4 Serious adverse events & 6 & 668 & Risk Ratio (IV, Random, 95\% Cl) & $0.48[0.33,0.70]$ \\
\hline 4.1 Primary prevention & 4 & 370 & Risk Ratio (IV, Random, 95\% CI) & $0.50[0.24,1.03]$ \\
\hline $\begin{array}{l}4.2 \text { Secondary preven- } \\
\text { tion }\end{array}$ & 2 & 298 & Risk Ratio (IV, Random, 95\% CI) & $0.44[0.31,0.64]$ \\
\hline $\begin{array}{l}5 \text { Non-serious adverse } \\
\text { events }\end{array}$ & 4 & & Risk Ratio (IV, Random, 95\% CI) & Subtotals only \\
\hline
\end{tabular}

Analysis 2.1. Comparison 2 Prevention trials: non-absorbable disaccharides versus placebo/no intervention, Outcome 1 Mortality.

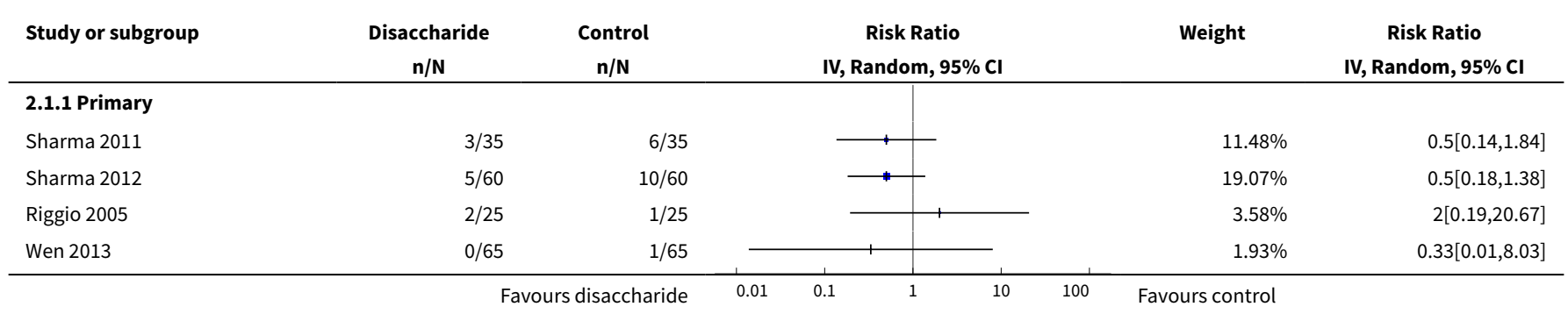




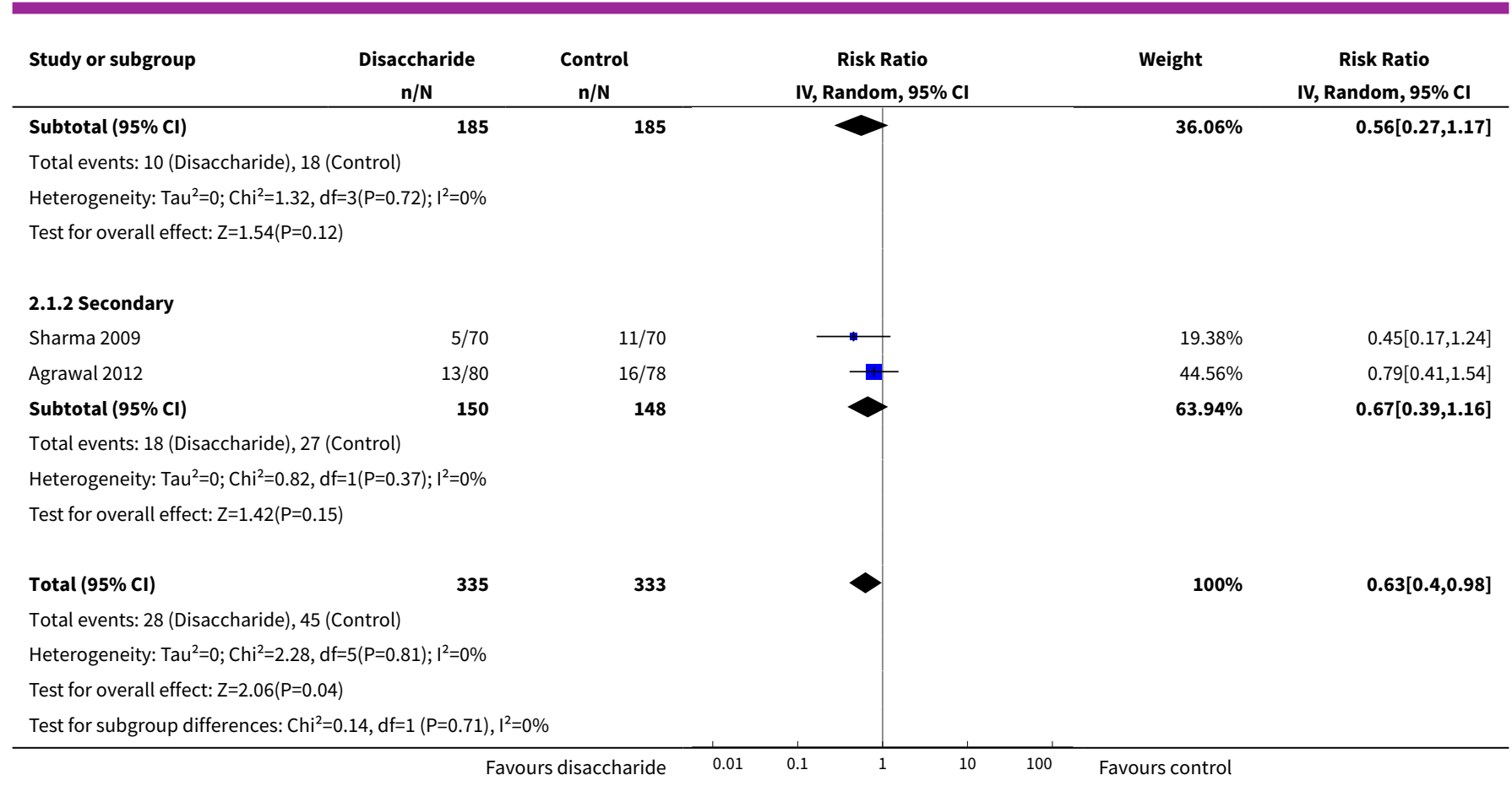

\section{Analysis 2.2. Comparison 2 Prevention trials: non-absorbable disaccharides versus placebo/no intervention, Outcome 2 Mortality and bias control.}

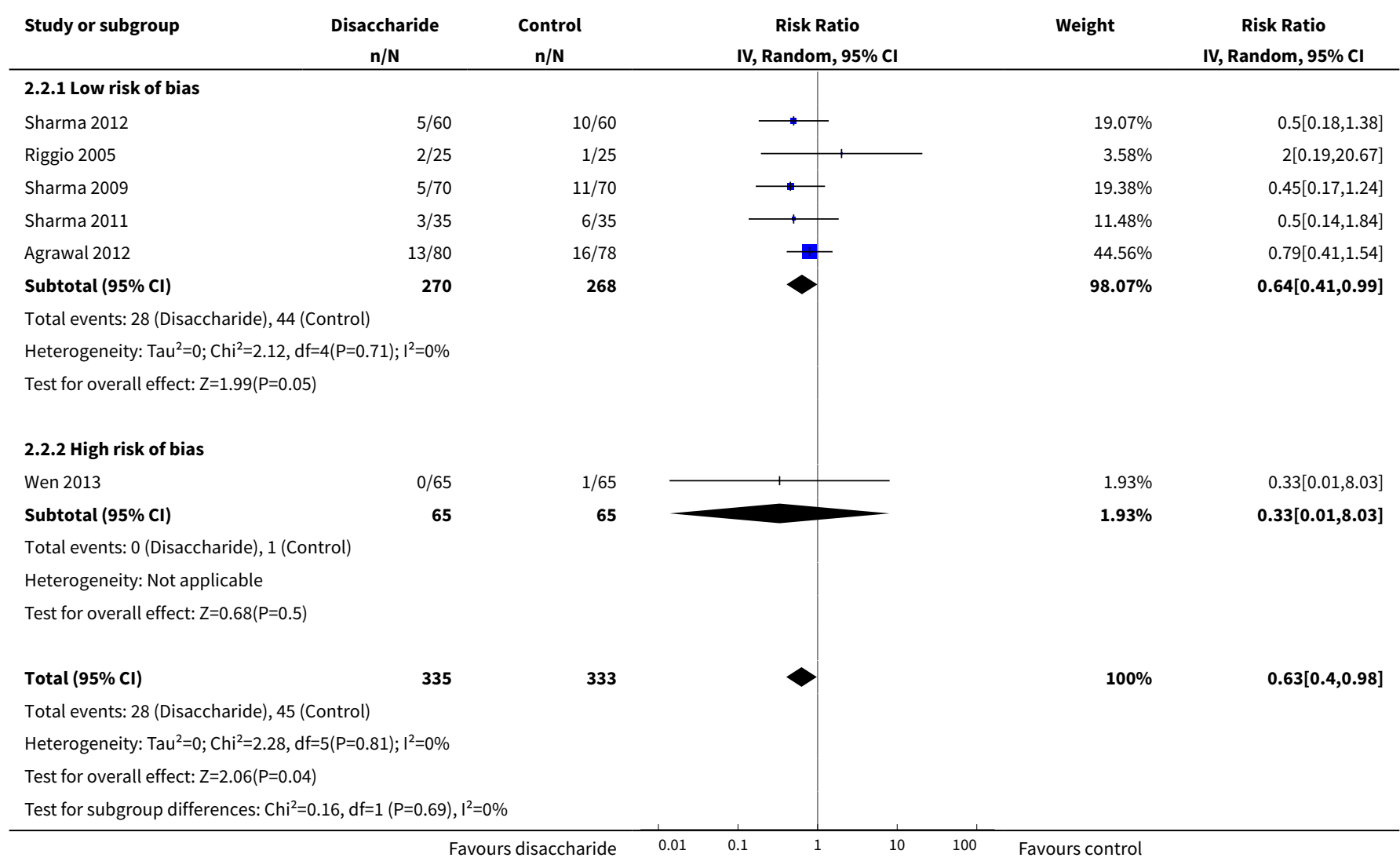

Non-absorbable disaccharides versus placebo/no intervention and lactulose versus lactitol for the prevention and treatment of hepatic 
Analysis 2.3. Comparison 2 Prevention trials: non-absorbable disaccharides versus placebo/no intervention, Outcome 3 Hepatic encephalopathy.

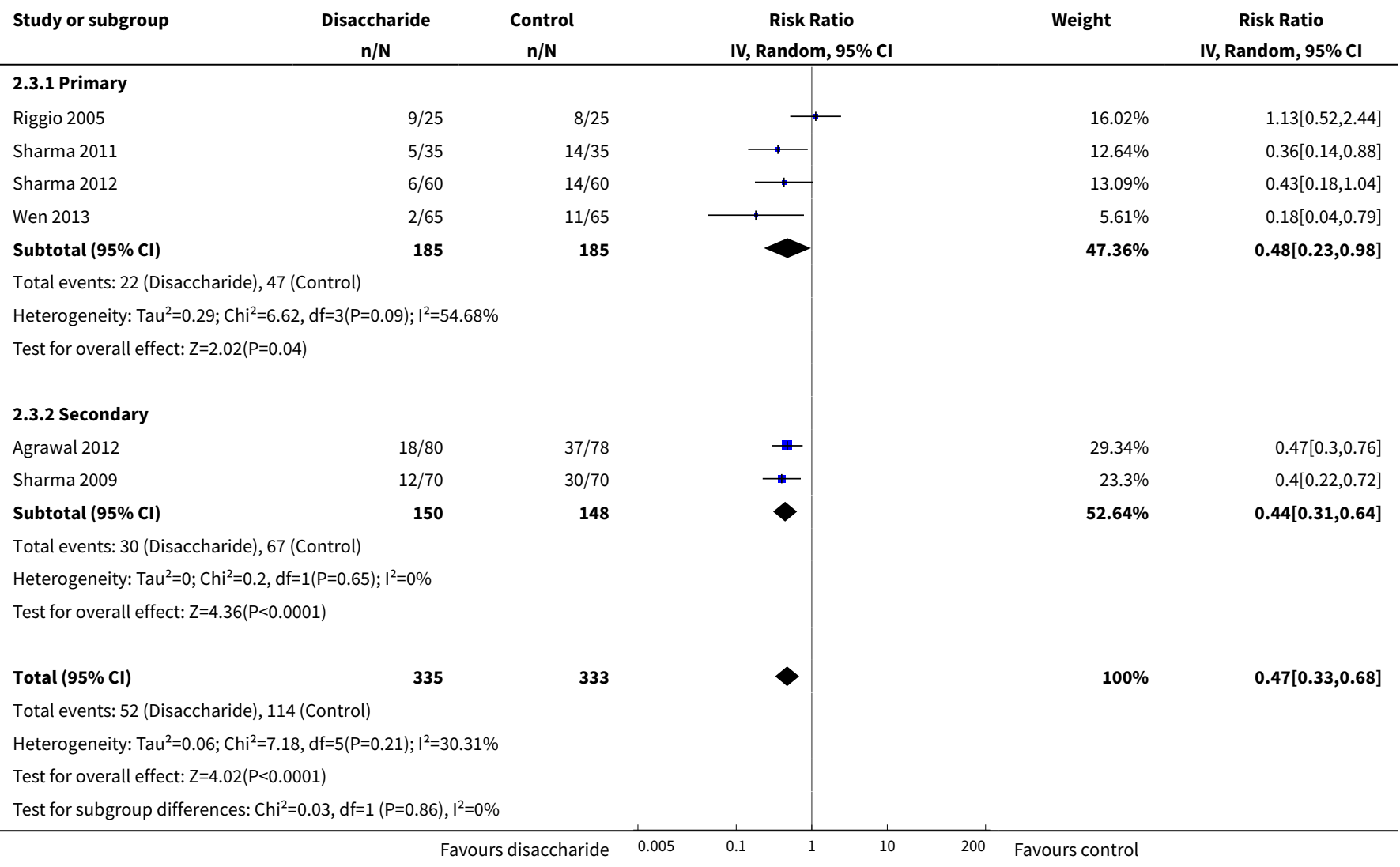

Analysis 2.4. Comparison 2 Prevention trials: non-absorbable disaccharides versus placebo/no intervention, Outcome 4 Serious adverse events.

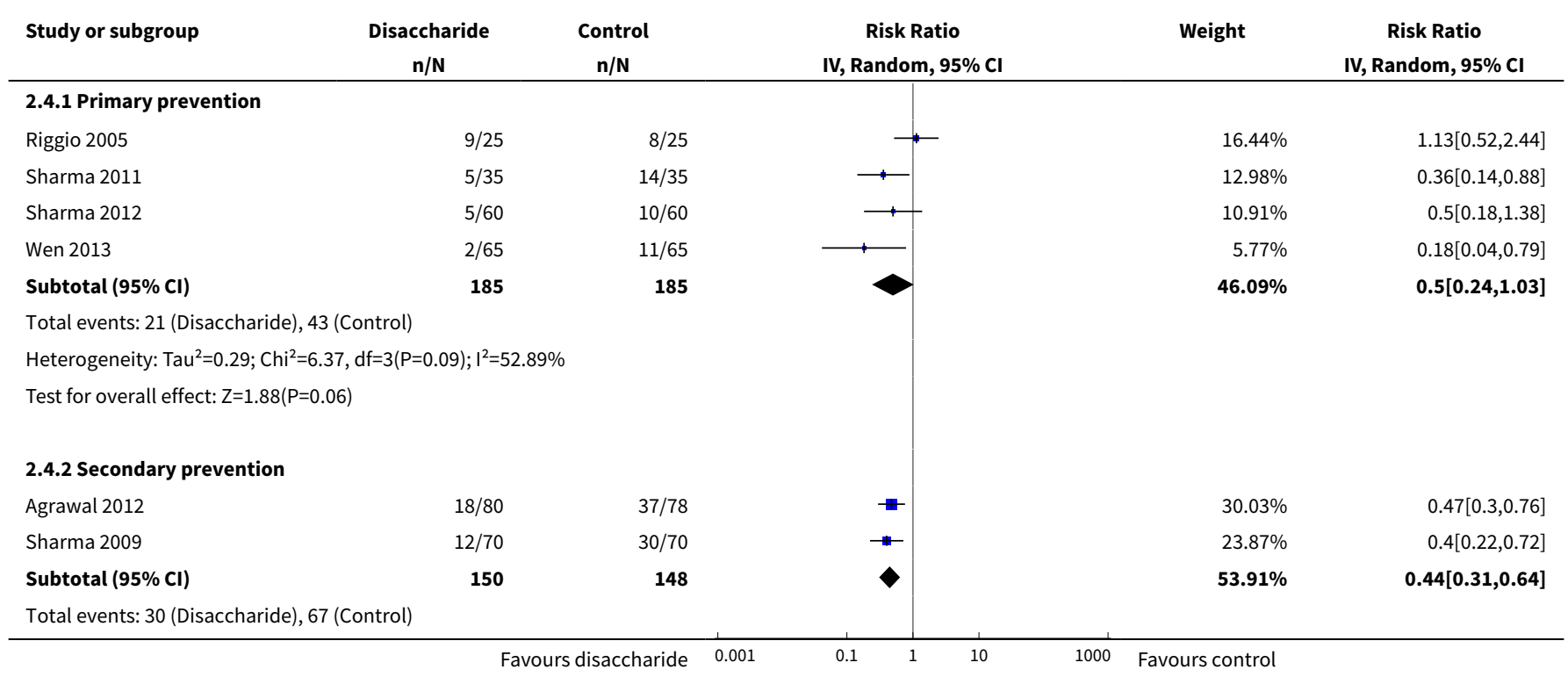

Non-absorbable disaccharides versus placebo/no intervention and lactulose versus lactitol for the prevention and treatment of hepatic 


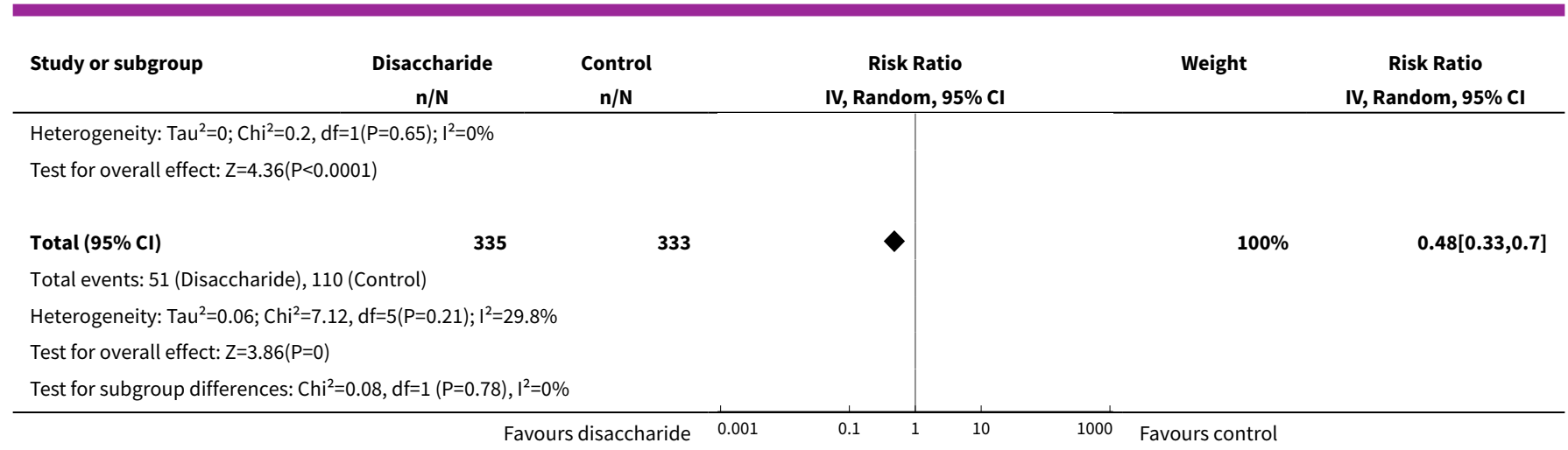

\section{Analysis 2.5. Comparison 2 Prevention trials: non-absorbable disaccharides versus placebo/no intervention, Outcome 5 Non-serious adverse events.}

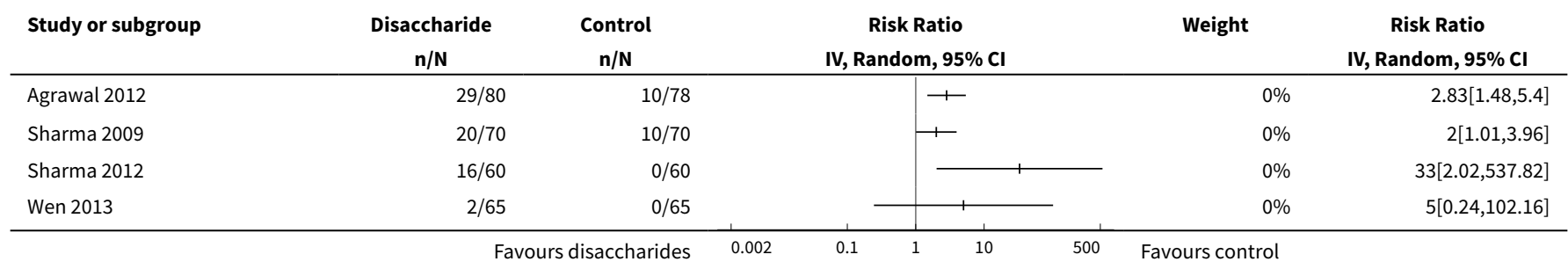

\section{Comparison 3. Treatment trials: non-absorbable disaccharides versus placebo/no intervention}

\begin{tabular}{|c|c|c|c|c|}
\hline $\begin{array}{l}\text { Outcome or subgroup ti- } \\
\text { tle }\end{array}$ & No. of studies & $\begin{array}{l}\text { No. of partici- } \\
\text { pants }\end{array}$ & Statistical method & Effect size \\
\hline 1 Mortality & 18 & 819 & Risk Ratio (IV, Random, 95\% CI) & $0.49[0.23,1.05]$ \\
\hline 1.1 Overt & 6 & 172 & Risk Ratio (IV, Random, 95\% CI) & $0.36[0.14,0.94]$ \\
\hline 1.2 Minimal & 12 & 647 & Risk Ratio (IV, Random, 95\% CI) & $0.82[0.24,2.86]$ \\
\hline $\begin{array}{l}2 \text { Mortality in trials with a } \\
\text { low risk of bias }\end{array}$ & 18 & 819 & Risk Ratio (IV, Random, 95\% CI) & $0.49[0.23,1.05]$ \\
\hline 2.1 Low risk of bias & 3 & 167 & Risk Ratio (IV, Random, 95\% CI) & $0.56[0.12,2.68]$ \\
\hline 2.2 High risk of bias & 15 & 652 & Risk Ratio (IV, Random, 95\% CI) & $0.47[0.20,1.13]$ \\
\hline $\begin{array}{l}3 \text { Mortality in acute or } \\
\text { chronic hepatic en- } \\
\text { cephalopathy }\end{array}$ & 6 & 172 & Risk Ratio (IV, Random, 95\% CI) & $0.36[0.14,0.94]$ \\
\hline 3.1 Acute & 3 & 102 & Risk Ratio (IV, Random, 95\% CI) & $0.36[0.14,0.94]$ \\
\hline 3.2 Chronic & 3 & 70 & Risk Ratio (IV, Random, 95\% CI) & $0.0[0.0,0.0]$ \\
\hline 4 Hepatic encephalopathy & 16 & 747 & Risk Ratio (IV, Random, 95\% CI) & $0.63[0.53,0.74]$ \\
\hline
\end{tabular}




\begin{tabular}{|c|c|c|c|c|}
\hline $\begin{array}{l}\text { Outcome or subgroup ti- } \\
\text { tle }\end{array}$ & No. of studies & $\begin{array}{l}\text { No. of partici- } \\
\text { pants }\end{array}$ & Statistical method & Effect size \\
\hline 4.1 Overt & 5 & 140 & Risk Ratio (IV, Random, 95\% CI) & $0.62[0.39,0.99]$ \\
\hline 4.2 Minimal & 11 & 607 & Risk Ratio (IV, Random, 95\% CI) & $0.63[0.52,0.76]$ \\
\hline $\begin{array}{l}5 \text { Acute or chronic hepatic } \\
\text { encephalopathy }\end{array}$ & 5 & 140 & Risk Ratio (IV, Random, 95\% Cl) & $0.62[0.39,0.99]$ \\
\hline 5.1 Acute & 3 & 102 & Risk Ratio (IV, Random, 95\% CI) & $0.59[0.34,1.00]$ \\
\hline 5.2 Chronic & 2 & 38 & Risk Ratio (IV, Random, 95\% CI) & $0.55[0.07,4.10]$ \\
\hline 6 Serious adverse events & 18 & 819 & Risk Ratio (IV, Random, 95\% CI) & $0.42[0.26,0.69]$ \\
\hline 6.1 Overt & 6 & 172 & Risk Ratio (IV, Random, 95\% Cl) & $0.40[0.16,1.02]$ \\
\hline 6.2 Minimal & 12 & 647 & Risk Ratio (IV, Random, 95\% CI) & $0.43[0.24,0.78]$ \\
\hline $\begin{array}{l}7 \text { Serious adverse events } \\
\text { in acute or chronic hepatic } \\
\text { encephalopathy }\end{array}$ & 6 & 172 & Risk Ratio (IV, Random, 95\% CI) & $0.40[0.16,1.02]$ \\
\hline 7.1 Acute & 3 & 102 & Risk Ratio (IV, Random, 95\% CI) & $0.40[0.16,1.02]$ \\
\hline 7.2 Chronic & 3 & 70 & Risk Ratio (IV, Random, 95\% Cl) & $0.0[0.0,0.0]$ \\
\hline $\begin{array}{l}8 \text { Non-serious adverse } \\
\text { events }\end{array}$ & 5 & 191 & Risk Ratio (IV, Random, 95\% Cl) & $2.12[0.62,7.28]$ \\
\hline
\end{tabular}

Analysis 3.1. Comparison 3 Treatment trials: non-absorbable disaccharides versus placebo/no intervention, Outcome 1 Mortality.

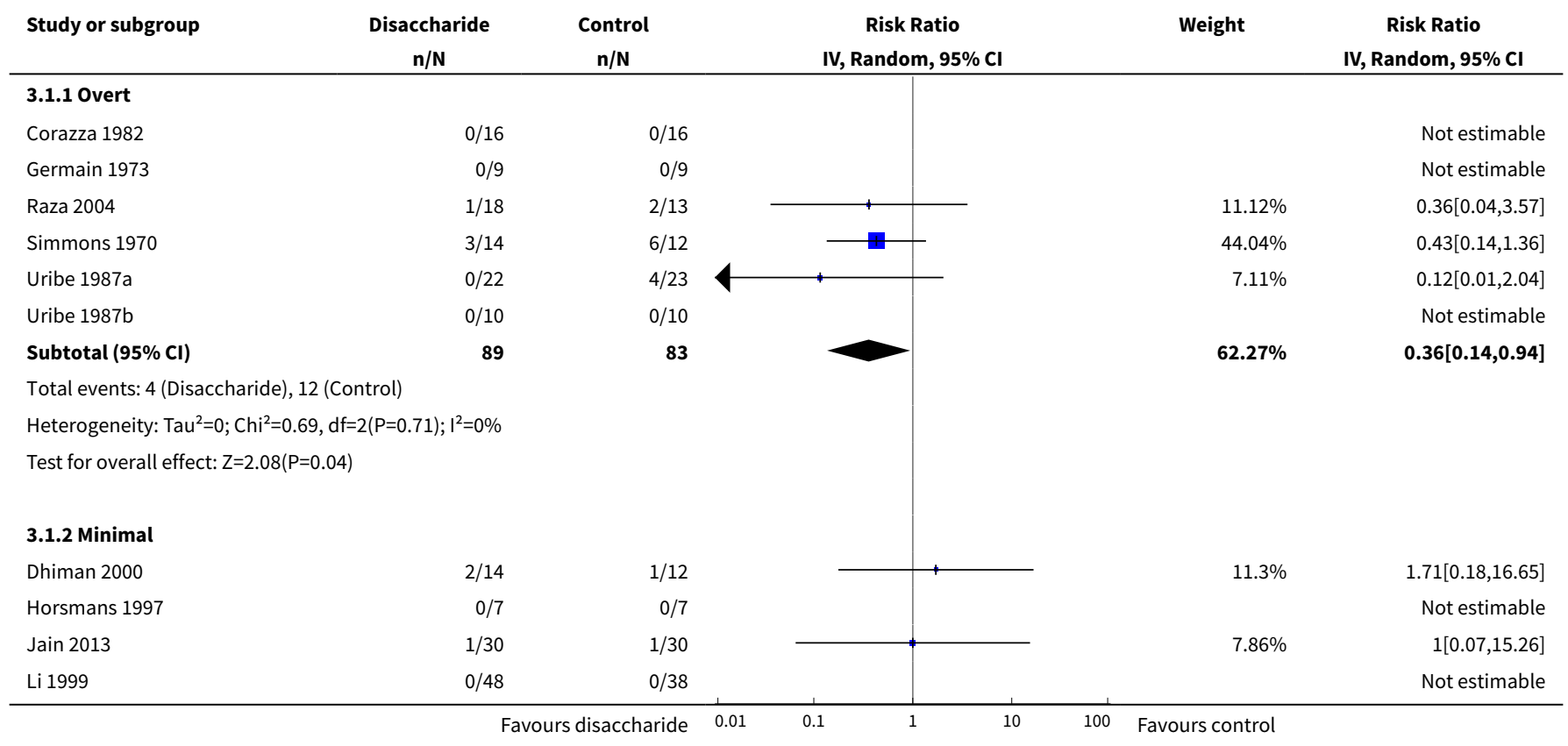




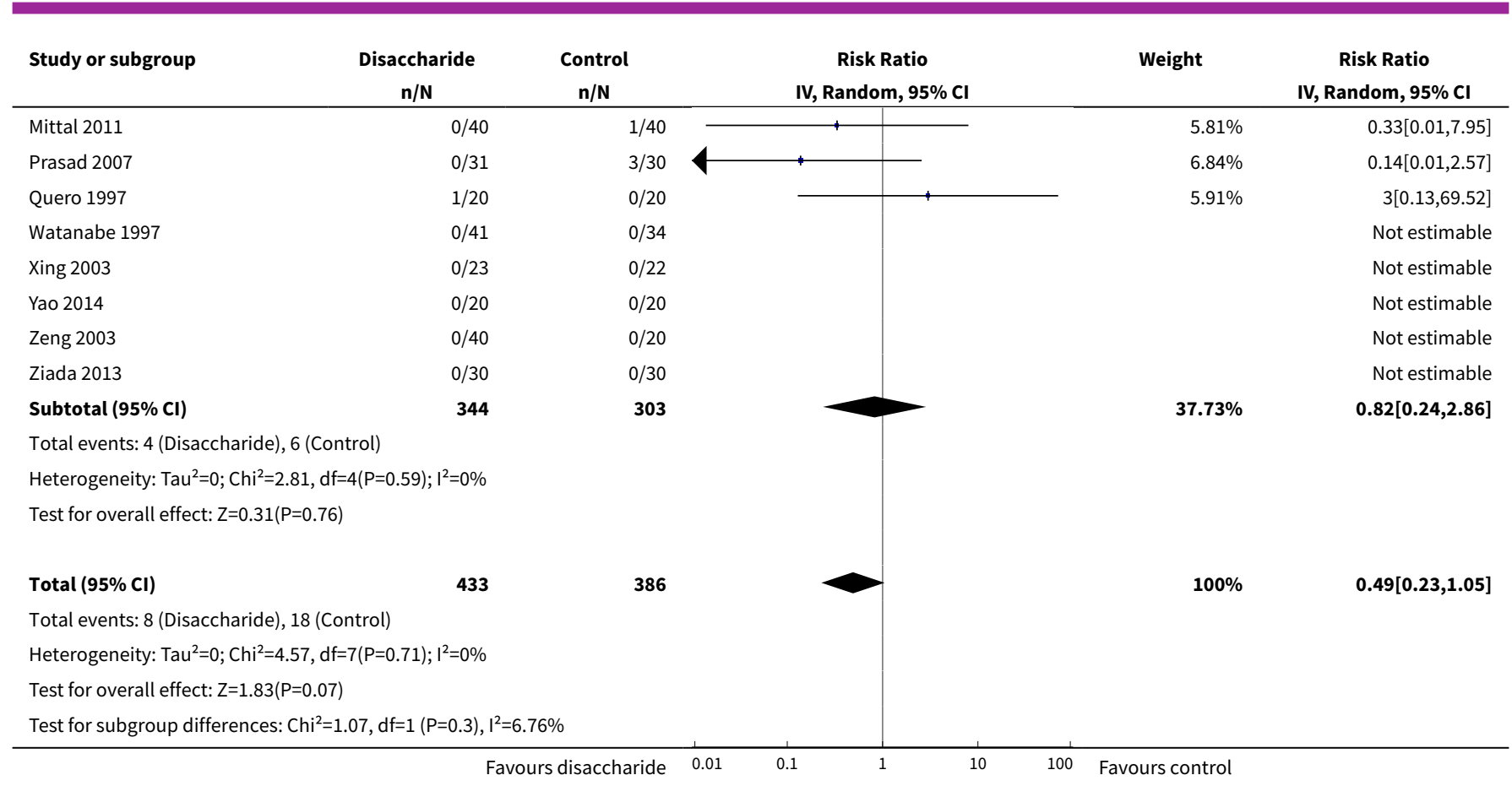

\section{Analysis 3.2. Comparison 3 Treatment trials: non-absorbable disaccharides versus placebo/no intervention, Outcome 2 Mortality in trials with a low risk of bias.}

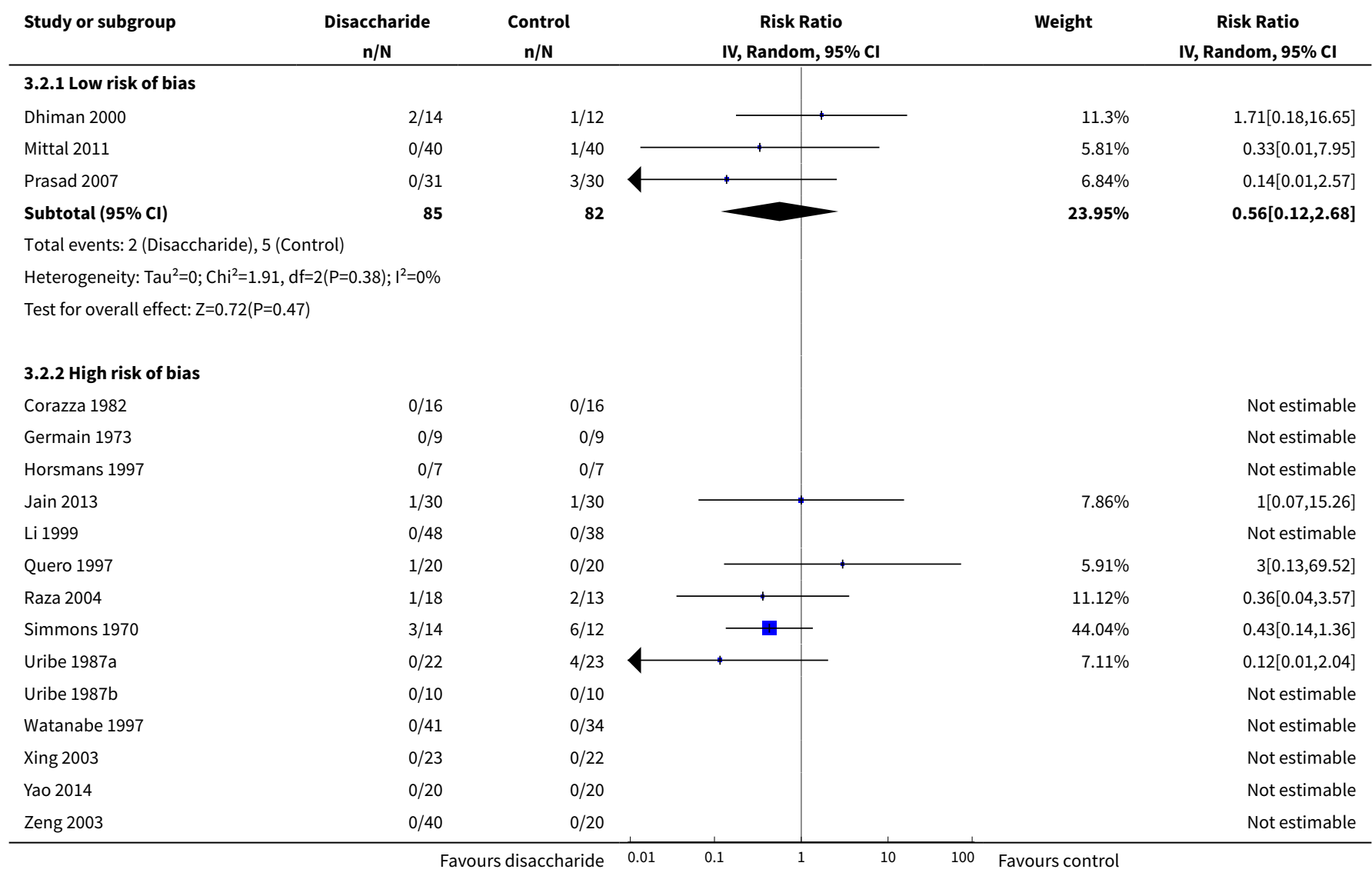




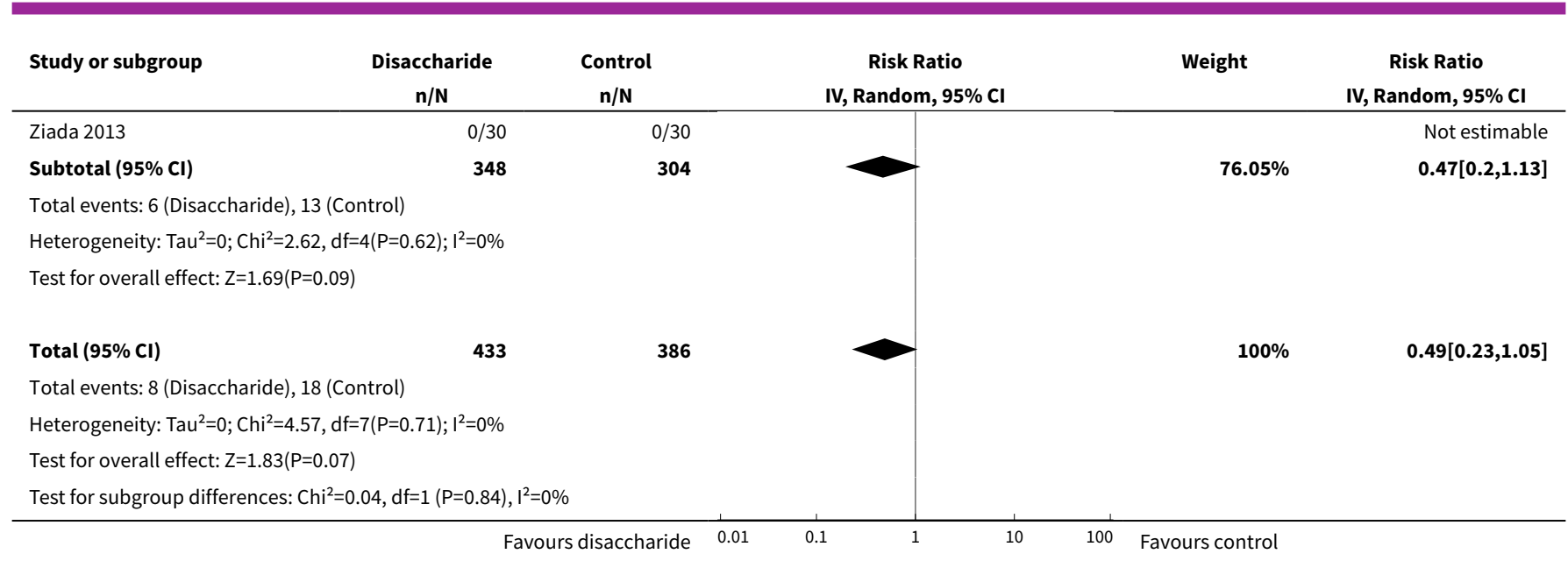

Analysis 3.3. Comparison 3 Treatment trials: non-absorbable disaccharides versus placebo/no intervention, Outcome $\mathbf{3}$ Mortality in acute or chronic hepatic encephalopathy.

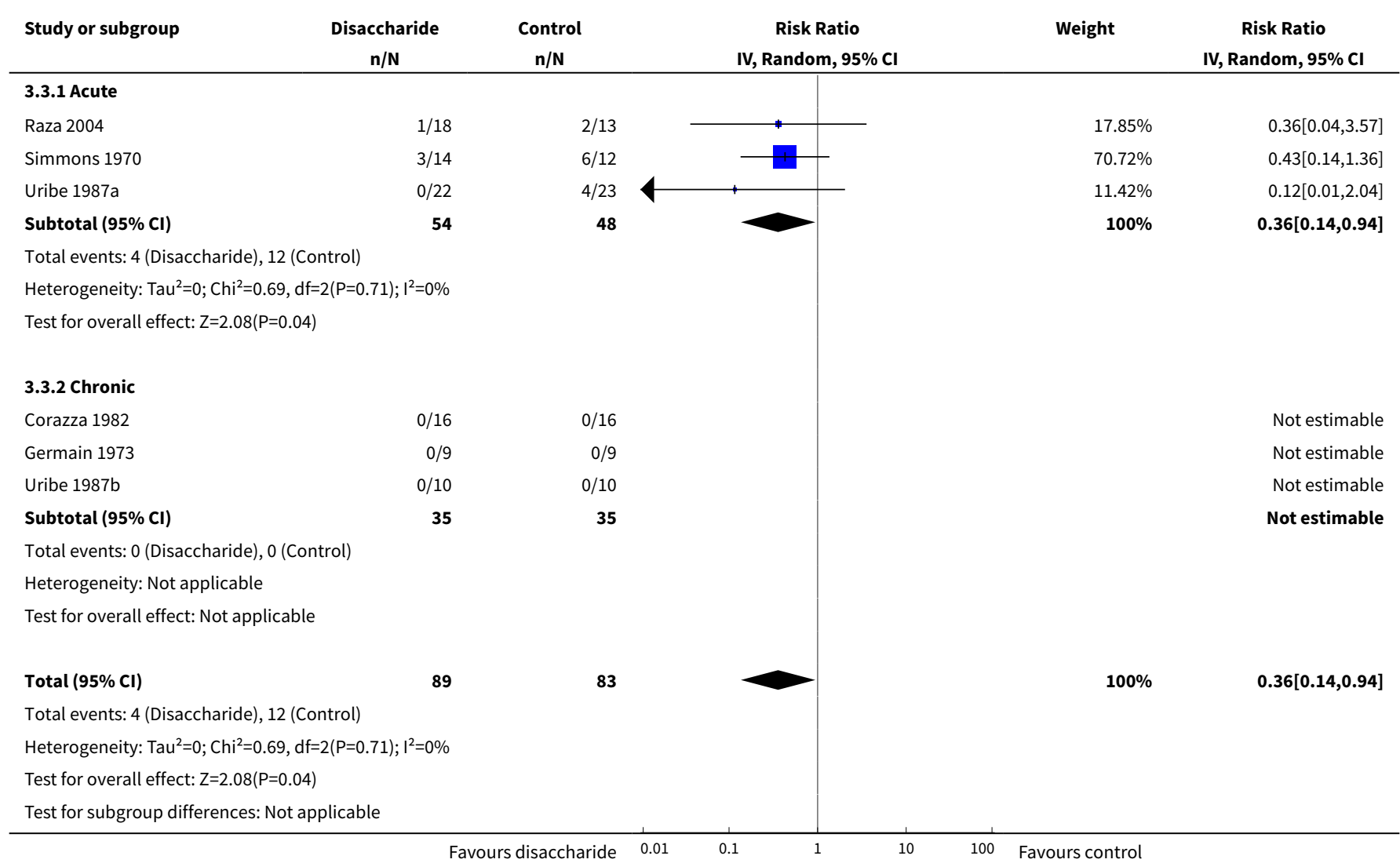


Analysis 3.4. Comparison 3 Treatment trials: non-absorbable disaccharides versus placebo/no intervention, Outcome 4 Hepatic encephalopathy.

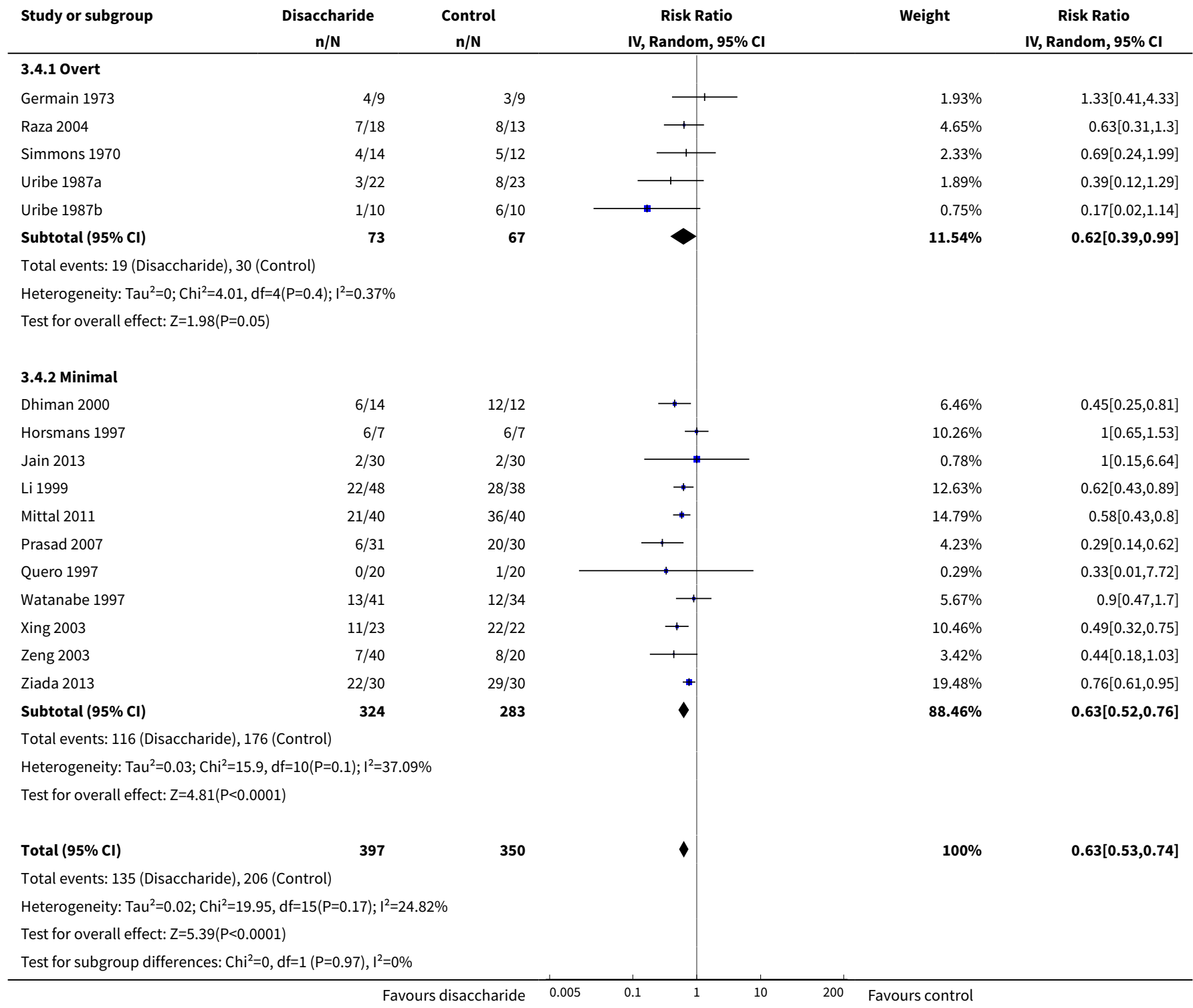

Analysis 3.5. Comparison 3 Treatment trials: non-absorbable disaccharides versus placebo/no intervention, Outcome 5 Acute or chronic hepatic encephalopathy.

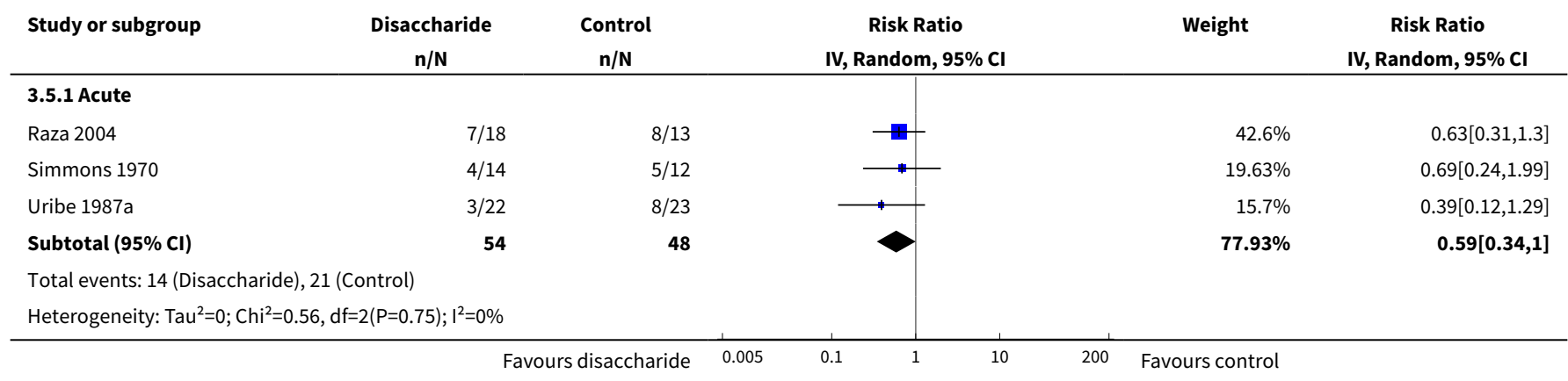

Non-absorbable disaccharides versus placebo/no intervention and lactulose versus lactitol for the prevention and treatment of hepatic 


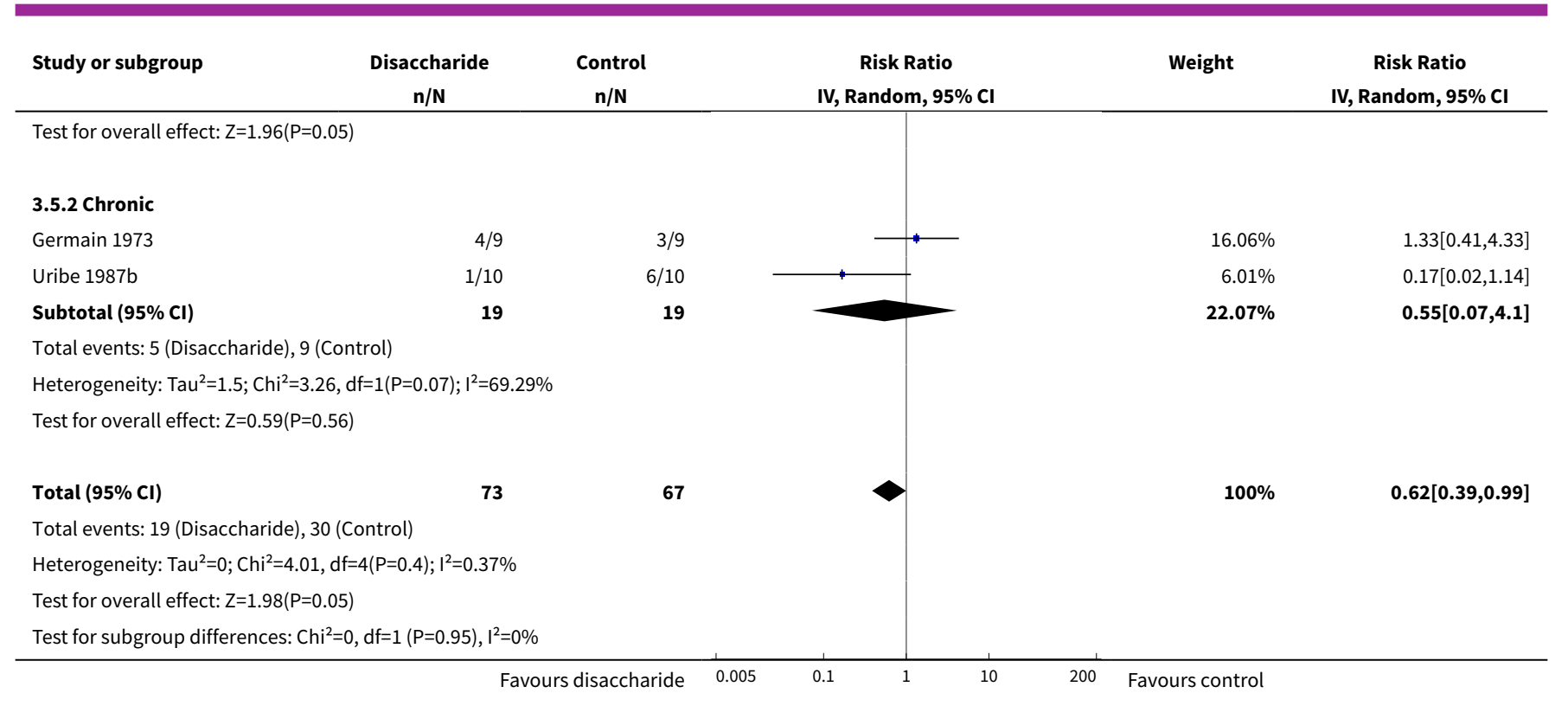

\section{Analysis 3.6. Comparison 3 Treatment trials: non-absorbable disaccharides versus placebo/no intervention, Outcome 6 Serious adverse events.}

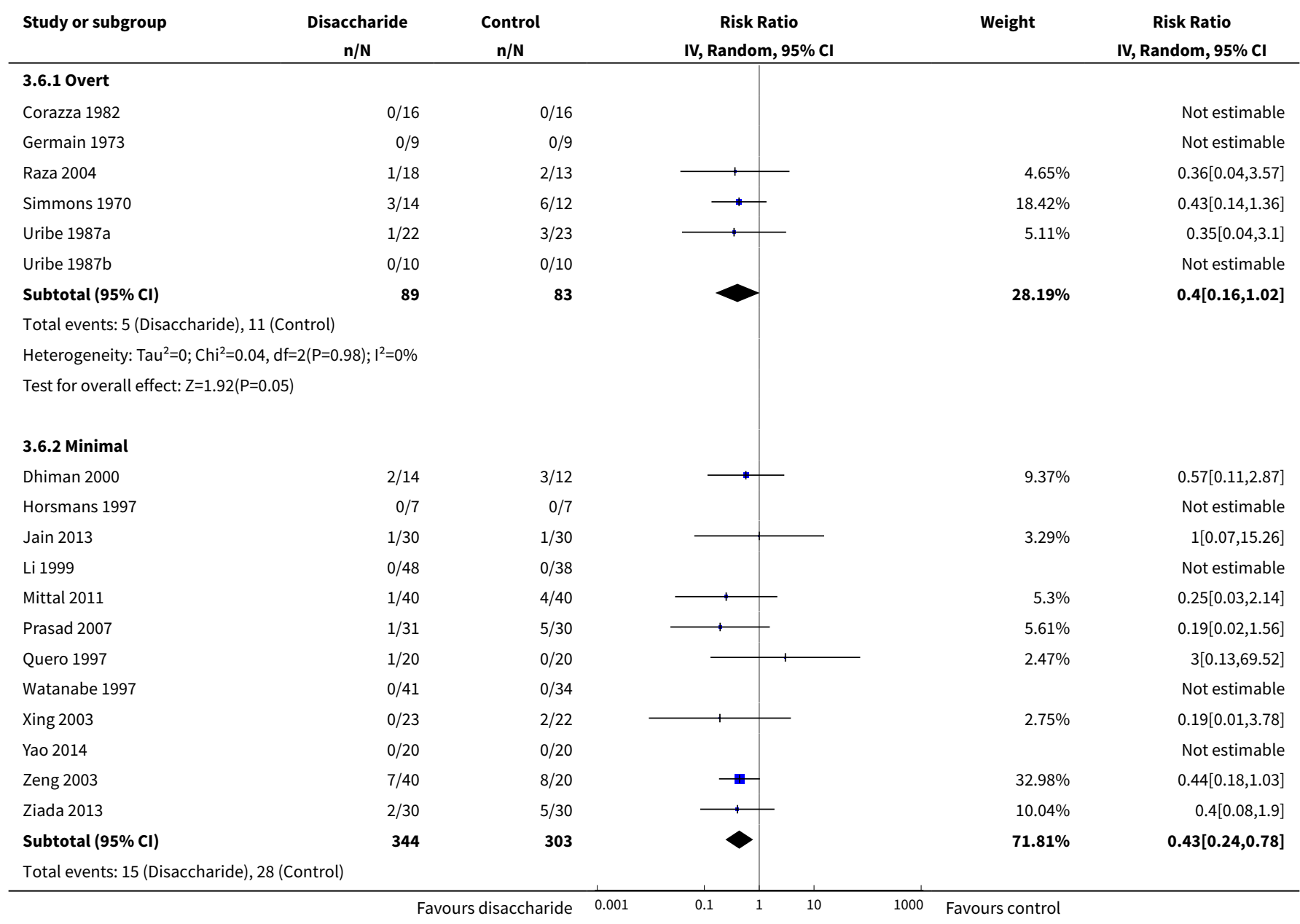

Non-absorbable disaccharides versus placebo/no intervention and lactulose versus lactitol for the prevention and treatment of hepatic 


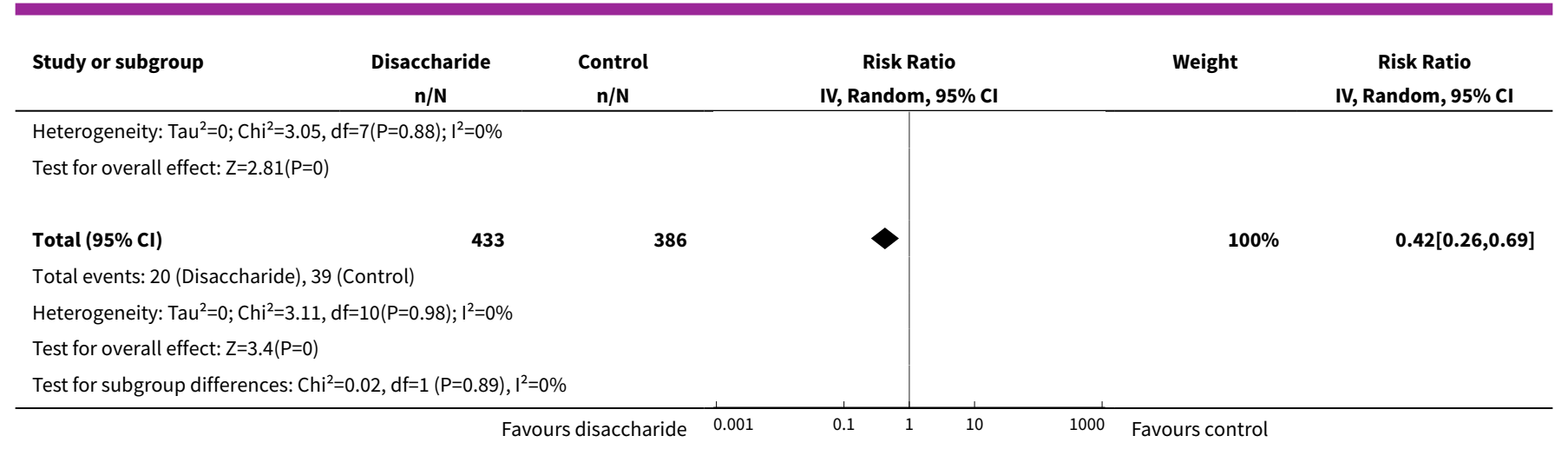

Analysis 3.7. Comparison 3 Treatment trials: non-absorbable disaccharides versus placebo/ no intervention, Outcome 7 Serious adverse events in acute or chronic hepatic encephalopathy.

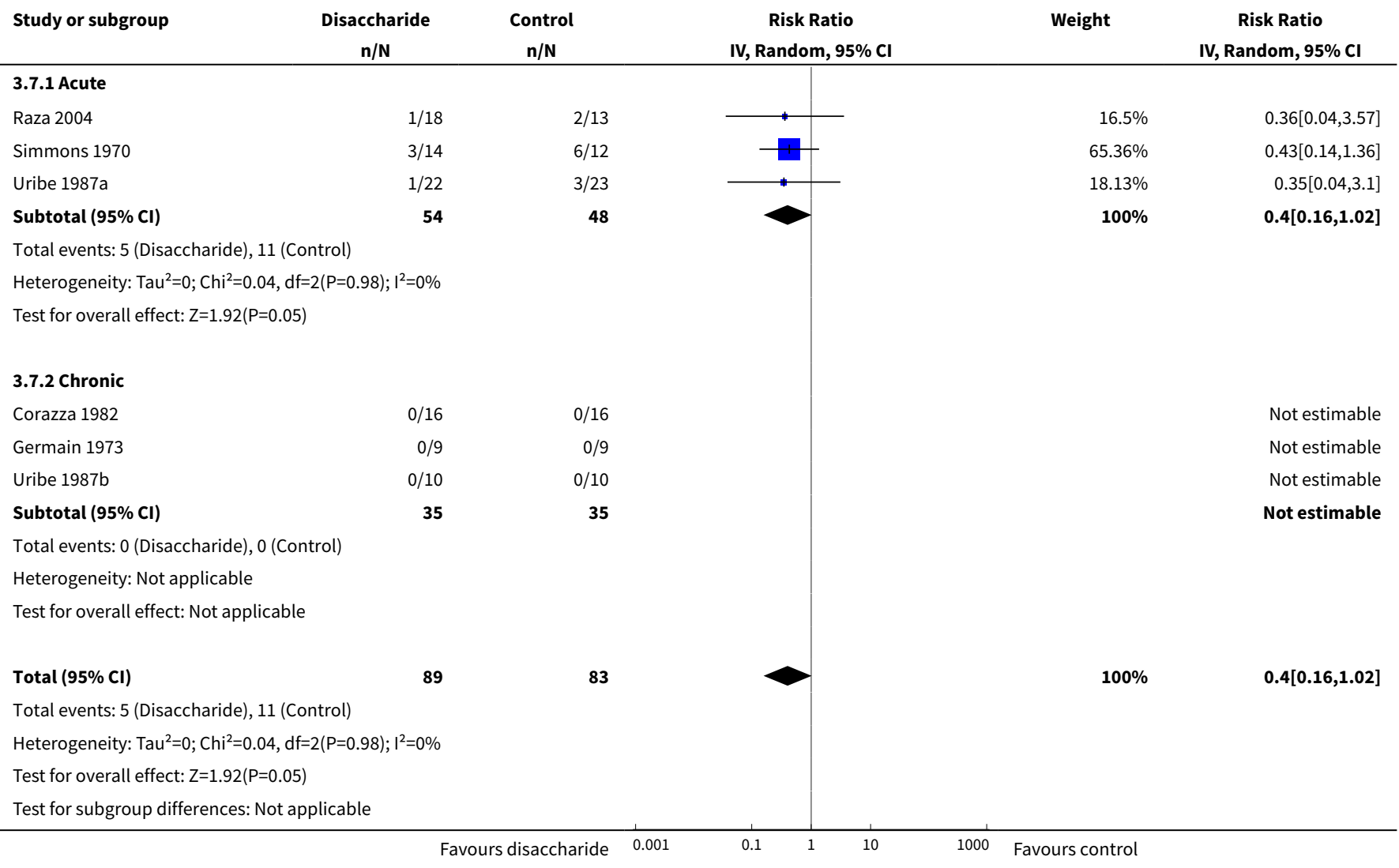

Analysis 3.8. Comparison 3 Treatment trials: non-absorbable disaccharides versus placebo/no intervention, Outcome 8 Non-serious adverse events.

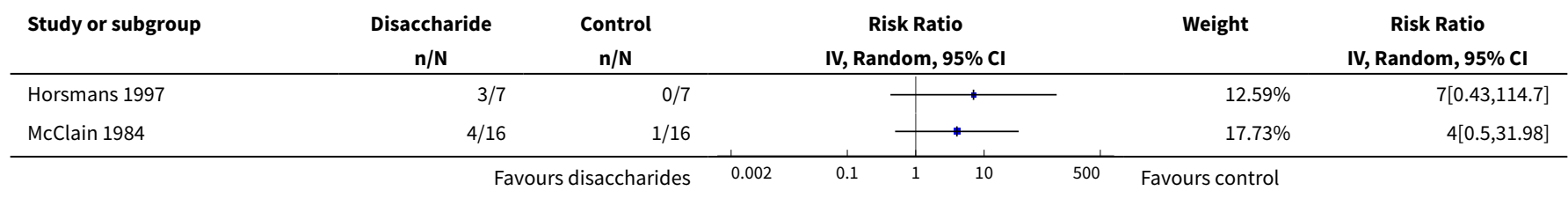

Non-absorbable disaccharides versus placebo/no intervention and lactulose versus lactitol for the prevention and treatment of hepatic 


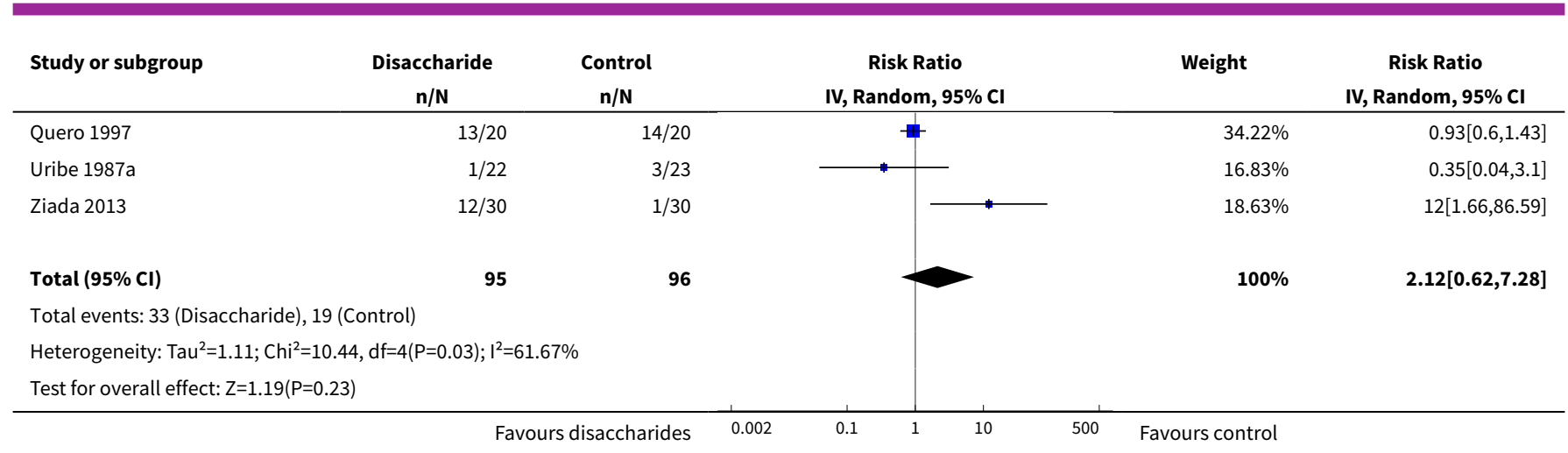

\section{Comparison 4. Lactulose versus lactitol}

\begin{tabular}{|c|c|c|c|c|}
\hline Outcome or subgroup title & No. of studies & $\begin{array}{l}\text { No. of partici- } \\
\text { pants }\end{array}$ & Statistical method & Effect size \\
\hline 1 Mortality & 8 & 225 & Risk Ratio (IV, Random, 95\% CI) & $1.30[0.59,2.85]$ \\
\hline $\begin{array}{l}1.1 \text { Overt hepatic en- } \\
\text { cephalopathy }\end{array}$ & 6 & 174 & Risk Ratio (IV, Random, 95\% Cl) & $1.30[0.59,2.85]$ \\
\hline $\begin{array}{l}1.2 \text { Minimal hepatic en- } \\
\text { cephalopathy }\end{array}$ & 1 & 20 & Risk Ratio (IV, Random, 95\% CI) & $0.0[0.0,0.0]$ \\
\hline $\begin{array}{l}\text { 1.3 Prevention of hepatic en- } \\
\text { cephalopathy }\end{array}$ & 1 & 31 & Risk Ratio (IV, Random, 95\% CI) & $0.0[0.0,0.0]$ \\
\hline 2 Hepatic encephalopathy & 7 & 194 & Risk Ratio (IV, Random, 95\% Cl) & $1.00[0.84,1.19]$ \\
\hline $\begin{array}{l}2.1 \text { Overt hepatic en- } \\
\text { cephalopathy }\end{array}$ & 5 & 162 & Risk Ratio (IV, Random, 95\% CI) & $1.08[0.60,1.96]$ \\
\hline $\begin{array}{l}2.2 \text { Minimal hepatic en- } \\
\text { cephalopathy }\end{array}$ & 1 & 20 & Risk Ratio (IV, Random, 95\% Cl) & $1.0[0.83,1.20]$ \\
\hline $\begin{array}{l}2.3 \text { Prevention hepatic en- } \\
\text { cephalopathy }\end{array}$ & 1 & 12 & Risk Ratio (IV, Random, 95\% CI) & $0.20[0.01,3.46]$ \\
\hline 3 Serious adverse events & 9 & 245 & Risk Ratio (IV, Random, 95\% CI) & $1.56[0.84,2.88]$ \\
\hline 4 Non-serious adverse events & 6 & & Risk Ratio (IV, Random, 95\% CI) & Subtotals only \\
\hline 4.1 Overall & 6 & 169 & Risk Ratio (IV, Random, 95\% Cl) & $1.55[0.88,2.74]$ \\
\hline 4.2 Diarrhoea & 3 & 61 & Risk Ratio (IV, Random, 95\% CI) & $0.80[0.39,1.64]$ \\
\hline 4.3 Bloating and flatulence & 4 & 128 & Risk Ratio (IV, Random, 95\% CI) & $2.20[1.06,4.54]$ \\
\hline 4.4 Nausea & 4 & 104 & Risk Ratio (IV, Random, 95\% CI) & $3.20[0.76,13.43]$ \\
\hline 4.5 Hyponatraemia & 1 & 25 & Risk Ratio (IV, Random, 95\% Cl) & $3.23[0.14,72.46]$ \\
\hline 4.6 Abdominal pain & 3 & 91 & Risk Ratio (IV, Random, 95\% CI) & $0.95[0.47,1.91]$ \\
\hline
\end{tabular}

Non-absorbable disaccharides versus placebo/no intervention and lactulose versus lactitol for the prevention and treatment of hepatic 


\begin{tabular}{lllll}
\hline Outcome or subgroup title & No. of studies & $\begin{array}{l}\text { No. of partici- } \\
\text { pants }\end{array}$ & Statistical method & Effect size \\
\hline 4.7 Asthenia & 1 & 31 & Risk Ratio (IV, Random, 95\% CI) & $0.35[0.02,8.08]$ \\
\hline $\begin{array}{l}5 \text { Number Connection Test: } \\
\text { end of treatment }\end{array}$ & 4 & 84 & $\begin{array}{l}\text { Mean Difference (IV, Random, 95\% } \\
\text { Cl) }\end{array}$ & $-4.22[-16.12,7.68]$ \\
\hline $\begin{array}{l}6 \text { Number Connection Test: } \\
\text { change from baseline }\end{array}$ & 1 & 25 & $\begin{array}{l}\text { Mean Difference (IV, Random, 95\% } \\
\text { Cl) }\end{array}$ & $0.20[-0.54,0.94]$ \\
\hline $\begin{array}{l}7 \text { Venous blood ammonia: } \\
\text { end of treatment }\end{array}$ & 3 & 72 & $\begin{array}{l}\text { Mean Difference (IV, Random, 95\% } \\
\text { Cl) }\end{array}$ & $6.47[-8.36,21.29]$ \\
\hline $\begin{array}{l}8 \text { Venous blood ammonia: } \\
\text { change from baseline }\end{array}$ & 1 & 25 & $\begin{array}{l}\text { Mean Difference (IV, Random, 95\% } \\
\text { Cl) }\end{array}$ & $-0.20[-0.80,0.40]$ \\
\hline
\end{tabular}

Analysis 4.1. Comparison 4 Lactulose versus lactitol, Outcome 1 Mortality.

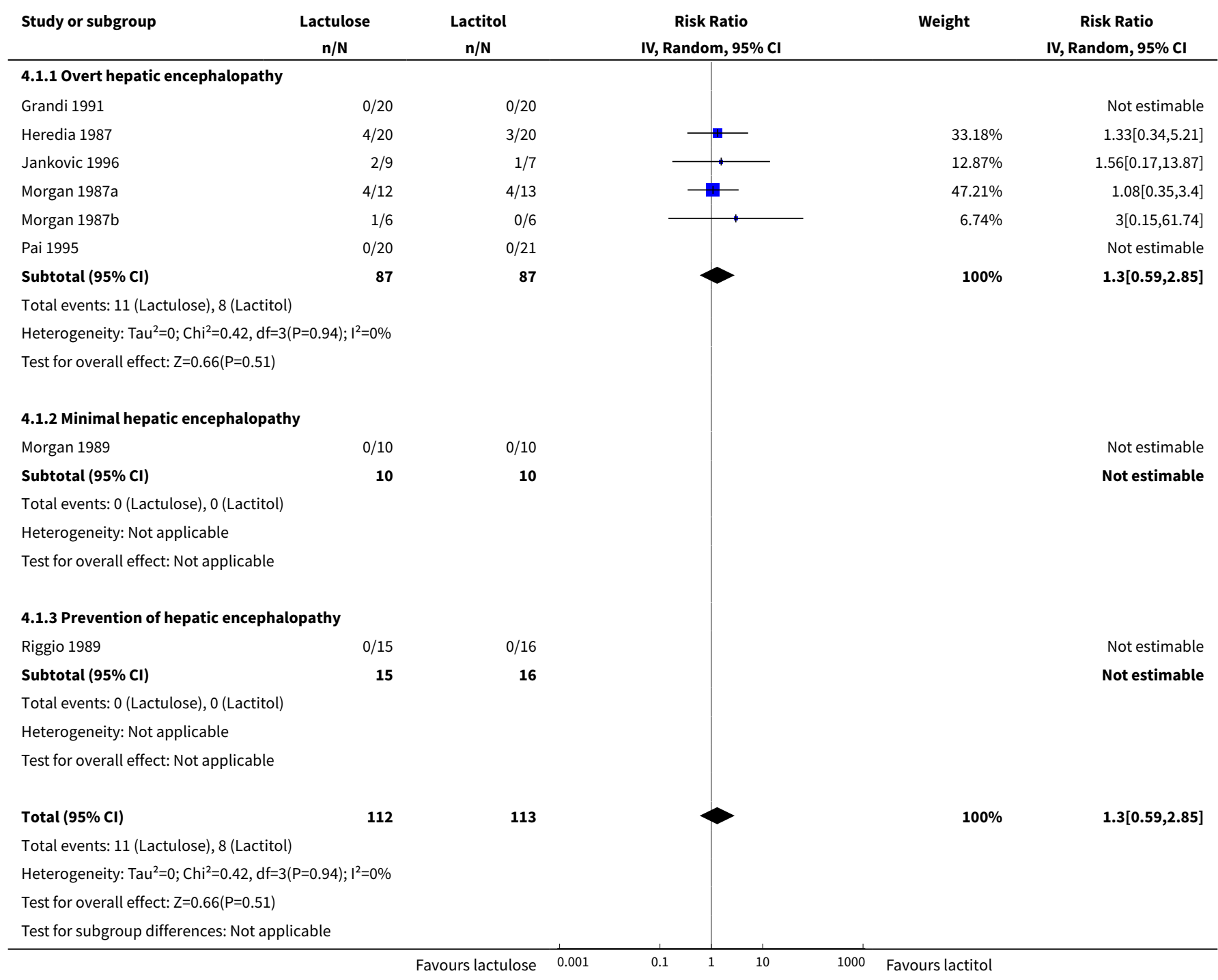


Analysis 4.2. Comparison 4 Lactulose versus lactitol, Outcome 2 Hepatic encephalopathy.

\begin{tabular}{|c|c|c|c|c|c|}
\hline Study or subgroup & $\begin{array}{c}\text { Lactulose } \\
\mathrm{n} / \mathrm{N}\end{array}$ & $\begin{array}{l}\text { Lactitol } \\
\mathrm{n} / \mathrm{N}\end{array}$ & $\begin{array}{c}\text { Risk Ratio } \\
\text { IV, Random, } 95 \% \mathrm{CI} \\
\end{array}$ & Weight & $\begin{array}{c}\text { Risk Ratio } \\
\text { IV, Random, } 95 \% \mathrm{CI}\end{array}$ \\
\hline \multicolumn{6}{|c|}{ 4.2.1 Overt hepatic encephalopathy } \\
\hline Grandi 1991 & $5 / 20$ & $4 / 20$ & 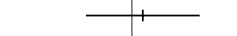 & $2.25 \%$ & $1.25[0.39,3.99]$ \\
\hline Heredia 1987 & $4 / 20$ & $3 / 20$ & & $1.63 \%$ & $1.33[0.34,5.21]$ \\
\hline Morgan 1987a & $4 / 12$ & $5 / 13$ & & $2.72 \%$ & $0.87[0.3,2.49]$ \\
\hline Morgan 1987b & $0 / 6$ & $0 / 6$ & & & Not estimable \\
\hline Pai 1995 & $4 / 22$ & $4 / 23$ & & $1.92 \%$ & $1.05[0.3,3.67]$ \\
\hline Subtotal $(95 \% \mathrm{Cl})$ & 80 & 82 & 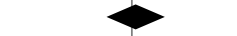 & $8.53 \%$ & $1.08[0.6,1.96]$ \\
\hline \multicolumn{6}{|c|}{ Total events: 17 (Lactulose), 16 (Lactitol) } \\
\hline \multicolumn{6}{|c|}{ Heterogeneity: $\mathrm{Tau}^{2}=0 ; \mathrm{Chi}^{2}=0.32, \mathrm{df}=3(\mathrm{P}=0.96) ; I^{2}=0 \%$} \\
\hline \multicolumn{6}{|c|}{ Test for overall effect: $Z=0.26(P=0.8)$} \\
\hline \multicolumn{6}{|c|}{ 4.2.2 Minimal hepatic encephalopathy } \\
\hline Morgan 1989 & $10 / 10$ & $10 / 10$ & & $91.1 \%$ & $1[0.83,1.2]$ \\
\hline Subtotal $(95 \% \mathrm{Cl})$ & 10 & 10 & $\bullet$ & $91.1 \%$ & $1[0.83,1.2]$ \\
\hline \multicolumn{6}{|c|}{ Total events: 10 (Lactulose), 10 (Lactitol) } \\
\hline \multicolumn{6}{|c|}{ Heterogeneity: Not applicable } \\
\hline \multicolumn{6}{|c|}{ Test for overall effect: Not applicable } \\
\hline \multicolumn{6}{|c|}{ 4.2.3 Prevention hepatic encephalopathy } \\
\hline Riggio 1989 & $0 / 6$ & $2 / 6$ & $\rightarrow$ & $0.37 \%$ & $0.2[0.01,3.46]$ \\
\hline Subtotal $(95 \% \mathrm{Cl})$ & 6 & 6 & & $0.37 \%$ & $0.2[0.01,3.46]$ \\
\hline \multicolumn{6}{|c|}{ Total events: 0 (Lactulose), 2 (Lactitol) } \\
\hline \multicolumn{6}{|c|}{ Heterogeneity: $\mathrm{Tau}^{2}=0 ; \mathrm{Chi}^{2}=0, \mathrm{df}=0(\mathrm{P}<0.0001) ; \mathrm{I}^{2}=100 \%$} \\
\hline \multicolumn{6}{|c|}{ Test for overall effect: $Z=1.11(P=0.27)$} \\
\hline Total $(95 \% \mathrm{Cl})$ & 96 & 98 & 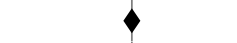 & $100 \%$ & $1[0.84,1.19]$ \\
\hline \multicolumn{6}{|c|}{ Total events: 27 (Lactulose), 28 (Lactitol) } \\
\hline \multicolumn{6}{|c|}{ Heterogeneity: $\operatorname{Tau}^{2}=0 ; \mathrm{Chi}^{2}=1.61, \mathrm{df}=5(\mathrm{P}=0.9) ; 1^{2}=0 \%$} \\
\hline \multicolumn{6}{|c|}{ Test for overall effect: $Z=0.01(P=0.99)$} \\
\hline \multicolumn{6}{|c|}{ Test for subgroup differences: $C \mathrm{Ch}^{2}=1.29, \mathrm{df}=1(\mathrm{P}=0.52), \mathrm{I}^{2}=0 \%$} \\
\hline
\end{tabular}

Analysis 4.3. Comparison 4 Lactulose versus lactitol, Outcome 3 Serious adverse events.

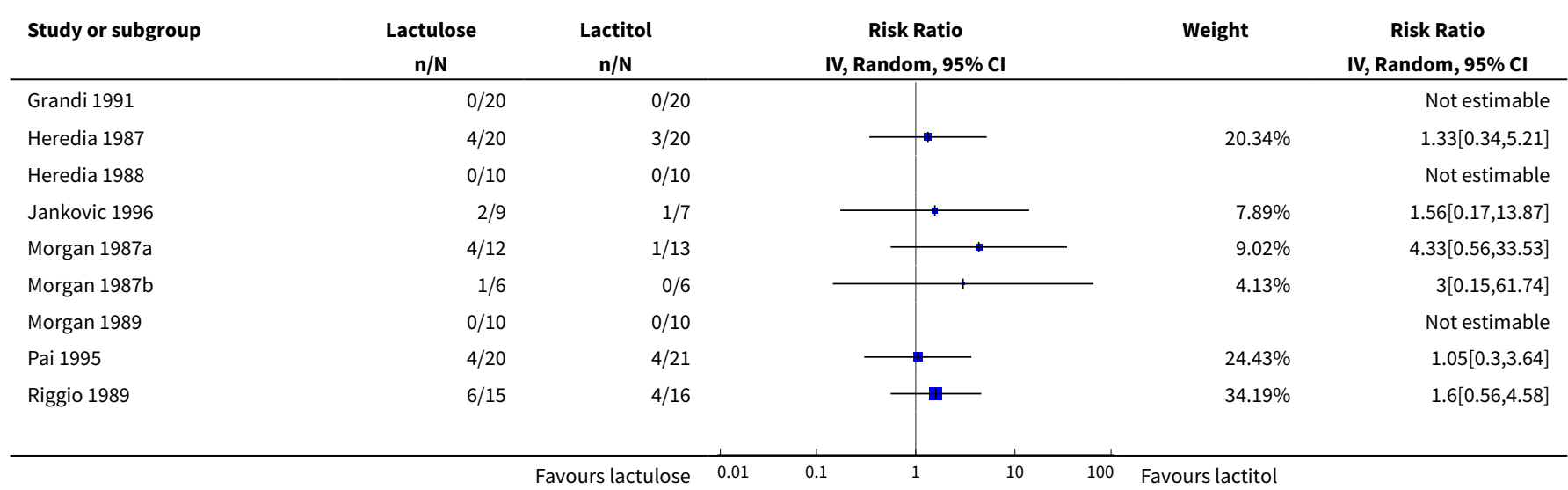

Non-absorbable disaccharides versus placebo/no intervention and lactulose versus lactitol for the prevention and treatment of hepatic 


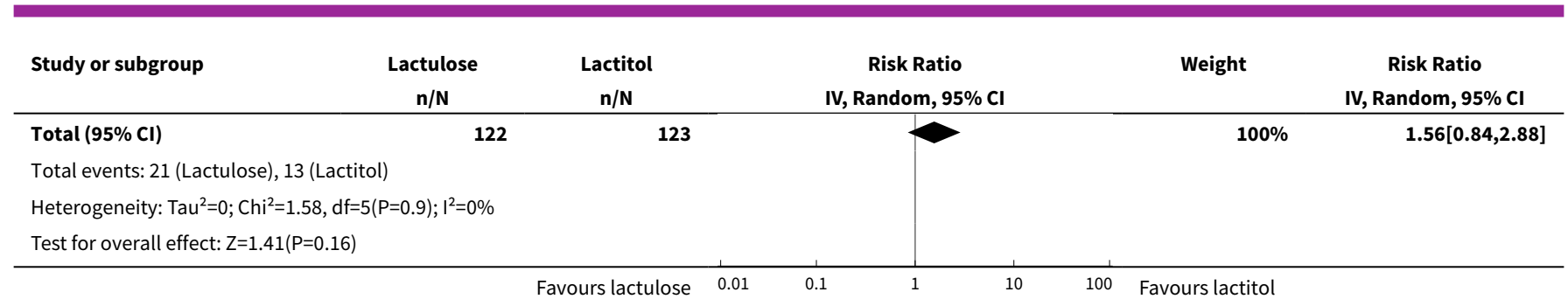

Analysis 4.4. Comparison 4 Lactulose versus lactitol, Outcome 4 Non-serious adverse events.

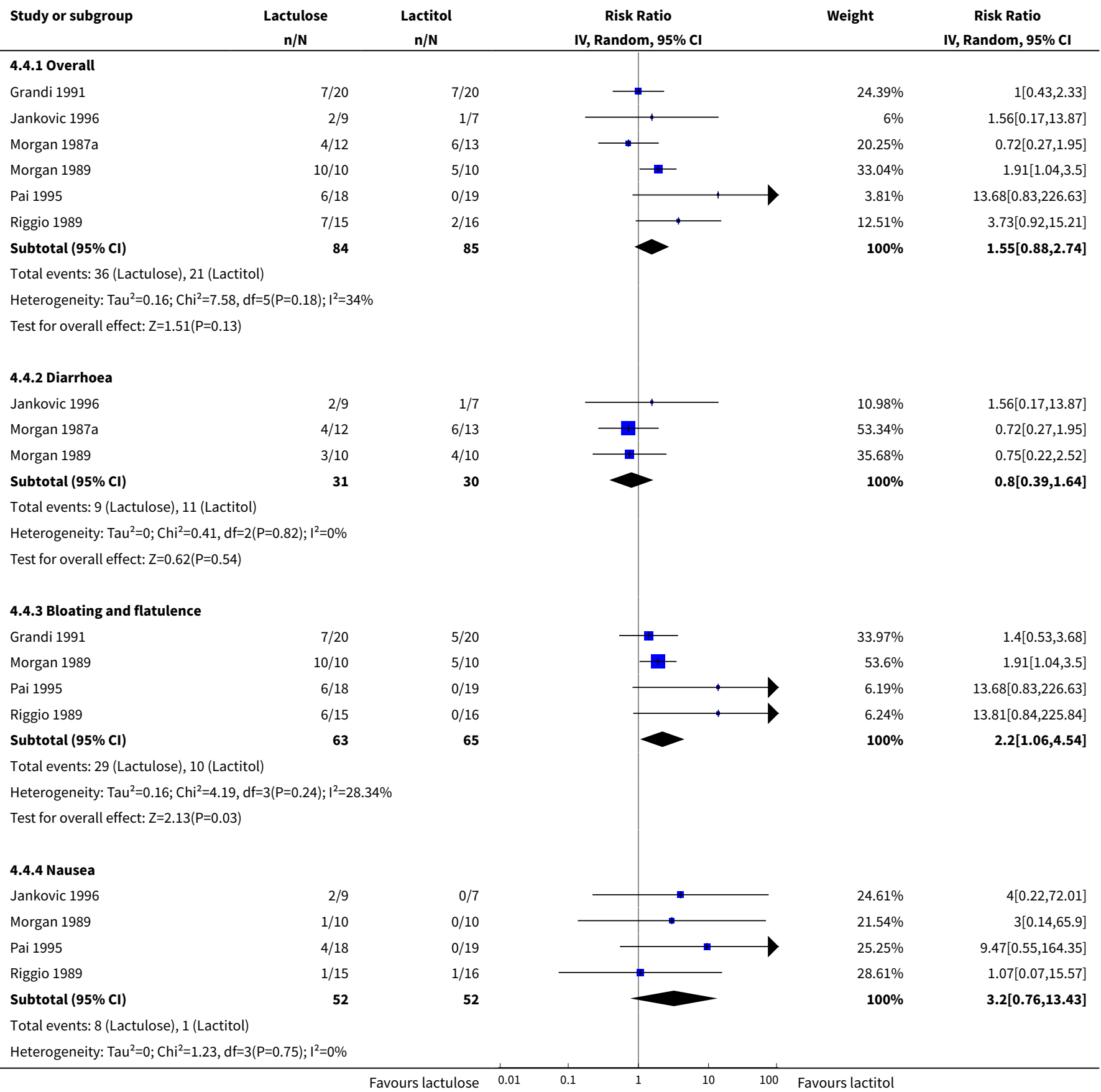

Non-absorbable disaccharides versus placebo/no intervention and lactulose versus lactitol for the prevention and treatment of hepatic 


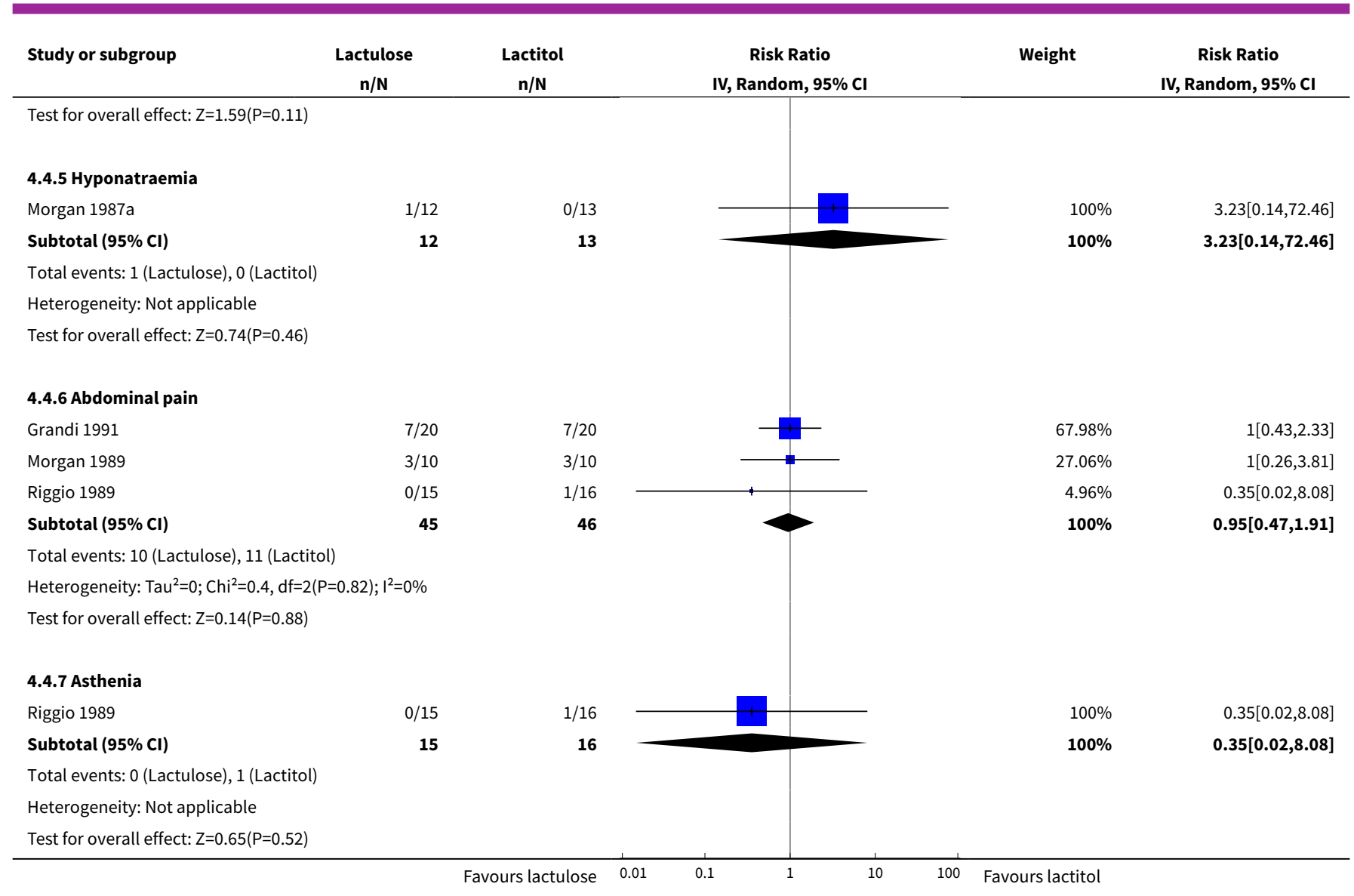

Analysis 4.5. Comparison 4 Lactulose versus lactitol, Outcome 5 Number Connection Test: end of treatment.

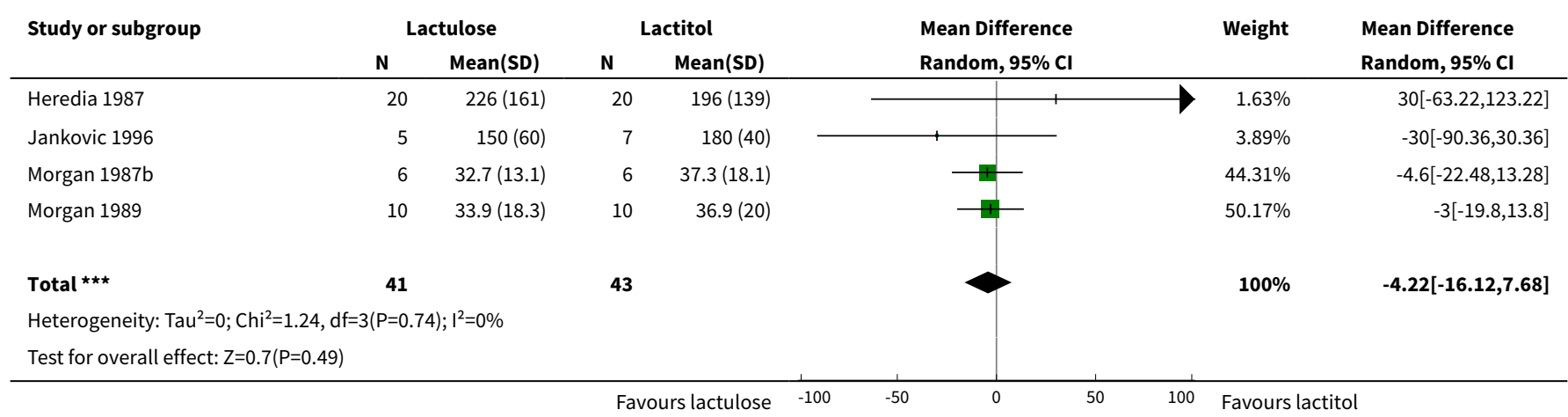

Analysis 4.6. Comparison 4 Lactulose versus lactitol, Outcome 6 Number Connection Test: change from baseline.

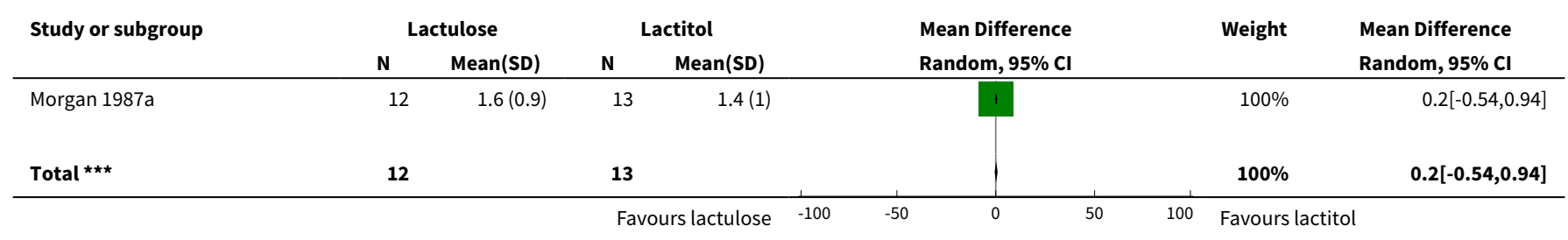

Non-absorbable disaccharides versus placebo/no intervention and lactulose versus lactitol for the prevention and treatment of hepatic 


\begin{tabular}{|c|c|c|c|c|c|c|c|c|c|c|}
\hline \multirow[t]{2}{*}{ Study or subgroup } & \multicolumn{2}{|c|}{ Lactulose } & \multicolumn{2}{|c|}{ Lactitol } & & \multirow{2}{*}{\multicolumn{2}{|c|}{$\begin{array}{l}\text { Mean Difference } \\
\text { Random, } 95 \% \mathrm{Cl}\end{array}$}} & \multirow{2}{*}{\multicolumn{2}{|c|}{ Weight }} & \multirow{2}{*}{$\begin{array}{l}\text { Mean Difference } \\
\text { Random, } 95 \% \mathrm{CI}\end{array}$} \\
\hline & $\mathbf{N}$ & $\operatorname{Mean}(S D)$ & $\mathbf{N}$ & $\operatorname{Mean}(S D)$ & & & & & & \\
\hline \multicolumn{11}{|l|}{ Heterogeneity: Not applicable } \\
\hline \multicolumn{11}{|l|}{ Test for overall effect: $Z=0.53(P=0.6)$} \\
\hline
\end{tabular}

Analysis 4.7. Comparison 4 Lactulose versus lactitol, Outcome 7 Venous blood ammonia: end of treatment.

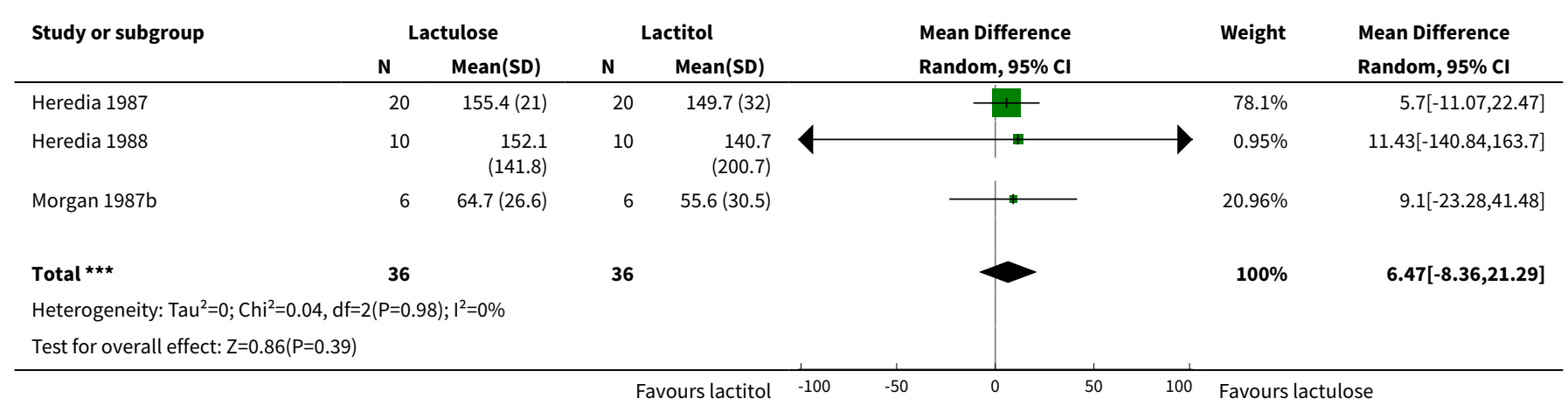

Analysis 4.8. Comparison 4 Lactulose versus lactitol, Outcome 8 Venous blood ammonia: change from baseline.

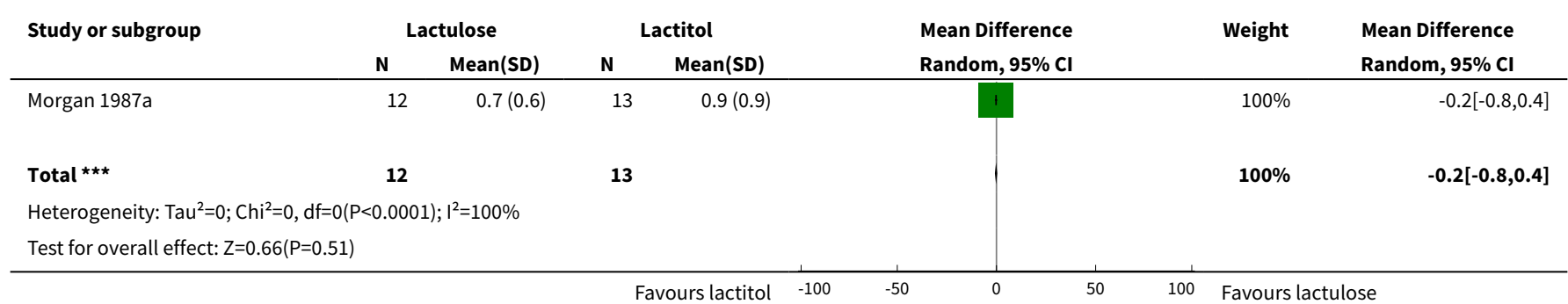

\section{ADDITIONAL TABLES}

Table 1. Definitions and assessment of overt hepatic encephalopathy with corresponding recommended definitions in the EASL/AASLD guidelines

\begin{tabular}{llll}
\hline Trial & $\begin{array}{l}\text { Definition in trial publica- } \\
\text { tion }\end{array}$ & $\begin{array}{l}\text { Definition based } \\
\text { on classification } \\
\text { in EASL/AASLD } \\
\text { guidelines }\end{array}$ & Assessment of hepatic encephalopathy \\
\hline Elkington 1969 & $\begin{array}{l}\text { Chronic persistent hepatic } \\
\text { encephalopathy }\end{array}$ & Persistent & $\begin{array}{l}\text { Mental status assessed using Parsons-Smith criteria } \\
\text { Arterial blood ammonia concentrations }\end{array}$ \\
& & Electroencephalogram \\
\hline
\end{tabular}


Table 1. Definitions and assessment of overt hepatic encephalopathy with corresponding recommended definitions in the EASL/AASLD guidelines (Continued)

\begin{tabular}{|c|c|c|c|}
\hline Simmons 1970 & $\begin{array}{l}\text { Acute, acute remittent, and } \\
\text { chronic remittent hepatic } \\
\text { encephalopathy }\end{array}$ & $\begin{array}{l}\text { Episodic (81\%) } \\
\text { Recurrent (19\%) }\end{array}$ & $\begin{array}{l}\text { Mental status assessed on a scale similar to but more } \\
\text { extensive than the West Haven Criteria } \\
\text { Venous blood ammonia concentrations }\end{array}$ \\
\hline Brown 1971 & $\begin{array}{l}\text { Chronic persistent hepatic } \\
\text { encephalopathy }\end{array}$ & Persistent & $\begin{array}{l}\text { Mental status } \\
\text { Blood ammonia concentrations } \\
\text { Electroencephalogram* }\end{array}$ \\
\hline Germain 1973 & $\begin{array}{l}\text { Chronic persistent hepatic } \\
\text { encephalopathy }\end{array}$ & Persistent & $\begin{array}{l}\text { Mental status assessed using Parson-Smith criteria } \\
\text { Psychometric tests } \\
\text { Venous blood ammonia concentrations } \\
\text { Electroencephalogram }\end{array}$ \\
\hline Rodgers 1973 & $\begin{array}{l}\text { Chronic persistent hepatic } \\
\text { encephalopathy }\end{array}$ & Persistent & $\begin{array}{l}\text { Clinical assessment of mental status } \\
\text { Blood ammonia concentrations } \\
\text { Electroencephalogram* }\end{array}$ \\
\hline Corazza 1982 & $\begin{array}{l}\text { Chronic persistent hepatic } \\
\text { encephalopathy }\end{array}$ & Persistent & $\begin{array}{l}\text { Encephalopathy Intensity Score } \\
\text { Plasma ammonia concentrations }\end{array}$ \\
\hline Heredia 1987 & $\begin{array}{l}\text { Acute hepatic encephalopa- } \\
\text { thy }\end{array}$ & Episodic/recurrent & $\begin{array}{l}\text { Conn score } \\
\text { Number Connection Test } \\
\text { Blood ammonia concentrations } \\
\text { Electroencephalogram }\end{array}$ \\
\hline Morgan 1987a & $\begin{array}{l}\text { Acute hepatic encephalopa- } \\
\text { thy }\end{array}$ & Episodic & Portal Systemic Encephalopathy Sum and Index \\
\hline Morgan 1987b & $\begin{array}{l}\text { Chronic persistent hepatic } \\
\text { encephalopathy }\end{array}$ & Persistent & Portal Systemic Encephalopathy Sum and Index \\
\hline Uribe 1987a & $\begin{array}{l}\text { Acute hepatic encephalopa- } \\
\text { thy }\end{array}$ & Episodic & Portal Systemic Encephalopathy Sum and Index \\
\hline Uribe $1987 b$ & $\begin{array}{l}\text { Chronic persistent hepatic } \\
\text { encephalopathy }\end{array}$ & Persistent & Portal Systemic Encephalopathy Sum and Index \\
\hline Heredia 1988 & $\begin{array}{l}\text { Chronic recurrent hepatic } \\
\text { encephalopathy }\end{array}$ & Persistent & Portal Systemic Encephalopathy Sum and Index ${ }^{\star}$ \\
\hline Grandi 1991 & $\begin{array}{l}\text { Chronic hepatic en- } \\
\text { cephalopathy }\end{array}$ & Persistent & $\begin{array}{l}\text { Portal Systemic Encephalopathy Sum and Index modi- } \\
\text { fied by omitting the electroencephalogram }\end{array}$ \\
\hline Pai 1995 & $\begin{array}{l}\text { Acute hepatic encephalopa- } \\
\text { thy }\end{array}$ & Episodic & Portal Systemic Encephalopathy Sum and Index \\
\hline Jankovic 1996 & $\begin{array}{l}\text { Acute hepatic encephalopa- } \\
\text { thy }\end{array}$ & Episodic & Mental status using West Haven criteria \\
\hline
\end{tabular}

Non-absorbable disaccharides versus placebo/no intervention and lactulose versus lactitol for the prevention and treatment of hepatic 
Table 1. Definitions and assessment of overt hepatic encephalopathy with corresponding recommended definitions in the EASL/AASLD guidelines (Continued)

Number connection Test A

Electroencephalogram*

\begin{tabular}{lll}
\hline Raza 2004 & $\begin{array}{l}\text { Acute hepatic encephalopa- Episodic } \\
\text { thy }\end{array}$ & $\begin{array}{l}\text { Clinical scoring } \\
\text { Modified Portal Systemic Encephalopathy Sum and In- } \\
\text { dex with electroencephalogram omitted and Digit Sym- } \\
\text { bol test replacing Number Connection Test A }\end{array}$
\end{tabular}

*The trial is not included in the analysis of hepatic encephalopathy, because we were unable to extract data on the number of participants with (or without) an overall improvement.

Table 2. Liver-related serious adverse events

\begin{tabular}{lll}
\hline Event & Non-absorbable disaccharides & Placebo/no intervention \\
\hline Variceal bleeding & $19 / 438(4 \%)$ & $17 / 336(5 \%)$ \\
\hline Hepatorenal syndrome & $10 / 196(5 \%)$ & $7 / 153(5 \%)$ \\
\hline Spontaneous bacterial peritonitis & $10 / 140(7 \%)$ & $16 / 138(12 \%)$ \\
\hline Liver failure & $9 / 189(5 \%)$ & $7 / 117(6 \%)$ \\
\hline
\end{tabular}

The overall risk of serious adverse events is analysed as one of the primary outcomes.

Table 3. Quero 1996: Sickness Impact Profile selected subscores

\begin{tabular}{lllll}
\hline End of treatment & Control $(\mathbf{n}=\mathbf{2 1})$ & & Lactulose $(\mathbf{n}=\mathbf{1 9})$ \\
\hline Psychological subscore & Mean & Standard deviation & Mean & Standard deviation \\
\hline Physical subscore & 8.0 & 11 & 10.9 & 14 \\
\hline
\end{tabular}

Table 4. Prasad 2007: Sickness Impact Profile selected subscores

\begin{tabular}{|c|c|c|c|c|}
\hline \multirow[t]{2}{*}{ Change from baseline } & \multicolumn{2}{|c|}{ Control $(n=20)$} & \multicolumn{2}{|c|}{ Lactulose $(n=25)$} \\
\hline & Mean & $\begin{array}{l}\text { Standard devia- } \\
\text { tion }\end{array}$ & Mean & $\begin{array}{l}\text { Standard devia- } \\
\text { tion }\end{array}$ \\
\hline \multicolumn{5}{|l|}{ Psychosocial scales } \\
\hline Social interactions & 0.5 & 0.68 & 8.5 & 1.35 \\
\hline Alertness & -0.75 & 1.13 & 10.43 & 1.73 \\
\hline Emotional behaviour & 2.76 & 1.83 & 8.98 & 1.55 \\
\hline
\end{tabular}


Table 4. Prasad 2007: Sickness Impact Profile selected subscores (Continued)

\begin{tabular}{|c|c|c|c|c|}
\hline Communication & 0.75 & 1.19 & 2.66 & 1.22 \\
\hline Total psychological subscore & 0.77 & 0.41 & 8.47 & 0.98 \\
\hline \multicolumn{5}{|l|}{ Physical scales } \\
\hline Ambulation & -1.89 & 1.12 & 3.67 & 0.80 \\
\hline Mobility & 1.22 & 1.18 & 5.36 & 1.35 \\
\hline Body care and movements & 0.72 & 0.42 & 1.62 & 0.55 \\
\hline Total physical subscore & 0.01 & 0.52 & 2.99 & 0.56 \\
\hline \multicolumn{5}{|l|}{ Independent scales } \\
\hline Sleep and rest & 2.29 & 1.35 & 9.04 & 1.95 \\
\hline Work & -0.06 & 1.44 & 15.83 & 4.45 \\
\hline Home management & 0.94 & 1.19 & 12.64 & 2.71 \\
\hline Recreation and pastimes & -0.28 & 1.11 & 11.59 & 1.97 \\
\hline Eating & -0.56 & 1.31 & 3.88 & 1.21 \\
\hline
\end{tabular}

Table 5. Mittal 2009: Sickness Impact Profile selected subscores

\begin{tabular}{|c|c|c|c|c|}
\hline \multirow[t]{2}{*}{ Change from baseline } & \multicolumn{2}{|c|}{ Control $(n=31)$} & \multicolumn{2}{|c|}{ Lactulose $(n=35)$} \\
\hline & Mean & $\begin{array}{l}\text { Standard devia- } \\
\text { tion }\end{array}$ & Mean & $\begin{array}{l}\text { Standard devia- } \\
\text { tion }\end{array}$ \\
\hline \multicolumn{5}{|l|}{ Subscores } \\
\hline Sleep and rest & 2.87 & 6.5 & 11.64 & 5.5 \\
\hline Emotional behaviour & 0.40 & 4.1 & 9.84 & 4.8 \\
\hline Body care and movements & -0.38 & 1.9 & 3.20 & 2.4 \\
\hline Home management & -0.25 & 5.7 & 6.34 & 5.20 \\
\hline Mobility & 0.59 & 5.5 & 4.64 & 4.3 \\
\hline Social interaction & 1.63 & 3.2 & 3.88 & 2.8 \\
\hline Alertness & 0.18 & 2.4 & 3.63 & 2.2 \\
\hline Ambulation & -0.18 & 2.9 & 5.10 & 4.2 \\
\hline Communication & 0.80 & 3.3 & 2.07 & 5.1 \\
\hline Work & 0.64 & 2.5 & 9.46 & 15.7 \\
\hline
\end{tabular}

Non-absorbable disaccharides versus placebo/no intervention and lactulose versus lactitol for the prevention and treatment of hepatic 
Table 5. Mittal 2009: Sickness Impact Profile selected subscores (Continued)

\begin{tabular}{llccc} 
Recreation and pastime & 3.06 & 4.4 & 7.74 & 5.7 \\
\hline Eating & 1.12 & 3.1 & 2.48 & 3.1 \\
\hline Psychosocial & 1.13 & 2.4 & 5.17 & 2.9 \\
\hline Physical & -0.05 & 2.0 & 3.59 & 2.1
\end{tabular}

Table 6. Zeng 2003: WHO-Bref selected subscores

\begin{tabular}{|c|c|c|c|c|c|c|}
\hline \multirow[t]{2}{*}{ End of treatment } & \multicolumn{2}{|c|}{ Control $(n=20)$} & \multicolumn{2}{|c|}{ Short term lactulose $(n=20)$} & \multicolumn{2}{|c|}{ Long-term lactulose $(n=20)$} \\
\hline & Mean & $\begin{array}{l}\text { Standard de- } \\
\text { viation }\end{array}$ & Mean & $\begin{array}{l}\text { Standard devia- } \\
\text { tion }\end{array}$ & Mean & $\begin{array}{l}\text { Standard devia- } \\
\text { tion }\end{array}$ \\
\hline Physical health & 28 & 19 & 37 & 18 & 54 & 19 \\
\hline Psychological health & 42 & 14 & 44 & 15 & 58 & 15 \\
\hline Social relationships & 38 & 16 & 42 & 15 & 60 & 17 \\
\hline Environment & 51 & 18 & 53 & 15 & 51 & 13 \\
\hline
\end{tabular}

\section{A P PEN DICES}

\section{Appendix 1. Search strategy}

\begin{tabular}{lll}
\hline Database & Time span & Search terms \\
\hline $\begin{array}{l}\text { The Cochrane Hepa- } \\
\text { to-Biliary Group Con- } \\
\text { trolled Trials Register }\end{array}$ & October 2015 & $\begin{array}{l}\left(\text { disaccharid }^{\star} \text { or lactulos }^{*} \text { or lactitol }^{\star}\right) \text { AND (encephalopath } \text { OR }^{*} \text { liver disease* }^{\star} \\
\text { OR cirrho }\end{array}$ \\
\hline
\end{tabular}

Cochrane Central Regis- Issue 10 of 12,2015 ter of Controlled Trials (CENTRAL)

\author{
\#1 MeSH descriptor: [Disaccharides] explode all trees \\ \#2 MeSH descriptor: [Lactulose] explode all trees \\ \#3 disaccharid* or lactulos* or lactitol ${ }^{\star}$ \\ \#4 \#1 or \#2 or \#3 \\ \#5 MeSH descriptor: [Hepatic Encephalopathy] explode all trees \\ \#6 MeSH descriptor: [Liver Diseases] explode all trees \\ \#7 MeSH descriptor: [Fibrosis] explode all trees \\ \#8 encephalopath* or liver disease* or cirrho* \\ \#9 \#5 or \#6 or \#7 or \#8 \\ $\# 10 \# 4$ and \#9
}


(Continued)
MEDLINE (Ovid SP)
1946 to October 2015
1. exp Disaccharides/
2. exp Lactulose/
3. (disaccharid* or lactulos* or lactitol $\left.{ }^{\star}\right) . \mathrm{mp}$. [mp=title, abstract, original title, name of substance word, subject heading word, keyword heading word, pro- tocol supplementary concept, rare disease supplementary concept, unique identifier]

\section{1 or 2 or 3}

5. exp Hepatic Encephalopathy/

6. exp Liver Diseases/

\section{7. exp Fibrosis/}

8. (encephalopath ${ }^{\star}$ or liver disease* or cirrho*).mp. [mp=title, abstract, original title, name of substance word, subject heading word, keyword heading word, protocol supplementary concept, rare disease supplementary concept, unique identifier]

\section{5 or 6 or 7 or 8}

\section{4 and 9}

11. (random* or blind* or placebo* or meta-analysis).mp. [mp=title, abstract, original title, name of substance word, subject heading word, keyword heading word, protocol supplementary concept, rare disease supplementary concept, unique identifier]

12. 10 and 11

\section{1. exp disaccharide/}

2. exp lactulose/

3. exp lactitol/

4. (disaccharid* or lactulos* or lactitol*).mp. [mp=title, abstract, subject headings, heading word, drug trade name, original title, device manufacturer, drug manufacturer, device trade name, keyword]

\section{1 or 2 or 3 or 4}

6. exp hepatic encephalopathy/

7. exp liver disease/

8. exp fibrosis/

9. (encephalopath* or liver disease* or cirrho*).mp. [mp=title, abstract, subject headings, heading word, drug trade name, original title, device manufacturer, drug manufacturer, device trade name, keyword]

\section{6 or 7 or 8 or 9}

\section{5 and 10}

12. $\left(\right.$ random $^{\star}$ or blind ${ }^{\star}$ or placebo* or meta-analys $\left.{ }^{\star}\right) . m p$. [mp=title, abstract, subject headings, heading word, drug trade name, original title, device manufacturer, drug manufacturer, device trade name, keyword]

13. 11 and 12 
(Continued)

\begin{tabular}{|c|c|c|}
\hline \multirow[t]{4}{*}{$\begin{array}{l}\text { Science Citation In- } \\
\text { dex Expanded (Web of } \\
\text { Science) }\end{array}$} & 1900 to October 2015 & $\begin{array}{l}5 \text { \#4 AND \#3 } \\
4 \text { TS=(random* or blind }{ }^{\star} \text { or placebo* or meta-analysis) }\end{array}$ \\
\hline & & 3 \#2 AND \#1 \\
\hline & & 2 TS=(encephalopath* or liver disease* or cirrho*) \\
\hline & & $1 \mathrm{TS}=\left(\right.$ disaccharid $^{\star}$ or lactulos ${ }^{\star}$ or lactitol $\left.{ }^{\star}\right)$ \\
\hline
\end{tabular}

WHAT'S NEW

\begin{tabular}{lll}
\hline Date & Event & Description \\
\hline 19 April 2016 & Amended & $\begin{array}{l}\text { Reference Gluud 2016 added to Other published versions of this } \\
\text { review. }\end{array}$
\end{tabular}

28 February $2016 \quad$ Amended Changes to the 'Risk of bias' assessment: We updated the 'Risk of bias' assessment included in the latest version of the review. The change included the addition of the domains 'for-profit funding' and 'overall bias assessment'. We made the updates following the recommendations in the Cochrane Hepato-Biliary Group module.

30 September $2015 \quad$ New search has been performed

The first version of this review, published in 2000, included 10 randomised clinical trials (RCTs) evaluating non-absorbable disaccharides versus placebo/no intervention and eight RCTs evaluating lactulose versus lactitol. An update in 2004 did not identify additional RCTs. This updated review includes 38 RCTs ( 29 evaluating non-absorbable disaccharides versus placebo/no intervention and nine evaluating lactulose versus lactitol). The methods of the review have been updated in accordance with the recommendations made in the Cochrane Handbook for Systematic Reviews of Interventions and the Cochrane Hepato-Biliary Group module. The changes include updated trial searches (the searches now include several trial registries), assessment of bias control and statistical analyses (regression analyses of small study effects, meta-regression analyses and Trial Sequential Analyses). The review includes 'Summary of findings' tables.

$\begin{array}{lll}26 \text { February 2015 } & \begin{array}{l}\text { New citation required and conclusions } \\ \text { have changed }\end{array} & \begin{array}{l}\text { The updated review found evidence that lactulose and lactitol } \\ \text { are associated with beneficial effects on mortality, hepatic en- } \\ \text { cephalopathy, and serious adverse events. }\end{array}\end{array}$

26 February $2015 \quad$ New search has been performed

\begin{abstract}
We excluded RCTs evaluating antibiotics for people with hepatic encephalopathy to avoid overlap with another planned review (Kimer 2015). Hence, we changed the review title 'Nonabsorbable disaccharides for hepatic encephalopathy' (Als-Nielsen 2000; Als-Nielsen 2004a; Als-Nielsen 2004b; Als-Nielsen 2005) to 'Non-absorbable disaccharides versus placebo/no intervention and lactulose versus lactitol for the prevention and treatment of hepatic encephalopathy in people with cirrhosis'.
\end{abstract}




\section{CONTRIBUTIONS OF AUTHORS}

LL Gluud drafted the revised review, identified and selected RCTs, contributed to the data extraction, analyses, and interpretation of the results, and revised the review. $\mathrm{H}$ Vilstrup identified and selected RCTs, contributed to the data extraction, analyses, and interpretation of the results, and revised the review. MY Morgan identified and selected RCTs, contributed to the data extraction, analyses, and interpretation of the results, and revised the review.

All authors agreed to the publication of the review.

\section{DECLARATIONS OF INTEREST}

Lise L Gluud received payment for presentations given at scientific meetings sponsored by Norgine.

All review authors have conducted previous reviews on hepatic encephalopathy and two authors (Hendrik Vilstrup and Marsha Morgan) have conducted RCTs on hepatic encephalopathy. These previous research activities are an academic bias based on the definitions given in the Cochrane Hepato-Biliary Group module.

\section{SOURCES OF SUPPORT}

\section{Internal sources}

- No funding received, Other.

\section{External sources}

- No funding received, Other.

\section{DIFFERENCES BETWEEN PROTOCOLAND REVIEW}

We have revised the methods used in the original protocol and the previous version of this review (Als-Nielsen 2000; Als-Nielsen 2004a; Als-Nielsen 2004b; Als-Nielsen 2005) with:

- exclusion of RCTs assessing non-absorbable disaccharides versus antibiotics;

- redefinition of primary and secondary outcomes (serious adverse events was previously a secondary outcome and is now a primary outcome);

- revised assessment of bias control based on the Cochrane Hepato-Biliary Group module (Gluud 2015). The changes include the addition of the domains missing outcome data; outcome reporting bias; other bias; for-profit funding; overall bias assessment.

- additional statistical analyses including regression analyses of small study effects; trial sequential analyses; worst-case scenario analyses; random-effects meta-regression.

\section{N DEX TERMS}

\section{Medical Subject Headings (MeSH)}

Disaccharides [adverse effects] [ ${ }^{*}$ therapeutic use]; Hepatic Encephalopathy [ ${ }^{*}$ drug therapy] [mortality] [ ${ }^{*}$ prevention \& control]; Lactulose [ ${ }^{*}$ therapeutic use]; Liver Cirrhosis [ ${ }^{*}$ complications]; Neomycin [therapeutic use]; Randomized Controlled Trials as Topic; Sugar Alcohols [*therapeutic use]; Watchful Waiting

\section{MeSH check words}

Humans

Non-absorbable disaccharides versus placebo/no intervention and lactulose versus lactitol for the prevention and treatment of hepatic 